\title{
Funktionsanalyse des Irx1-Gens
}

\author{
Dissertation \\ zur Erlangung des Doktorgrades \\ der Mathematisch-Naturwissenschaftlichen Fakultäten \\ der Georg-August-Universität zu Göttingen
}

vorgelegt von

Armin Uwe Zülch

aus Homberg/Efze

Göttingen 2001 


\section{Diese Arbeit wurde am Max-Planck-Institut für biophysikalische Chemie, Karl-Friedrich-Bonhoefer-Institut Abteilung: Molekulare Zellbiologie Direktor: Prof. Dr. Peter Gruss durchgeführt.}

Referentin: Professorin Dr. M. Schäfer

Korreferent: Professor Dr. P. Gruss

Tag der mündlichen Prüfung: 28.06.2001 


\section{$\operatorname{Irx1-}$}

ein Vormustergen,

essentiell für die murine Gastrulation 


\section{INHALTSVERZEICHNIS}

I. Einleitung 1

II. Ergebnisse 13

II.1. Strukturanalyse des Ir $x$ 1-Gens 13

II.1.1. Durchmusterung einer cDNA-Bibliothek zur Komplettierung der 14 Irx1-Sequenz

II.1.2 Sequenzanalyse der Irx1-cDNA 15

II.1.3. Das Irx1-Antiserum $\quad 21$

II.2. Analyse des räumlichen und zeitlichen Expressionsmusters des 24 Irx1-Gens

II.2.1. Analyse des Irx1-Transkripts während der Mausentwicklung 24

II.2.2. Irx1-Expression während der frühen Gastrulation (E6,0 bis E7,5) 25

II.2.3. Irx1-Expression während des Neurulation (E8,5 bis E9,0) 27

II.2.4. Irx1-Expression während der Organogenese (E9,5 bis E14,5) 29

II.2.5. Spezielle Beispiele der Expression von Irx-Genen während der 29 Organogenese

II.3. Die Funktion des Irx1-Gens 38

II.3.1. Die Zn-Finger-Gene Gli1 und Gli2 kontrollieren die Irx1- 38 Expression

II.3.2. Das Irx1-Gen aktiviert nicht den Mash1-Promotor $\quad 40$

II.4. Analyse der Irx1-Mausmutante $\quad 42$

II.4.1. Analyse der chromosomalen Lokalisation des Irx1-Gens 43

II.4.2. Kartierung und genomische Organisation des Irx1-Gens 45

II.4.3. Herstellen eines Irx1-Rekombinationskonstruktes für die 46 homologe Rekombination in ES-Zellen

II.4.4. Gentransfer in ES-Zellen $\quad 50$ 
II.4.5. Morula-Aggregation von ES-Zellen 55

II.5. Analyse der Irx1-defizienten Mäuse 59

II.5.1 Irx1-defiziente Mäuse sterben während der embryonalen 59 Entwicklung

II.5.2 Irx 1-defiziente Mäuse zeigen einen starken embryonalen $\quad 60$ Phänotyp

II.5.3. Irx 1 ist wesentlich für die Gastrulation der Maus 63

$\begin{array}{ll}\text { III. Diskussion } & 72\end{array}$

$\begin{array}{lr}\text { IV. Material und Methoden } & 89\end{array}$

$\begin{array}{lr}\text { IV.1. Organismen } & 89\end{array}$

IV.1.1 Mäuse und Embryonen $\quad 89$

$\begin{array}{ll}\text { IV.1.2 Bakterien } & 89\end{array}$

IV.1.3 ES-Zellen $\quad 89$

IV.2 Materialien $\quad 90$

IV.2.1 Chemikalien $\quad 90$

$\begin{array}{ll}\text { IV.2.2 Radiochemikalien } & 90\end{array}$

IV.2.3 Verbrauchsmaterial $\quad 90$

IV.2.4 Enzyme $\quad 90$

IV.2.5 Reaktionssets (“Kits") 90

IV.2.6 Membranen $\quad 91$

IV.2.7 DNA-Bibliotheken 91

IV.2.8 Vektoren $\quad 91$

IV.2.9 Größenmarker $\quad 91$

IV.2.10 Oligonukleotide $\quad 92$

IV.2.11 Filme $\quad 92$

IV.2.12 Photoarbeiten und Sequenzbearbeitung $\quad 92$

IV.2.13 Zellinien $\quad 93$

IV.2.14 in-situ-Hybridisierungssonden $\quad 93$

IV.2.15 Medien, Nährböden, Standard-Lösungen 93

IV.3 Methoden $\quad 95$

IV.3.1 Isolierung von Plasmid-DNA aus Bakterien $\quad 95$

IV.3.2 Konzentrationsbestimmung von Nukleinsäuren 97 
IV.3.3 Agarose-Gelelektrophorese $\quad 97$

IV.3.4 Gewinnung von DNA-Fragmenten aus Agarosegelen mit dem 97 QIA-quick Gel Extraction Kit

IV.3.5 Restriktionsspaltung von DNA 98

IV.3.6 Aufreinigung von DNA-Lösungen mittels Phenol/Chloroform- 98 Extraktion

IV.3.7 Ethanolfällung von DNA aus wässrigen Lösungen 99

IV.3.8 Isopropanolfällung von DNA aus wässrigen Lösungen 99

IV.3.9 Ligation von DNA-Fragmenten 100

IV.3.10. "blunt end"-Klonierung 100

IV.3.11 Transformation von Bakterien $\quad 100$

IV.3.12 Sequenzierung ("Cycle sequencing") 102

IV.3.13 Polymerase-Kettenreaktion (PCR) 103

$\begin{array}{ll}\text { IV.3.14 Southern-Blot-Analyse } & 104\end{array}$

IV.3.15 Radioaktive Markierung von DNA- und RNA-Blots 105

IV.3.16 Durchmustern einer cDNA- oder genomischen Maus-DNA- $\quad 107$

Bibliothek nach rekombinanten Bakteriophagen und deren Isolierung

IV.3.17 Präparation genomischer Maus-DNA 110

IV.3.18 Arbeiten mit RNA 111

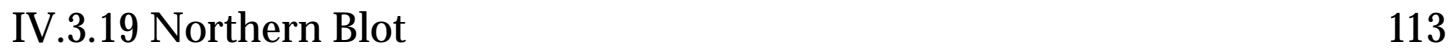

IV.3.20 Radioaktive mRNA-in-situ-Hybridisierung an Schnitten $\quad 115$

IV.3.21 mRNA-in-situ-Hybridisierung an ganzen Embryonen ("whole- 120 mount"-Hybridisierungstechnik)

IV.3.22 Nachweis von $\beta$-Galaktosidase (X-Gal-Färbung) 126

IV.3.23 Methoden zur Arbeit mit eukaryotischen Zellen $\quad 127$

IV.3.24 Maus-FISH-Analyse der transgenen ES-Zellen 131

IV.3.25 Herstellung von Maus-Chimären aus ES-Zellen durch 132 Morulaaggregation

$\begin{array}{ll}\text { IV.3.26 Zellbiologische Methoden } & 135\end{array}$

IV.3.27 Herstellung von Antisera (Irx1-Antikörper) 136

$\begin{array}{ll}\text { IV.3.28 Western-Blot } & 139\end{array}$

IV.3.29 Immunhistochemie $\quad 142$ 
IV.3.30 Histologische Methoden 143

IV.3.31 Arbeiten mit Gli1- und Gli2-Mausmutanten 144

V. Glossar, Abkürzungen und Symbole $\quad 145$

VI. Zusammenfassung 152

VII. Literaturverzeichnis $\quad 154$

VIII. Danksagung 173

IX. Publikationen 175

$\begin{array}{ll}X . \text { Lebenslauf } & 176\end{array}$ 


\title{
I. EINLEITUNG
}

\author{
"I I IS nOt BIRTH, MARRIAGE, OR DEATH, BUT \\ GASTRULATION, WHICH IS TRULY THE MOST \\ IMPORTANT TIME IN YOUR LIFE."
}

LEWIS WOLPERT (1986)

Zu den faszinierensten Vorgängen der Biologie zählt die Entwicklung eines multizellulären Organismus aus einer einzelnen Zelle, der Zygote. Neben der Bildung von neuen Zellen vollzieht sich während dieses Prozesses auch deren Organisation und Differenzierung. Durch die graduelle Differenzierung der Zellen, die die verschiedenen Zelltypen eines Organismus bilden, werden zelluläre Unterschiede definiert.

In den letzten Jahren hat die Entwicklungsbiologie, durch die Kombination der Genetik, der Zell- und Molekularbiologie zu einem bemerkenswerten Verständnis der molekularen Basis der Embryonalentwicklung geführt. Heute wissen wir, daß die Entwicklung eines hochkomplexen Organismus unter der präzisen Kontrolle eines genetischen Programmes steht. Die anfänglich totipotente Zygote entwickelt sich mittels eines zeitlich und räumlich koordinierten Abrufens von genetischer Information zu differenzierten und determinierten Tochterzellen. Diese Zellen nehmen, entsprechend ihrer späteren Position und Funktion, definierte Aufgaben im Organismus wahr.

Bezüglich zellulärer Interaktionen und genetischer Regulationen sind dabei so unterschiedliche Prozesse wie die Entwicklung der Sinnesborstenzellen in Drosophila melanogaster und der Mausgastrulation auf molekularer Ebene vergleichbar. 
Das in dieser Arbeit vorgestellte Irx1-Gen spielt in der embryonalen Entwicklung der Maus eine entscheidende Rolle. Zum besseren Verständnis der molekularen Prozesse der Iroquois-Regulation wird zunächst die genetische Regulation der Mechanorezeptorenbildung bei Drosophila melanogaster vorgestellt, um dann analoge Prozesse, die evolutiv konserviert sind, im Modellsystem Maus zu erläutern.

\section{DIE SPEZIFIZIERUNG VON ZELLIDENTITÄTEN IM NERVENSYSTEM VON DROSOPHILA M.}

DIFFERENZIERUNG DER MECHANOSENSORISCHEN SINNESORGANE WÄHREND DER ENTWICKLUNG VON DROSOPHILA MELANOGASTER.

Auf der Körperoberfläche der Fruchtfliege Drosophila melanogaster befinden sich Haare und Borsten, welche mechanosensorische Sinnesorgane darstellen und Berührung sowie Luftwiderstände wahrnehmen. Interessanterweise ist die Zahl und auch die genaue Position der großen Borsten exakt festgelegt und so bilden diese definierte Reihen mit gleichbleibender Dichte. Diese Sinnesorgane werden während des Larven- und Puppenstadiums schrittweise angelegt. Die Entstehung der sensorischen Vorläuferzelle (SOM; sensomotoric mother cell) wird über die Aktivität der Vormustergene (prepattern genes), der proneuralen Gene und des Notch-Delta-Signalweges gesteuert. Aus der SOM entwickelt sich nach mehreren Zellteilungen das sensorische Organ. (Posakony, 1994; Simpson, 1997; Heitzler et al., 1996; Leyns et al., 1996; Gómez-Skarmeta et al., 1995; Gómez-Skarmeta et al., 1996).

\section{IN DROSOPHILA M. GEHEN AUS PRONEURALEN ZELLGRUPPEN NEURONEN HERVOR}

Bevor ein Mechanorezeptor gebildet werden kann, muß der Ort der Entstehung definiert sein. In der Imaginalscheibe sind Proteine durch Diffusion verteilt und bilden einen Konzentrationsgradienten aus. Dies entspricht einem „Vormuster"(prepattern), welches bereits von Stern 1954 aufgrund seiner achaete-scute-Mosaik-Analyse postuliert wurde (Stern, 1954). Bisher konnten nur wenige potentielle Vormustergene identifiziert werden. Die Genprodukte von hairy und panier sowie die Gene des Iroquois-Komplex (IRO-K) stellen solche 
Vormustergene dar (Ramain et al., 1993; Leyns et al., 1996). Der IRO-Komplex umfaßt die Gene araucan, caupolitan und mirror (Leyns, 1991; Gómez-Skarmeta et al., 1996; McNeill et al., 1997). Während Hairy einen Repressor der proneuralen Gene des Achaete-Scute-Komplexes darstellt, handelt es sich bei den Genen des Iroquois-Komplexes um Aktivatoren (Skeath and Carroll, 1991; Rushlow et al., 1989; Ohsako et al., 1994; Gómez-Skarmeta et al., 1996; Gómez-Skarmeta et al., 1995).

Iro wurde genetisch als die $T p(3,3)$ iro $^{1}{ }^{-}$-Mutante beschrieben und die rezessive Mutation führt zum Fehlen der lateralen sensorischen Borsten auf dem Notum (Dambly-Chaudière und Leynes, 1992). Dieser Phänotyp korreliert mit der Abwesenheit der dazugehörigen achaete-scute- (as-sc-) exprimierenden proneuralen Zellgruppen. Bei den Genprodukte des IRO-Komplexes handelt es sich um Homeobox-Transkriptionsfaktoren, die die bisher einzigen bekannten positiven und direkten Regulatoren des Achaete-Scute-Komplex (AS-K) sind. So aktivieren auracan und caupolitan den AS-Komplex in bestimmten proneuralen Zellgruppen (Gómez-Skarmeta et al., 1996). Da ihre Expression räumlich größer ist, als die des aktivierten $A S-K$, muß es noch weitere Kofaktoren geben, die an der räumlichen Begrenzung beteiligt sind. Als ein Regulator des IroquoisKomplexes wird das Genprodukt des Segmentpolaritätsgen cubitus interruptus (ci) (Orenic et al., 1987) beschrieben (Gómez-Skarmeta und Modolell, 1996). Weiterhin wird das Expressionsmuster durch Gene wie decapentaplegic (dpp) und wingless (wg) reguliert, die den Imaginalscheiben Positionsinformationen liefern (Vervoort, 2000).

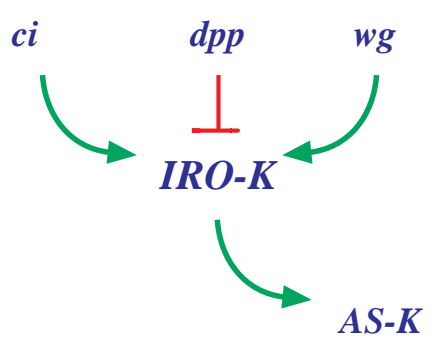

Abb. I.1: Regulation des Iroquois-Komplexes in D. melanogaster (modifiziert nach (Vervoort, 2000; Gómez-Skarmeta und Modolell, 1996)). 


\section{LATERALINHIBITION ZUR BESTIMMUNG VON NEURONALEN VORLÄUFERN}

Nachdem das Vormuster definiert wurde, entsteht in den Vorläuferzellen die neuronale Kompetenz. Dies erfolgt durch die Aktivität der proneuralen Gene, wie achaete und scute (Simpson, 1997; Heitzler et al., 1996).
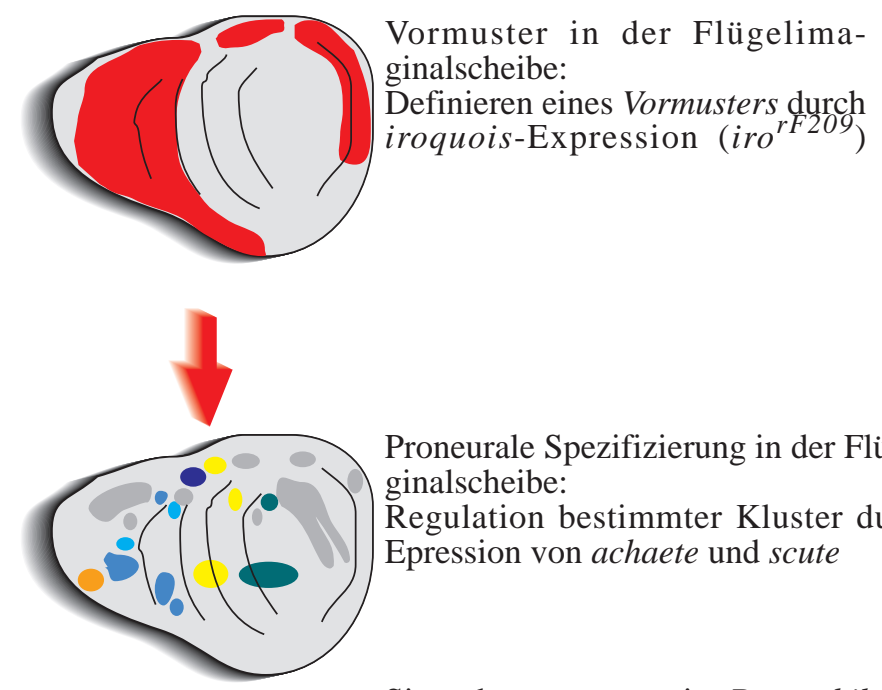

Proneurale Spezifizierung in der Flügelimaginalscheibe:

Regulation bestimmter Kluster durch die Epression von achaete und scute

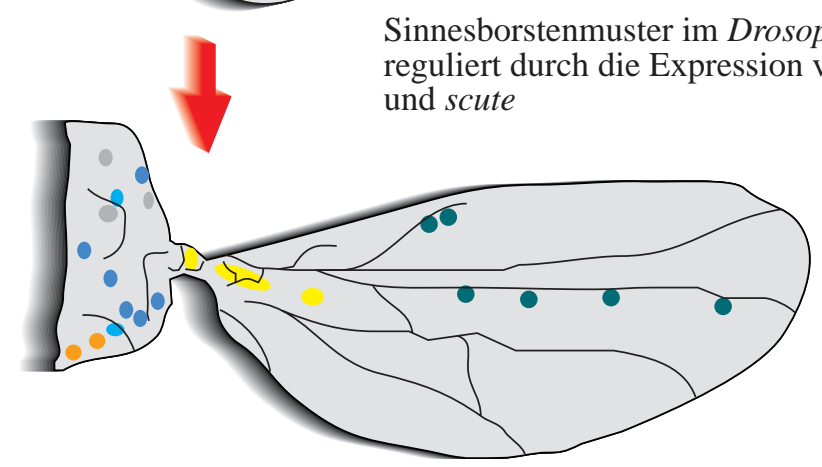

Abb. I.2: Festlegung des Sinnesborstenmusters auf dem Drosophila-Flügel.

Bei der Bildung der sensomotorischen Organe spielt die bereits erwähnte Regulation des Iroquois-Komplexes eine ganz wesentliche Funktion. Die essentielle Rolle der Iroquois-Gene in der Kontrolle der neuronalen Entwicklung wird durch die Tatsache unterstrichen, daß Teile dieser Regulation hochkonserviert sind und bei allen höheren Eumetazoen, von Nematoden, über die Maus bis hin zum Menschen vorhanden sind (Artavanis-Tsakonas et al., 1999). 


\section{DIE SPEZIFIZIERUNG VON ZELLIDENTITÄTEN IN WIRBELTIEREN}

\section{IN WirbeLTIEREN ENTSTAMMT DAS NERVENSYSTEM DER NEURALPLATTE}

Alle Zellen des Zentralnervensystems (ZNS) entstammen in Wirbeltieren entweder der Neuralplatte oder den sensorischen Plakoden der Kopfregion. Bei der Neuralplatte handelt es sich um eine zylindrische Epithelregion, die im dorsalen Ektoderm während der Gastrulation induziert wird. Gegen Ende der Gastrulation faltet sich die Neuralplatte einwärts und bildet das Neuralrohr. In der dorsalen Hälfte des Neuralrohres verlassen Neuralleistenzellen die Struktur und bilden nach der Umwandlung ihres epithelialen in einen mesenchymalen Charakters die sensorischen Neuronen des peripheren (PNS) und des vegetativen Nervensystems. Das aus Gehirn und Rückenmark bestehende ZNS wird aus dem verbleibenden Neuralrohr gebildet.

IN WiRbELTIEREN WERDEN NEURONALE VORLÄUFER DURCH LATERALE INHIBITION BESTIMMT

In Wirbeltieren erfolgt die Spezifizierung neuronaler Vorläuferzellen in einer ganz ähnlichen Weise wie in der Fruchtfliege. Betrachtet man die frühen Embryonen des Krallenfrosches Xenopus laevis, so ist zu erkennen, daß dort die künftigen Neuronen nicht aus der gesamten Neuralplatte entstehen, sondern aus drei exakt definierten Längsstreifen auf beiden Seiten der Mittellinie. So gehen aus den flankierenden Streifen die sensorischen Neuronen und Interneuronen hervor. Dagegen bildet der mittlere Streifen, der später zur Ventralregion des Neuralrohres wird, die Motoneuronen. Ein ganz wesentliches Gen für diese neuronale Differenzierung ist Neurogenin (Ma et al., 1996). Dieses Gen gehört zur Familie der basischen Helix-Loop-Helix-Transkriptionsfaktoren und ist mit den Genen achaete und scute aus Drosophila verwandt. Die Selektion der neuronalen Zellen erfolgt durch die Lateralinhibtion, u.a. vermittelt durch die Gene Notch und Delta (Chitins et al., 1995; Ma et al., 1996). Dabei dient Delta als Ligand, welcher an das Rezeptorprotein Notch bindet und dadurch eine intrazelluläre Reaktion in der empfangenden Zelle auslöst. In dieser Empfängerzelle wird die neuronale Differenzierung durch Hemmung der 
Neurogenin-Synthese gestoppt. Produziert eine Zelle mehr Delta-Protein als ihre Nachbarzelle, unterdrückt sie deren Delta-Expression. Dies bedeutet wiederum, daß ihre eigene Neurogenin-Expression nicht mehr unterdrückt wird und somit entwickelt sich diese Zelle im weiteren Verlauf zu einem Neuron (Chitins et al., 1995; Ma et al., 1996).

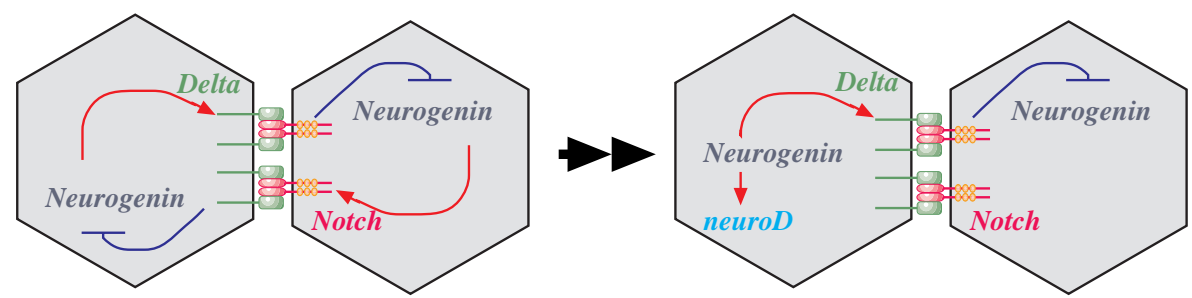

Abb. I.3: Durch laterale Inhibition werden im Nervensystem der Wirbeltiere einzelne Zellen zu neuronalen Vorläufern determiniert.

Es stellt sich die Frage, ob Entwicklungsprozesse von Insekten und Säugern identisch sind. Die Analyse in verschiedenen Organismen zeigt, daß viele Prozesse in ihren wesentlichen Zügen vergleichbar sind.

\section{Drosophila}

Expression der Gene des IroquoisKomplexes definieren das "Vormuster" (prepattern) im Drosophila Neuroektoderm

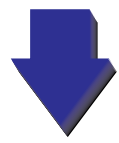

Induktion der Gene des Achaete-ScuteKomplexes im proneuralen Kluster

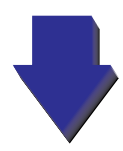

infolge von Lateralinhibition, vermittelt durch den Notch-Delta-Signalweg, wird eine Zelle des Klusters zum neuronalen Vorläufer

\section{Wirbeltiere}

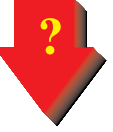

neuronale Vorläufer, die Neurogenin oder Mash1 exprimieren

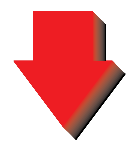

infolge von lateraler Inhibition, vermittelt durch den Notch-Delta-Signalweg, werden neuronale Vorläufer bestimmt

Abb. I.4: Die Festlegung der neuronalen Identitäten in D. melanogaster und in Wirbeltieren. 
Die Lateralinhibition ist ein gutes Beispiel darfür, wie stark Musterbildungsprozesse und die daran beteiligten Gene in der Evolution konserviert sein können (Tanabe und Jessel, 1996; Jessell und Sanes, 2000; McMahon, 2000). Es darf aber darüber weder die Varianz, die Vielfältigkeit noch die Einzigartigkeit einzelner Entwicklungsschritte vergessen werden.

\section{DIE FRÜHE ENTWICKLUNG DER MAUS}

Nach erfolgter Befruchtung benötigt der Mausembryo 19 Tage bis zur Geburt. Dabei weicht die frühe Phase der Entwicklung der Amnioten stark von der anderer Wilbeltiere ab. Denn die Entwicklung im Mutterleib stellt neue Erfordernisse an das Überleben des Embryos.

Die Eier sind sekundär dotteram und vollziehen eine totale Furchung. So bezieht der Embryo Nahrung von der Mutter, das heißt, daß die Eier keinen Dottervorrat mitzubringen brauchen, da sie von der Mutter über die Plazenta versorgt werden. Dies bedeutet, daß die Embryonen sehr früh mit der Mutter Kontakt aufnehmen müssen, um ihre Versorgung sicherzustellen (Tam und Behringer, 1997; Hogan et al., 1994). Es ist zu erwarten, daß an diesem Punkt der Entwicklung neue Mechanismen entstanden sind, auf der genetischen Grundlage des vorhandenen Repertoires an Genen. Es könnten bekannte Gene und bekannte Geninteraktionen mit zusätzlicher Funktion auftreten.

Die Befruchtung des Eies und die Furchung erfolgen im Eileiter und benötigen mehrere Tage. Bis zum 8-Zellstadium sind die Blastomeren noch totipotent. Beim Übergang zum 16-Zellstadium kommt es zur Kompaktion, die zur Morula führt. Dabei werden die Blastomere mittels bestimmter Zelladhäsionsmolekülen eng miteinander verknüpft. In diesem Morula-Stadium kommt es zu einer ersten Differenzierung. Die inneren Zellen der Morula bilden die innere Zellmasse (Embryoblast), die äußeren Zellen das Trophoektoderm. Dabei werden die Zellen des Trophoektoderms polyploid, d.h. sie amplifizieren ihr Genom, wohingegen die Zellen der inneren Zellmasse diploid bleiben. Während sich aus dem Trophoektoderm extraembryonale Strukturen wie die Plazenta bilden, entwickelt sich der eigentliche Embryo aus dem Embryoblasten. Die entstandene Blastozyste stellt einen flüssigkeitsgefüllten 
Hohlkörper dar, der im weiteren Verlauf aus seiner schützenden Zona pellucida "schlüpft". Nun kann sich die Blastozyste, nach viereinhalb Tagen (E4,5), in die Gebärmutterwand einnisten (implantieren). Ebenfalls zu diesem Zeitpunkt unterteilt sich die innere Zellmasse (IZM): zum einen entsteht das primitive Endoderm, und zwar aus Zellen, die der flüssigkeitsgefüllten Blastozystenhöhle zugewandt sind, und zum anderen bildet sich aus den übrigen Zellen der inneren Zellmasse das primitive Ektoderm (Epiblast). Das primitive Endoderm ist an der Bildung extraembyonaler Membranen beteiligt, wohingegen der Epiblast sowohl den eigentlichen Embryo, wie auch extraembyonalen Membranen ausbildet (Tam und Behringer, 1997; Hogan et al., 1994).

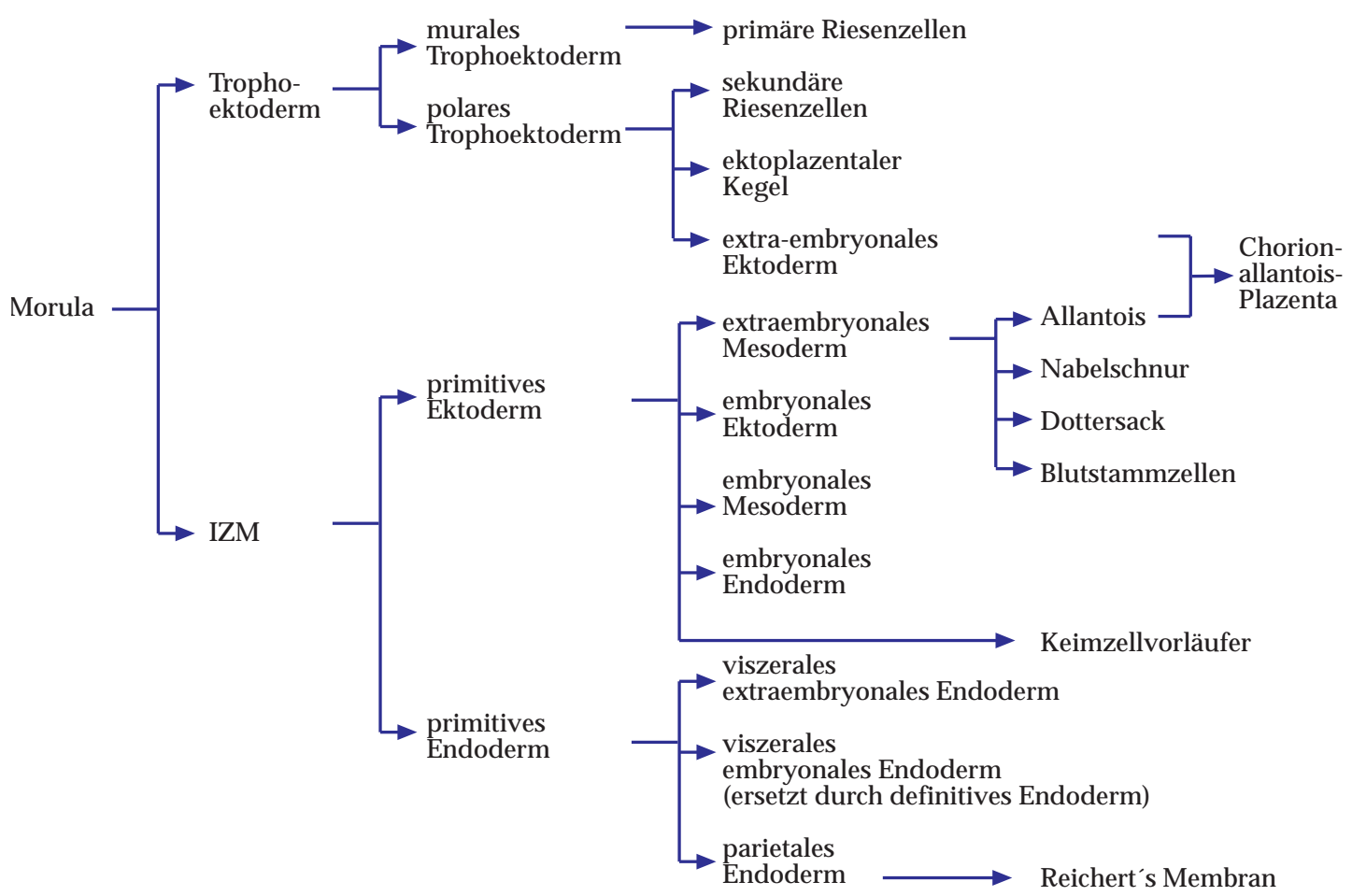

Abb. I.5: Zellinien im frühen Mausembryo

(modifiziert nach (Bard und Kaufmann, 1994))

\section{DIE GASTRULATION IM MAUSEMBRYO}

Sechs Tage nach der Befruchtung $(E 6,0)$ besteht die Blastula aus Trophoblast, Blastocoel und Epiblast. Nach sechseinhalb Tagen setzt die Gastrulation mit der Bildung des Primitivstreifens ein und zum ersten Mal ist damit auch eine 
zukünftige Körperachse (anterior-posterior) morphologisch zu erkennen. Der Primitivstreifen beginnt als eine lokale Verdickung am proximo-posterioren Ende des eigentlichen Embryos. Die Innenseite des Embryos wird zur Dorsalseite. Während der Gastrulation wandern proliferierende Epiblastenzellen durch den Primitivstreifen hindurch, und zwar zwischen Ektoderm und viszeralem Endoderm nach rostral und lateral: es bildet sich die mesodermale Zellschicht (Hogan et al., 1994).

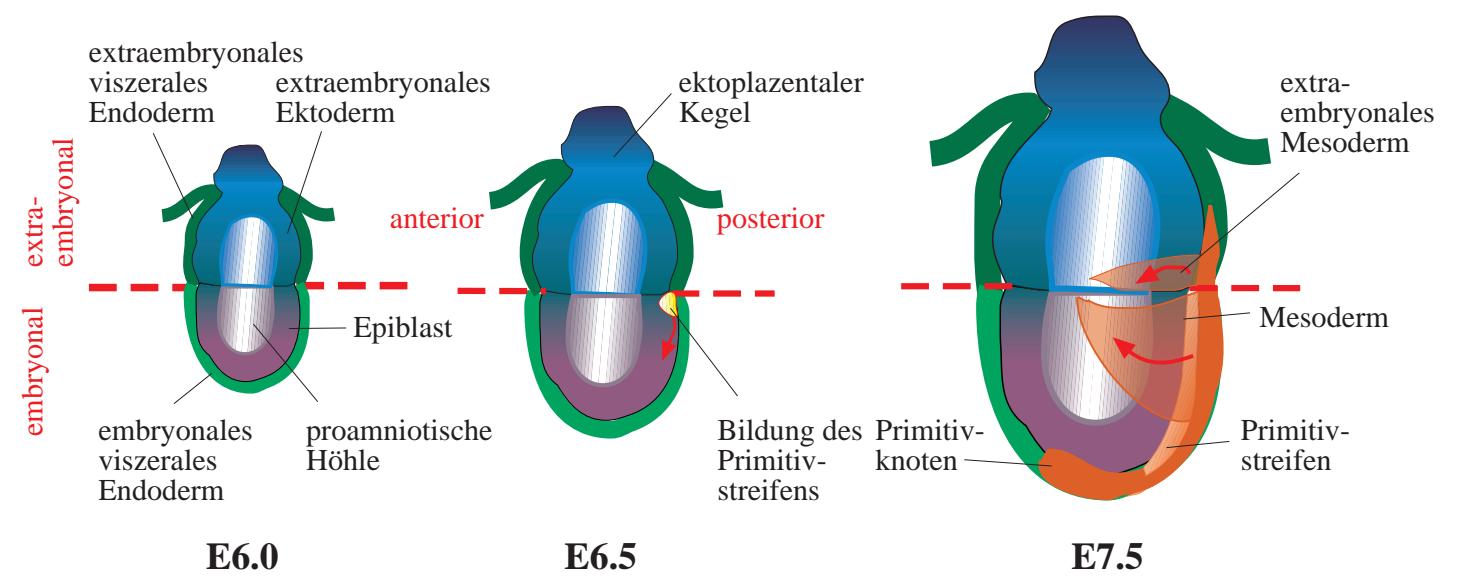

Abb. I.6: Die Mausgastrulation

Der Primitivstreifen verlängert sich in die Richtung des späteren Vorderendes des Embryos. Am anterioren Punkt der Zellwanderung bildet sich der Primitivknoten, der aus einer Ansammlung dicht gepackter Zellen besteht und funktionell dem Hensenschen Knoten im Hühnerembryo entspricht (Patten, 1971; Hamburger und Hamilton, 1951). Einige Zellen wandern durch den Primitivknoten nach vorne und bilden die Chorda dorsalis. Die Chorda und auch die Somiten entwickeln sich Schritt für Schritt anterior des Primitivknotens. Einige Epiblastenzellen dringen in das viszerale Endoderm ein, ersetzen dieses und bilden so das endgültige Endoderm, aus dem z.B. der Darm gebildet wird (Gardner und Rossant, 1979; Hogan et al., 1994; Bürki, 1986; Tam und Behringer, 1997; Theiler, 1989; Rugh, 1990).

Im Alter E8,5 geht die Gastrulation zu Ende und die Neurulation beginnt mit der Bildung der Neuralwülste im vorderen Bereich auf der dorsalen Seite des Embryos. Im neuralen Gewebe beginnt durch laterale Inhibition die spezifische 
Zellentwicklung. In diesem Stadium kommt es zu umfangreichen Faltungen im Embryo, in dessen Verlauf sich das Endoderm, welches bisher den ventralen Bereich des Embryos darstellte, nach innen verlagert und den Darm bildet. Nun beginnt sich auch der Kopf abzuzeichnen. Im Zeitraum zwischen E8,5 bis E9,5 vollzieht der Mausembryo ein komplexe Drehung um seine eigene Achse und nach Abschluß dieser Drehung ist er völlig vom schützenden Amnion und der Amnionflüssigkeit umgeben. Nach neun Tagen beginnt die Organogense (Hogan et al., 1994; Bürki, 1986; Tam und Behringer, 1997; Theiler, 1989; Rugh, 1990).

NOCH VOR DER GASTRULATION LIEGT EINE SYMMETRISCHE MORPHOLOGY UND GENEXPRESSION VOR

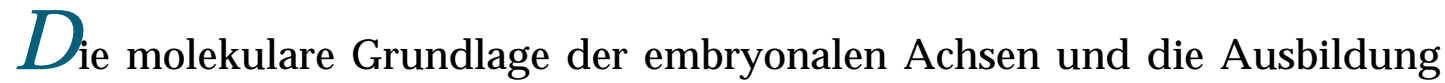
des Primitivstreifens sind noch umstritten. Klassische Überlegungen gehen davon aus, daß die Interaktion zwischen dem Epiblast und dem axialen Mesoderm für die Achsenbildung verantwortlich ist. Im Gegensatz dazu postulieren neuere Arbeiten ein anterior-posteriores Muster noch vor der Gastrulation (Beddington und Robertson, 1998). Es konnte sogar gezeigt werden, daß die Spermieneintrittstelle von Bedeutung ist (Piotrowska und Zernicka-Goetz, 2001).

Die Expression des Irx1 Gens beginnt noch vor der Gastrulation im extraembryonalen Gewebe. Aufgrund des interessanten Expressionsmusters während der Gastrulation ist eine Funktion dieses Gens in diesem entwicklungsbiologisch so bedeutsamen Prozeß der Regionalisierung gut denkbar.

\section{Vormustergene DER MAUS: DIE IROQUOIS-HOMEOBOX-GENE}

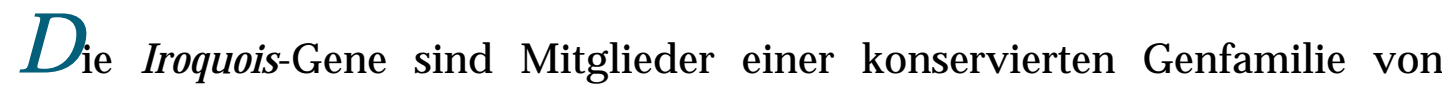
Homeodomänen-kodierenden Transkriptionsfaktoren (Burglin, 1997), die in der embryonalen Musterbildung und Regionalisierung sowohl bei Invertebraten wie auch Vertebraten eine wesentliche Rolle spielen (Gómez-Skarmeta et al., 1996; Gómez-Skarmeta et al., 1998). Von den Iroquois homeobox- (Irx-) Genen 
konnten bisher sechs Familiemitglieder in der Maus beschrieben werden - Irx1, Irx2, Irx3, Irx4, Irx 5 und Irx6 (Bosse et al., 1997; Bosse et al., 2000; Peters et al., 2000; Cohen et al., 2000; Bruneau et al., 2000). Es erfolgten noch keine funktionellen Beschreibungen dieser Mausgene und die vorliegende Arbeit stellt somit die erste funktionelle Analyse dar. Es gibt ebenfalls humane IrxHomologe und zwar hIRX1, hIRX2 (Lewis et al., 1999), hIRX3, hIRX4 (Bruneau et al., 2000), hIRX5 und hIRX6. Auch hier gibt es noch keine funktionelle Beschreibung. Für das hIRX2 liegen es erste funktionelle Hinweise aus der Analyse von humanem Brustkrebs (Lewis et al., 1999) vor. Weitere Analysen in Vertebraten wurden in Xenopus laevis, Gallus gallus und in Caenorhabditis elegans durchgeführt. Im Xenopus laevis konnte den Iroquois-Genen Xiro1, Xiro2 und Xiro3 eine Rolle während der Neurogenese zugeschrieben werden (Bellefroid et al., 1998; Gómez-Skarmeta et al., 1998). Im Huhn wurden bisher cIrx2 (Goriely et al., 1999), cIrx3 (Funayama et al., 1999), cIrx4 (Bao et al., 1999) identifiziert und in C. elegans Ziro3 (Tan et al., 1999). Dabei zeigen erste Hinweise, daß cIrx4 eine wichtige Rolle während der Herzentwicklung spielt und cIrx3 während der Coelombildung von Bedeutung ist (Bao et al., 1999; Funayama et al., 1999).

Eine Reihe von homologen Genen, die während der Entwicklung der sensomotorischen Organe der Fruchtfliege eine Rolle spielen, haben auch eine wesentliche Funktion während der Embryogenese der Maus (Tanabe und Jessel, 1996; Jessell und Sanes, 2000; McMahon, 2000). Daher ist es von größtem Interesse, mögliche konservierte und auch nicht konservierte genetische Interaktionen der Iroquois-Gene zu charakterisieren.

\section{ZIEL DIESER ARBEIT}

Ziel dieser Arbeit ist es, das Iroquois homeobox Gen Irx1 (Iroquois homeobox $\underline{1}$; (Zülch, 1997; Bosse et al., 1997)) strukturell und funktionell zu charakterisieren. Dazu wurde zunächst das zeitliche und räumliche Expressionsmuster bestimmt. Desweiteren nutzte ich die Möglichkeit, die Funktion des Gens in Mausmutanten der potentiellen Regulatorgene $\mathrm{zu}$ analysieren und so auch ein mögliches Netzwerk mit regulierenden und kontrollierten Genen ("upstream" und "downstream") zu erstellen. Die funktionelle Analyse wurde mit Hilfe der 
ES-Zell-Technologie durchgeführt, wobei ich durch gezielte Mutagenese die Rolle des Irx1-Gens während der Entwicklung der Maus untersuchte. 


\section{ERGEBNISSE}

Grundlage dieser Arbeit war meine vorangegangene Analyse des Irx1-Gens, vormals Irx2 genannt, die das Thema meiner Diplomarbeit ausmachte. Zu Beginn meiner Doktorarbeit lag ein in Ansätzen charakterisierter genomischer und cDNA-Klon des Irx1-Gens vor. Durch RNA in-situ-Analyse war die Expression von Irx1 während der ZNS-Entwicklung von E9,5 bis E11,5 beschrieben worden (Zülch, 1997).

Ziel der Doktorarbeit ist die detaillierte Expressions- und Funktionsanalyse des Irx1-Gens in der Maus. Meine Arbeit beinhaltet die Untersuchung der Irx1Genstruktur sowie des zeitlichen und räumlichen Expressionsmusters durch RNA in-situ-Analyse. Ferner wird die Funktion des Irx1-Gens in Mausmutanten und in-vitro-Experimenten mit potentiellen regulativen Partnern untersucht. Die gezielte Mutagenese des Irx1-Gens durch homologe Rekombination bildet die Grundlage der Phänotypanalyse. Die Irx1-defizienten Mäusen wurden im Anschluß detailliert analysiert und charakterisiert.

\section{II.1. STRUKTURANALYSE DES IRX1-GENS}

Die vollständige Kenntnis der kodierenden Sequenz ist die Voraussetzung für weitere Analysen, ins besondere für Funktionsanalysen. Von der Nukleotidsequenz kann man auf die Aminosäuresequenz schließen und dies ist die Grundlage, um konservierte Bereiche in der Nukleotid- bzw. Aminosäuresequenz zu finden. 


\section{II.1.1. DURCHMUSTERUNG EINER CDNA-BIBLIOTHEK ZUR KOMPLETTIERUNG DER IRX1-SEQUENZ}

$U_{m}$ die vorhandene Irx1-cDNA-Sequenz zu vervollständigen (Zülch, 1997), wurde eine Maus-cDNA-Bibliothek (Stratagene) mit einer Irx1-spezifischen Sonde durchgemustert. Die gewonnene Irx1-cDNA wurde aus dem Phagenvektor in einen Plasmidvektor umkloniert und die weiteren Analysen mittels Restriktions- und Sequenzuntersuchungen durchgeführt.

\section{HERSTELLEN DER IRX1-SONDE}

Da der bis dahin vorhandene Irx1-Klon nicht vollständig im 5'-Bereich war, mußte die zu verwendende Sonde möglichst weit 5' gelegen sein. Ferner sollte die Sonde keine Homeobox enthalten, um ein möglichst spezifisches Durchmustern $\mathrm{zu}$ ermöglichen. Der vorhandene Klon wurde mittels Restriktionsendonukleasen geschnitten, so daß ein BS300-Fragment, den Vorgaben entsprechend, entstand.

\section{ISOLIERUNG DES 5'-BEREICHS DER IRX1-CDNA}

Für die Identifizierung der Irx1-cDNA Klone wurde eine E10,5-Maus-cDNABibliothek mit der Irx1-BS300-Sonde durchgemustert. Dabei wurden 200.000 Phagen ausplattiert, deren inserierte DNA das 4 - 8-fache des Mausgenoms abdeckte. Durch Hybridisierung mit der Sonde bei hoher Stringenz und anschließender Subklonierung der hybridisierenden Fragmente konnten 12 Klone isoliert werden, die unterschiedliche Restriktionsmuster aufwiesen. Die Analyse der 12 Klone ergab drei unterschiedliche Irx1-cDNA Fragmente, genannt Irx1-a, Irx1-b, Irx1-c und Irx1-d. Irx1-a stellt das ursprüngliche

Fragment dar. Das Irx1-d-Fragment beinhaltet die größte neue Sequenzinformation im 5'-Bereich.

\section{KLONIERUNG DER KOMPLETTEN IRX1-CDNA}

Um die ganze Irx1-cDNA in einem Klon zur Verfügung zu haben, wurden die Fragmente Irx1-a und Irx1-d mittels einer MseI-Restriktionsschnittstelle 
zusammenkloniert und ergaben den Klon Irx1-500. Dieser Klon beinhaltet die komplette kodierende Irx1-Sequenz (2.390 bp).
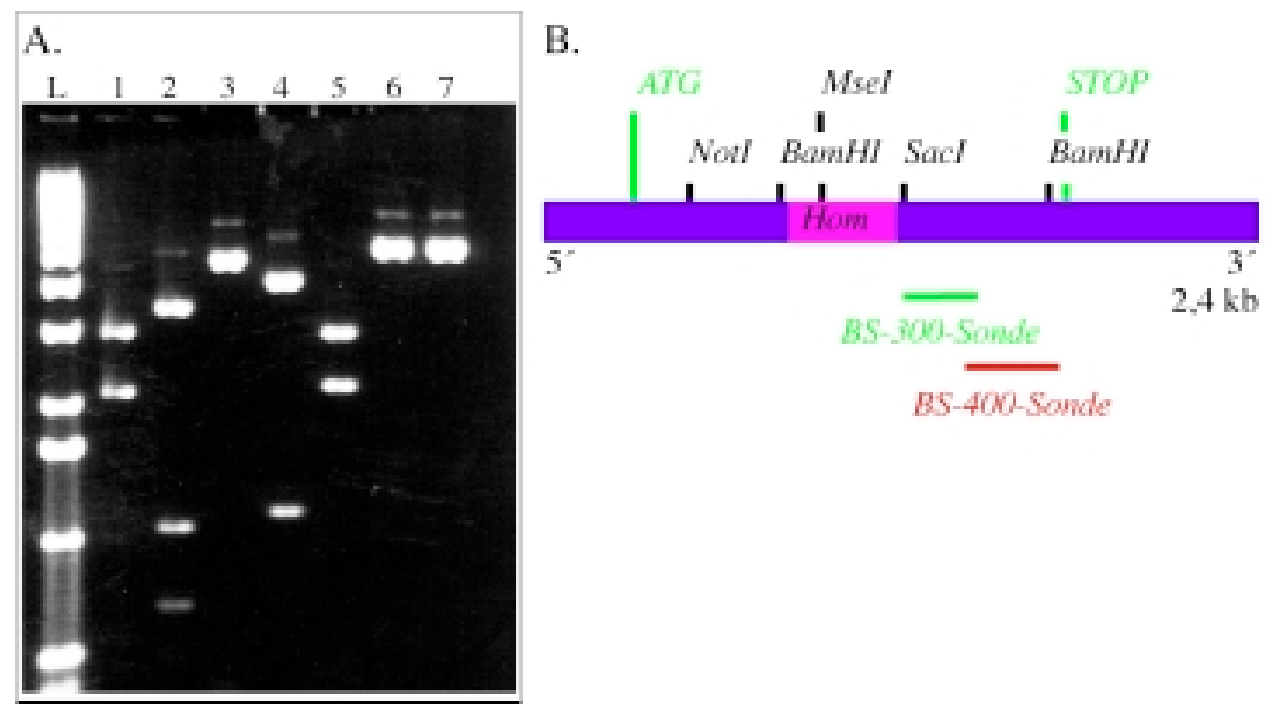

Abb. II.1: Die Irx1-cDNA

A. Die Abbildung zeigt Kontollanalysen der Klonierung Irx1-500. Dieser Klon wurde aus den Irx1-Einzelklonen hergestellt.

B. Die Abbildung zeigt eine schematische Darstellung der 2.390 bp großen Irx1cDNA. Dieser Klon umfaßt auf der 5'-Seite den Transkriptionsstart (ATG) gefolgt von der Homeobox (Hom). Im 3'-Bereich befindet sich der Transkriptionsstop (STOP; TGA). Ferner sind die beiden Hybridisierungssonden BS-300 und BS-400 angegeben.

Abkürzungen: Restriktionsanalysen \#1-\#7: EcoRI, BamHI, Notl, Sacl, Clal+Spel, Clal, Spel; L: 1kb-DNA-Marker

\section{II.1.2 SEQUENZANALYSE DER IRX1-CDNA}

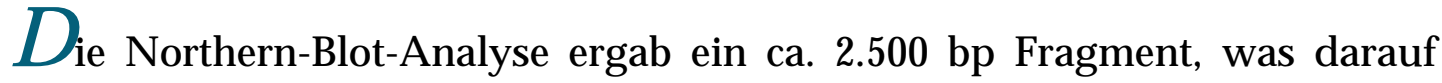
hindeutet, daß in dem Irx1-Klon die gesamte kodierende Nukleotidinformation vorhanden ist. Der 2.390 bp große Irx1-Klon ist vollständig sequenziert. Der Translationsstart (ATG) des Irx 1 Gens liegt bei der Position 308 bp und das Ende (TGA) bei Position 1.691 bp. Dieses Iroquois-Gen weist eine Homeobox (Gehring, 1994) auf, die sich von 629 bp bis 816 bp erstreckt. Ferner beinhaltet die kodierende Irx1-Sequenz im 3'-Bereich eine sog. Iro-Box (Burglin, 1997; 1178 bp bis $1217 \mathrm{bp})$. 


\section{Die Nukleotid- wie auch Aminosäuresequenz von Irx1 ist im folgenden}

\section{abgedruckt.}

IRX1-NUKLEOTIDSEQUENZ:

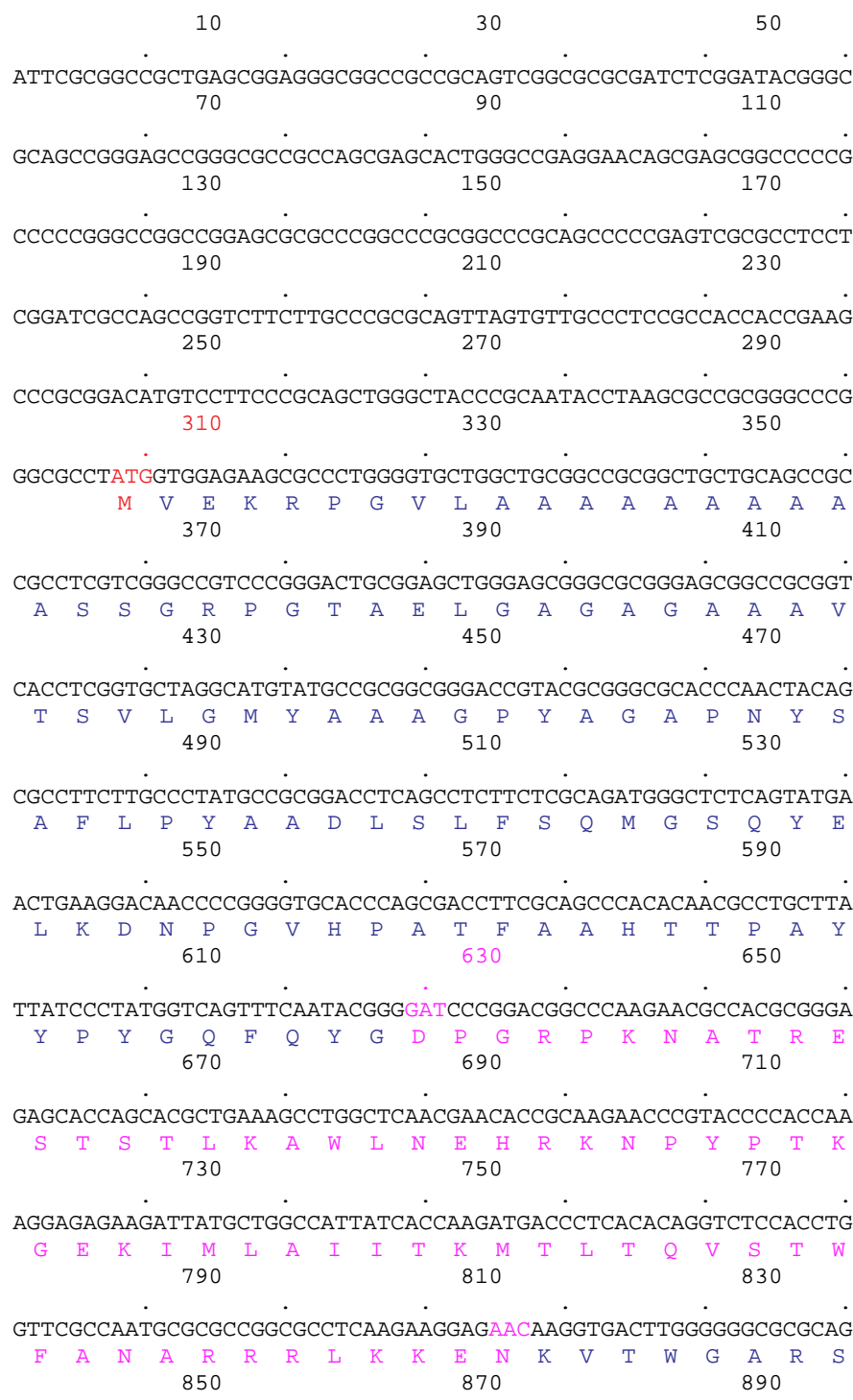

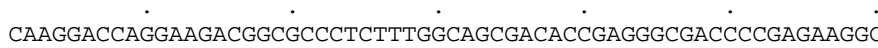

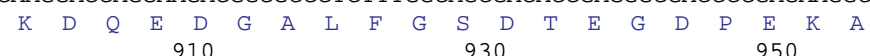
CGAGGACGACGAGGAGATCGACCTGGAGAGCATTGACATCGATCAGATCGACGAGCGTGA $\begin{array}{llllllllllllllllllll}E & D & D & E & E & I & D & L & E & S & I & D & I & D & Q & I & D & E & R & D\end{array}$ TGGCGACCAGAGCAACGAAGACGAAGAGGACAAGGCGGAGGCTCCTAGGGCGCCGTACC $\begin{array}{lllllllllllllllllllll}G & D & Q & S & N & E & D & E & E & D & K & A & E & A & P & R & A & R & V & P\end{array}$ $1030 \quad 1050 \quad 1070$

CCCTCCCGCCTCAGCTCGGGACCAGAGCTCCCCATTGTCGGCTGCTGAGACACTCAAGTC $\begin{array}{llllllllllllllllllllll}\text { P } & \text { P } & \text { A } & \text { S } & \text { A } & R & \text { D } & \text { Q } & \text { S } & \text { S } & \text { P } & \text { L } & \text { S } & \text { A } & \text { A } & \text { E } & \text { T } & \text { L } & \text { K } & \text { S }\end{array}$ $1090 \quad 1110 \quad 1130$ TCAAGATTCGCCCTTGGGCCTGGTTAAGGAGGTCTCAGAGCCCGGCAGCACACGCCTGCT $\begin{array}{llllllllllllllllllllll}\text { Q } & \text { D } & \text { S } & \text { P } & \text { L } & G & \text { L } & \text { V } & \text { K } & \text { E } & \text { V } & \text { S } & \text { E } & \text { P } & \text { G } & \text { S } & \text { T } & \text { R } & \text { L } & \text { L }\end{array}$ $11501170 \quad 1190$

GAGTCCTGGCGCCGCGGCGGTCGGCCTGCÄGGCGCGCCGCACAGCAAGCCCAAGATCTG $\begin{array}{llllllllllllllllllll}\text { S } & \text { P } & G & \text { A } & \text { A } & \text { A } & \text { V } & G & \text { L } & Q & G & \text { A } & \text { P } & \text { H } & \text { S } & \text { K } & \text { P } & \text { K } & \text { I } & \text { W } \\ 1210 & & & & & & 1230 & & & & & & 1250 & & \end{array}$ 
GTCTCTGGCTGAGACAGCCACTAGCCCCGACGGTGCGCCTAAGGCGTCTCCACCGCCAC.

$\begin{array}{lllllllllllllllllllllll}S & \text { L } & \text { A } & \text { E } & \text { T } & \text { A } & \text { T } & \text { S } & \text { P } & \text { D } & \text { G } & \text { A } & \text { P } & \text { K } & \text { A } & \text { S } & \text { P } & \text { P } & \text { P } & \text { P }\end{array}$

$\begin{array}{rrrrr}1270 & 1290 & 1310\end{array}$

CTCAAGCCACGCCAGCGCACACGGGCCGCCCAGCGGCTCACCCCTGCAACACCCGGCCTT

$\begin{array}{llllllllllllllllllll}\text { S } & S & H & A & \text { S } & \text { A } & \text { H } & G & \text { P } & \text { P } & \text { S } & \text { G } & \text { S } & \text { P } & \text { L } & \text { Q } & \text { H } & \text { P } & \text { A } & \text { F } \\ & & & 1330 & & & & & & 1350 & & & & & & 1370 & & \end{array}$

TCTACCCAGCCACGGACTGTACACCTGTCACATAGGCAAGTTTTCCAACTGGACCAACG'

$\begin{array}{llllllllllllllllllll}L & P & S & H & G & \text { L } & Y & \text { T } & C & H & I & G & \text { K } & \text { F } & \text { S } & \text { N } & \text { W } & \text { T } & N & G\end{array}$ $1390 \quad 1410 \quad 1430$

CGCGTTCCTÄGCACAGGGCTCGCTGCTGAÄATGCGATCTTTCCTGGGCGTCAGCGCGCC $\begin{array}{llllllllllllllllllll}\text { A } & F & L & A & Q & G & S & L & L & N & M & R & S & F & L & G & V & S & A & P\end{array}$ $1450 \quad 1470 \quad 1490$

GCATGCAGCACCTCACGGCCCACACCTGACAGCACCACCACCTCCACAGCCGCCAGTCCA $\begin{array}{llllllllllllllllllll}\text { H } & \text { A } & \text { A } & \text { P } & \text { H } & \text { G } & \text { P } & \text { H } & \text { L } & \text { T } & \text { A } & \text { P } & \text { P } & \text { P } & \text { P } & \text { Q } & \text { P } & \text { P } & \text { V } & \text { Q }\end{array}$ $\begin{array}{lll}1510 & 1530 & 1550\end{array}$

GGTTGCCACCGGGGTGCTCCATGGTGAGAAGGCCTCCGCACGCAGCAGTCCTGCACTTCC $\begin{array}{lllllllllllllllllllll}\text { V } & \text { A } & \text { T } & G & \text { V } & \text { L } & \text { H } & G & \text { E } & \text { K } & \text { A } & \text { S } & \text { A } & R & \text { S } & \text { S } & \text { P } & \text { A } & \text { L } & \text { P }\end{array}$ $\begin{array}{lll}1570 & 1590 & 1610\end{array}$

AGAGAGAGACCTAGTCACCAGACCGGATTCGCCCCCACAÄAAGTTAAAGTCGCCCTTCCA

$\begin{array}{llllllllllllllllllllll}E & R & D & L & V & T & R & P & D & S & P & P & Q & Q & L & K & S & P & F & Q\end{array}$ $\begin{array}{rrrrrrr}1630 & 1650 & & & 1670\end{array}$

GCCGGTGCGCGACAACTCGCTGGCCCCGCÄGAGGGAACGCCTCGGATCCTCGCAGCCCT $\begin{array}{cccccccccccccccccccc}\text { P } & V & R & D & N & \text { S } & \text { L } & \text { A } & \text { P } & Q & \text { E } & G & \text { T } & \text { P } & \text { R } & \text { I } & \text { L } & \text { A } & \text { A } & \text { L } \\ 1690\end{array}$ CCCGTCTGCCTGATTAAGGGGGGTCATCTTTTACTTTTGCGGGGGGAGGGGAGGGGGA $\dot{\cdot}$ $\begin{array}{llllllll} & \text { P } & \text { S } & \text { A } & * & \text { L } & \text { R } & \\ 1750 & & & & 1770 & & 1790\end{array}$ GGTTGGGGGGGAGGAGACGAGGGAAGAATTAAGACAAATATTTGAGACTTGTGTAAAGGA $1810 \quad 1830 \quad 1850$

CAAACGTGACGGCAGCGTCAGTGATTCTCACACATCGCTCTCTGCAGAAAGGGGCTCATCं $1870 \quad 1890 \quad 1910$

CTGCCTAAGCGCTTGGGAAGGGGGGAGTAÄGGCTCAGCCTCGCCGCTCGGATtGATtATC $\begin{array}{rr}1930 & 1950 \\ \end{array}$

CGATTCGGTAAATGCCCCCCTCCCACTTCTGTGTTTGTGTCTTCTTTGTTTCTTTTTCC $1990 \quad 2010 \quad 2030$

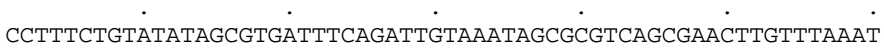
$20502070 \quad 2090$

CATATATtTTtGTCTAATAAACTAAATGAAACGATGTCCACGCGGCTACAGCTGTTTGTCं $2110 \quad 2130 \quad 2150$

CCTGTCCTCCTGCGTTTTGGGGGAGGCCATGATGTtTGCGATCTTGAAATCCTGGGCACA $21702190 \quad 2210$

GTTCAGGGGCTATGGTTTCGCCAGACTCTTTTGGGAGAAGGGTCTTGGAACAGTGTTTCC $22302250 \quad 2270$

ACCGAGTGTCAGGCGCACAGTCCGTGATGGTAGTGGTTGAATTTGTTCGTTTTGCTCCTA $2290 \quad 2310 \quad 2330$ $\begin{array}{ccc}\text { GGCCAGCTTCTTGTTGGCAGTGTAAATCTTTGCCACGCTTAGACAAGCGTTTATCTGGAG } \\ 2350 & 2370 & 2390\end{array}$

CAgCCTtTtTAAGTACATAAATGCGTTCAATtTAGACAGTTTACAAAAAA

Abb. II.2: Irx1-cDNA Sequenz

Die Abbildung zeigt die Irx1-Nukleotidsequenz der cDNA und die kodierte Aminosäuresequenz. Der Transkriptionsstart (ATG; 308 bp) und der Transkriptionsstop (TGA; $1691 \mathrm{bp}$ ) sind eingezeichnet und farblich markiert. Ebenso ist die Homeobox (629 bp bis 816 bp) und die Iro-Box (178bp bis 1217bp) eingezeichnet.

Abkürzungen: ATG: START; TGA: STOP; DPG ... KEN: Homeodomaine; PHS ... ETA: Iro-Domäne 


\section{IRX1-PROTEINSEQUENZANALYSE}

Mittels zweier algorhythmischer Berechnungen konnte eine potentielle Sekundärstrukturvorhersage des Irx1-Proteins getroffen werden. Dazu wurden Berechnungen mit dem Chou-Fassmann-(CF) und dem Ganier-OsguthhorpeRobson (GOR)-Algorhythmus angestellt (Chou und Fasman, 1978; Garnier et al., 1978). Diese dienen dazu, $\alpha$-Helices, $\beta$-Faltblattstrukturen und Drehungen in der sekundären Aminosäuresequenz vorherzusagen. Aus diesen Berechnungen ergibt sich im Bereich der Homeodomäne eine zu erwartende Helix-SchleifeHelix-Struktur. Ferner sind im Bereich der Iro-Domäne potentielle $\beta$ Faltblattstrukturen erkennbar, die durch ein vermehrtes Auftreten von Prolin begründbar sind. Das Irx1-Protein weist einen Alanin-reichen Bereich (10 - 19 aa), eine potentielle Phosphorylierungsstelle für eine MAP-Kinase (mitogenactivated protein kinase; 416 - 449 aa) und einige saure Aminosäurenbereiche im mittleren Teil (180 - 230 aa) auf. Dieser sauren Region wird eine Rolle in der Aktivierung der Transkription zugesprochen (Burglin, 1997).

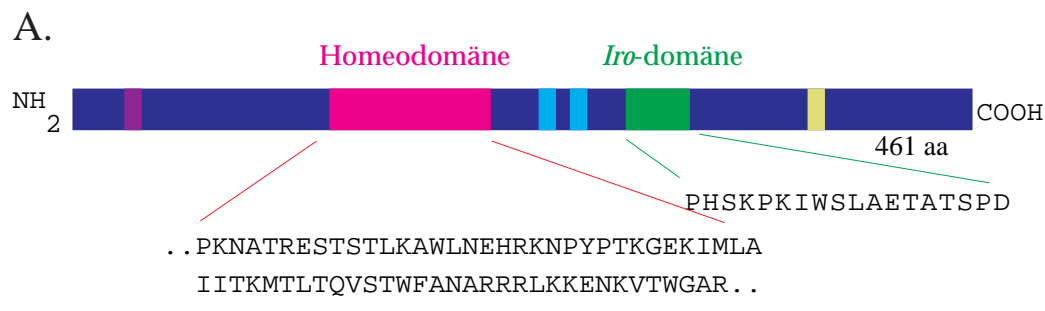

B.

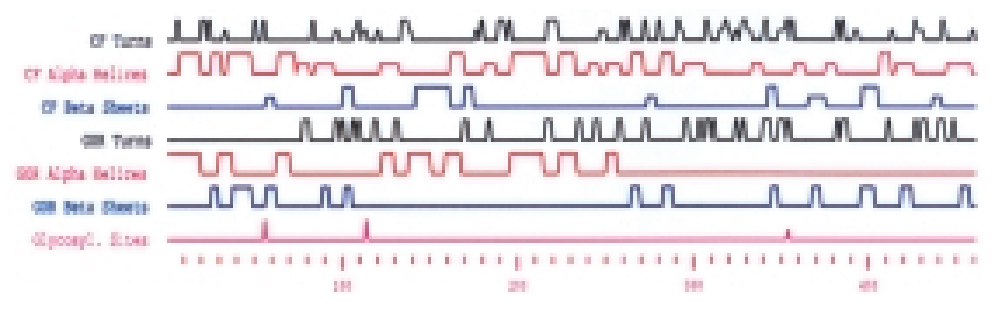

Abb. II.3: Struktur Irx1-Proteins

A. Die Struktur des 461 aa großen Irx1-Proteins mit der Homeodomäne (rosa) und Iro-Domäne (grün). Ferner ist der Alaninstrech (lila), die sauren Bereiche (türkis) und die potentielle MAPK-Stelle (gelb) markiert. 
B. Die Abbildung stellt die Ergebnisse der Sekundärstrukturvorhersage mittels algorhythmischer Berechnungen dar. Es wurden Chou-Fassmann-(CF) und GanierOsguthhorpe-Robson (GOR) Berechnungen zu Grunde gelegt. Erkennbar ist die Helix-Schleife-Helix-Struktur im Bereich der Homeodomäne (Hom) und die $\beta$ Faltblattstrukturen im Bereich der Iro-Domäne (IRO).

Das Irx1-Gen kodiert für ein theoretisches Protein aus 461 aa mit einem Molekulargewicht von 55 kDa. Davon bilden 63 aa die Homeodomäne, die aus vier $\alpha$-Helices besteht, und 14 aa die Iro-Domäne.

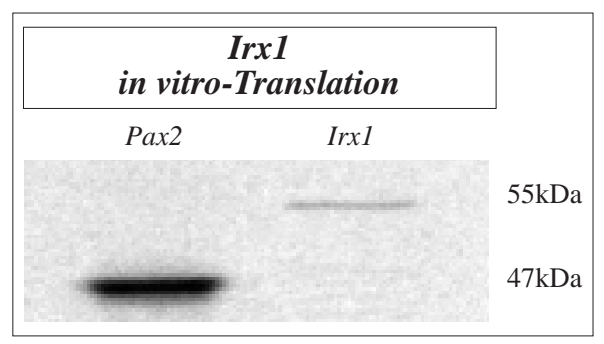

Abb. II.4: Die Abbildung zeigt eine Irx1-in-vitro-Translation.

Die in-vitro Translation wurde mit der Irx1-cDNA (Irx1-500) durchgeführt (T7-RNAPolymerase; pBSKS+). Das Irx1-Gen kodiert für ein 55 kDa großes Protein. Als positive Kontrolle diente die Pax2 -cDNA, die für ein 47 kDa großes Protein kodiert.

Alle Iroquois-Gene zeigen einen hohen Grad an evolutiver Konservierung der Sequenz in der Homeodomäne. Innerhalb der Maus Irx-Gene (Irx1, Irx2, Irx3, Irx4, Irx5 und Irx6) liegen Übereinstimmungen von $90-100 \%$ auf Aminosäureebene vor. Typischerweise zeigen alle Mitglieder der IroquoisProteinfamilie ein Alanin an der Aminosäureposition 50 der Homeodomäne. Keine andere bekannte Homeodomäne zeigt an dieser Stelle ein Alanin, die von besonderer Bedeutung ist, da dies die Aminosäureposition 9 der Erkennungshelix ist. Diese Position ist entscheidend an der DNA-Bindung beteiligt (Treisman et al., 1989).

Aminosäurevergleich der murinen Iroquois-Genfamilie:

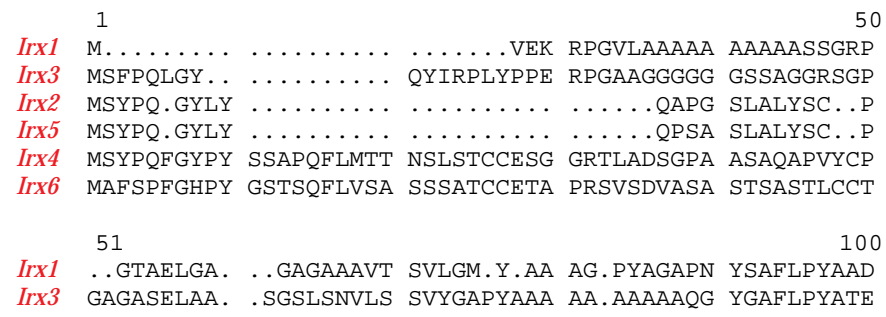


Irx2 AYGASALAAP RSEELARSAS GSAFSPYPGS AAFTAQAATG FGSPLQYSAD Irx5 AYSTSVISGP RTDELGRSSS GSAFSPYAGS TAFTA.PSPG YNSHLQYGAD Irx4 VYESRLLATA RHELNSAAAL GVYGSPYGS. ............... YGNYVTYGSE Irx6 PYDSRLLGSA RPEL.. GAAL GIYGAPYAA. ........AQS YPGYLTYGPE

101

Irx1 LSLF.SQMGS QYELKDNPGV .HPA.TFAA. .HTTPAYYPY GQFQY.... Irx3 LPIF.PQLGA QYELKDSPGV QHPA. TAAAF PHPHPAFYPY GQYQF .... Irx2 AAAA. AAAGF P.SYVGSPYD THTT.GMTGA ISYHPYGSAA YPYQL..... Irx5 PAAA. AAAAF ...SYVGSPYD . HTP.GMAGS LGYHPYAAPL GSYPY..... Irx4 ASAFY.SLN. SFESKDGTGS SHAGLPPTAA AAYYPYEPAL SQYPYDRYGT Irx6 PPTLCGALNP QYEFKDAAGS FAPSL..TQP GAYYPYETTL GQYQYDRYGG

151

200

Irx1 ...GDPGRPK NATRESTSTL KAWLNEHRKN PYPTKGEKIM LAIITKMTLT Irx3 ...GDPSRPK NATRESTSTL KAWLNEHRKN PYPTKGEKIM LAIITKMTLT Irx2 ...NDPAYRK NATRDATATL KAWLNEHRKN PYPTKGEKIM LAIITKMTLT Ir $x 5$...GDPAYRK NATRDATATL KAWLNEHRKN PYPTKGEKIM LAIITKMTLT Irx4 VD..SGTRRK NATRETTSTL KAWLOEHRKN PYPTKGEKIM LAIITKMTLT Irx6 VELSSAGRRK NATRESTSAL KAWLHEHRKN PYPTKGEKIM LAIITKMTLT

201

IrxI OVSTWF NAR RRIKKENKVT WGARSKDOED GALFGSDTEG DPEKAEDDEE Irx3 QVSTWFANAR RRLKKENKMT WAPRSRTDEE GNAYGSEREE EDEE.EDEEE Irx2 QVSTWFANAR RRLKKENKMT WAPRNKSEDE DEDEG.DASR SKEESSDKAQ Irx5 OVSTWF NAR RRLKKENKMT WTPRNRSEDE EEEENIDLEK NDEDEPOKPE Irx4 QVSTWFANAR RRLKKENKMT WPPRNKCADE KRPYGEGEEE EAGEEESREE Irx6 QVSTWFANAR RRLKKENKMT WAPKNK..........GGEER KADSGEDSLG

251

Irx1 I.DLE.SIDI DQIDERDG....... . DQSNE DEE....... . DKAEAPRA Ir $x 3$ S.KRELEMEE EELAGRGGGH GGRGAGRRRR DEEIDL.... E NLDSAAAGSE Irx 2 D.GTETSAED EGISLHVDSL TDHSCSAESD GEKLPCRAGD ALCESGSECK Irx5 D.KGDLEGPE SG...GAEQK ATAGCE.RLQ GPLSP..AGK ETEGSLSDSD Irx4 PLKSAKSEGH AGKDDKELEL SDLEDFDPLD AETSECELKT PFQSLDSGPE Irx6 CLNGDTKDAT ASQEARGLRL SDLED... LE EEEEEEEAEE ...EAAVSAAR

301 350

Irx1 RVPPPASARD QS...S.PLS AAETLKSQDS .......PLG LVK...... Ir $x 3$ LTLAGAAHRN GDFGLG.PIS DCKTSDSDDS SEGLEDRPLS VLSLAPPPPP Irx2 DKFEDLEDEE DEEDEC.ER. .DLAPPKPVT S..SPLTGVE APLLSPAPEA Ir $x 5$ FKESSSEGRH DELPRP.PRA GESSPAGPAT ARLAEDAGPH YPASVPAPGP Irx4 RIPASSDGPG TGKEASTTLR MPLGTAGGAV MDGDLERARN CLRSTVVVPD Irx6 RL....... ADFQKST... QPLPAPCAAA QEGCLE.SRE C...GLGLPR

351

Irx1 EVSEPG S. TRLLSPG AAAVGLOGAP HSKPKTWSTA ETATSPDGAP Ir $x 3$ VARAPASPPS P..PSSLDPC APAPAPSSA. LQKPKIWSLA ETATSPDN.P Irx2 APRG.....G SGGKTPLGSR TSPGAPP..P ASKPKLWSLA EIATSDLKQP Irxy HPSAGELPPG SGGSSVIHSP PPPPPPPPAV LAKPKLWSLA EIATSSDKVK Irx4 SGAEGGPPAC EAKLTFAQAG APPNL..... ETKPRIWSLA HTATAAAATA Irx6 FSFTEAPQSG EADFITAEPG GPTMILHYPS GHKPRIWSLA HTAAASAVES

401

450

Irx1 KASPPPP...S SHASA...HG PPS..GSPLQ HPAFLPSHGL YTCHIGKFSN Irx3 RRSPPGAGGS PPGAA...VA PPTLQLSPAA AAAAAAAHRL VSAPLGKFPA Irx2 SLG..........PGC....G P.....PGL PAAAAPASTG APPGGSPYSA Irx5 DGG.GGSEGS PCPPC...PG PMGGQTLGGS RASPAPAPAR SPSAQCPFPG Irx4 LSQT....EF PSC.MLKRQG PTGVSATTPA SSPAVTAPSG ALDRHQDSPV Irx6 APSTPPRAQS PECHMIPRQ. PSSIRRLLVP RDSEGEEDSP AAKAFGNSTF

451

500

Irx1 WT. NGA.F LA. . QGSLLN MRSFLGVSAP HAAPHGPHLT APPPPQPPVQ

Irx3 WT..NRP..F PGPPAGPRPH PLSMLG.SAP Q.....HLL GLPG.....

Irx2 SPLLGRHLYY TSPFYGNYTN YGNLNAALQG QGLLRYNTAA SSPGETLHAM

Irx5 GTVLSRPLYY TAPFYPGYTN YGSFGHLHGH PGPGPSPTA. . GPGSHFNGL

Irx4 TSLRNWVDGV FHDPILRHST LN. QAWATAK GALLDPGPLG RNLGAGTNVL

Irx6 T.LQGLPLNC APYPRRREPE VRFQYPSGAE G

501

Irx1 VATGVLH.GE KASARSSPAL PE..RDLVTR PDSPPQQLKS PFQPVRDNSL

Irx3 .AAG..HPAA AAAAYARPAE PESGTDRCSA LEVEKKLLKT AFQPV...PR

Irx2 PKA.A...SD TGKAGSHSLE SHYR...PPG GGYEPKKDTS EGCAVVGAGV

Irx5 NQT.VLNRAD VLAKDPKMLR SQSQLDLCKD SPYELKKGMS DI

Irx4 TTPLACSFPP TVPQDVPPAG ASRELLATPK AGGKPFCT

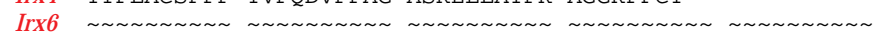

551

568

Irx1 APQE. .GTPR ILAALPSA

Irx3 RPQNRLDAAL VLSALSSS

Irx2 QTYL

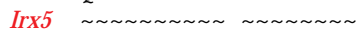

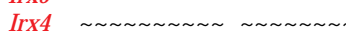

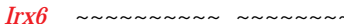

Abb. II.5: Aminosäurevergleich der Iroquois-Proteine der Maus. 


\begin{abstract}
Innerhalb der Homeodomäne weisen die Irx-Gene eine nahezu 100\%ige Übereinstimmung in der Aminosäuresequenz auf (rosa markiert). Bemerkenswert ist dabei auch das Alanin an Position 50 der Homeodomäne (türkis markiert). Das Protein weißt weiterhin Bereiche auf mit überdurchschnittlicher Übereinstimmung der Aminosäuresequenz (blau markiert). Die flankierenden Regionen weisen hingegen keine große Konservierung der Aminosäurequenzen auf. Eine Ausnahme bildet die hoch konservierte Iro-Domäne (hellgrün markiert).
\end{abstract}

Die Iro-Domäne zeigt ebenfalls eine sehr hohe Konservierung innerhalb der Maus-Irx-Gene, auch im Vergleich zu den anderen Mitgliedern der IroquoisFamilie (Daten nicht gezeigt (Burglin, 1997)). Bisher kann diesem kurzen Motiv keine Funktion zugeordnet werden, theoretisch kann es als Proteininteraktionsdomäne fungieren: Mittels eines Yeast-Two-Hybrid-Screens wurde ein neues Zn-Finger-Protein identifiziert, welches an dieses Iro-Motif bindet. Allerdings ist die Funktion dieses Proteins noch unklar (Zusammenarbeit mit J.L. Gómez-Skarmeta, Madrid).

\title{
II.1.3. DAS IRX1-ANTISERUM
}

Zur Herstellung eines spezifischen Antiserums gegen das Irx1-Protein wurden Proteinfragmente in E. coli überexprimiert, welche dann zur Immunisierung von Kaninchen benutzt wurden. Im Gegensatz zur Herstellung synthetischer Peptide hat dies den Vorteil, daß die Proteine länger und damit spezifischer sind, und entsprechend mehr Antikörper gebunden werden können.

Voraussetzung dafür war eine erfolgreiche Überexpression und Aufreinigung der Irx1-Fragmente. Dazu wurden verschiedene Irx1-cDNAFragmente, die über PCR-Amplification hergestellt worden waren, in einen Vektor kloniert, der eine starke Expression ermöglichte und die Möglichkeit bot, die exprimierten Proteine über eine kurze, fusionierte Sequenz mit Hilfe der sehr effizienten Affinitätsreinigung zu isolieren. Ein solches System stellt das Bakteriophage-T7-Promotor/Histidinhexamer-System dar (Stüber et al., 1990; Studier et al., 1990).

Alle Fragmente befinden sich im carboxyterminalen Bereich des Irx1-Proteins und beinhalten weder die Homeodomäne noch die Iro-Domäne. Es wurde dieser Bereich gewählt, um aufgrund der hohen Sequenzähnlichkeit zu anderen 
Ir $x$-Proteinen eine Kreuzreaktion auszuschließen. Es zeigte sich, daß das Irx1TI1-Fragment von Aminosäure 345-461 gut exprimiert wurde, und so wurde es zur Herstellung des Irx1-Antiserums benutzt.

A Homeodomäne Iro-domäne

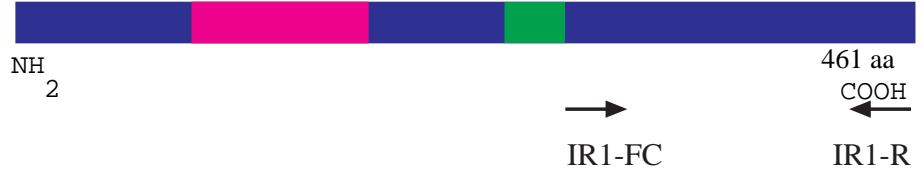

Irxl-TI1-Fragment

B.

C.

His-Tag Irxl-TI1-Fragment in $\mathrm{pET} 19 \mathrm{~b}$

MGHHHHHHHHHHSSGHIDDDDKHMLEGPPSGSPLQHPAFFLA QGSLLNMRSFLGVSAPHAAPHGPHLTAPPPPQPPVQVATGVLH GEKASARSSPALPERDLVTRPDSPPQQLKSPFQPVRDNSLAP QEGTPRIRLAAALPSA

Abb. II.6: Herstellung der Irx1-Fragmente

A. Die Abbildung zeigt den amplifizierten Irx1-Bereich (345-461aa), welcher als Irx1TI1-Fragment subkloniert, überexprimiert und zur Herstellung des Irx1-Antiserums benutzt wurde (Benutzte PCR-Primer: IR1-FC, IR1-R).

B. Die Abbildung zeigt das Irx1-TI1-Fragment mit His-Tag in pET19b kloniert.

C. Die Abbildung zeigt die Aminosäuresequenz des His-Irx1-TI1-Fragments. (Der His-Tag ist in türkis markiert und der Histidinbereich unterstrichen, während die Irx1Sequenz in lila markiert ist).

Dieses Fragment wurde exprimiert, gereinigt und in Kaninchen injiziert. Um Proteine hoher Reinheit $\mathrm{zu}$ erhalten, wurden die Bakterienextrakte zur Affinitätsreinigung zweimal über eine Nickelchelatsäule gegeben. Die Immunisierung führte zu einem funktionellen Antiserum mit guten Ergebnissen bei der Analyse von Western-Blots. 


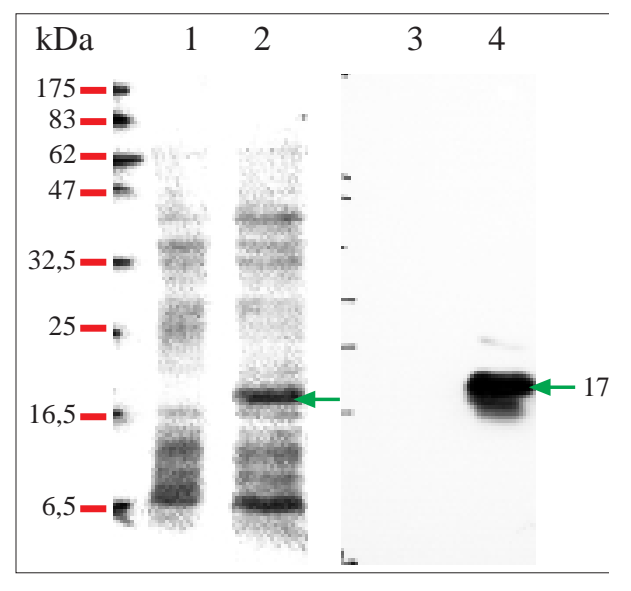

\begin{abstract}
Abb. II.7: Irx1-Antiserumreaktion
Die Abbildung zeigt Western-Blots, die mit Irx1-Antiserum inkubiert wurden. Dafür wurde ein Western-Blot aus Bakterienextrakt hergestellt. Die Bakterien wurden zuvor mit dem His-Irx1-TI1-pET19b transformiert $(2,4)$, während die Kontrolle mit pET19b transformiert worden war $(1,3)$. Beide Extrakte wurden in einem Proteingel aufgetrennt, mit Coomassie gefärbt $(1,2)$ und mit den Irx1-Antiserum inkubiert $(3,4)$. Deutlich ist die His-Irx1-TI1-Fragmentbande erkennbar (Pfeil). Exakt diese Irx1-TI1Bande wird durch das Irx1-Antiserum markiert (4), wohingegen kein Signal bei dem pET19b-Bakterienextrakt vorhanden ist. Da die Bakterien mit pET19b ebenfalls einen His-Tag exprimieren und kein Signal erkennbar ist, ist das Irx1-Antiserum spezifisch gegen $\operatorname{Ir} x 1$.
\end{abstract}

(Antiserum aus Kaninchen \#9111; 10\% Gel, 1\% Milchpulver)

Bei der Verwendung des Serums in der Histologie, vorrangig während der Analyse von Cyrostatschnitten, erwies sich der Antikörper jedoch nur als bedingt geeignet, da Hintergrundreaktionen auftraten. 


\section{II.2. ANALYSE DES RÄUMLICHEN UND ZEITLICHEN EXPRESSIONSMUSTERS DES IRX1- GENS}

Das Wissen über einen räumlichen und zeitlichen Expressionsverlauf eines Gens gibt erste Anhaltspunkte über dessen Funktion. Folgende methodische Ansätze wurden benutzt, um verschiedene Entwicklungsstadien der Maus zu untersuchen:

1) RNA-Analyse mittels Northern-Blot-Hybridisierung

2) nicht radioaktive Gesamtköper (whole-mount-) in-situ-Hybridisierungen

3) radioaktive in-situ-Hybridisierungen auf Mausparaffinschnitten.

\section{II.2.1. ANALYSE DES IRX1-TRANSKRIPTS WÄHREND DER} MAUSENTWICKLUNG

Zur Analyse des Transkriptes wurde eine Northern-Blot-Analyse durchgeführt. Diese ermöglicht zwei wesentliche Aussagen. Zum einen ermittelt man die Größe des untersuchten Transkriptes und zum anderen wird der zeitliche und räumliche Verlauf einer Expression gezeigt.

Für die Northern-Blot-Analyse wurde Gesamt- bzw. PolyA-RNA aus verschiedenen Entwicklungsstadien und Organen der Maus präpariert.

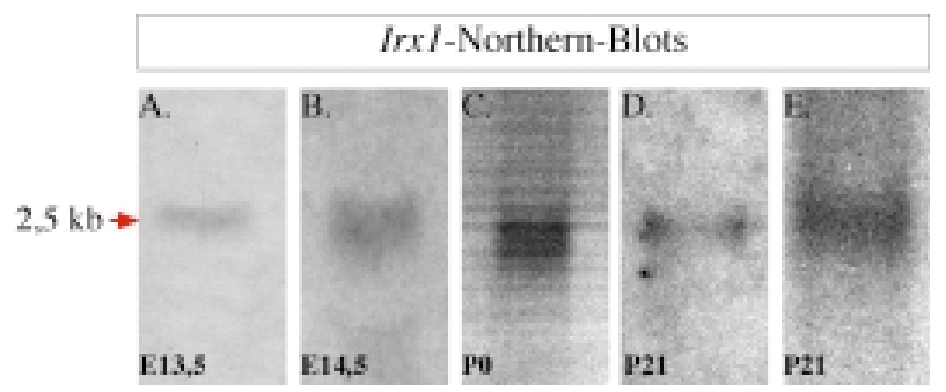

Abb. II.8: Irx1-Northern-Blot-Analyse 
Die Abbildung zeigt fünf verschiedene Maus-Northern-Blots, die alle mit einer 0,4 kbIrx1-Sonde (B/S400) hybridisiert wurden. Diese 3'-Sonde beinhaltet nicht die Homeobox. In allen Northern-Blots ist ein 2,5 kb Transkript markiert.

A.: Die Abbildung zeigt einen Gesamt-RNA Northern-Blot von E13,5 alten Embryonen.

B.: Die Abbildung zeigt einen PolyA-RNA Northern-Blot von E14,5 alten Embryonen.

C.: Die Abbildung zeigt einen PolyA-RNA Northern-Blot von neugeborenen Mäusen (Gehirn).

D.: Die Abbildung zeigt einen PolyA-RNA Northern-Blot von 21d alten Mäusen (Gehirn).

E.: Die Abbildung zeigt einen Gesamt-RNA Northern-Blot von 21d alten Mäusen (Lunge).

In den untersuchten Stadien und Organen konnte ein Irx1-Transkript von einer Länge von 2,5 kb nachgewiesen werden. Es konnte gezeigt werden, daß Irx1 embyonal (E13,5 und E14,5), im Stadium der Geburt (P0) und auch 21 Tage nach der Geburt (P21) aktiv ist. Die klonierte Irx1-cDNA ist 2,5 kb groß (s.o.), was im Vergleich mit dem nachgewiesenen Transkript darauf schließen läßt, daß die komplette kodierende Sequenz vorliegt.

\section{II.2.2. IRX1-EXPRESSION WÄHREND DER FRÜHEN GASTRULATION (E6,0 BIS E7,5)}

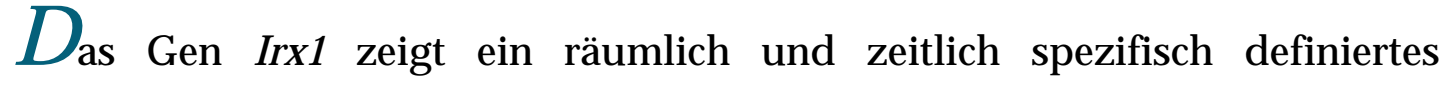
Expressionsmuster.

In RNA-in-situ-Hybridisierung von Embryonalstadien zeigte sich Irx1Expression im frühesten untersuchten Stadium am Tag 6,0 (E6,0). Das ist das Eizylinderstadium (E5,5-E6,0), an dem sich der eingenistete Embryo zu differenzieren beginnt. In diesem frühen Stadium ist $I r x 1$ im extraembryonalen Ektoderm exprimiert. Der Übergang zwischen extraembryonalem und embryonalem Gewebe entspricht exakt der distalen Grenze der Irx1-Expression. Einen halben Tag später $(E 6,5)$ beginnt die Gastrulation des Mausembryos, in deren Verlauf der frühe Primitivstreifen erkennbar wird und erste Mesodermzellen erscheinen (Hogan et al., 1994). Auch in diesem Stadium (E6,5) 
ist Irx1 noch immer im extraembryonalen Ektoderm an der extraembryonalembryonalen Grenze exprimiert.

Diese Irx1-Expression verändert sich einen Tag später $(E 7,0$ - 7,5) ganz wesentlich. Nun ist Irx1 in den lateral auswandernden Mesodermzellen aktiv. Im Stadiumder Gastrulation dehnt sich der Primitivstreifen weiter aus und auch die Bildung der Kopfanlagen beginnt. Mesodermale Zellen wandern vom Primitivstreifen lateral und posterior zwischen den anderen Keimblättern aus, aber niemals nach anterior.

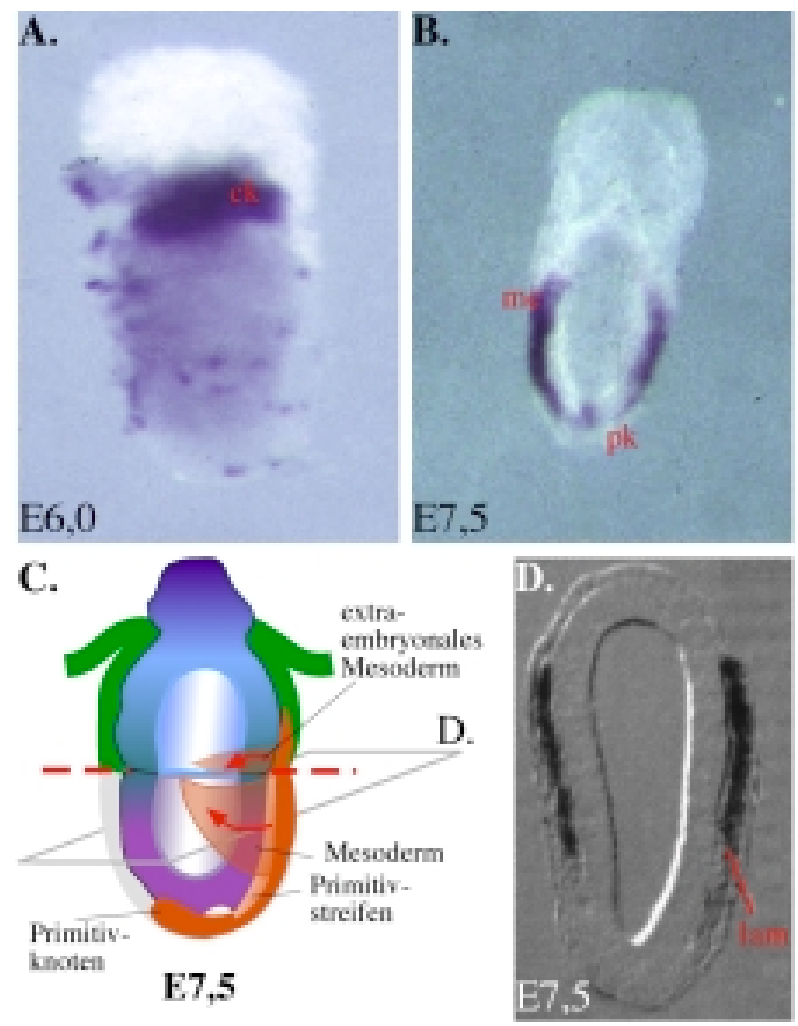

Abb. II.9: Irx1-Expression während der Gastrulation der Maus.

Die Abbildungen zeigen whole mount-in-situ-Analysen von Embryonen der Stadien E6,5 und E7,5 (A, B). Der E7,5 alte Embryo (B) wurde transvers geschnitten (D). Die Schnittebene ist in der Schemazeichnung (C) dargestellt.

A.: Die Expression von Irx1 ist gut im extraembryonalen Ektoderm erkennbar.

B.: Die Irx1-Expression wechselt in das laterale Mesoderm und den Primitivknoten. Abbildung B aus A. Zülch (Zülch, 1997)

C.: Die Schemazeichnung zeigt die Zellwanderungen der mesodermalen Zellen im Stadium E7,5 und gibt die Schnittebene des transversen Schnittes (D) wieder. 
D.: Die Abbildung zeigt einen transversen Schnitt durch den E7,5 Embryo im Bereich des embryonalen, lateralen Mesoderms.

Abkürzungen: ek: extraembryonales Ektoderm, lam: lateral-embryonales Mesoderm, me: embryonales Mesoderm, pk: Primitivknoten

In dem Stadium E7,5 verdichten sich am anterioren Ende des Eizylinders die Zellen des extraembryonalen Ektoderms und bilden die Kopfanlage. Irx1 ist auch im Primitivknoten exprimiert.

\section{II.2.3. IRX1-EXPRESSION WÄHREND DES NEURULATION (E8,5 BIS E9,0)}

Nach 8,0 bis 8,5 Tagen endet die Gastrulation, und die Neurulation beginnt mit der anterioren Bildung der Neuralwülste auf der dorsalen Seite des Embryos. Das Endoderm verlagert sich nach innen bildet und den Darm. Der Kopf wird erkennbar und Organe wie Leber und Herz nehmen ihre endgültige Position ein. Der Embryo dreht sich und wird nun vollständig von seinen extraembryonalen Membranen eingehüllt.

Im Stadium E8,5 ist Irx 1 in der Hirnanlage exprimiert und dabei am stärksten in den dorsolateralen Wänden der kranialen Neuralfalte erkennbar, welche die Mesenzephalonanlage darstellen. Ferner ist in Sagitalschnitten eine schwache Expression in der Rhombenzephalon-Anlage und in der posterioren Region des Neuralrohres erkennbar. Weiterhin ist I $r x 1$ im sich entwickelnden Vorderdarm aktiv. 

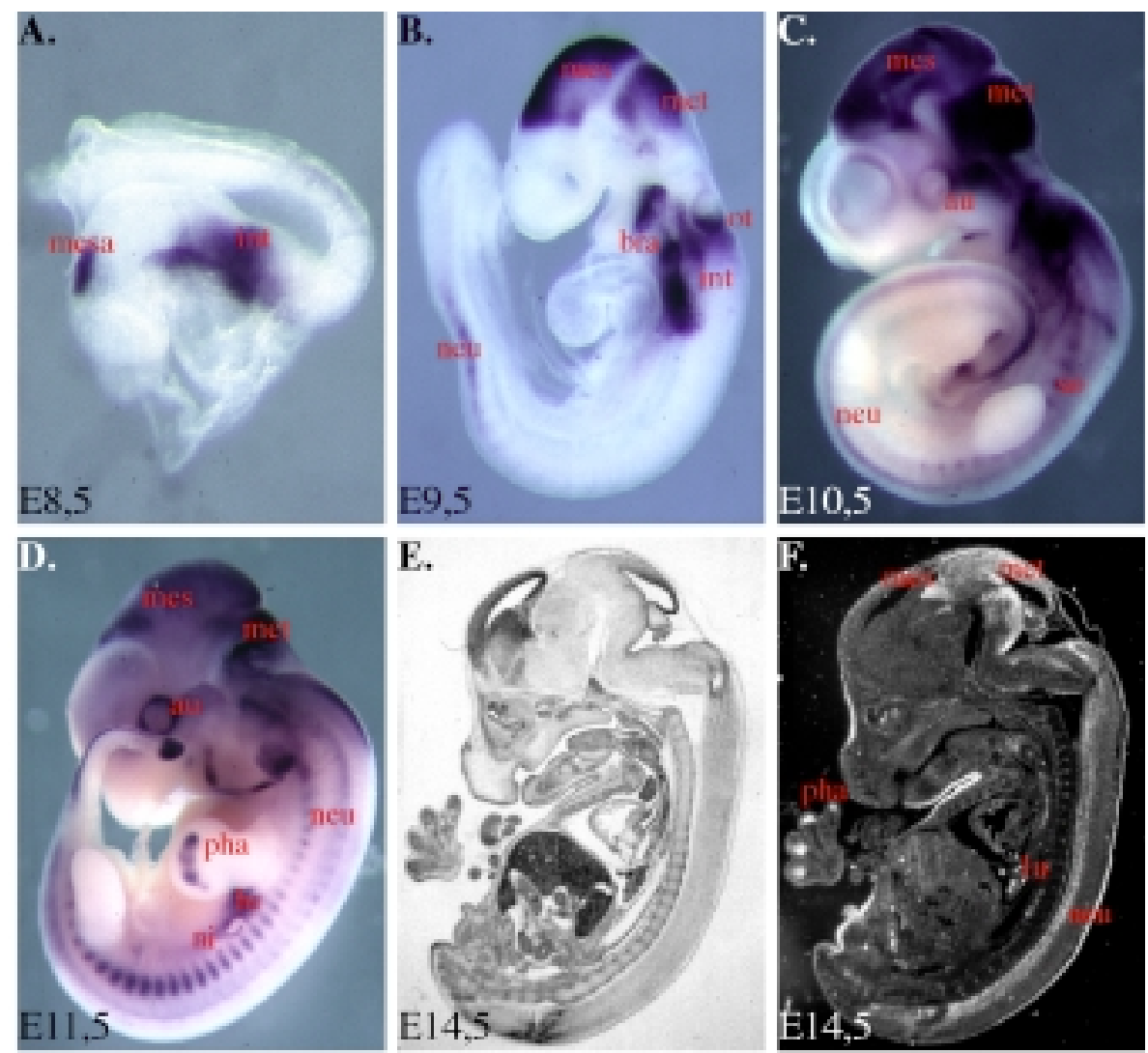

Abb. II.10: Irx1-Expression während der embryonalen Entwicklung der Maus.

Expressionsmuster von Irx1 während der Embryonalentwicklung zwischen E8,5 E14,5 (A-F; (Zülch, 1997)). Die Analyse erfolgte mittels whole-mount-in-situHybridisierung (A-D) und radioaktiv markierter in-situ-Analyse (E,F).

A.: Im Stadium E8,5 setzt sich die Irx1-Expression in der Mesenzephalon- und Intestinalanlage fort.

B.: Einen Tag später $(E 9,5)$ erweitert sich die Expression im Nervensystem, so daß Aktivität im Mesen- und auch Metenzephalon, sowie im Neuralrohr und den Branchialbögen erkannbar ist.

C.: Im Stadium E10,5 setzt sich die Expression im ZNS fort und weitere Bereiche, wie die Somiten und das Mesenchym um die Augenanlage, zeigen Irx1-Genaktivität.

D.: Im Stadium E11,5 beginnt die Irx1-Expression in den sich entwickelnden Fingern, der Lunge und der Niere. Die ZNS-Expression bleibt weiter bestehen und verstärkt sich weiter im Breich des Rhombenzephalons.

E. und F.: Beide Abbildungen stellen dasselbe Objekt dar, wobei $E$ eine Hellfeldaufnahme und $\mathrm{F}$ eine Dunkelfeldaufnahme gibt. Gut ist die Expression von Irx1 im ZNS mit ventralen Neuralrohr, der Lunge und den Fingern erkennbar. 
Abkürzungen: au: Augenanlage; bra: Branchialbögen; em: extraembryonales Mesoderm; int: Intestinalanlage, lu: Lunge, me: embryonales Mesoderm; mesa: Mesenzephalonanlage, Mes: Mesenzephalon, met: Metenzephalon, neu: Neuralrohr, ni: Nierenanlage, ot: Ohranlage, pk: Primitivknoten, pha: Phalangenanlage, so: Somitenanlage

\section{II.2.4. IRX1-EXPRESSION WÄHREND DER ORGANOGENESE (E9,5 BIS E14,5)}

Nach 9,5 Tagen ist die Gastrulation beendet und sowohl die Neurogenese als auch die Organogenese setzten ein.

Irx1 ist entlang der anterior-posterioren Achse des Neuralrohres exprimiert. Eine starke Expression ist im Tektum und Tegmentum des Mesenzephalons erkennbar. Im Rhombenzephalon ist Irx 1 exprimiert, wobei die Rhombomere 2, 3 und 4 keine Expression aufweisen. Die Grenze zwischen Mesenzephalon und Rhombenzephalon ist expressionsfrei. Im Neuralrohr weist Irx1 eine Aktivität kaudal zum sich entwickelnden Hinterhirn auf.

Im Stadium E10,5 bleibt das charakteristische Expressionsmuster von Irx 1 erhalten. Es dehnt sich aber weiter in das dorsale Dienzephalon aus und die rostrale Expressionsgrenze bildet die zukünftige Zona limitans intrathalamica. Weiterhin bleibt die Genaktivität im ventralen Bereich des Neuralrohres bestehen, wobei die stärkste im kaudalsten Teil zu finden ist.

Die spezifische Expression im Gehirn mit Mesenzephalon, Pons, Cerebellum und Medulla bleibt bis zur Geburt erhalten. Im Alter von 14,5 Tagen nach der Befruchtung ist Irx1-Genaktivität im Dienzephalon im dorsalen Thalamus und in der Zona limitans intralamica vorhanden (Zülch, 1997).

Im Neuralrohr dehnt sich die Expression zwischen E10,5 und E11,5 auf den medialen Teil und die distale Schwanzspitze aus. Dort ist sie ab E12,5 jedoch nicht mehr nachweisbar. Statt dessen tritt Irx1-Expression im ventralen Teil des Neuralrohres auf und die Aktivität ist dort bis zur Geburt nachweisbar. 


\section{II.2.5. SPEZIELLE BEISPIELE DER EXPRESSION VON IRX-GENEN WÄHREND DER ORGANOGENESE}

Irx1 und auch, ein weiteres Mitglied der Iroquois Genfamilie der Maus Irx2, sind in spezifischen, nicht neuronalen Organen wie den Extremitäten und der Lunge exprimiert (Zülch et al., 2001; Becker et al., 2001).

\section{IRX1 UND IRX2 EXPRESSION WÄHREND DER FINGERENTWICKLUNG DER EXTREMITÄTEN}

Im Embryonalstadium E11,5 sind sowohl die Vorder-, als auch die Hinterextremitäten gut erkennbar, wobei die vordere weiter entwickelt ist. Die Extremitäten bilden flache Strukturen, die Hand- und Fußplatte. Einen Tag später, im Stadium E12,5, zeigen die Handplatten keine runde, sondern eher eine "wellige" Struktur an der distalen Oberfläche. Es zeichnen sich bereits die Strukturen der zukünftigen Finger (Phalangen) ab (Rugh, 1990). Die Fußplatte ist noch immer paddelförmig.

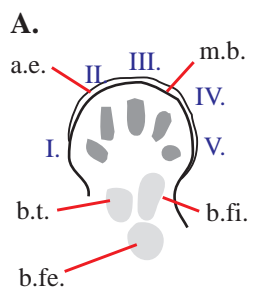

$E 11,5$
B.

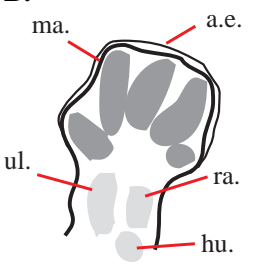

$E 12,5$

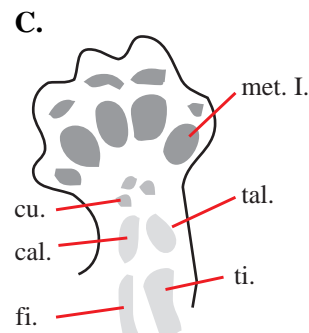

$E 13,5$

Abb. II.11: Schema der Phalangenentwicklung der Maus zwischen E11,5 bis E13,5 (A-C) (modifiziert nach: Rugh, 1990; Gruneberg, 1963).

Abkürzungen: a.e: apicale Ektodermalleiste, b.fi: Fibulablastem, b.fe: Femurblastem, b.t: Tibiablastem, cal: Calcaneus, cu: Cuboideum, hu: Humerus, ma: Marginalsinus, m.b: Marginalblutsinus, met: Metatarsalia, ra: Radius, tal: Talus, ti: Tibia, ul: Ulna.

Irx1-Expression zeigt sich bereits vor der morphologischen Ausprägung exakt in den Bereichen, die später die Finger bilden. Daher bietet sich Irx 1 als Marker für die Entwicklung der Finger an. 
Die Expression von Irx1 beginnt im Stadium E11,5 in den Extremitätenknospen. Zunächst ist es in den sich entwickelnden Phalangen II bis IV aktiv und einen Tag später auch in den Fingern I und V.

Die karpale Region ist zum ersten Mal im Alter von E12,5 - 13,5 erkennbar. Zu dieser Zeit sind die Entwicklungsregionen der Finger der Handplatte sowie die Interphalangealregionen erkennbar. Dies ist eine kritische Phase in der Fingerentwicklung, da es sich um den Übergang vom Mesenchym hin zum Knorpelvorläufer handelt. Im Stadium E12,5 ist eine starke Expression in den gesamten Phalangen, mit einer scharfen proximalen Grenze zu beobachten. Einen Tag später sind die Extremitätenanlagen weiter gewachsen, und der distalste Teil hat sich in frühe (mesenchymale) Phalangen differenziert, welche aber noch nicht vollständig voneinander getrennt sind. Während des Stadiums E13,5 zeigt Irx1 eine Aktivität im metatarsalen Knorpel und dem Knorpel der Phalangen. 14,5 Tage nach der Befruchtung sind die Finger der Vorder- und Hinterextremität gespreizt. Das Irx1-Gen ist weiterhin im metatarsalem Knorpel und dem Knorpel der Finger exprimiert .

Neben Irx 1 ist auch Irx2 während der Extremitätenentwicklung aktiv. Dieses Iroquois-Gen weist ein mit Irx1 überlappendes Expressionsmuster in den späteren Entwicklungsstadien auf. Die Aktivität startet jedoch erst später und zeigt ein anderes Muster in den ersten Stadien der Expression. Irx2 startet im Stadium E12,5 wesentlich schwächer in der Intensität, und zwar im metatarsalen Knorpel. Weiterhin ist die erste Expression auf die Phalangen I und V beschränkt. Ähnlich wie Irx1 zeigt auch Irx2 eine Genaktivitätsgrenze in der proximalen Region der Finger. In E13,5 alten Embryonen ist Irx 2 im Knorpel der Phalangen nur schwach exprimiert. 


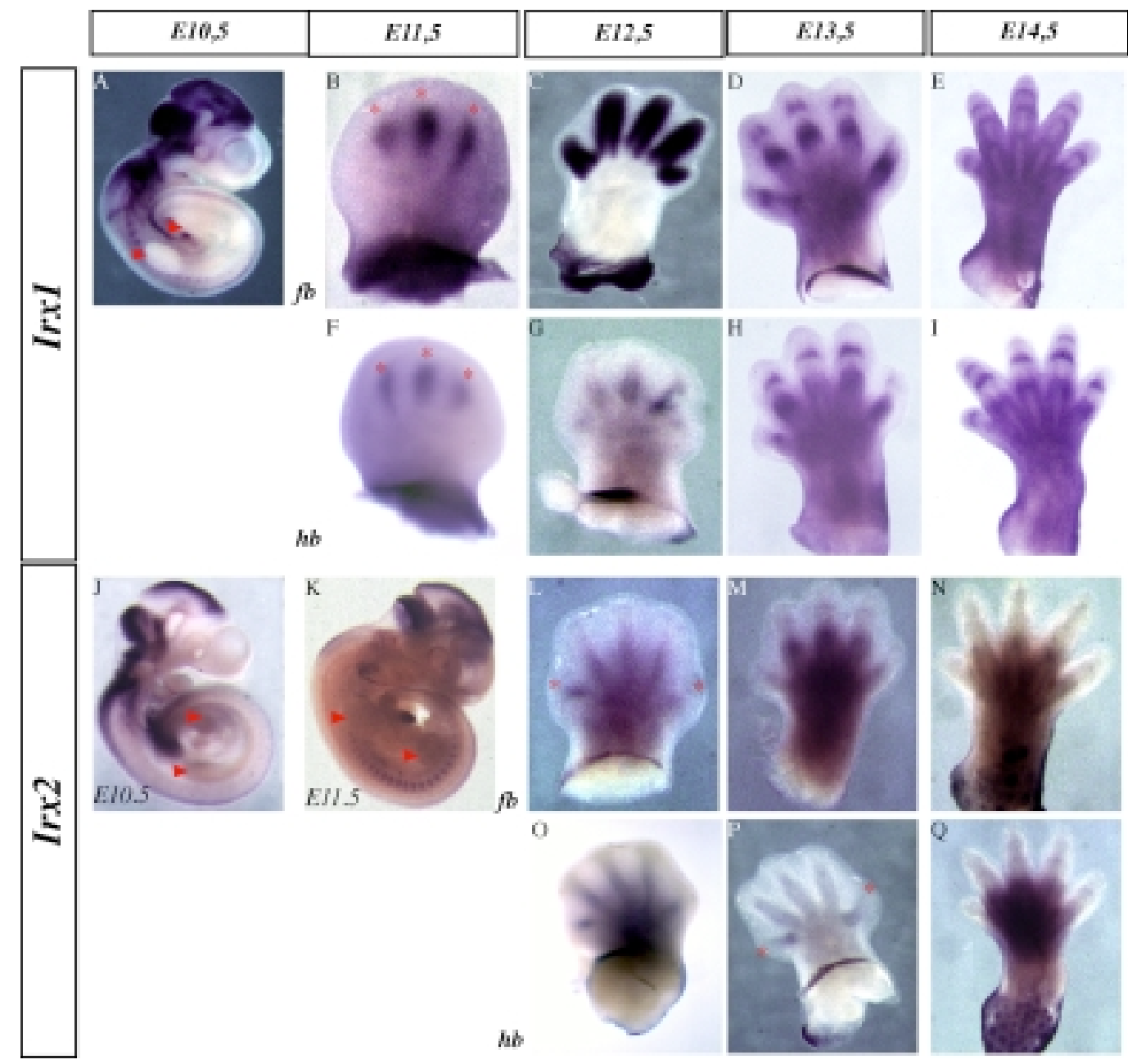

Abb. II.12: Irx1-und Irx2-Expression während der Entwicklung der Phalangen

Expressionsmuster von Irx1 in der Phalangenentwicklung im Vergleich zu Irx 2 während der Embryonalstadien E11,5 E - E14,5 (A-Q). Die Analyse erfolgte mittels whole-mount-in-situ-Hybridisierung. Die Pfeile markieren die Region der Extremitätenknospen. Die Sterne markieren die Bereiche der Irx -Expression in den Fingeranlagen.

Abkürzungen: fb.: Vorderextremität; hb.: Hinterextremität

In D. melanogaster konnte gezeigt werden, daß cubitus interruptus (ci) einen Regulator des Iroquois-Komplexes darstellt (Gómez-Skarmeta und Modolell, 1996). Die Maus-Homologe von ci (Gli1,- 2,-3) sind spezifisch während der frühen Extremitätenentwicklung von E9,5 bis E12,5 exprimiert (Theil et al., 1999). Es wurde ein Vergleich der Expression mit den Iroquois-Genen während der Fingerentwicklung in den Stadien E12,5 bis E14,5 erstellt. 
Die Expression von Gli1 started in den Extremitätenknospen bei E9,5. In diesem Stadium sind Gli2 und Gli3 entlang der anterior-posterioren Achse der Extremitätenknospe exprimiert (Büscher und Rüther, 1998; Theil et al., 1999).

Im Stadium E12,5 zeigen Irx1 und Gli1 vergleichbare Expressionmuster. Beide Gene sind im Stadium E13,5 und E14,5 in dem metatarsalen Knorpel und dem Knorpel der Phalangen aktiv. Die Expression von Gli2 ist ähnlich zu Gli1, aber wesentlich schwächer. Die Genaktivität von Gli2 ist gut mit der von Irx2 vergleichbar. Ein weiteres ci-Homolog, Gli3, zeigt keine Expression in den sich entwickelnden Knorpeln.

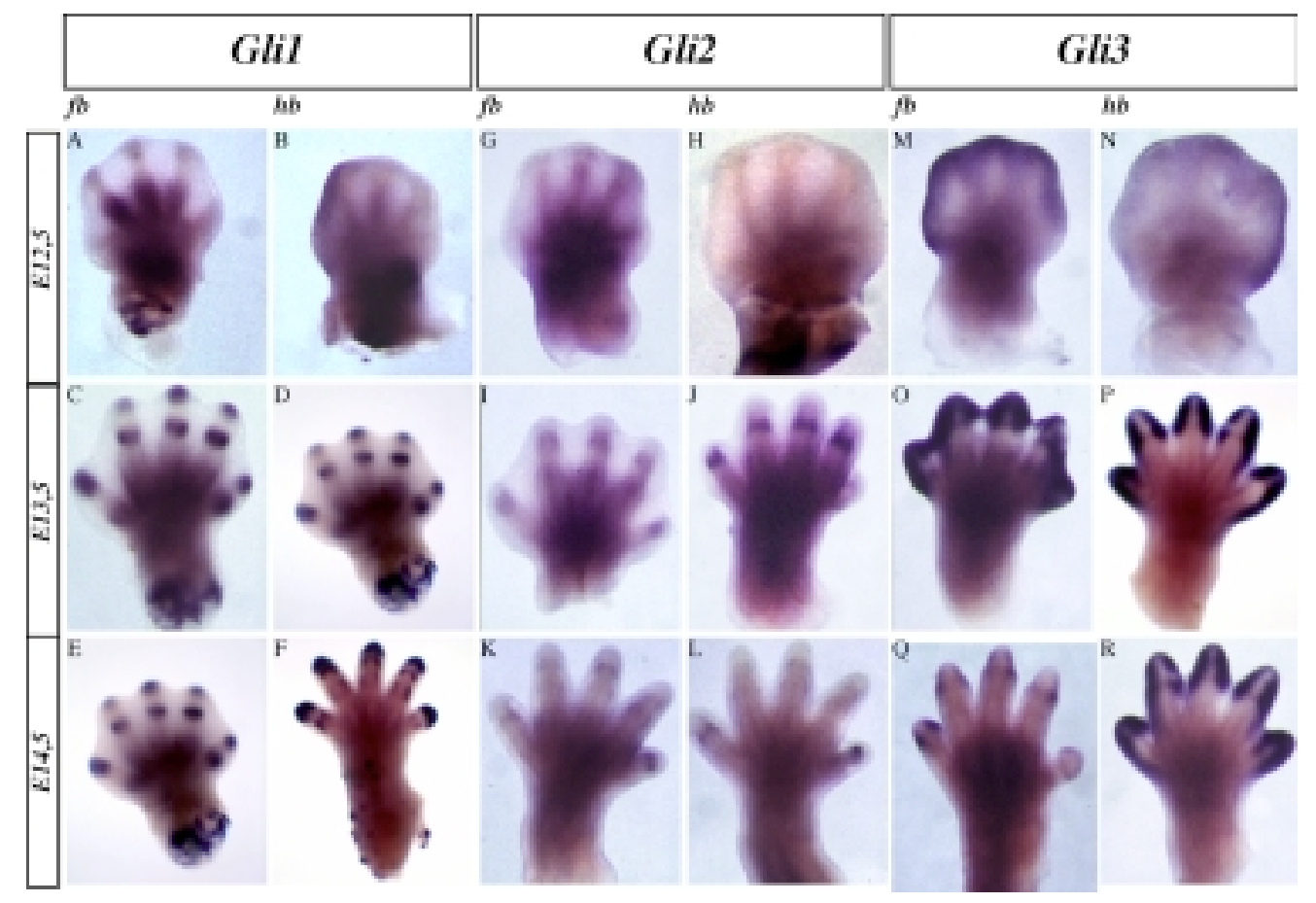

Abb. II.13: Expression von Gli1, Gli2 und Gli3 während der Phalangenentwicklung

Expressionsmuster der Gli-Gene während der Phalangenentwicklung der Embryonalstadien E11,5 E - E14,5 (A-R) im Vergleich.

Im Stadium E12,5 beginnt eine zweite Phase der Gli-Genexpression während der Extremitätenentwicklung. Transkripte von Gli1 (A, B) und Gli2 (G, H) sind im Stadium E12,5 im kondensierenden Mesenchym zu finden, wohingegen Gli3 (M, N) im umgebenden Mesenchym aktiv ist. Gli1 ist im Stadium E13,5 im metatarsalen Knorpel und im Knorpel der Phalangen exprimiert (C, D). Diese Expression wird im Stadium E14,5 beibehalten (E, F). Die Expression von Gli2, obwohl sie schwächer ist, ist vergleichbar mit Gli1. So ist Gli2 im Stadium E12,5 in der metatarsalen Knorpelanlage schwach aktiv $(\mathrm{G}, \mathrm{H})$. Zwischen E13,5 und E14,5 ist Gli2-mRNA im metatarsalen 
Knorpel und im Knorpel der Phalangen nachweisbar ( $\mathrm{I}-\mathrm{L})$. Dagegen zeigt Gli3 ein ganz anderes Expressionsmuster. Es ist nicht in den Phalangen exprimiert ( $M-R)$.

Abkürzungen: fb: Vorderextremität; hb: Hinterextremität

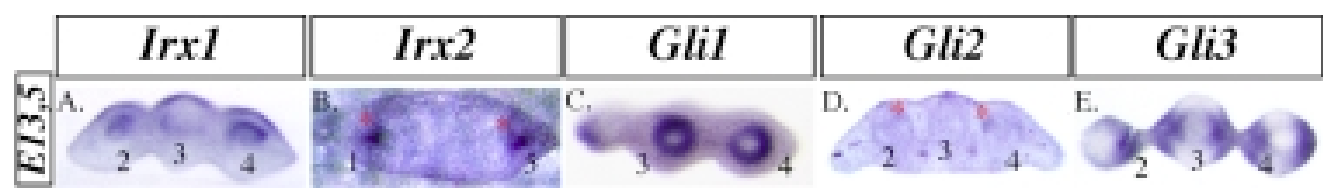

Abb. II.14: Transversschnitte von Vorderextremitäten von E13,5 alten Mausembryonen, die mittels einer in-situ-Hybridisierung analysiert wurden.

Irx1 ist im Stadium E13,5 im Knorpel der Finger 2 bis 4 exprimiert (A). In ähnlicher Weise ist Irx $2 \mathrm{im}$ kondensierenden Mesenchym der Phalangen 1 und 5 aktiv (B). Gli1 und Gli2 sind im metatarsalen Knorpel der Finger 1 bis 5 exprimiert (C, D). Im Gegensatz dazu ist Gli3 im umgebenden Mesenchym aktiv (E).

Abkürzungen: 1, 2, 3, 4, 5: Nummern der Finger; *: markieren besonders schwache Expression

Zusammenfassend läßt sich feststellen, daß die Expressionsdomänen von Irx1-Gli1 und von Irx2-Gli2 Übereinstimmungen zeigen, wohingegen kein überlappender Bereich zwischen Gli3-Irx1 bzw. Gli3-Irx2 zu beobachten ist.

\section{IRX1-EXPRESSION WÄHREND DER LUNGENENTWICKLUNG}

Während der frühen Säugerentwicklung bilden sich aus dem Endoderm eine Reihe von Organen wie Leber, Pancreas und Lunge. Die Lungenknospen entstehen aus dem Vorderdarm der kaudalen Pharynxregion und bestehen aus epithelialen Endodermschichten, die von Mesenchym umgeben sind (Hogan und Yingling, 1998). Zwischen dem Glandularstadium und dem Kanalikularstadium der Lungenentwicklung wachsen die Lungenknospen aus, bilden dabei zwei Bronchi und viele Bronchiolen und verzweigen in einem komplexen Muster (Ten Have-Opbroek, 1991).

Die Expression von Irx1 beginnt bereits im Stadium E8,5 im Vorderdarmbereich, u. a. in der Region, in der sich die laryngo-tracheale Falte und anschließend das tracheale Diverticulum bildet (Kaufmann und Bard, 1999). Der proximale Teil dieses Diverticulums bildet die Trachea und der distale die zwei primären Lungenknospen. Irx1 ist im Stadium E10,5 
ausschließlich in der Epithelschicht der Lungenknospen, nicht aber in der mesenchymalen Schicht exprimiert.

Während der nächsten Entwicklungsphase, dem Kanalikularstadium, bleibt Irx 1 weiterhin epithelial in den sich entwickelnden Bronchii exprimiert. Im Stadium E12,5 konzentrieren sich die Irx1-Transkripte vorrangig auf den distalen Bereich der sich formenden Lungen. Diese Expression in den epithelialen Bereichen bleibt auch noch im Stadium E13,5 erhalten, wenn die terminalen Bronchii und die 5 Lungenlappen gebildet werden. Ferner zeichnet die Irx1-Ganaktivität die Verzweigung der Bronchiolen nach. Einen Tag später ist die Expression auf die Randbereiche der Lungen beschränkt. Die Irx1 Aktivität stoppt mit dem Beginn der Alveolarphase (Becker et al., 2001).

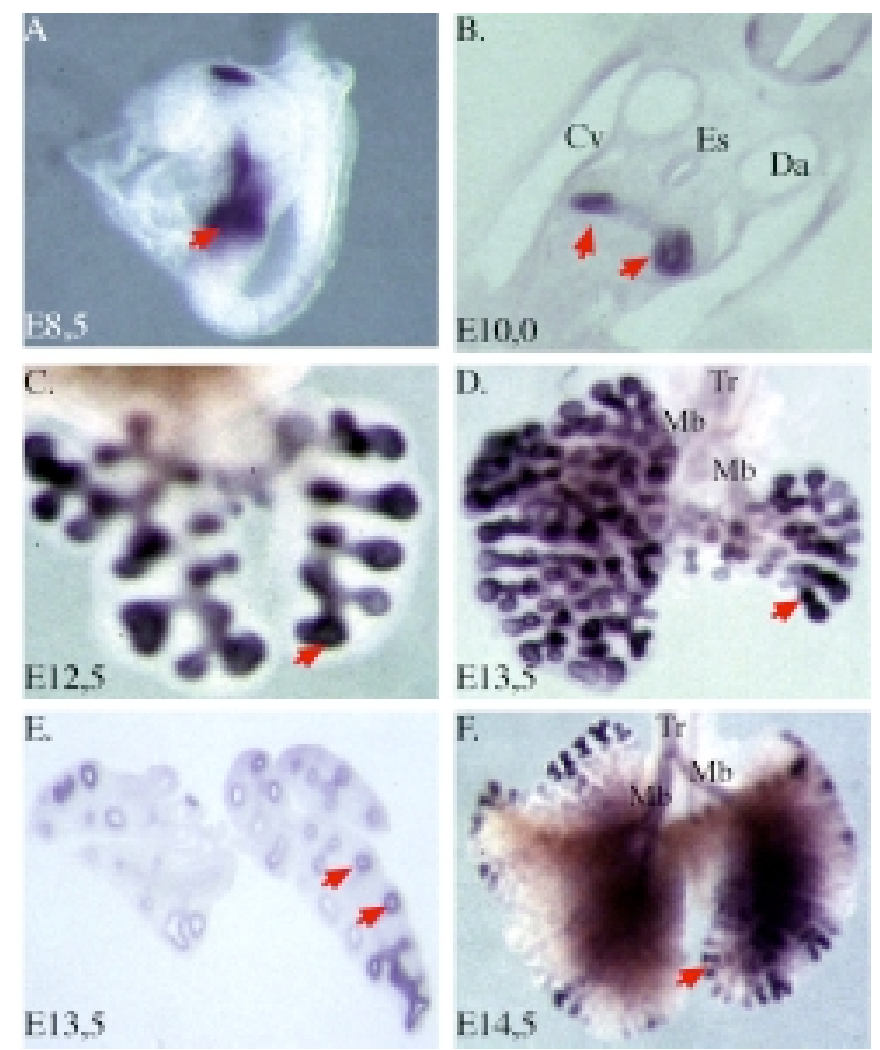

Abb. II.15: $\operatorname{Ir} x 1$ während der Lungenentwicklung

Whole-mount-in-situ-Expression von Irx1 während der Lungenentwicklung zwischen E8,5 und E14,5. 
A.: Das Bild zeigt einen E8,5 jungen Embryo. Der Pfeil markiert den Bereich der Intestinalanlage.

B.: Diese Abbildung zeigt einen Vibratomschnitt $(30 \mu \mathrm{m})$ durch einen $\mathrm{E} 10,0$ alten Mausembryo. Die spezifische Irx1-Expression ist in der epithelialen Zellschicht erkennbar.

C.: Die Abbildung zeigt eine E12,5-Lunge. Die distale Expression ist mit einem Pfeil markiert.

D.: Die Abbildung zeigt eine E13,5-Lunge. Die distale Expression ist mit einem Pfeil markiert.

E.: Die Abbildung zeigt einen transversen Schnitt durch eine E13,5-Lunge. Irx1 ist klar in der epithelialen Schicht der Lunge exprimiert.

F.: Die Abbildung zeigt eine E14,5-Lunge. Die distale Expression ist mit einem Pfeil markiert.

Abkürzungen: Cv: Cardinalvene, Da: dorsale Aorta, Es: Ösophagus, Tr: Trachea, Mb: Hauptbronchie

Mash1 spielt eine wesentliche Rolle während der Enstehung eines bestimmten Typus von humanem neuroendocrinem Lungenkrebs (Kleinzell-Lungenkrebs; SCLC: small cell lung cancer) (Ball et al., 1993). Da Mash1 ein potentielles Zielgen von $\operatorname{Irx} 1$ ist, wurde das $\operatorname{Ir} x 1$ Gen auf eine Beteiligung an der Krebsbildung analysiert. Dazu wurden Northern-Blot-Analysen veschiedener Lungenkrebszellinien im Vergleich $\mathrm{zu}$ normaler humaner Lungen-RNA durchgeführt.

A.
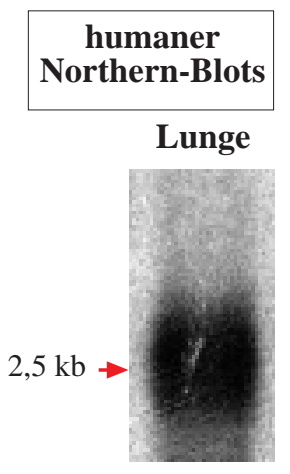

B.

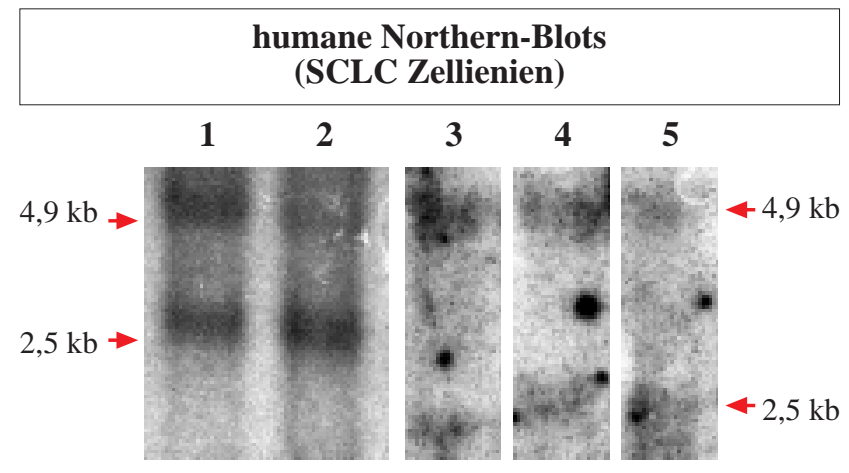

Abb. II.16: humane Irx1-Northern-Blot-Analyse 
Die Abbildung zeigt sechs verschiedene Nothern-Blots, die alle mit einer 0,4 kb-Irx1Sonde (B/S400) hybridisiert wurden. Im normalen, gesunden Lungengewebe (Pfeil in A) wurde ein 2,5 kb Fragment identifiziert. In allen untersuchten Lungenkrebszellinien (SCLC: small cell lung cancer) wurden zwei Transkripte beobachtet, 4,9kb und 2,5kb (Pfeile in B).

A.: Die Abbildung zeigt einen Northern-Blot mit humaner Gesamt-RNA einer normalen adulten Lunge

B.: Die Abbildung zeigt Gesamt-RNA-Northern-Blots verschiedener SCLC-Zellienien

Abkürzungen: 1: NCl-H82; 2: NCl-H592; 3: NCl-H69; 4: NCl-H345; 5: NCl-N417

Es konnte gezeigt werden, daß in der adulten humanen Lunge Irx1 normalerweise aktiv ist. Ferner konnte gezeigt werden, daß dort, ähnlich wie in der Maus, ein 2,5 kb Transkript vorliegt. In den Zellinien, die aus humanem Lungenkrebs (SCLC) hergestellt wurden, ist dagegen ein abweichendes Bild zu beobachten. Hier treten zwei Transkripte von 2,5 kb und 4,9 kb Länge auf. Dies läßt auf eine veränderte Expression des humanen Irx1 Gens im Falle dieses Lungenkrebstypus schließen. 


\section{II.3. DIE FUNKTION DES IRX1-GENS}

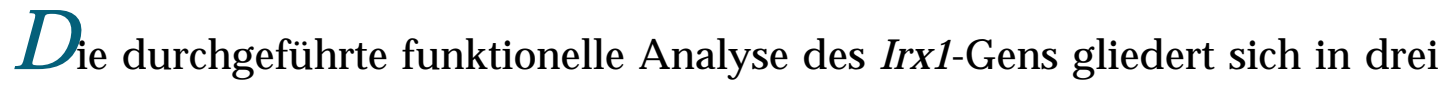
wesentliche Teile.

1. Irx1 ist ein mögliches Zielgen der Gli-Gene. Daher wurde eine Analyse der GliMutanten durchgeführt.

2. Analyse der Interaktion von Irx1 mit Mash1, einem potentiellen Zielgen von Irx1.

3. Analyse der Funktion des Irx1-Gens durch Herstellung einer gezielten Verlustmutante und Untersuchung des daraus resultierenden Phänotyps.

Dieser Ansatz ermöglichte es mir verschiedene Aspekte der Funktion von Irx1 zu beschreiben.

\section{II.3.1. DIE ZN-FINGER-GENE GLI1 UND GLI2 KONTROLLIEREN DIE IRX1-EXPRESSION}

Das Drosophila-Gen cubitus interruptus (ci) reguliert positiv den IroquoisKomplex (Gómez-Skarmeta und Modolell, 1996). Dies war die Grundlage für den experimentellen Ansatz, eine mögliche Regulation der murinen Irx-Gene durch die cubitus interruptus-Homologe zu analysieren.

Gli1-defiziente Mäuse sehen äußerlich unauffällig aus und verhalten sich normal (Park et al., 2000). Dagegen zeigen Gli2-Mausmutanten eine Reihe von Skelettdefekten und abnormale Lungen (Mo et al., 1997; Motoyama et al., 1998).

Daher stellte sich die Frage, ob auch die Regulation von $c i$ auf den IroquoisKomplex in Vertebraten konserviert geblieben ist, d.h. ob eine Interaktion zwischen Gli1 bzw. Gli2 mit Irx1 besteht. Die Mäuse wurden entsprechend der Angaben von Park et al. (2000) und Mo et al. (1997) verpaart und genotypisiert. Mit den homozygoten Embryos wurden whole-mount-Hybridisierungsanalysen durchgeführt, um eine mögliche Veränderung des Irx1-Expressionsmusters zu untersuchen. 


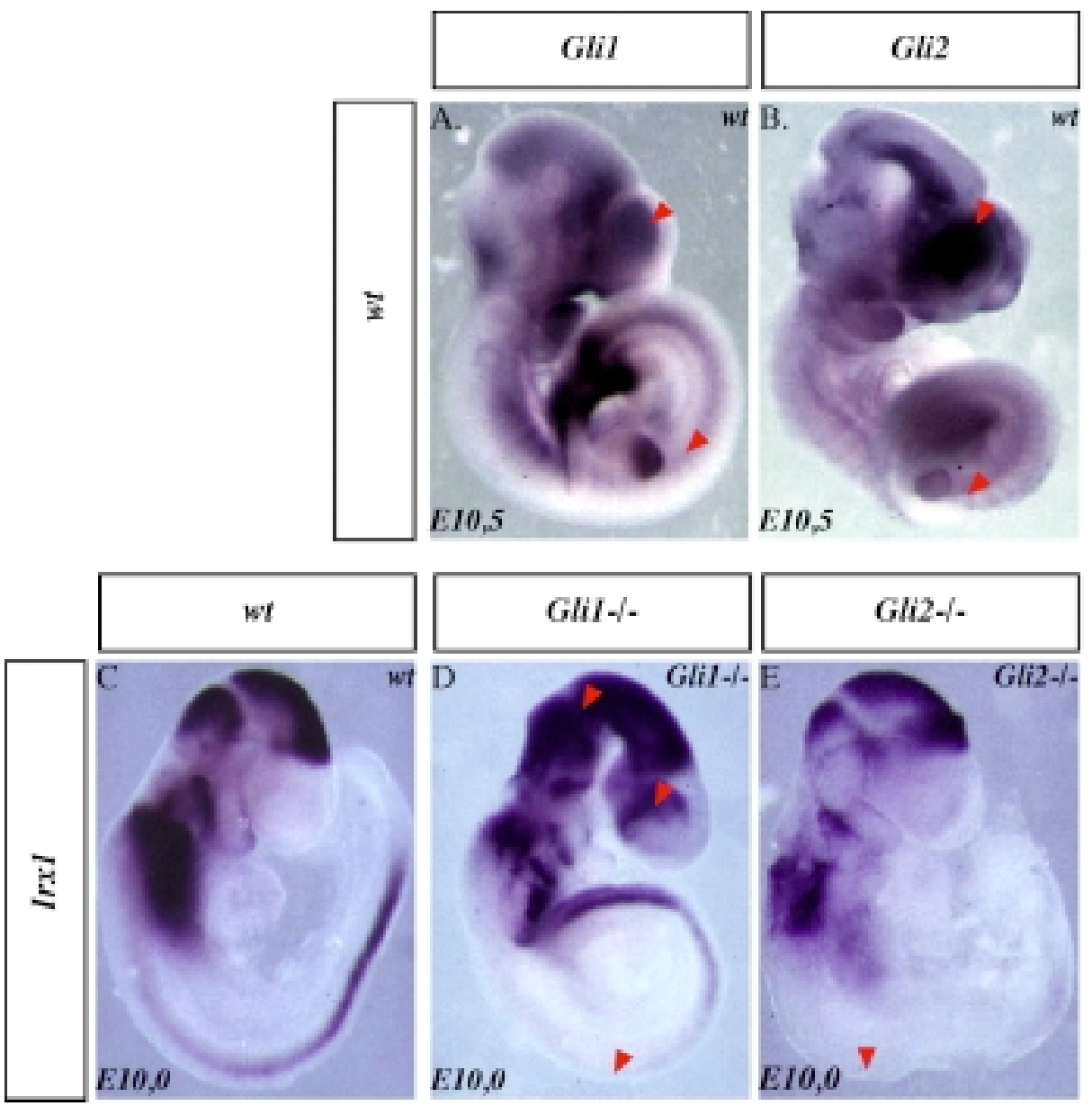

Abb. II.17: Gli1 und Gli2 regulieren Irx1

Die Abbildungen zeigen whole-mount-in-situ-Hybridisierungsanalysen von Gli1 und Gli2 in E10,5 alten Embryonen (A, B). Ferner wird die veränderte Expression von Irx1 in den Mutanten von Gli1 bzw. Gli2 in E10,0 alten Embryonen gezeigt (D, E). In der Gli1-Mutante zeigt Irx1 eine breitere Expressionsdomäne (D; Expression in der Mesenzephalon-Metenzephalon-Grenze und im Telenzephalon). Im Neuralrohr ist ein teilweiser Verlust der Expression zu konstatieren (D). In der Gli2-/- Mutante liegt eine normale Expression von Irx $1 \mathrm{im}$ Gehirn vor, aber die Irx1-Aktivität im Neuralrohr ist runterreguliert. Irx1 wird durch die beiden Zn-Finger-Proteine Gli1 und Gli2 reguliert. Als Vergleich dient eine normale Irx1-Expression in einem E10,0 alten Embryo (C).

In den homozygoten Gli1-Mutanten ist ein deutlich verändertes Irx1Expressionsmuster erkennbar. Dabei sind sowohl die Verstärkung von Signalen und ektopische Expressionen zu beobachten, wie auch ein Verschwinden von Expressionsdomänen. So ist Irx1 in der Gli1-Mutante im Telenzephalon und auch in der Mesenzephalon-Metenzephalon-Grenze aktiv. Beides sind Bereiche, 
die normalerweise kein Irx1 exprimieren. Andererseits ist die Genaktivität von Irx1 im medialen Teil des Neuralrohres in der Gli-Mutante verschwunden.

Auch in der Gli2 Mutante ist die Irx1-Aktivität verändert. Während in den Gli1-defiziente Mäusen kein Irx1-Transkript im medialen Teil des Neuralrohres vorhanden ist, ist in den Gli2-defiziente Mäusen keine Expression im gesamten Neuralrohr erkennbar. Unverändert ist dagegen die Aktivität von Irx1 im Mesenzephalon und Metenzephalon.

\section{II.3.2. DAS IRX1-GEN AKTIVIERT NICHT DEN MASH1-PROMOTOR}

In Drosophila melanogaster ist der Achaete-Scute-Komplex (AS-K) ganz wesentlich an der Bildung der proneuralen Kluster (Zellgruppen) beteiligt. Positive und direkte Aktivatoren des AS-K stellen die Gene des IroquoisKomplexes dar.

Homologe Gene des AS-K sind Mash1 und Mash2 (Guillemot et al., 1994; Guillemot et al., 1993). Mash1 besitzt eine Funktion in der embryonalen Entwicklung des zentralen und peripheren Nervensystems, des Riechepitheliums und der Retina (Guillemot et al., 1993).

Aufgrund der überlappenden Expressionsbereiche von Irx1 und Mash1 während der Entwicklung des Zentralnervensystems und der Regulation der homologen Gene in Drosophila m. wurde eine mögliche Interaktion zwischen Irx1 und Mash1 geprüft.

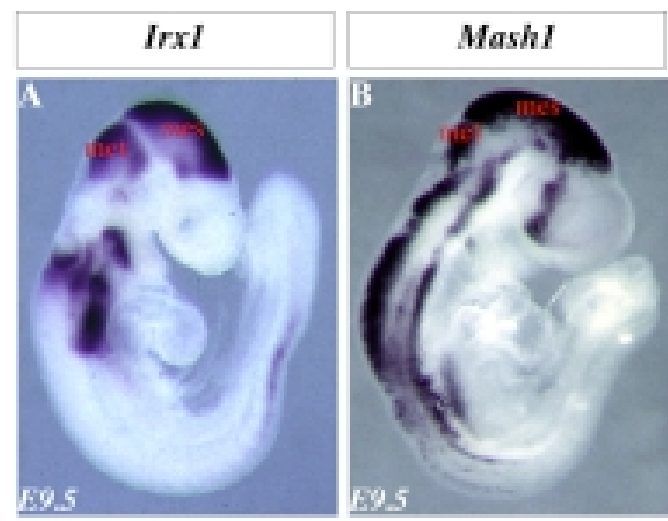

Abb. Il.18: Überlappende Expressionsbereiche von Irx1 und Mash1. 
Die Abbildungen zeigen whole-mount-in-situ-Analysen von E9,5-alten Embryonen. Irx1 (A) und Mash1 (B) zeigen überlappende Expressionsbereiche während der Entwicklung des ZNS und insbesondere im Mesenzephalon und Metenzephalon.

Abkürzungen: mes: Mesenzephalon; met: Metenzephalon

Die Analyse erfolgte durch Messung der Aktivität des Mash1-Promotors unter dem Einfluß von Irx1-Protein. Zu diesem Zweck wurde PC12-Zellen gleichzeitig mit einem vom Mash1-Promotor kontrollierten Rezeptorgen (lacZGen) und einem Irx1-Expressionsvektor transformiert und die Reporteraktivität wurde analysiert. Drei unterschiedliche Reporter-Konstrukte kamen dabei zum Einsatz.

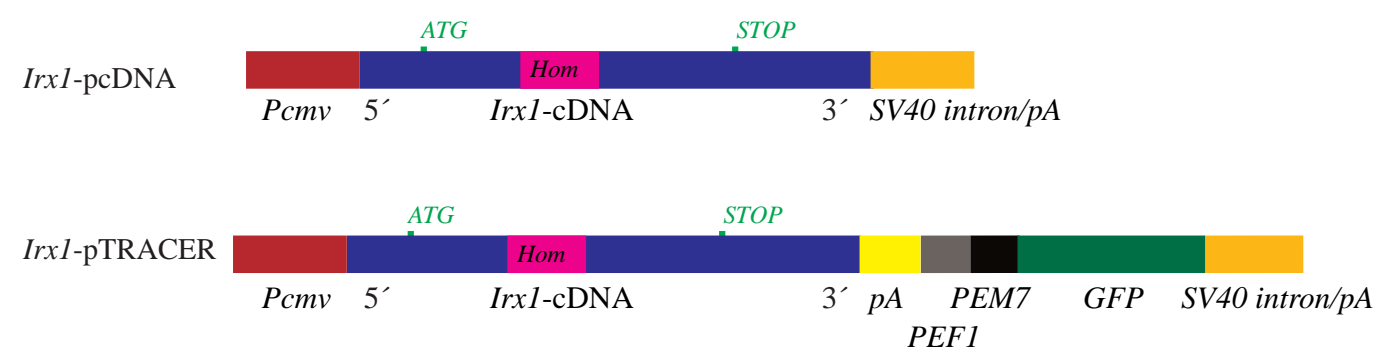

Abb. II.19: Irx1-Konstrukte zur Überexpression in Zellkultur

Irx1-pcDNA stellt ein Konstrukt dar, bei dem Irx1 unter der Kontrolle des CMVPromotor steht. Bei Irx1-pTracer liegt dies ebenfalls vor, aber weiterhin ist eine GFPSequenz nachgeschaltet (Grünes-Fluoreszens-Protein), die es ermöglicht, die Aktivität des Irx1-Gens visuell zu verfolgen.

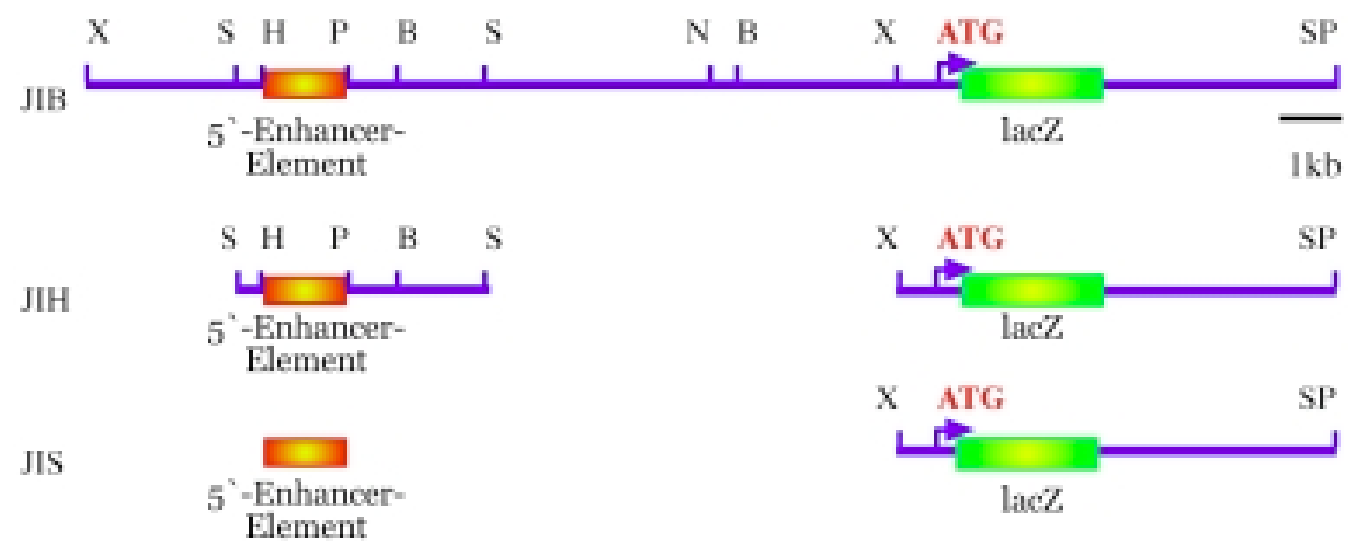

Abb. II.20: Mash1-Promotor Konstrukte 
Die Abbildung zeigt die drei benutzten genomischen Mash1-Bereiche, die das 5'Enhancer-Element beinhalten (Verma-Kurvari et al., 1998). Das 1158bp-Element liegt

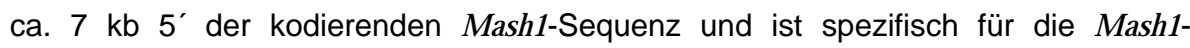
Expression während der Entwicklung des ZNS. Im JIB-Fragment liegt die gesamte 5'Region upstream der kodierenden Mash1-Sequenz vor, während bei JIH und JIS die 5 '-Bereiche verkürzt wurden. Diese Konstrukte wurde in einen $\beta$-GalactosidaseVektor kloniert, wobei das lacZ durch das endogene ATG reguliert wird.

Keines der drei Konstrukte zeigte eine Aktivierung durch Irx1, obwohl jedes das bereits beschriebene für die Mash1-Expression essentielle Enhancerfragment enthält (Verma-Kurvari et al., 1998).

\section{II.4. ANALYSE DER IRX1-MAUSMUTANTE}

$D_{\text {ie Integration exogener genetischer Information in die Mauskeimbahn hat }}$ sich als nützliches Mittel für die Analyse der Funktion eines Gens bewährt. Der klassische Weg zur Herstellung transgener Mäuse mittels der DNAMikroinjektion weist jedoch den Nachteil auf, daß die Integration des DNAKonstruktes in das Genom zufällig erfolgt. Erst die embryonale Stammzell-(ESZell-) Technologie in Verbindung mit der zelleigenen homologen Rekombination ermöglicht es, eine gezielte Veränderung eines bestimmten Genlokus durchzuführen und dieses stabil in der Keimbahn zu etablieren. Gezielt hergestellte Mausmutanten ermöglichen es, die Funktion eines Gens zu erklären.

Säugerzellen besitzen eine enzymatische Maschinerie, welche homologe Rekombination zwischen eingebrachteten DNA-Molekülen und ihrem endogenen chromosomalen Locus ermöglichen (Doetschman et al., 1988; Bronson und Smithies, 1994; Capecchi, 1989). Diese Möglichkeit, gezielt Gene in ES-Zellen zu mutieren und daraus Verlustmutanten in der Maus herzustellen, wurde im Laufe der Jahre technisch verfeinert, um die Häufigkeit der homologen Rekombination zu optimieren. Um ein Gen gezielt auszuschalten, ist 
ein Rekombinationskonstrukt notwendig, welches in-vitro hergestellt wird. Generell beinhaltet ein Rekombinationskonstrukt einen Selektionsmarker (in der Regel das Neomycin-Resistenzgen), welcher flankiert ist von homologen Regionen des genomischen Lokus. Während der homologen Rekombination wird dann die endogene Sequenz in den ES-Zellen, gegen die des Zielkonstruktes ausgetauscht.

\section{II.4.1. ANALYSE DER CHROMOSOMALEN LOKALISATION DES IRX1-GenS \\ Zu Beginn der Arbeit waren drei Iroquois-Homeoboxgene in der Maus} bekannt und beschrieben, ihre chromosomale Organisation war jedoch unbekannt (Zülch, 1997; Bosse et al., 1997).

Um eine funktionelle Analyse durchzuführen ist die Kenntnis über die chromosomale Organisation von entscheidender Bedeutung. Eine tandemartige Anordnung könnte zu Wechselwirkungen der Gene, z.B. in einer Verlustmutante, führen. Eine solche Tandemorganisation wurde bei den Iroquois-Genen in D. melanogaster gefunden. So ist es beispielsweise möglich, daß der Promotor des Selektionsgens eines Rekombinationskonstruktes andere Mitglieder einer tandemartigen Organisation mitreguliert und somit sekundäre Phänotypen verursacht (Meyers et al., 1998).

Aus diesem Grund wurde eine chromosomale Analyse des Irx1-Gens mittels FISH in-situ Analyse durchgeführt. Es wurden Maus-ES-Zellen benutzt, bei denen die Chromosomen in der Mitose arretiert wurden. Diese so vorbereiteten Chromosomen wurden auf Objektträgern gespreizt und mit einem genomischen Irx1-Klon (ga1.2) hybridisiert. Es stellte sich bei diesen Untersuchungen heraus, daß Irx 1 und Irx 2 sehr nah beieinander auf Chromosom 13 lokalisiert sind (M.B. Becker, pers. Mitteilung). Daher wurde zur Abstandsmessung zwischen Irx1 und Irx2 eine Fiber-FISH-Analyse durchgeführt (mit freundlicher Unterstützung von W. Engel, Göttingen). Diese Analyse ergab einen Abstand zwischen Irx1 und Irx2 von ca. $200 \mathrm{~kb}$. Aus einer Datenbankanalyse konnte mittlerweile ein weiteres Mitglied der Iroquois-Genfamilie, Irx4, auf Chromosom 13 lokalisiert werden. Auch hier ist der Abstand zu den anderen Familienmitgliedern mit ca. $400 \mathrm{~kb}$ gering. 
A.

\section{Maus-Chromosom 13}

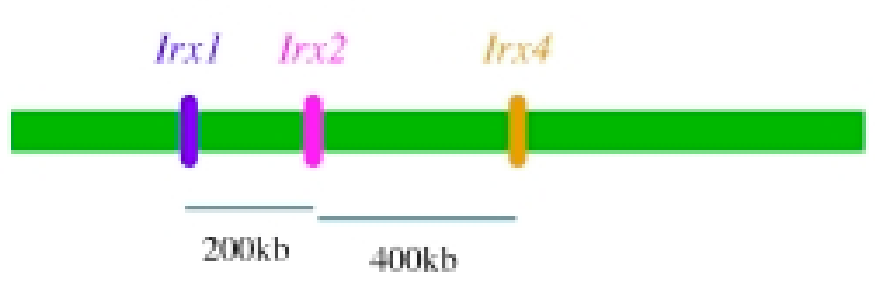

B.

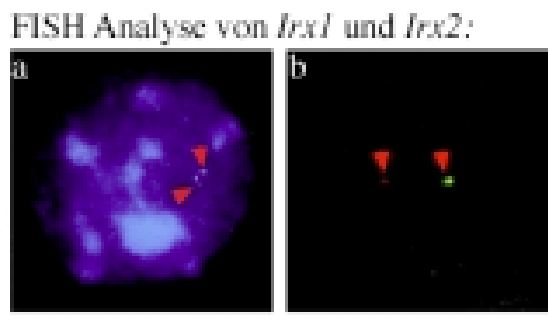

Abb. II.21: Chromosomale Organisation von Irx1

In der Maus sind die Gene Irx1, Irx 2 und Irx4 auf Chromosom 13 tandemartig organisiert. Der Abstand zwischen innen beträgt $200-400 \mathrm{~kb}$ (A). Die Abbildung B zeigt ein Beispiel für die FISH-Analyse mit $\operatorname{Irx} 1$ und $\operatorname{Ir} x 2$ (a). Die Fiber-FISH Analyse ergab einen Abstand von Irx1 zu Irx2 von ca. 200 kb (b). Die Fluoreszenssignale sind (rot: $\operatorname{Irx1}$, grün: $\operatorname{Ir} x 2$ ) durch Pfeile markiert.

Diese tandemartige Organisation ist auch im Menschen konserviert. So sind die humanen Homologe ( $h \operatorname{Ir} x 1, h \operatorname{Ir} x 2$ und $h \operatorname{Ir} x 4)$ in vergleichbaren Abständen auf Chromosom 5 (5p15) organisiert. Dieses deutet darauf hin, daß neben den Genen an sich auch deren chromosomale Organisation konserviert ist.

A.

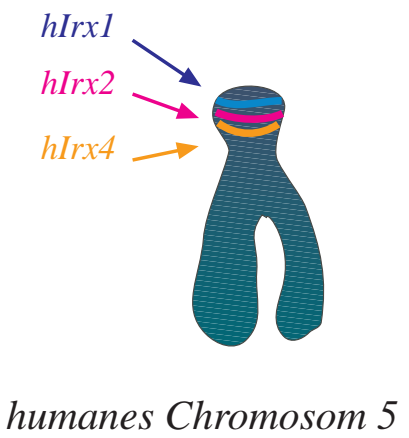

B.

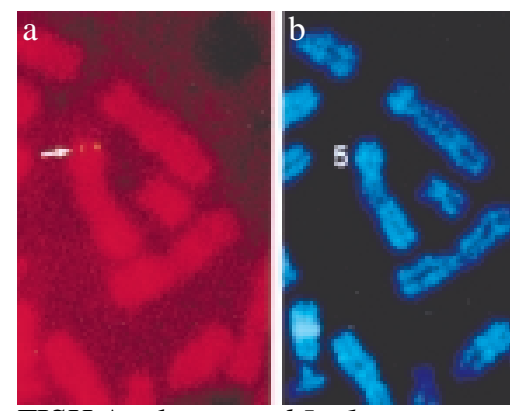

FISH Analyse von hIrxI

Abb. II.22: Chromosomale Organisation der humanen Iroquois-Gene hIrx1, hIrx2 und $\mathrm{h} \operatorname{Irx} 4$

Die generelle Organisation von hIrx1, hIrx2 und hIrx4 ist zwischen Maus und Mensch konserviert. Auch im Menschen liegen diese drei Gene tandemartig vor und zwar auf Chromosom 5 (A). In Abbildung B ist ein Beispiel für die humane FISH-in-situ-Analyse mit $\operatorname{Ir} x 1$ dargestellt. 


\section{II.4.2. KARTIERUNG UND GENOMISCHE ORGANISATION DES IRX1-GENS}

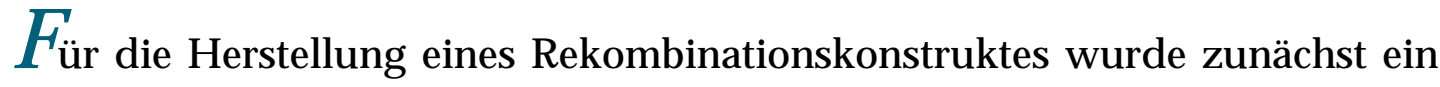
genomischer Irx1-Klon charakterisiert (Zülch, 1997). Dieser entstammt einer genomischen $\lambda$-Phagenbank, welche aus ES-Zellen des Mausstammes 129Sv hergestellt wurde (Kaestner et al., 1993). Das Durchmustern der Phagenbank ergab insgesamt neun Klone und nach einer ersten Analyse der Klone wurden vier davon weiterbearbeitet. Der Klon ga1.2 (vormals: \#1.1.3.1 (Zülch, 1997)) wurde schließlich kartiert und mit der partiellen Irx1-cDNA hybridisiert.

Mit den genomischen Irx1-Klone ga2.2, ga3.2 und ga4.2 erfolgte ebenfalls eine Charakterisierung mittels Kartierung und Sequenzierung. ga2.2 und ga4.2 befinden sich innerhalb, wohingegen sich ga3.2 sich 5'-Ende über den Klon ga1.2 hinaus erstreckt.

Eine detailliertere Kartierung und Sequenzanalyse des Klons Irx1-ga1.2 lieferte die genaue Struktur des Irx1-Locus. Es ist aus vier Exons aufgebaut, wobei sich das Start-ATG im ersten Exon befindet. Die Homeobox und die IroBox liegen auf dem zweiten Exon und das vierte Exon beinhaltet das STOPCodon. Die kodierende Sequenz wird durch drei Introns unterschiedlicher Länge unterbrochen.

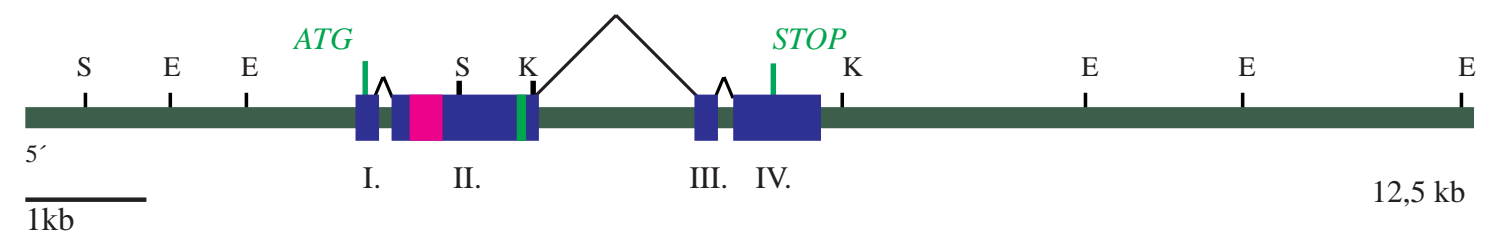

Abb. II.23: Die genomische Organisation des Irx1-Gens

Die genomische Organisation des Gens Ir $x 1$ ist anhand des Klons ga1.2 schematisch dargestellt (B). Irx1 ist in vier Exons organisiert (I. II. III. und IV.), wobei sich die Homeobox (lila) und die IRO-Box (hellgrün) auf dem zweiten Exon (II.) befinden. Das Start-ATG befndet sich auf dem ersten (I.) und das STOP-Signal auf dem letzten Exon (IV.).

Abkürzungen: E: EcoRl; K: Kpnl; S: Sacll 


\section{II.4.3. HERSTELLEN EINES IRX1-REKOMBINATIONSKONSTRUKTES FÜR DIE HOMOLOGE REKOMBINATION IN ES-ZELLEN}

Ziel eines Rekombinationskonstruktes ist es, die Funktion eines Zielgens zu zerstören. Im Falle von Irx1 bedeutet dies, z.B. die funktionell wichtige Homeobox zu entfernen, um das Protein funktionsunfähig zu machen. Für das Entwerfen eines Rekombinationskonstruktes ist es von Vorteil, wenn sich die gesamte kodierende Information auf einem Klon befindet. Dann ist gewährleistet, daß keine regulativen Bereiche neben der Region, die entfernt werden soll, mitdeletiert werden und so zu möglicherweise verfälschenden Phänotypen führen. Es hat sich gezeigt, daß die Größe des Homologiebereiches für die Effizienz des Rekombinationsereignisses von großer Bedeutung ist (Thomas und Capecchi, 1987). Um eine hohe homologe Rekombinationsfrequenz zu erhalten, sollte diese nicht kleiner als 10kb gewählt werden (Mansouri, 2001). Die zu deletierende Region umfaßt die funktionelle Domäne, also in diesem Falle die Homeodomäne, da so die Funktion des IrxProteins zerstört wird, aber nicht dessen Regulation. So ist gewährleistet, daß nur das Irx1-Gen von der gezielten Mutation betroffen ist. In dem gewählten Irx1-ga1.2-Klon liegen diesen Überlegungen entsprechend optimale Bedingungen vor, da die Homeobox nahezu mittig liegt und von ausreichend Sequenz flankiert wird (5'der Homeobox befinden sich 3,5 kb und 3 'der Homeobox 8,5 kb homologe Sequenz)

Zur Herstellung des Irx1-Rekombinationskonstruktes wurde der genomische Irx1-ga1.2-Klon wie folgt modifiziert. Zunächst wurde ein 0,5 kb großer Bereich auf der 5'-Seite des Klons als spätere sog. externe Sonde herauskloniert (NotI, SacII). Diese Sonde spielt eine entscheidende Rolle bei der späteren Genotypisierung der Mäuse. Sie ist nicht im fertigen Konstrukt enthalten und nimmt auch nicht an der homologen Rekombination teil, sondern sie dient als Hybridisierungssonde, um die korrekte Integration in den Irx1-Lokus zu überprüfen. Dieses Fragment wird im weiteren Verlauf als ga0,5 bezeichnet. Aus dem verbleibenden genomischen Klon wird die Homeobox in Exon II entfernt (als XbaI-SacII-Fragment) und durch eine Selektionskassettte ersetzt. Die Deletion umfaßt ein 500 bp-Fragment. Aufgrund von starken 
Rekombinationsereignissen war es notwendig, die Klonierungen in einem speziellen Vektor ("very.low.copy"-DT-Plasmid; von D. Treichel (Göttingen) hergestellt und freundlicherweise zur Verfügung gestellt) und mit reparaturdefizienten Bakterien (XL-10Gold; Stratagene) durchzuführen. Ferner mußte ein $1 \mathrm{~kb}$ Bereich auf der 3'-Seite des Irx1-ga1.2-Klons (ScaI-SacII) entfernt werden, da dieser Bereich offentsichtlich maßgeblich Rekombinationsereignisse provozierte.

A.

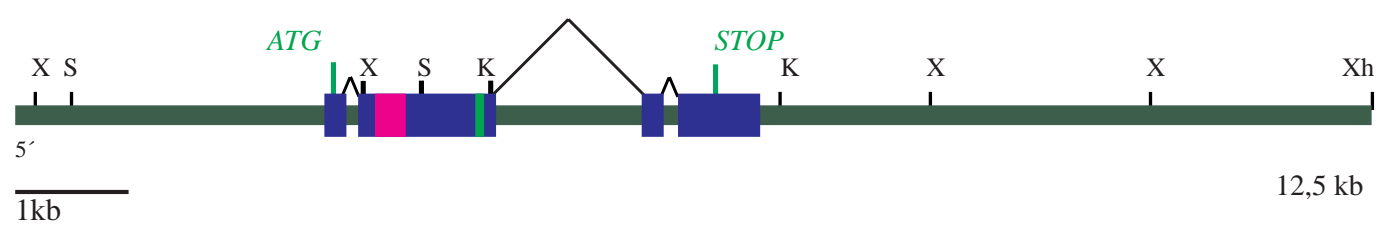

B.

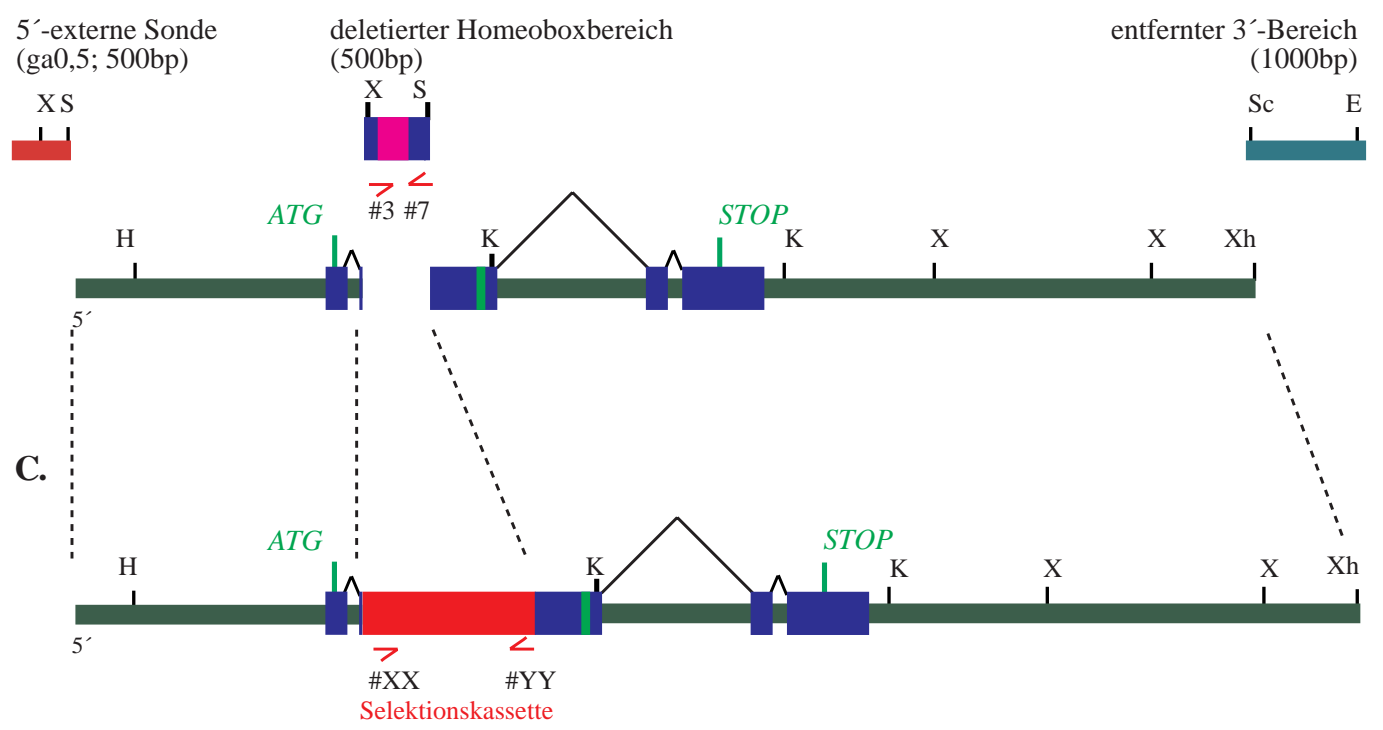

Abb. II.24: Strategie zur Herstellung des Irx1-Rekombinationskonstruktes

Im Verlauf der Umklonierung des Irx1-ga1.2-Klons (A) wurde zunächst das ga0,5Fragment auf der 5 '-Seite entfernt und separat als externe Sonde kloniert (B). Ferner wurde die Homeobox als 500bp-Xba-Sacll-Fragment deletiert und durch die Selektionskassette ersetzt. Aus Gründen der Rekombination in Bakterien wurde weiterhin ein $3^{\prime}$-Bereich entfernt $(1 \mathrm{~kb})$. Das fertige Rekombinationskonstrukt besitzt mit 2,7 kb 5'-flankierender und 7,5 kb 3'-flankierender Sequenz ausreichende Bereiche für die homologe Rekombination. 
Ferner sind die Positionen der Genotypisierungs-PCR-Primer (rote Pfeile) angegeben. Dabei variieren die Primerkombinationen mit dem Rekombinationskonstrukt.

Abkürzungen: H: HindIII; I: IRES, K: Kpnl; S: Sacll; Sc: Scal; Tk: HSV-ThymidinKinase-Gen; X: Xbal; Xh: Xhol; \#3; \#4; \#XX; \#YY: verschiedene GenotypisierungPCR-Primer

Als Selektionskassetten wurden zwei Versionen benutzt und in die Mauskeimbahn eingebracht. Zum einen kam eine 9,5 kb große IRES-TAU-lacZloxPNeoloxP-Kassette zum Einsatz (die IRES-TAU-lacZ-Kassette wurde freundlicherweise von P. Mombaerts (New York) und die loxPNeoloxP-Kassette von W. Wurst (Heidelberg) zur Verfügung gestellt). Das IRES-TAU vor dem lacZ-Gen ermöglicht die $\beta$-Galaktosidase-Expression in Nervenaxonen. Normalerweise ist die $\beta$-Galaktosidase kernlokalisiert. Mit dem Rinder-tauProteinsignal wird sie in die Axone transportiert. Das IRES (aus EMCV) dient dazu, die Elemente in der Kassete auch im Falle eines beschädigten endogenen Translationsstarts anzuschalten. Das Neomycin-Gen dient als positiver Selektionsmarker für die ES-Zellen nach der Elektroporation. Es wird von loxPSequenzen flankiert, damit man es nach der Selektion mittels Cre-Rekombinase entfernen kann. Dieses ist im Falle der Tandemanordnung der Ir $x$-Gene vorzuziehen, da das Neomycin-Gen von einem Pgk1-Promotor angetrieben wird und dieser sehr starke rekombinierende Wirkungen aufweist und somit Einfluß auf die Expression der benachbarten Gene nehmen kann (Meyers et al., 1998). Aus diesem Grund wurde das Pgk-Neomycin nach dem Selektionsschritt mittels Cre-Rekombination in ES-Zellen entfernt. Es wurden anschließend sowohl ESZellen mit, als auch ohne Neomycin aggregiert und in die Keimbahn eingebracht.

Mit der zweiten Deletionskassette wird der Bereich der Homeobox durch ein Puromycin-Gen ersetzt ( $p K O$-puro; Stratagene). Das Puromycin-Gen ist wie Neomycin ein positiver Selektionsmarker nach der ES-Zell-Elektroporation. Der Vorteil von Puromycin ist, daß es effizienter als Neomycin wirkt und dadurch die Selektion schneller beendet werden kann. Weiterhin wurde bei dieser Kassette auf der 5'-Seite außerhalb des homologen Bereiches die HSV-Thymidin-Kinase als negativer Selektionsmarker eingebaut. Als Basis der Klonierung dient der 
Vektor pKO-\#1908 (Stratagene), der sich ähnlich wie das "very.low.copy"-DTPlasmid (s.o.) als rekombinationsarm erwiesen hat.

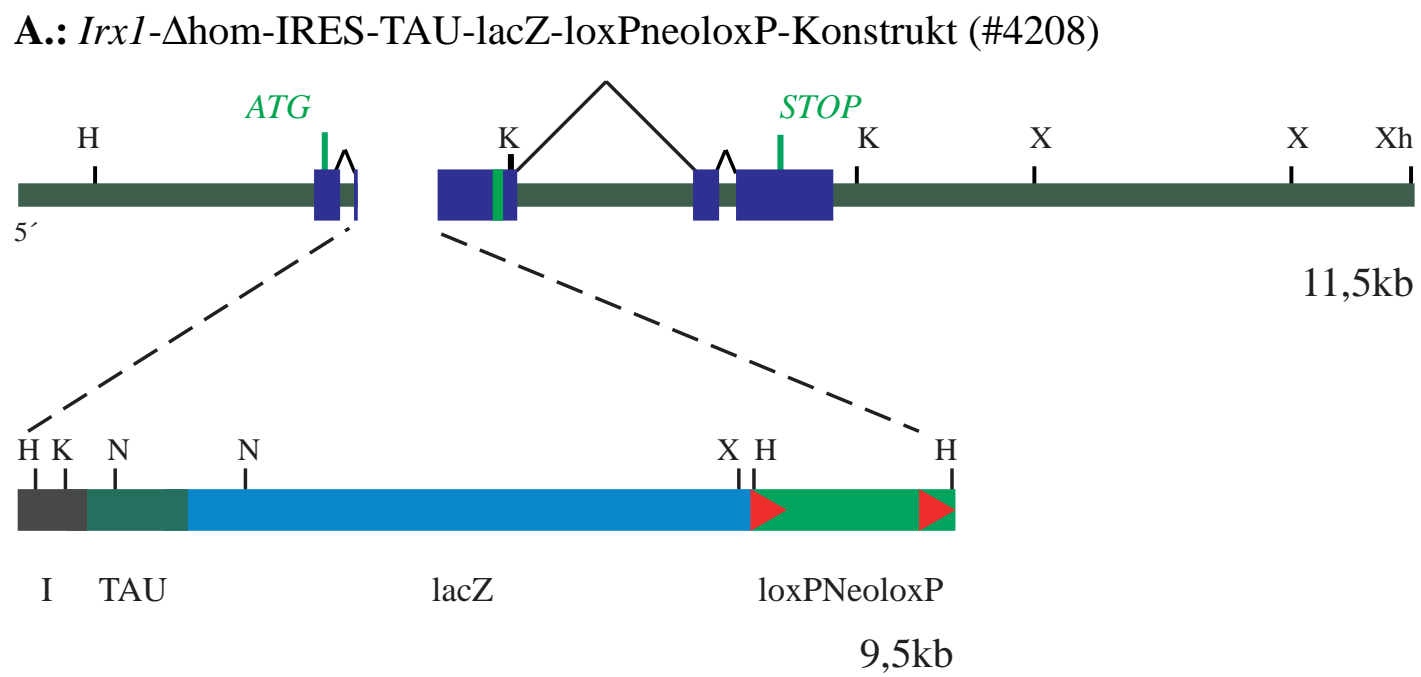

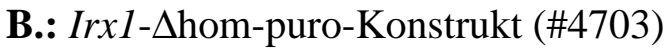

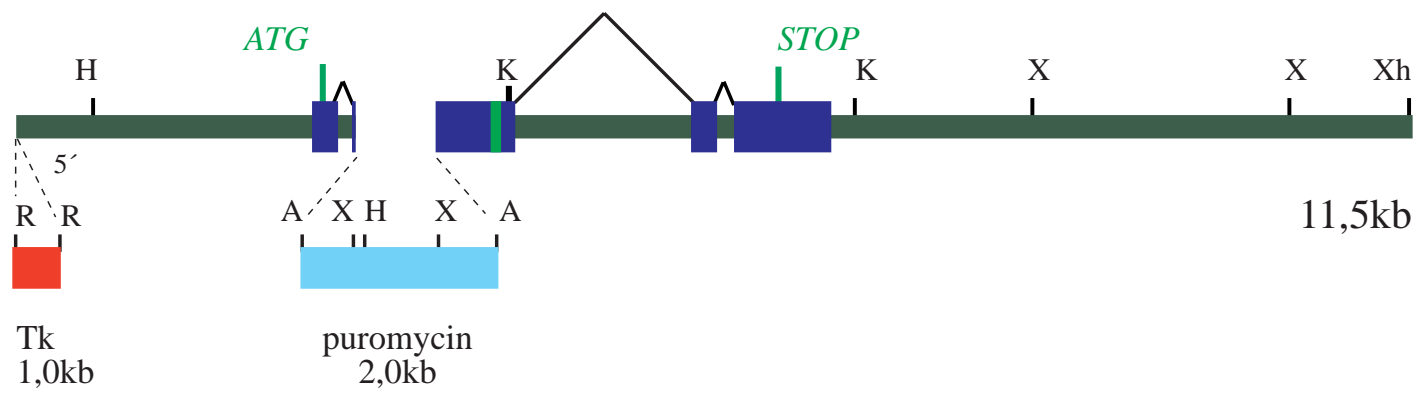

Abb. II.25: Die beiden Irx1-Rekombinationskonstrukt-Varianten

Das 500bp-Homeoboxfragment wird durch ein 9,5 kb großes IRES-TAU-lacZloxPNeoloxP-Rekombinationskonstrukt ersetzt (A). Dieses Konnstrukt ermöglicht es $\beta$ Galaktosidase (lacZ; hellblau) an den Orten der Irx1-Aktivität zu exprimieren und zusätzlich die Expression in den Axonen zu verfolgen (TAU; dunkelgrün). Ferner ermöglicht es, das Neomycin-Gen (hellgrün), welches von loxP-Sequenzen flankiert wird (rote Dreiecke), mittels einer Cre-Rekombinase zu entfernen.

In der zweiten Variante wird die Homeobox-Region durch das Selektionsgen Puromycin (pKO-puro) ersetzt (B). Desweiteren wurde am 5'-Ende des homologen Bereiches das HSV-Thymidin-Kinase-Gen als ein negativer Selektionsmarker eingeführt. Dieses Konstrukt ermöglicht eine doppelte Selektion und dient ferner als Kontrolle dafür, daß das große IRES-TAU-lacZ-loxPNeoloxP-Konstrukt (A).

Abkürzungen: $\Delta$ hom: deletierte Homeobox; H: HindIII; I: IRES; K: Kpnl; lacZ: $\beta$ Galaktosidasegen; S: Sacll; Tk: HSV-Thymidin-Kinase-Gen; X: Xbal; Xh: Xhol 


\section{II.4.4. GENTRANSFER IN ES-ZELLEN}

$E_{\text {mbryonale Stammzellen (ES-Zellen) werden aus der inneren Zellmasse der }}$ Mausblastozyste gewonnen und können in Kultur gehalten werden. Wenn sie auf embryonalen Fibroblasten oder in Anwesenheit von LIF (leukaemia inhibitory factor) kultiviert werden, behalten sie ihre Pluripotenz (Mansouri, 2000; Mansouri, 2001).

Die Rekombinationskonstrukte wurden in die MPI-II-ES-Zellinie

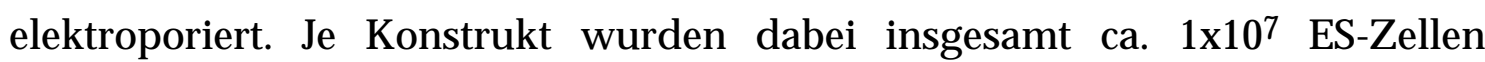
verwendet und auf das homologe Rekombinationsereignis selektiert.

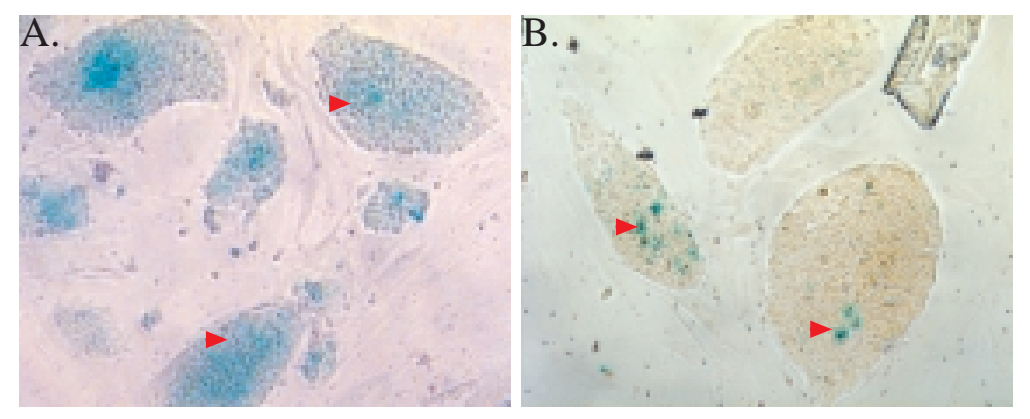

Abb. II.26: Embryonale Stammzellen

Die Abbildung zeigt Beispiele (A,B) von embryonalen Stammzellen. Die einzelnen ESZellen entwickeln sich klonal, so daß "Kolonien" aus klonalen embryonalen Stammzellen entstehen. Die transgenen ES-Zellen (hier mit Irx1- $\Delta$ hom-IRES-TAUlacZ-loxPNeoloxP) wurden auf ihre $\beta$-Galaktosidaseaktivität hin, mittels $\mathrm{X}$-GalFärbung, getestet. Die Aktivität ist an der blauen Färbung (rote Dreiecke) zu sehen.

IRX1-AHOM-IRES-TAU-LACZ-loxPNeoloxP

Die mit dem Irx1-_hom-IRES-TAU-lacZ-loxPNeoloxP-Konstrukt transformierten Zellen wurden mit Geneticin (G418) selektiert. Nach der Selektion konnten insgesamt 135 ES-Zell-Klone isoliert werden. Zur Identifizierung des homologen Rekombinationsereignisses wurde genomische DNA aus den ES-Zellen gewonnen. Für die Southern-Blot-Analyse wurde eine externe (ga0,5; $500 \mathrm{bp}$ ) und eine interne Sonde (neo; $2 \mathrm{~kb}$ ) benutzt. Der Verdau der genomischen DNA mit KpnI führt in der Southern-Blot-Analyse mit der externen Sonde $\mathrm{zu}$ einer 4,7 $\mathrm{kb}$ Bande für das Wildtyp-Allel und einer zusätzliche 3,7 kb Bande für das homolog rekombinierte Allel. Bei der 
Hybridisierung mit der internen Sonde wird jeweils das mutierte Allel der entsprechenden Größe (KpnI-Verdau: 7,5 kb und BamHI-Verdau: 3,5 kb) nachgewiesen. Von den 135 ES-Zell-Klonen zeigten aufgrund der Analysen sechs das richtige Rekombinationsereignis, welches einer Frequenz von 1:23 entspricht.

A.
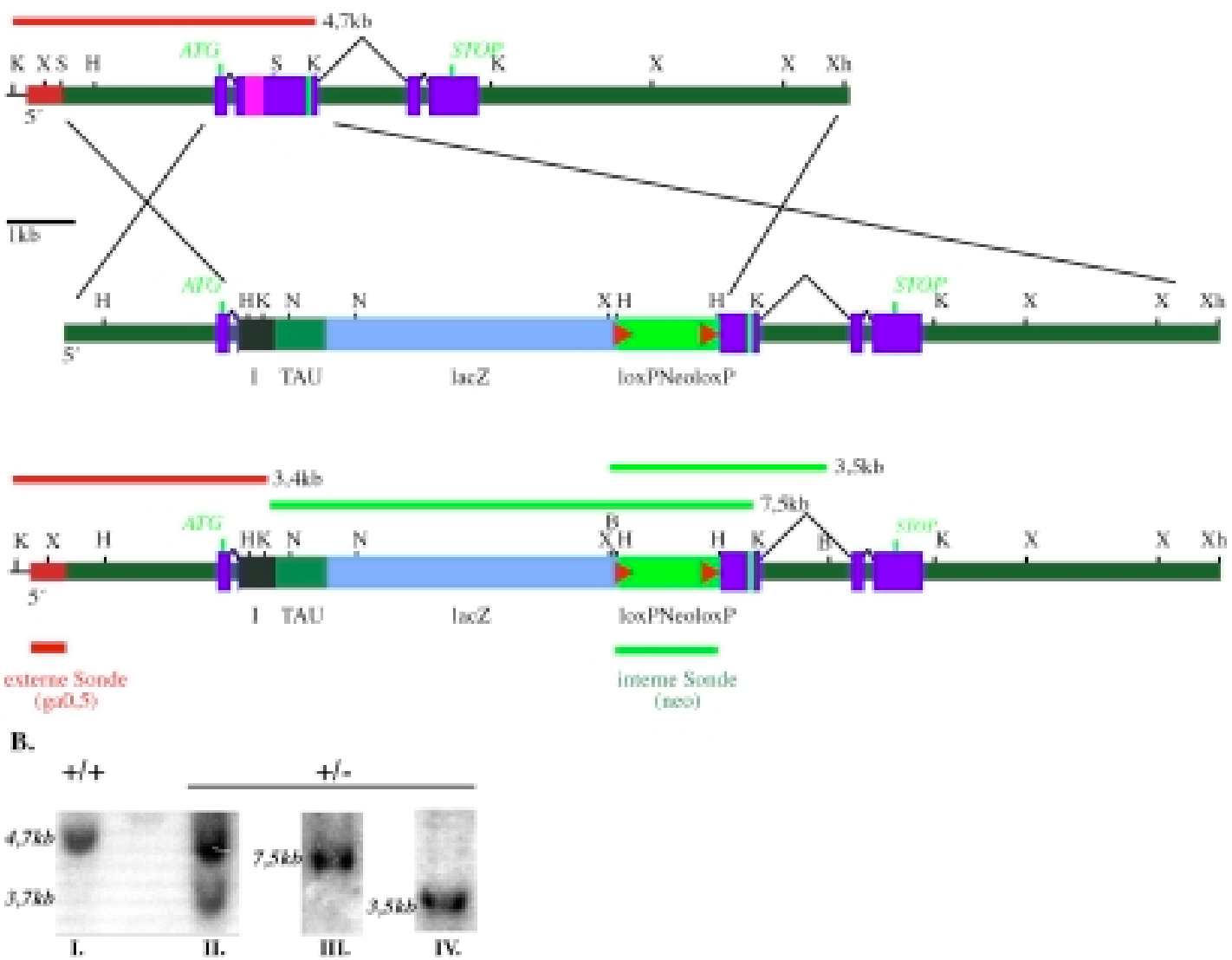

Abb. II.27: Rekombinationsschema sowie Analyse der mit dem Irx1- $\Delta$ hom-IRESTAU-lacZ-loxPNeoloxP-Konstrukt transformierten ES-Zellen

A. Darstellung der mittels homologer Rekombination erzeugten Mutation im Irx1-Gen. Die obere Zeile gibt die genomische Organisation des Irx1-Allels an, die mittlere Zeile das Rekombinationskonstrukt (Irx1-Ahom-IRES-TAU-lacZ-loxPNeoloxP-Konstrukt) und die untere Zeile die erwartete Struktur des mutierten Irx1-Allels.

B. Southern-Blot-Analyse genomischer DNA von ES-Zellen, welche mit Kpnl verdaut und mit externer und interner Sonde hybridisiert wurden. Dabei wurde I und II mit der Sonde ga0,5 (externe Sonde) hybridisiert. Die obere Bande entspricht dem Wildtyp $(4,7 \mathrm{~kb})$ und die untere dem mutierten Allel (3,7 kb). Die Spur III. wurde ebenfalls mit Kpnl verdaut und mit der interen Sonde (neo) hybridisiert. Diese markiert nur das mutierte Allel (7,5 kb). Die Spur IV. ist mit BamHI verdaut und ebenfalls mit der internen Sonde (neo) hybridisiert. Diese markiert gleichfalls nur das mutierte Allel (3,5 
kb). Die interne Sonde gibt weiterhin Auskunft über die korrekte Struktur des Rekombinationskonstruktes.

Abkürzungen: $\Delta$ hom: deletierte Homeobox; H: HindlII; I: IRES; K: Kpnl; lacZ: $\beta$ Galaktosidasegen; S: Sacll; X: Xbal; Xh: Xhol

Neben dem Irx1-Ahom-IRES-TAU-lacZ-loxPNeoloxP-Konstrukt wurden noch zwei weitere Konstrukte elektroporiert.

\section{IRX1- $\triangle H O M-P U R O-K O N S T R U K T$}

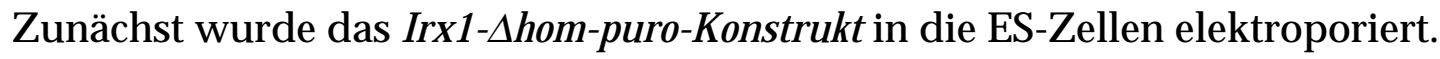
Die Zellen wurde auf Puromycin- und Gancyclovir-Resistenz (gegen Tk) selektiert. Es konnten 290 ES-Zell-Klone nach der Selektion isoliert werden. Aus diesen Klonen wurden zur Identifizierung der homologen Rekombination DNA präpariert und einer Southern-Blot-Analyse mit verschiedenen Sonden unterzogen. Als externe Sonde wurde wieder das ga0,5-Fragment benutzt und als interne das Puromycin-Gen. Die genomische DNA wurde mit KpnI verdaut und zeigte nach der Hybridisierung mit ga0,5 eine 4,7 kb Bande für das Wildtyp-Allel und eine 6,7 kb Bande für das rekombinierte Allel. Mit der internen Sonde (puromycin) konnte jeweils das mutierte Allel nachgewiesen werden (KpnI-Verdau: 6,7 kb und XbaI-Verdau: 6,5 kb). Von den 290 ES-ZellKlonen wurde für sieben eine korrekte homologe Rekombination nachgewiesen (Frequenz von $1: 40$ ) 


\section{A.}
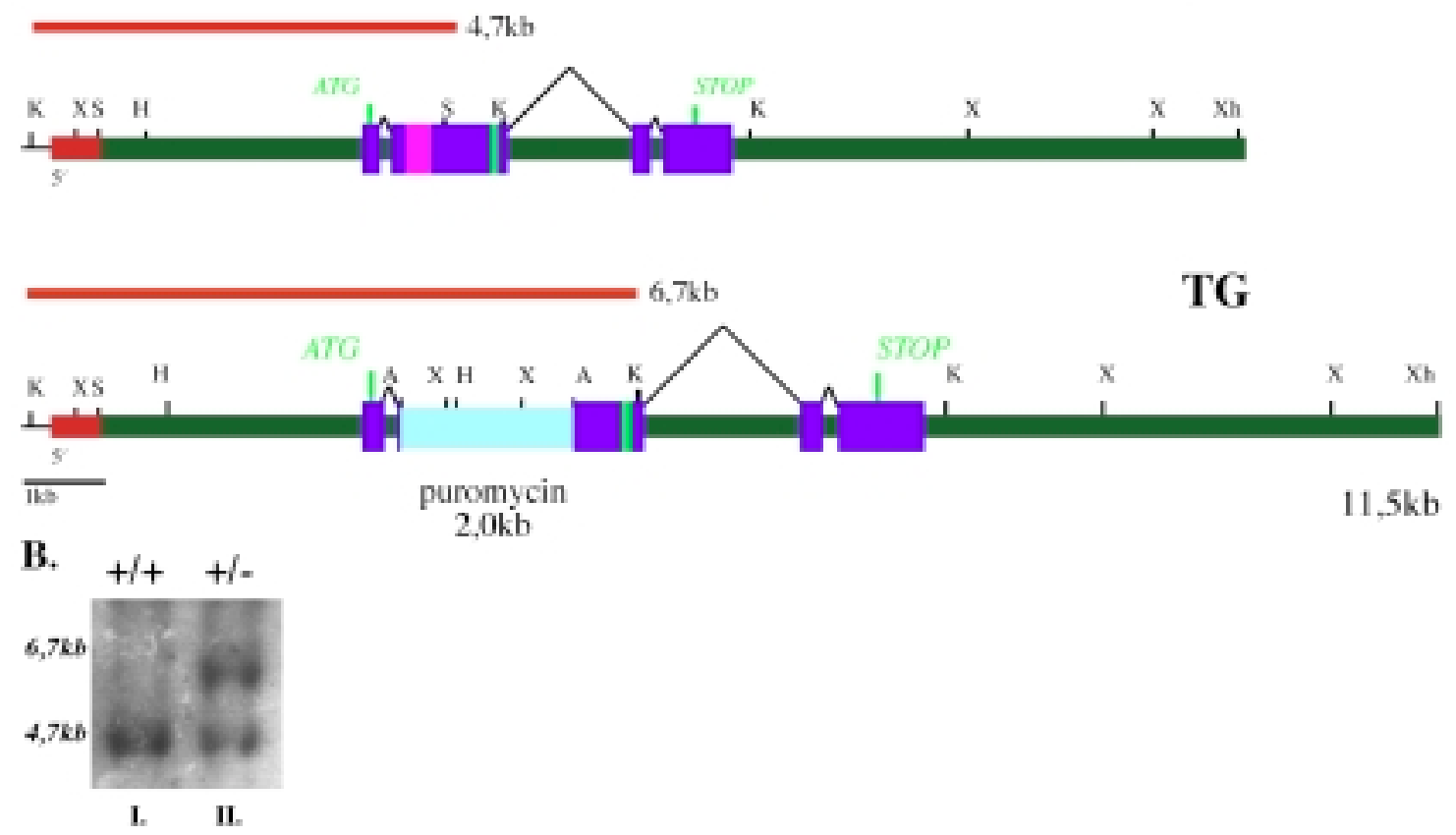

Abb. II.28: Irx1- $\Delta$ hom-puromycin-Konstrukt: Rekombinationsschema und Durchmusterung der ES-Zellen

A. Irx1-Mutation mittels homologer Rekombination. Die genomische Organisation des Wildtyp-Allels wird in der oberen Zeile und die erwartete Struktur des mutierten Irx1 Allels in der unteren angegeben.

B. ES-Zell-Southern-Blot-Analyse der genomischer DNA. Diese wurden mit Kpnl verdaut und mit der Sonde ga0,5 (externe Sonde) hybridisiert. Die untere Bande entspricht dem Wildtyp- (4,7kb; I.) und die obere dem mutierten Allel $(6,7 \mathrm{~kb}$; I. und II.).

Abkürzungen: $\Delta$ hom: deletierte Homeobox; H: HindlII; I: IRES, K: Kpnl; lacZ: $\beta$ Galaktosidasegen; S: Sacll; TG: transgenes Allel; Tk: HSV-Thymidin-Kinase-Gen; WT: Wildtyp Allel; X: Xbal; Xh: Xhol

\section{IRX1- $\Delta H O M-I R E S-T A U-L A C Z-l o x P \Delta N e O$}

Die dritte durchgeführte Elektroporation hatte zum Ziel, das Neomycin-Gen aus den Irx1-Ahom-IRES-TAU-lacZ-loxPNeoloxP positiven ES-Zellen zu deletieren, um Irx1-Ahom-IRES-TAU-lacZ-loxPANeo zu erhalten. Das NeomycinGen sollte entfernt werden, da der Pgk-Promotor des Neomycin-Gens in Gengruppen manchmal zu Fehlexpressionen oder zu "Rearrangements" führen kann (Meyers et al., 1998). Für das Entfernen wurde das Cre-loxP-System benutzt, bei dem das Neomycin-Gen von loxP-Sequenzen flankiert wird. 
Dazu wurde der ES-Zell-Klon Irx1-_hom-IRES-TAU-lacZ-loxPNeoloxP-\#92 mit einem Cre-Puromycin-Plasmid elektroporiert (Taniguchi et al., 1998). Dieses Plasmid zeichnet sich dadurch aus, daß es eine Cre-Rekombinase und einen Puromycin-Selektionsmarker enthält. Nach der Elektroporation vermittelte das Cre-Enzym in den betroffenen ES-Zellen die Entfernung des LoxPNeo durch Rekombination der LoxP-Stellen. Mittels des Puromycin-Selektionsmarkers ist es möglich, die positiv elektroporierten ES-Zellen $\mathrm{zu}$ selektieren. Das CrePuromycin-Plasmid wird aber nicht in das Mausgenom integriert, da es als Plasmid und nicht linear transferriert wird (Watanabe et al., 1995; Taniguchi et al., 1998).

Die ES-Zellen werden wie bei der Elektroporation des Irx1-Dhom-IRES-TAUlacZ-loxPNeoloxP-Konstruktes beschrieben, mit KpnI verdaut und mit der externen ga0,5-Sonde durchgemustert (Wildtyp: 4,7 kb; mutiertes Allel: 3,4 kb).

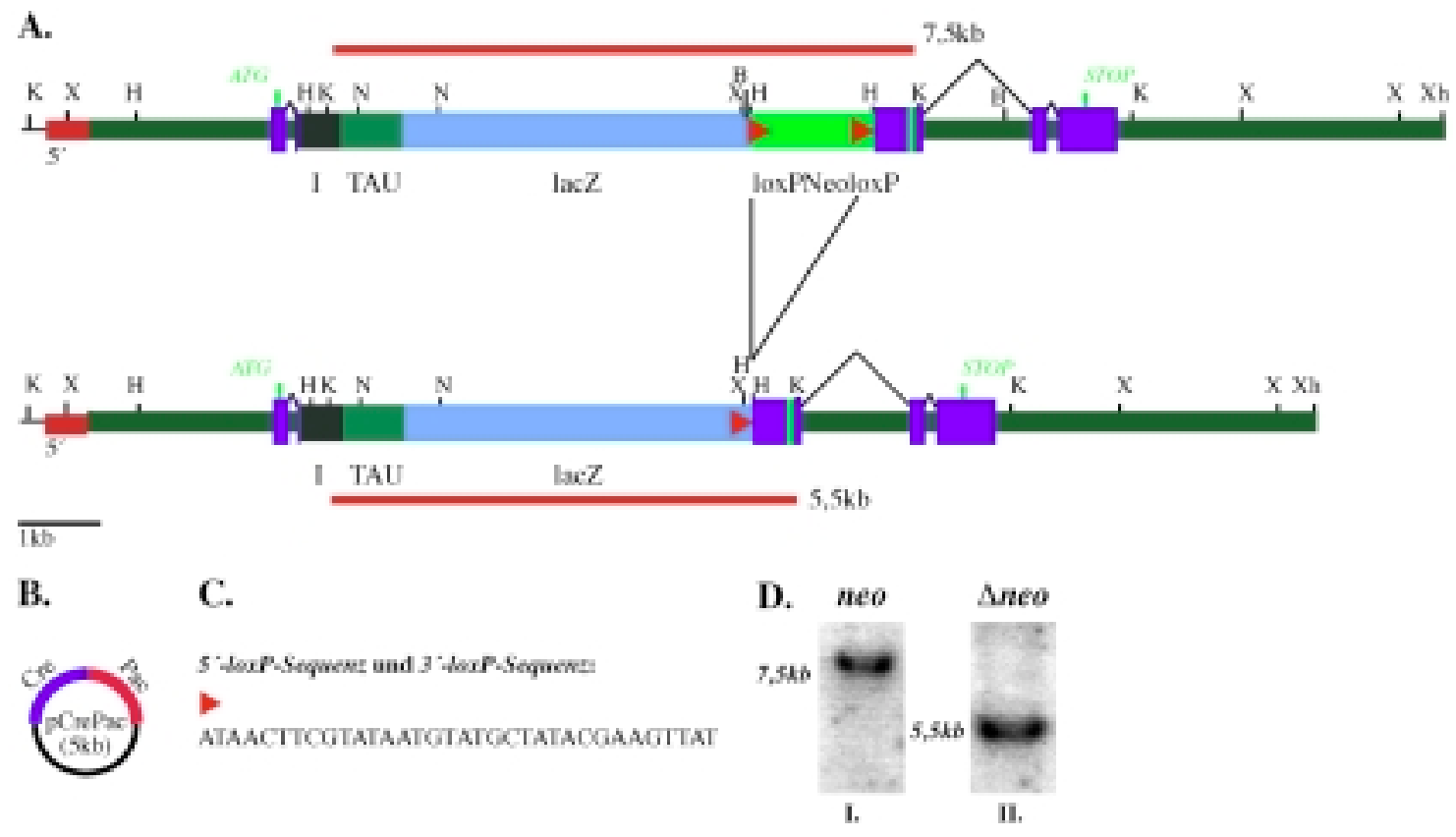

Abb. II.29: Entfernen des Neomycin-Gens aus Irx1- $\Delta$ hom-IRES-TAU-lacZloxPNeoloxP-\#92: Rekombinationsschema und Durchmusterung der ES-Zellen für die Herstellung von Irx1- $\Delta$ hom-IRES-TAU-lacZ-loxP $\Delta$ Neo.

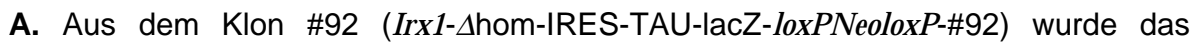
Neomycin-Gen mittels einer Rekombinase-Reaktion entfernt. Das Neomycin-Gen ist von loxP-Sequenzen flankiert (rote Dreiecke) und läßt sich mit einer CreRekombinase deletieren. Die obere Reihe zeigt die Organisation des Klons \#92 und 
die untere Zeile die erwartete Struktur des mutierten Irx1-Allels ohne loxPNeo. Eine loxP-Sequenz verbleibt nach der Rekombinationsreaktion im Mausgenom.

B. Die Abbildung zeigt das pCrePac-Plasmid, welches in den ES-Zellen benutzt wurde, um mittels einer Cre-Rekombinasereaktion das loxPNeo herauszuschneiden (Taniguchi et al., 1998).

C. Die Abbildung zeigt die 34 Nucleotide lange loxP-Sequenz (rotes Dreieck), wie sie im Irx1- $\Delta$ hom-IRES-TAU-lacZ-loxPNeoloxP-Rekombinationskonstrukt benutzt wurde.

D. ES-Zell-Southern-Blot-Analyse mit genomischer DNA. Diese wurde mit Kpnl verdaut und mit einer externe und interne Sonde hybridisiert. Die Spur I. und II. wurde mit Kpnl verdaut und mit der interen Sonde (lacZ) hybridisiert (mutiertes Allel mit loxPNeo: 7,5kb; mutiertes Allel ohne loxPNeo: 5,5kb). Diese interne Sonde gibt Aufschluß darüber, ob das loxPNeo deletiert ist.

Abkürzungen: Cre: Cre-Rekombinase; H: Hindlll; I: IRES; K: Kpnl; lacZ: bGalaktosidasegen; Pac: Puromycin-Gen; S: Sacll; Tk: HSV-Thymidin-Kinase-Gen; $\mathrm{X}$ : Xbal; Xh: Xhol

Die interne Sonde ist diesmal die wichtigere, da sie dazu dient, die Deletion von Neomycin nachzuweisen. Für die Hybridisierung mit der internen 4,2 kblacZ-Sonde wird die genomische DNA mit KpnI verdaut und hybridisiert (mutiertes Allel mit loxPNeo: 7,5 kb; mutiertes Allel ohne loxPNeo : 5,5 kb). Die erzielte Frequenz war $1: 23$.

\section{II.4.5. MORULA-AGGREGATION VON ES-ZELLEN}

$D_{\text {ie }}$ Pluripotenz der embryonalen Stammzellen wurde anhand der Herstellung von Chimären durch Blastozysteninjektion von ES-Zellen oder durch ES-Zell-Aggregation in eine Morula gezeigt. Die Chimären entwickeln sich normal und die ES-Zellen beteiligen sich an der Entwicklung aller embryonalen Gewebetypen, einschließlich der Keimbahn. Daher eignen sie sich hervorragend zur Herstellung von Mausmutanten (Mansouri, 2001; Robertson, 1987).

Je Irx1-Rekombinationskonstrukt (Irx1--4hom-IRES-TAU-lacZ-loxPNeoloxP-,

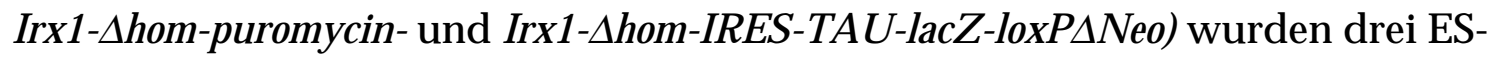
Zell-Klone zur Herstellung chimärer Mäuse durch Morula-Aggregation verwandt (s. Tabelle). Die ES-Zellen wurden mit Morulae aggregiert, die aus dem NMRI-Mausstamm gewonnen wurden und pro ES-Zell-Klon wurden 
durchschnittlich 250 Aggregationen durchgeführt. Da sich nicht alle Morulae außerhalb des Körpers weiterentwickeln, wurden ca. $90 \%$ der aggregierten Embryonen retransferiert. Ebenso entwickeln sich nicht alle transferierten Embryonen zu Chimären. Entscheidend für die Weiterentwicklung sind Faktoren wie die der Synchronisation der Ammenmütter oder die Sauberkeit während des Retransfers. Die Ergebnisse der Morula-Aggregation sind in den folgenden Tabellen zusammengefaßt:

Morula-Aggregation von Irx1-Ahom-IRES-TAU-lacZ-loxPNeoloxP-ES-Zellen:

GEPICKTE KLONE:

135
POSITIVE KLONE: $\quad 6 \mathrm{x}: \# 9$, \#15. \#23,

\#27, \# 41. \#92

\begin{tabular}{|c|c|c|c|c|}
\hline ES-ZELL-KLON & $\begin{array}{c}\text { AGGREGATION } \\
\text { (ES-ZELLEN) }\end{array}$ & $\begin{array}{c}\text { ANZAHL DER } \\
\text { CHIMÄREN }\end{array}$ & KEIMBAHN & $\begin{array}{c}\text { F1- } \\
\text { GENERATION }\end{array}$ \\
\hline AZ-27 & 255 & $10 / 46$ & $100 \%$ & ok \\
\hline AZ-41 & 210 & $1 / 40$ & & \\
\hline AZ-92 & 240 & $5 / 54$ & & \\
\hline
\end{tabular}

Tabelle II.1: Ergebnisse der Morula-Aggregation von Irx1- $\Delta$ hom-IRES-TAU-lacZloxPNeoloxP. Aus der Elektroporation der ES-Zellen wurden sechs korrekte transgene ES-Zell-Klone erhalten (6:135). Bei diesem Irx1-Rekombinationskonstrukt wurden drei ES-Zell-Klone aggregiert, wobei z.B. für Klon \#27 10 Chimären aus 46 Neugeborenen hervorgingen. Die Chimären des ES-Zell-Klons \#27 (AZ-27) ermöglichten den Keimbahntransfer.

Morula-Aggregation von Irx1-Ahom-Puromycin-ES-Zellen:

GEPICKTE KLONE: 290 POSITIVEKLONE: 7x: \#6, \#8. \#10, \#11, \#116, \#160, \#185

\begin{tabular}{|c|c|c|c|c|}
\hline ES-ZELL-KLON & $\begin{array}{c}\text { AGGREGATION } \\
\text { (ES-ZELLEN) }\end{array}$ & $\begin{array}{c}\text { ANZAHL DER } \\
\text { CHIMÄREN }\end{array}$ & $\begin{array}{c}\text { KEI- } \\
\text { GENERATION }\end{array}$ & ok \\
\hline AZ-2-116 & 255 & $10 / 46$ & $100 \%$ & \\
\hline AZ-2-160 & 370 & $9 / 24$ & & ok \\
\hline AZ-2-185 & 230 & $8 / 32$ & $100 \%$ & \\
\hline AZ-2-6 & 240 & $5 / 26$ & & \\
\hline AZ-2-8 & 180 & $6 / 30$ & & \\
\hline
\end{tabular}




\begin{tabular}{|c|c|c|c|c|}
\hline AZ-2-11 & 160 & $15 / 23$ & $100 \%$ & ok \\
\hline
\end{tabular}

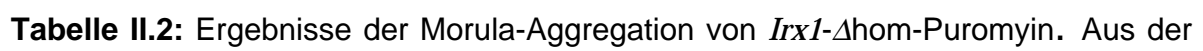
Elektroporation der ES-Zellen wurden sieben korrekt transgene ES-Zell-Klone erhalten (7:290). Bei diesem Irx1-Rekombinationskonstrukt wurden sechs ES-ZellKlone aggregiert, wobei aus dreien Chimären hervorgingen, die das Transgen in die Keimbahn tranferrierten. Die Chimären der ES-Zell-Klone \#6, \#11 und \#116 (AZ-2-6, AZ-2-11 und AZ-2-116) führten zum Keimbahntransfer, und es konnten daraus jeweils Mauslinien etabliert werden.

Morula-Aggregation von Irx1-Ahom-IRES-TAU-lacZ-loxPANeo-ES-Zellen:

GEPICKTE KLONE:

\begin{tabular}{|c|c|c|c|c|}
\hline ES-ZELL-KLON & $\begin{array}{c}\text { AGGREGATION } \\
\text { (ES-ZELLEN) }\end{array}$ & $\begin{array}{c}\text { ANZAHL DER } \\
\text { CHIMÄREN }\end{array}$ & KEIMBAHN & $\begin{array}{c}\text { F1- } \\
\text { GENERATION }\end{array}$ \\
\hline AZ-3-72 & 240 & $5 / 45$ & $1 \times 1 \%$ & ok \\
\hline AZ-3-90 & 270 & $9 / 98$ & $1 \times 100 \%$ & ok \\
\hline AZ-3-116 & 300 & $12 / 53$ & $1 \times 100 \%$ & ok \\
\hline
\end{tabular}

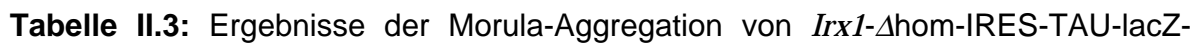
loxP $\Delta N e o$. Aus der Elektroporation der ES-Zellen wurden fünf korrekt transgene ESZell-Klone erhalten (5:117). Bei diesem Irx1-Rekombinationskonstrukt wurden 3 ESZell-Klone aggregiert, welche zu Chimären führten. Die Chimären der ES-Zell-Klone \#72 \#90 und \#116 (AZ-3-72, AZ-3-90 und AZ-3-116) führten zum Keimbahntransfer und es konnten daraus jeweils Mauslinien (AZ-3-72 1x; AZ-3-90: 2x; AZ-3-116: 2x) etabliert werden.

Nach ca. sechs Wochen wurden die Chimären mit NMRI-Wildtypmäusen verpaart. Der Grad des Chimärismus ist dabei anhand der Fellfarbe erkennbar. Je höher dieser Grad, desto höher ist auch die prozentuale Wahrscheinlichkeit, daß die chimäre Maus die transgene Information auch in ihren Keimzellen trägt und somit diese Information an ihre Nachkommen weitergibt. Eine Keimbahntransmission konnte bei den Nachkommen anhand der Augenfarbe erkannt werden. Mäuse mit schwarzen Augen entstammten der Keimbahn der transgenen ES-Zellen (Stamm: 129SV), wohingegen Mäuse mit roten Augen von den nicht-transgenen ES-Zellen (Stamm: NMRI) abstammen. Keimbahntransmitierende Chimären wurden auf dem Inzuchtstamm SV129 
und dem Auszuchtstamm NMRI weitergezüchtet. Der Mausstamm SV129 bietet die Vorteile eines genetisch "sauberen (reinen)" Hintergrundes, da auch die ESZellen diesem entstammen. Leider ist bei diesen aber die Zahl der Nachkommen und auch die Pflegebereitschaft der Mütter eingschränkt. Diese letztgenannten Probleme treten nicht in einem NMRI-Hintergrund auf, dafür liegt ein genetischer Mischhintergrund vor, der bei Phänotyp-Analysen zu beachten ist. Daher entstammen alle folgenden Daten den Verpaarungen mit 129SV-Mäusen, außer sie werden ausdrücklich erwähnt. Heterozygote Tiere der F1-Generation wurden miteinander bis zur Homozygotie verpaart.

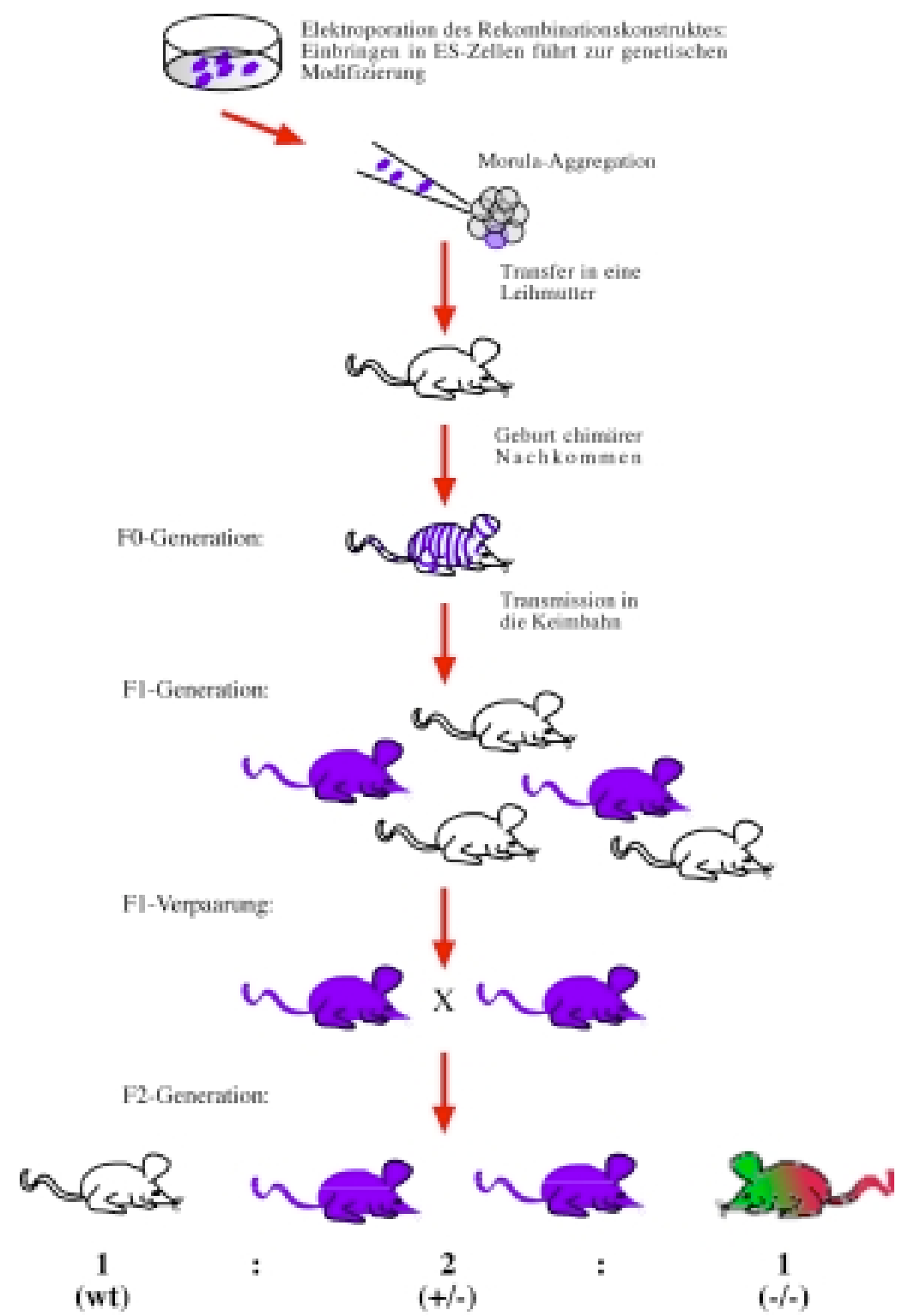

Abb. II.30: Schematische Darstellung der Aggregation und des Verpaarungsschema 
Nach der Aggregation wurden die chimären Mäuse (F0, blau-weiß) mit WildtypMäusen verpaart. Die Transmission in die Keimbahn konnte über die Fellfarbe (weiß/ blau) nachgewiesen werden. Irx1-heterozygote F1-Mäuse wurden miteinander zur Homozygotie verpaart. Der Genotyp der Nachkommen entspricht der zweiten Mendelschen Regel und teilt sich wie folgt auf:

1(wildtyp; wt) $\quad: \quad 2$ (heterozygot; +/-) $\quad: \quad 1$ (homozygot; -/-)

Es konnten insgesamt sieben Mauslinien etabliert und daraufhin analysiert werden, die jeweils unabhängigen ES-Zell-Klonen entstammen. Diese wiederum zeichnen sich durch jeweils verschiedene Chimären aus.

\begin{tabular}{|c|c|}
\hline REKOMBINATIONSKONSTRUKT: & MAUSLINIE \\
\hline Irx1- $\Delta$ hom-IRES-TAU-lacZ-loxPNeoloxP : & AZ-27 \\
\hline \multirow[t]{3}{*}{ Irx1-Ahom-puromycin : } & AZ-2-11 \\
\hline & AZ-2-116 \\
\hline & AZ-2-160 \\
\hline \multirow[t]{3}{*}{ Irx1- $\Delta$ hom-IRES-TAU-lacZ-loxP $\Delta$ Neo : } & AZ-3-72 \\
\hline & AZ-3-90 \\
\hline & AZ-3-116 \\
\hline
\end{tabular}

Die sieben Mauslinien (NMRI-Hintergrund) wiesen keinen Unterschied im Phänotyp auf und so wurde für die weitere Analyse der Irx1-defiziente Mausstamm AZ-27 ausgewählt.

\section{II.5. ANALYSE DER IRX1-DEFIZIENTEN MÄUSE}

\section{II.5.1 IRX1-DEFIZIENTE MÄUSE STERBEN WÄHREND DER EMBRYONALEN ENTWICKLUNG}

Die genotypische Analyse von Mäusen der F2-Generation ergab, daß Irx1homozygot defiziente Mäuse nicht geboren werden. Alle untersuchten Irx1heterozygoten Tiere waren phänotypisch unauffällig und ließen sich normal verpaaren. In weiteren Analysen wurden die Stadien E18,5, E15,5, E12,5 und E10,5 auf mögliche homozygote Embryonen hin untersucht. Es traten nie 
homozygote Irx1-Mutanten auf. Unter 356 Embryonen und Mäusen, die untersucht wurden, ergab sich ein Verhältnis von 117 (Wildtyp) zu 239 (heterozygot) zu null (homozygot). Das beobachtete Verhältnis der Genotypen (1:2:0) läßt darauf schließen, daß die homozygoten Embryonen bereits vor dem Stadium E10,5 sterben. Eine Auflistung der untersuchten Mäuse findet sich in folgender Tabelle:

MAUSLINIE:

AZ-27 :

AZ-2-X

(AZ-2-11; AZ-2-116; AZ-2-160)

AZ-3-Y

(AZ-3-72; AZ-3-90; AZ-3-116)

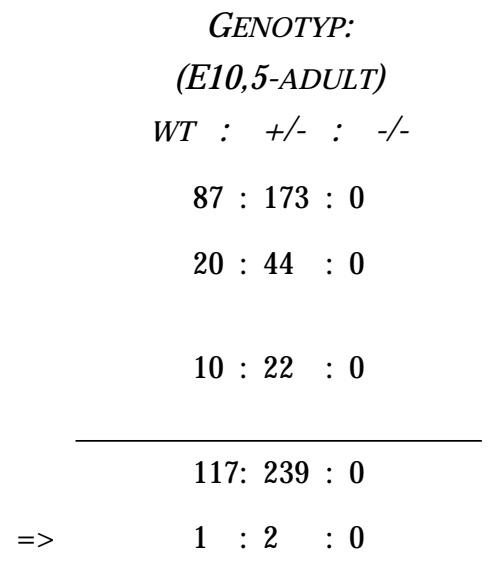

GENOTYP:

$87: 173: 0$

$20: 44: 0$

$10: 22: 0$

117: $239: 0$

$1: 2: 0$

Dieses Ergebnis blieb über mehere Generationen konsistent (Es wurden bisher bis zur vierten Generation untersucht).

\section{II.5.2. IRX1-DEFIZIENTE MÄUSE ZEIGEN EINEN STARKEN EMBRYONALEN PHÄNOTYP}

In der weiteren Analyse wurden noch frühere embryonale Stadien (E5,5E10,0) untersucht. Bei E10,0 treten die ersten abnormen "Gewebe" auf. Diese Irx1-defizienten Körper zeigen Strukturen von kleinen Bällen aus embryonaler Membran. Es ist keine zelluläre Organisation wie z.B. eine Achsenbildung erkennbar, ferner sind weder neuronale noch einfache axiale Anlagen erkennbar. Die Embryonen weisen lediglich eine runde Form ohne ersichtliche Organisation und Strukturierung auf. 


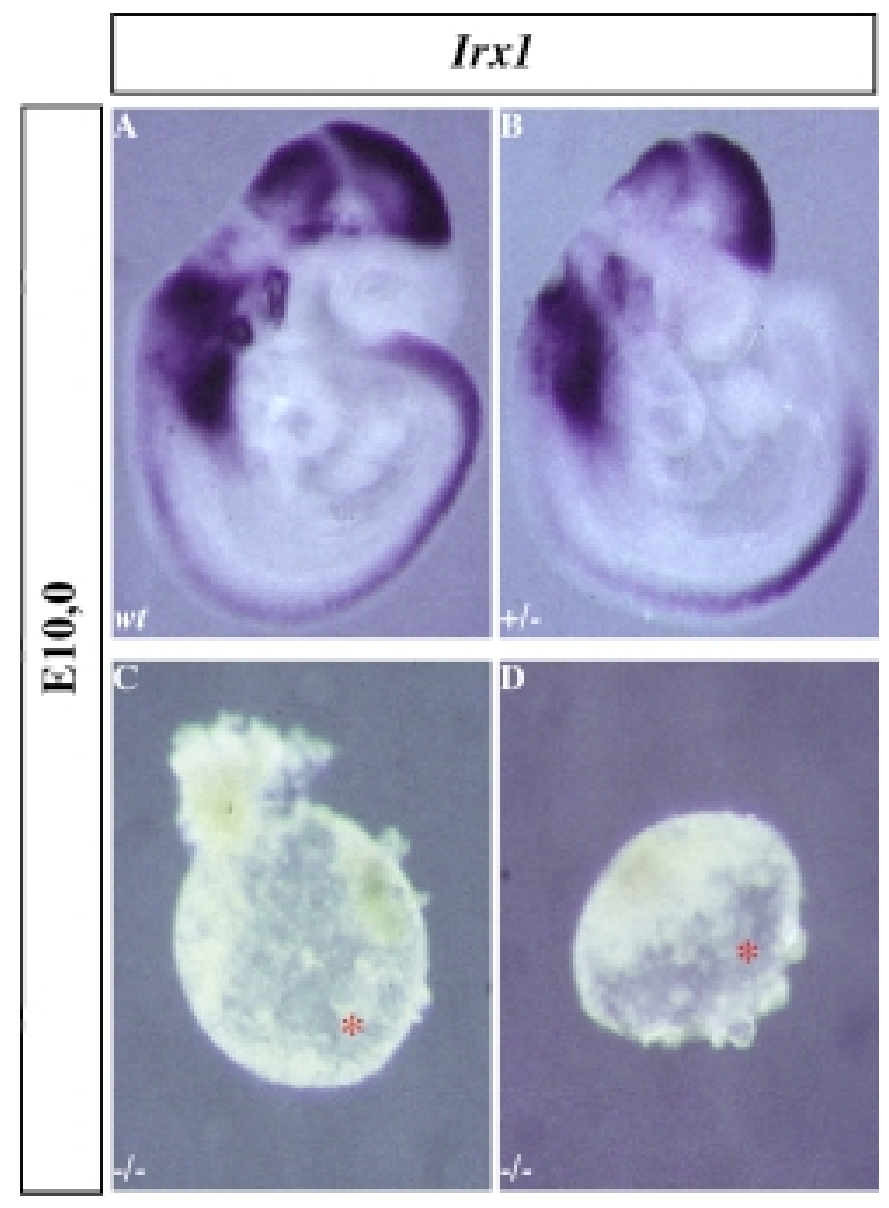

Abb. II.31: Irx1-Phänotyp im Stadium E10,0

Die Abbildung zeigt eine Irx1-whole mount-Analyse eines heterozygoten Wurfes. Die analysierten Embryonen befinden sich Stadium E9,5-10,0. Die heterozygoten Embryonen (B) zeigen im Vergleich zu einem Wildtyp-Embryo (A) eine normale Irx1Expression und ein normales Erscheinungsbild, sind also phänotypisch unauffällig. Es ist allerdings erwähenswert, daß der heterozygote Embryo etwas jünger erscheint $(E 9,5)$. Dieses spiegelt die normale Variabilität eines Wurfes wieder. Dagegen sind die Irx1-Mutanten (C, D) in ihrer ballförmigen Struktur ganz wesentlich zurückgeblieben und bestehen aus embryonalen Membranen (roter Stern), die keine weiteren Organisation oder Differenzierung zeigen.(Diese Analyse wurde auf einem SV129-Inzuchtstamm durchgeführt.)

Die Genotypisierung der Irx1-Mäuse erfolgte mittels einer Southern-Blotbzw. einer PCR-Analyse. Für die frühen embryonalen Stadien wurde auf die PCR-Technologie zurückgegriffen. Dies ermöglich den Einsatz von weniger DNA als in der Southern-Blot-Analyse, was vor allem bei den winzigen homozygoten Embryonen nötig war. 

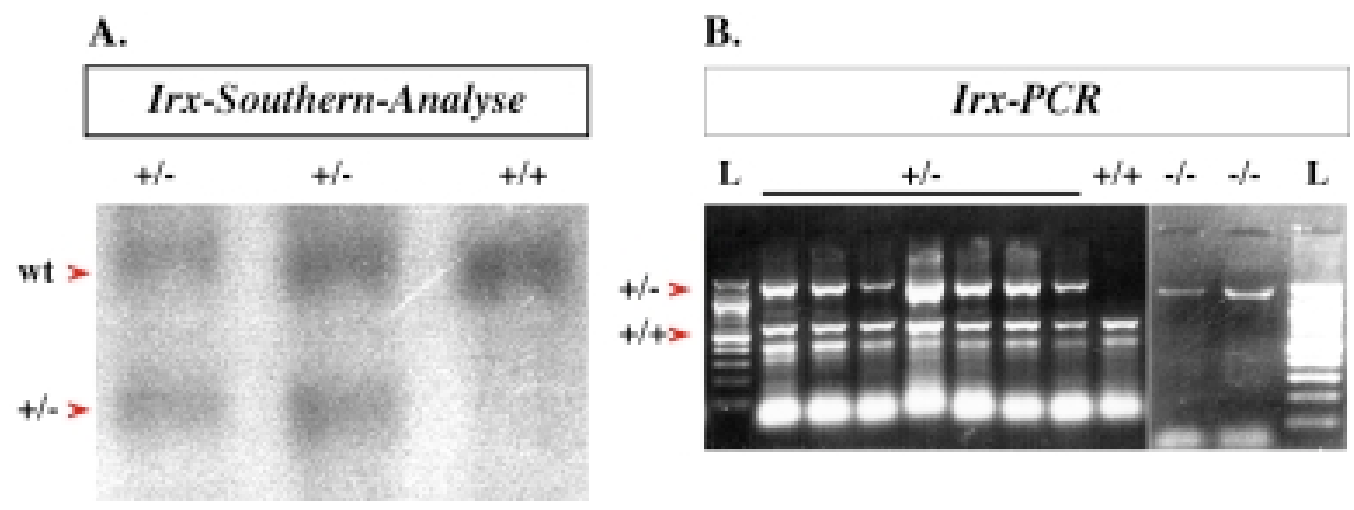

Abb. II.32: Genotypisierung der Irx1-Mutanten

Die Genotypisierung der Irx1-Mutanten erfolgte mittels Southern-Blot-Analyse (E8,5 bis adult). Dazu wurde mit der externen Sonde $(\mathrm{ga0}, 5)$ gearbeitet, die im Wildtyp-Fall eine 4,7 kb Bande und im heterozygoten Zusatnd eine zusätzliche 3,7 kb Bande anzeigt (A). Für die Genotypisierung jüngerer Stadien (E6,0 - E8,5) wurde auf die PCR-Analyse zurückgegriffen. Dazu wurde eine PCR auf der Irx1-Homeobox und auf das Rekombinationskonstrukt (Neomycin oder $\beta$-Galaktosidase) durchgeführt. Die Kombination aus Irx1-Homeobox- mit Neomycin-PCR ergab, wie in B gezeigt, folgende Größen: Wildtyp: 620 bp; heterozygot: 1200 bp + 620 bp; homozygot: 1200 bp).

Abkürzungen: L: 100bp-DNA-Marker

Für die Analyse eines frühen Phänotyps kann der genetische Hintergrund von entscheidender Bedeutung sein, da sich $\mathrm{zu}$ diesem Zeitpunkt Modulationen wesentlich stärker auswirken. Das bedeutet, daß in einem Auszuchtstamm (wie z.B. der verwendete NMRI-Mausstamm) durch genetisches Gleichgewicht der Phänotyp milder ausfallen kann, als in einem Inzuchstamm (wie der untersuchte SV129-Mausstamm) (Winnier et al., 1995). Daher wurde die Analyse der Embryonalentwicklung auch mit dem NMRIMausstamm durchgeführt. Bei Analyse der Mausmutanten auf diesem genetischen Hintergrund, schreitet die Entwicklung der Embryonen etwas weiter fort (überleben bis E10,5). Auch in diesem Falle liegen kleine ballförmige Strukturen vor, diese zeigen aber in deren Mitte fingerförmige embryonale Überreste, die auf eine gewisse axiale Strukturierung hindeuten. 
Aus diesen Reststrukturen ist ersichtlich, daß die Irx1-defizienten Mausembryonen ein Problem während der frühen embryonalen Entwicklung haben.

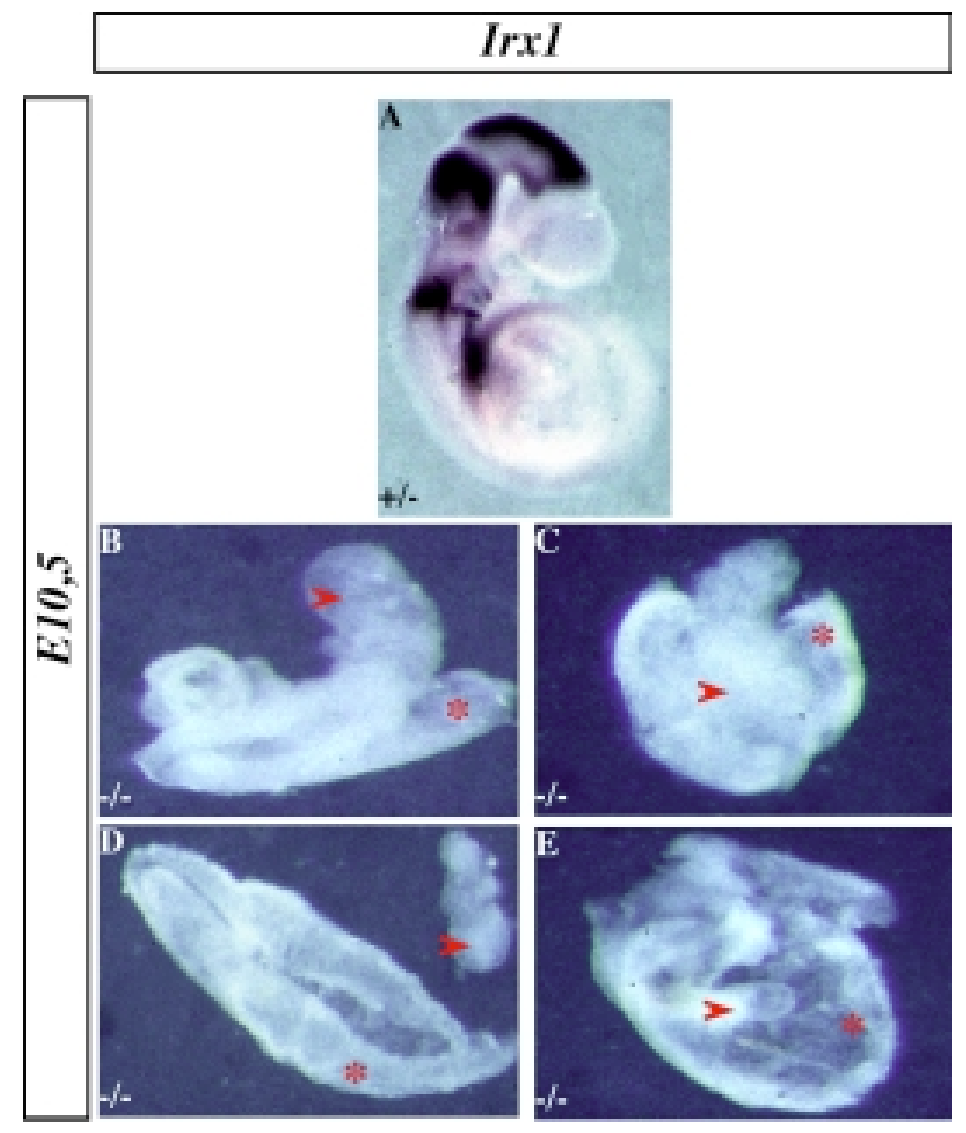

Abb. II.33: Irx1-Phänotyp im Stadium E10,5

\begin{abstract}
Auf einem genetischen Hintergrund eines Mausauszuchtstammes (NMRI) entwickeln sich die Irx1-defizienten Embryonen bis zu einem Alter von E10,5 (B - E). Die Embryonen wurden mittels einer Irx1-whole-mount-Analyse untersucht. In der Abbildung $A$ ist ein heterozygoter Embryo $(E 10,5)$ desselben Wurfes dargestellt. Dieser zeigt eine normale Irx1-Expression und ist phänotypisch unauffällig. Die Embryonenreste der Mutanten (B - E) sind als fingerförmige, nicht differenzierte Strukturen (rote Pfeile) erkennbar. Es wurden die Embryonalhüllen geöffnet (rote Sterne), um den Embryo freizulegen.
\end{abstract}

\title{
II.5.3. IRX1 IST WESENTLICH FÜR DIE GASTRULATION DER MAUS
}

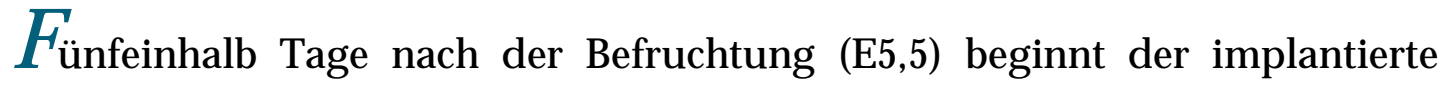
Mausembryo mit der Gastrulation, d.h. mit der Bildung von Keimblättern. Während dieses Stadiums ist der Embryo ca. $250 \mu \mathrm{m}$ lang und im Durchmesser 
$70 \mu \mathrm{m}$ und besteht aus Endoderm und Ektoderm. Bis zum Stadium E6,0 ist der Eizylinder in zwei Teile unterteilt. Die proximale Region besteht aus extraembryonalem Ektoderm, und im distale Bereich liegt das embryonale Ektoderm vor. Es entstehen im embryonalen Bereich die proamniotische und im extraembryonalen Teil die ektoplazentale Höhle. Im Mausembryo liegt innen als dicke Zellschicht das Ektoderm und außen als dünne Schicht das Endoderm. Das große Lumen des Dottersacks wird erst nach und nach durch die extraembryonalen und embryonalen Teile aufgefüllt. Zellen aus dem extraembryonalen Ektoderm teilen sich zur dorsalen Seite hin und bilden den ektoplazentalen Kegel. Dieser wandert in das mütterliche Gewebe ein, zerstört auf seinem Weg Blutzellen und bildet Riesenzellen aus. Es wird später ein Teil der Plazenta werden (Rugh, 1990).

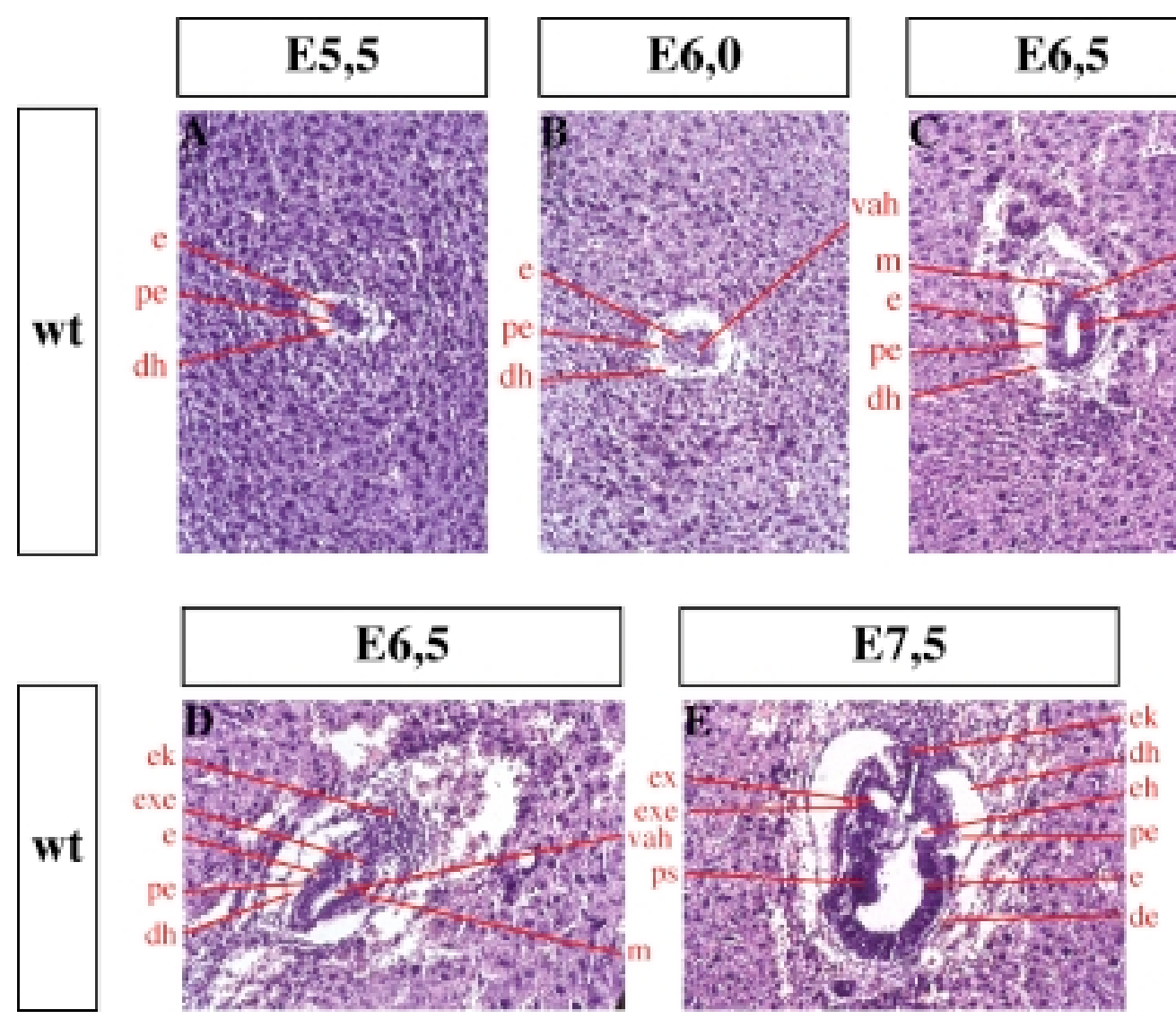

Abb. II.34: Saggitale und transverse Paraffinschnitte von Wildtyp-Embryonen der Stadien E5,5 bis E7,5.

Die Abbildung zeigt Embryonen, die in den Uteri belassen und analysiert wurden. Sie wurden in Paraffin eingebettet, geschnitten $(15 \mu \mathrm{m})$ und mit Hämatoxylin-Eosin gefärbt. Die Schnitte $A$ bis $C$ stellen transverse und $D$ und $E$ saggitale Schnitte dar. 
(Hämatoxylin-Eosin-Färbung (HE-Färbung): Hämatoxylin färbt die Zellkerne (dunkellila) und Eosin das Plasma (lila-rosa) an.)

Abkürzungen: de: distales Endoderm; dh: Dottersackhöhle; e: Ektoderm; eh: ektoplazentale Höhle; ek: ektoplazentaler Kegel; ex: Exocoelom; exe: extraembryonales Ektoderm; m: Mesoderm; pe: proximales Endoderm; ps: Primitivstreifen; vah: voramniotische Höhle

Im Stadium E6,5 ist der Primitivstreifen im proximalen Teil des Embryos als eine Verdickung des Ektoderms $\mathrm{zu}$ erkennen. Die Zellen der dritten Keimschicht, dem Mesoderm, sind als einzelne runde, mesenchymale Zellen zwischen dem Primitivstreifen und dem proximalen Endoderm erkennbar. Die frischen Mesodermzellen wandern zwischen Ektoderm und Endoderm nach lateral und posterior, aber nicht nach anterior aus. Einige der Mesodermzellen wandern auch in den extraembryonalen Bereich, wo sie im weiteren Verlauf eine Höhle, das Exocoelom, die Dottersackmembran und die proamniotische Falte bilden (Rugh, 1990).

Nach 7 Tagen $(E 7,0$ - 7,5) beginnt die Bildung der Kopfanlage. Das embryonale Ektoderm verdickt sich am distalen Ende des Eizylinders und Zellen wandern aus dem Primitivstreifen nach lateral und anterior. Die Zellen wandern nach anterior bis zur Grenze zwischen extraembryonalem und embryonalem Gewebe und bilden dort die Kopfanlage (Hogan et al., 1994).

Im Stadium von E6,5 beginnt die Irx1-Expression im extraembryonalen Bereich des Embryos und markiert die Grenze am extraembryonalen zum embryonalen Übergang. In der Irx1-Mutante ist ein Phänotyp mit Auftreten des ersten Mesoderms erkennbar. Dieses wird normalerweise in der Region der Primitivstreifenanlage gebildet und wandert von dort aus. Dabei wird mehr oder weniger zeitlich parallel (Beddington und Robertson, 1999) das embryonale und extraembryonale Mesoderm gebildet.

Bis zur Bildung des extraembryonalen Mesoderms sehen die Irx1-defizienten Embryonen phänotypisch unauffällig aus. Nach Beginn der Mesodermbildung akkumulieren im Bereich des extraembryonalen Mesoderms Zellen, die im Wildtyp-Embryo nicht vorhanden sind. Die Zellen zeigen keine großen Vakuolen wie Endodermzellen, noch sind sie in einem epithelialen Zellverband organisiert wie ektodermale Zellen. Ihre Zellform ist rundlich und mit ihrer 
lockeren Zellorganisation ähneln sie mesodermalen Zellen. Mit dem Einsetzen der Mesodermbildung wird wesentlich mehr extraembryonales Mesoderm als normal gebildet. Weiterhin bildet sich kein Exocoelom aus, wohingegen aber die ektoplazentale Höhle vorhanden ist.

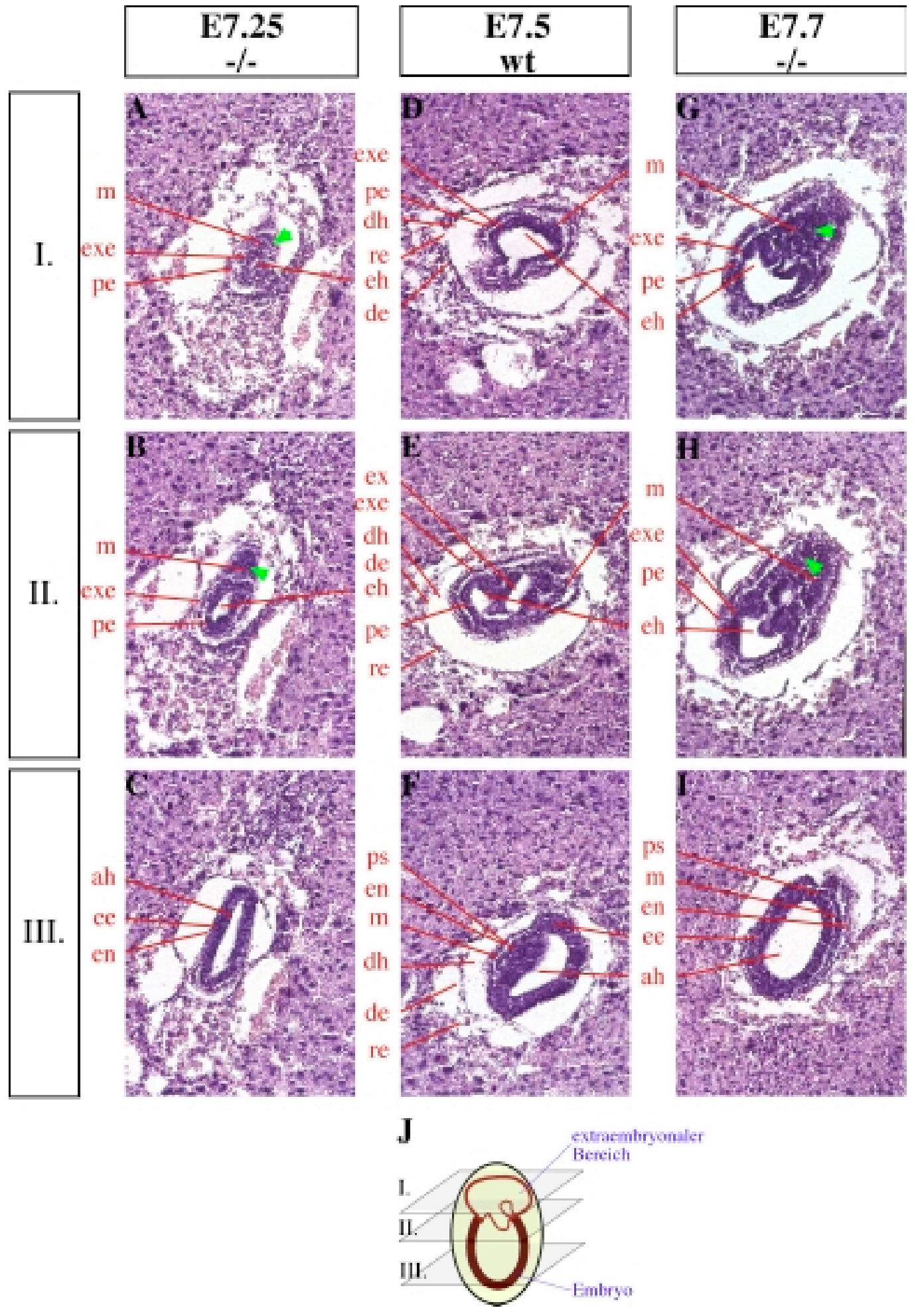

Abb. II.35: Irx1-defiziente Embryonen zeigen eine vermehrte Bildung an Zellen im Bereich des extraembryonalen Mesoderms. 
Die Abbildungen zeigen transverse Schnitte durch Embryonen mit dem umgebenden Uterus (A - I). Die Schnitte wurde mit Hämatoxylin-Eosin gefärbt. In der ersten Säule ist ein veränderter Embryo im Stadium E7,25 anhand von drei transversen Schnitten gezeigt $(A-C)$. In der zweiten Säule ist ein E7,5 alter Wildtyp-Embryo (D - F) und in der dritten ein E7,5 alter Irx1-defizienter Embryo in derselben Weise gezeigt (G - I). In den Irx1-defizienten Embryonen ist eine stärkere Zellproliferation im Bereich des extraembryonalem Mesoderms ersichtlich $(B+H)$. Im Stadium E7,5 ist ein Fehlen des Exocoeloms erkennbar. Dieser Phänotyp ist nicht bei dem E7,25 alten Embryo zu sehen, da dort die Membranbildungen im extraembryonalen Bereich noch nicht soweit fortgeschritten sind. Das Genotypisieren der Irx1-defizienten Embryonen erfolgte anhand der Morphologie, da eine Genotypisierung nach der HE-Färbung nicht möglich ist. (Diese Analyse wurde auf einem NMRI-Auszuchtstamm gemacht.)

Abkürzungen: ah: amniotische Höhle; ee: embryonales Ektoderm; eh: ektoplazentale Höhle; en: Endoderm; exe: extraembryonales Ektoderm; de: distales Endoderm; dh: Dottersackhöhle; m: Mesoderm; pe: proximales Endoderm; ps: Primitivstreifen; re: Reicherts Membran

Normalerweise ist der Embryo während der Implantation mit seiner Längsachse im $90^{\circ}$ Winkel zur Längsachse des Uterus angeordnet. Da sich der Embryo nach ventral $\mathrm{zu}$ seinem Eizylinder entwickelt, befindet sich seine dorsoventrale Achse im 90 Winkel zur Längsachse des Uterus, und seine anterior-posteriore Achse ist im 90 Winkel zum Mesometrium. Bei ca. 65\% der Irx1-mutanten Embryonen ist dieser Winkel verändert, und der Embryo ist um ca. $90^{\circ}$ gedreht.
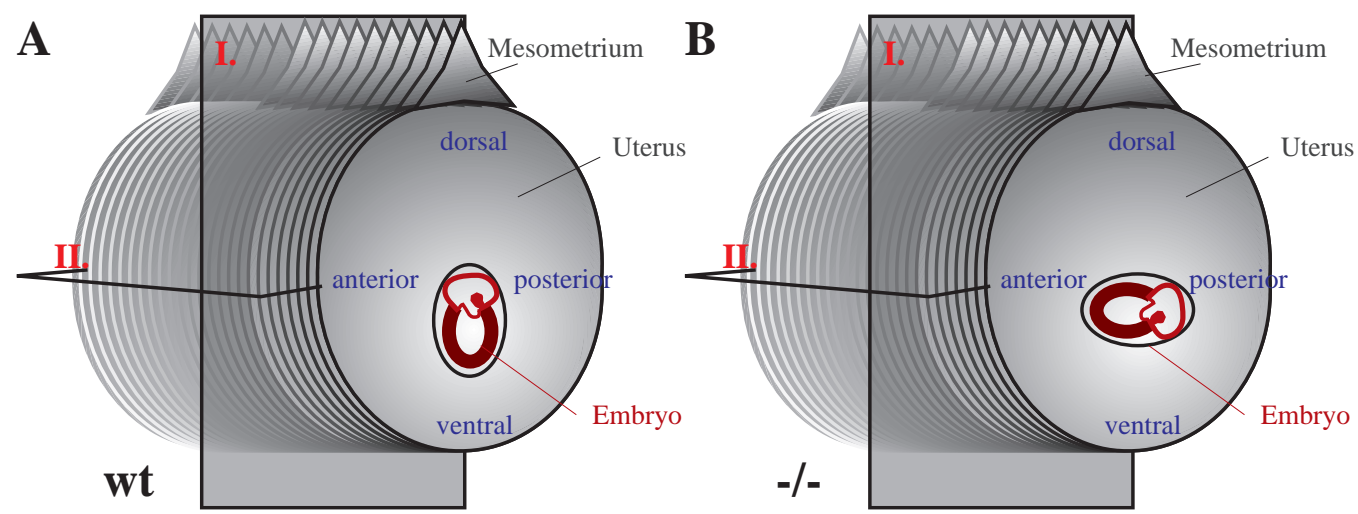

Abb. II.36: Die Abbildung zeigt die Orientierung des Embryos zum Uterus im normalen und im Irx1-defizienten Fall.

Der Embryo ist im $90^{\circ}$ Winkel zur Uteruslängsachse und seine anteriore-posteriore Achse ist um $90^{\circ}$ zum Mesoterium orientiert (A). Diese Orientierung ist in der Mutante aufgehoben und der Embryo ist um weitere $90^{\circ}$ gedreht.

Weiterhin sind die Schnittebenen angegeben: 
Der Phänotyp der Irx1-defizienten Embryonen ist an verschiedenen Zeitpunkten der Entwicklungen variabel, sogar innerhalb eines Wurfes. In einigen Fällen äußert sich der Phänotyp derart, daß später in der Entwicklung nur leere Deziduen vorliegen und in anderen Fällen traten leere Dottersäcke oder sehr kleine und vollständig unorganisierte oder tote Embryonen auf. Die meisten Mutanten stoppen in ihrer Entwicklung während der Gastrulation. Eine ähnliche Phänotypvarianz trat auch bei den BMP4- und Smad2-defizienten Embryonen auf (Winnier et al., 1995; Nomura und Li, 1998).

\section{EXPRESSION GASTRULATIONSSPEZIFISCHER MARKER IN DER Irx1-MUTANTE}

Neben den morphologischen Veränderungen sind auch noch eine Reihe von genetischen Veränderungen $\mathrm{zu}$ beobachten. So sind die gastrulationsspezifischen Gene BMP4, Brachyury (T), Otx2 und auch Gbx2 während der Gastrulation fehlexprimiert.

BMP4 ist normalerweise mit Beginn der Gastrulation im extraembryonalen Ektoderm exprimiert (Winnier et al., 1995). Es stellt somit einen Marker für den extraembryonalen Bereich dar. Diese Expression verschiebt sich in der Irx1Mutante nach distal und so ist BMP4 nicht nur im extraembryonalen Bereich, sondern auch im embryonalen Bereich exprimiert.

Eine weitere Genexpression, die in der Irx1 Mutante verändert ist, ist die von T. Dieses ist im Wildtyp-Zustand in den frisch aus dem Primitivstreifen auswandernden Mesodermzellen aktiv und stellt ist ein Marker für die embryonalen Zellen des Mesoderms und auch indirekt für den Primitivstreifen (Herrmann et al., 1990; Wilson et al., 1995). $T$ ist in den Irx1-defizienten Embryonen nicht exprimiert. 


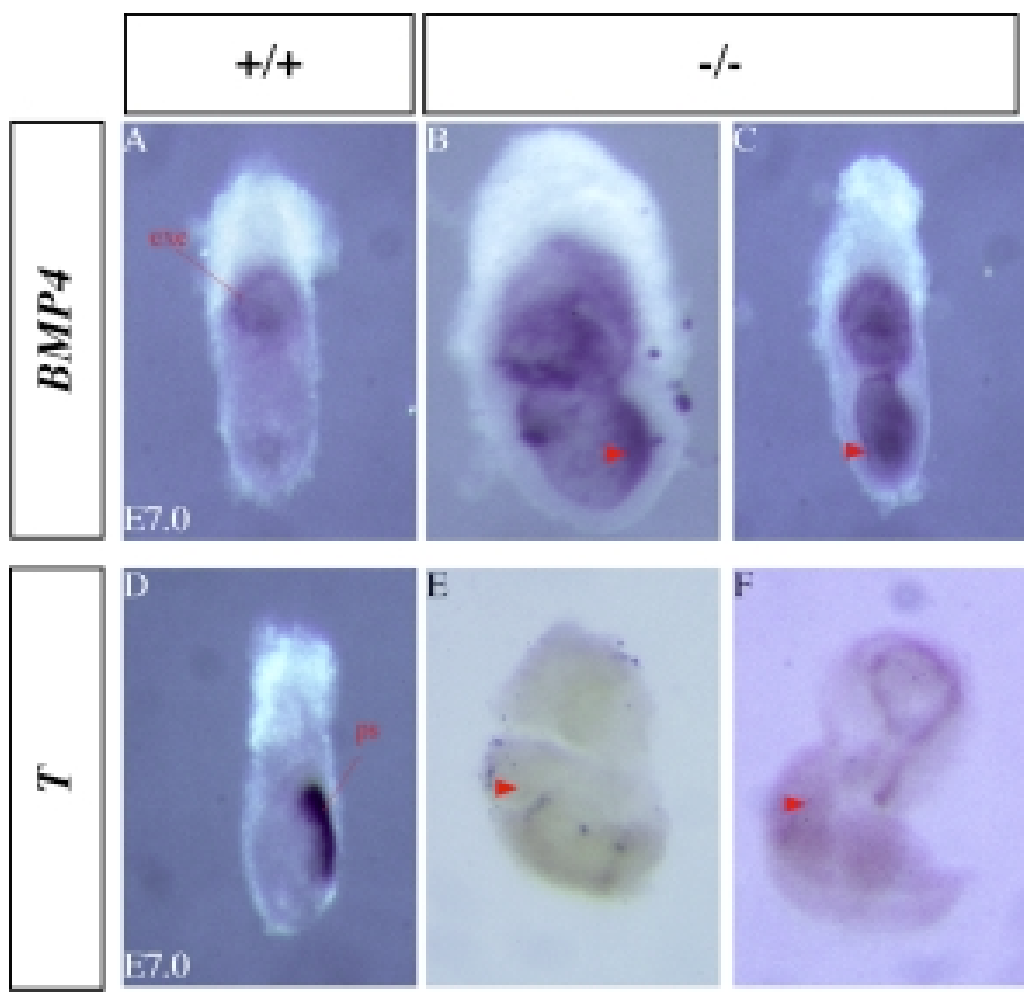

Abb. II.38: BMP4 und T sind in der Irx1 Mutante fehlexprimiert.

Die Abbildung zeigt in-situ-Hybridisierungen (whole mount) mit BMP4- und Brachyury (T)-RNA-Sonden auf Wildtyp- und Irx1-defiziente Embryonen. Die Embryonen entstammen jeweils (je Sonde) einem Wurf des Alters E7,0.

BMP4 ist Wildtyp Fall im extraembryonalen Ektoderm mit der distalen Grenze zum Epiblasten exprimiert (A). Diese Expression verschiebt sich in der Irx1-Mutante nach distal und BMP4 ist ebenfalls in den Derivaten des Epiblasten exprimiert. (Diese Analyse wurde mit einem NMRI-Auszuchtstamm gemacht.)

Brachyury $(\mathrm{T})$ ist normalerweise in den frisch gebildeten Mesodermzellen entlang des Primitvstreifens exprimiert (D). In Embryos, die defizient für Irx1 sind, ist die TExpression verschwunden $(E+F)$.

Abkürzungen: exe: extraembryonales Ektoderm; ps: Primitivstreifen

Neben BMP4 und T sind auch Otx2 und Gbx2 durch den Wegfall von Irx 1 betroffen. Die Expression von Otx2 ist ein guter Marker für das anteriore viszerale Endoderm (AVE) (Acampora et al., 1995). Dies markiert die zukünftige Kopfregion. Normalerweise ist Otx2 zunächst in einem breiten Muster exprimiert, um sich dann in der Region des AVE zu konzentrieren. Diese Veränderung der Otx2-Expression ist in den Irx1-defizienten Embryonen gestört 
und nicht zu beobachten. Dort ist Otx2 stets im gesamten embryonalen Bereich exprimiert.

Als ein weiterer Marker für die zukünftige Kopfanlage dient Gbx2 (Wassarman et al., 1997). Auch dieses Gen ist in der AVE exprimiert, aber schwächer und auf die AVE konzentriert. In Embryonen, die defizient für Irx1 sind, weist die Gbx2-Aktivität Veränderungen auf. So ist sie in den Mutanten nicht konzentriert, sondern breit im gesamten Embryo und damit auch im extraembryonalen Bereich exprimiert.

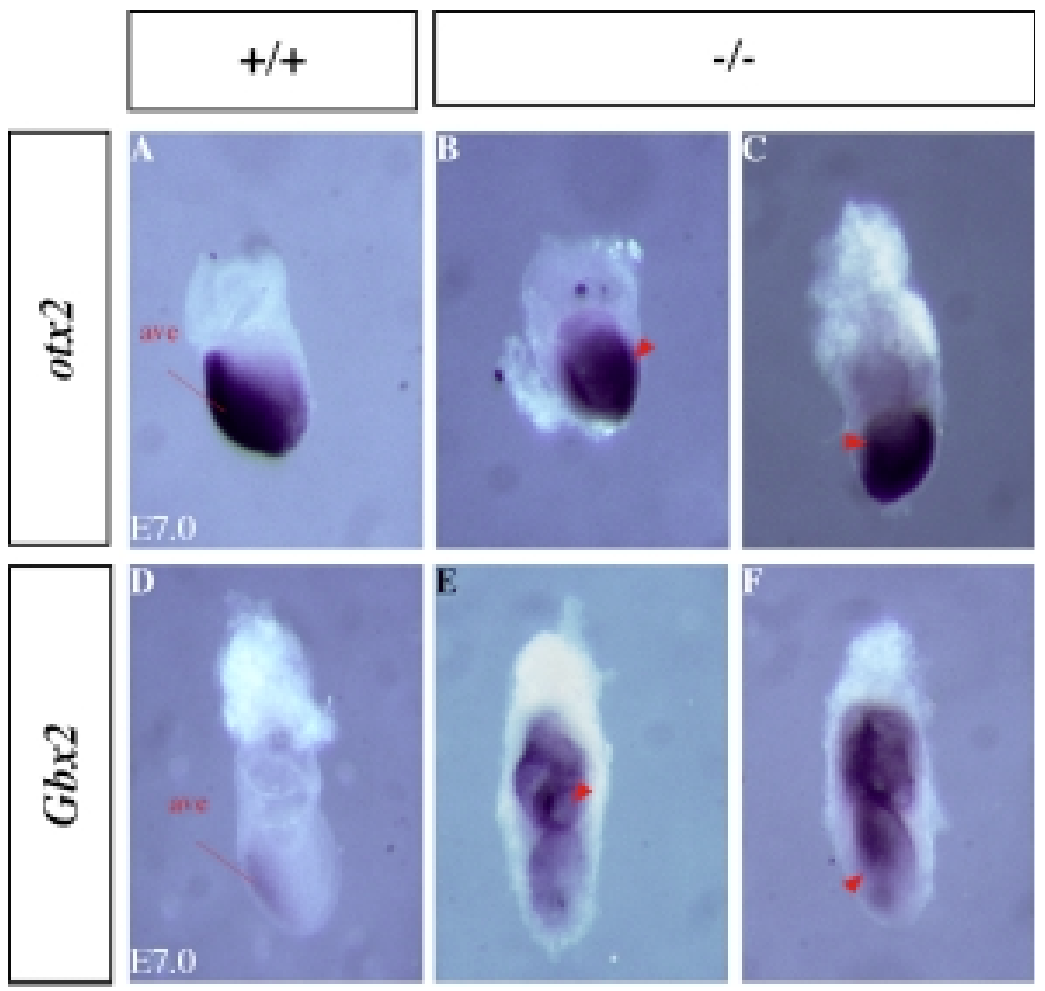

Abb. II.39: Otx2 und Gbx2 sind in der Irx1-Mutante fehlexprimiert.

Die Abbildung zeigt whole-mount-in-situ-Hybridisierungen mit Otx2- (A - C) und Gbx2(D - F) RNA-Sonden auf Wildtyp- und Irx1-defizienten Embryonen. Die Embryonen entstammen jeweils (je Sonde) einem Wurf des Alters E7,0. (Diese Analysen wurde mit einem NMRI-Auszuchtstamm gemacht.)

Otx2 (A - C)ist im normalen Embryo im embryonalen Ektoderm exprimiert. Dabei zeigt Otx2 zunächst $(E 6,5)$ eine sehr breite Expression, um sich dann im Bereich der späteren AVE zu konzentrieren. Diese beginnende Konzentrierung ist gut zu beobachten (A). In den Irx1-defizienten Embryos findet keine Otx2-Konzentrierung in der AVE-Region statt, sondern Otx2 bleibt im gesamten embryonalen Bereich exprimiert. 
Gbx2 (D - F) markiert im Wildtyp-Fall, ähnlich wie Otx2, die Region der zukünftigen AVE-Region. Dabei zeigt Gbx2 im Stadium E7,0 schon sehr deutlich den AVE-Streifen an (D). In den Irx1-mutanten Embryonen ist Gbx2 im gesamten embryonalen Bereich exprimiert und nicht auf die AVE beschränkt $(E+F)$.

Abkürzungen: ave: Region des anterior viszeralen Endoderm 


\title{
III. DISKUSSION
}

\begin{abstract}
Molekulargenetische Untersuchungen in anderen Organismen zeigten, daß Vormustergene eine Rolle in der embryonalen Musterbildung spielen. Die Klärung der Funktion des Irx1-Gens als Vertreter der Iroquois-Genfamilie steht im Mittelpunkt der hier beschriebenen Studie.
\end{abstract}

\section{DIE STRUKTUR DES IRX1-GENS}

$D_{\text {ie }}$ Analyse ergab eine Lokalisation des Irx1-Gens auf dem MausChromosom 13. Es liegt mit Irx 2 und Irx 4 in einer tandemartigen Organisation vor, wobei die Abstände der einzelnen Irx-Gene mit 200 - 400 kb äußerst gering sind. Diese Tandemanordnung trifft ebenfalls bei $\operatorname{Ir} x 3$, Irx 5 und $\operatorname{Ir} x 6 \mathrm{zu}$ (Peters et al., 2000). Die Analyse der humanen Homologen Irx1, Irx2 und Irx4 bewies die evolutive Konservierung der genomischen Organisation. Sie sind ebenfalls auf einem Abschnitt des Chromosoms 5 lokalisiert. Es gibt also neben der spezifischen Regulation der einzelnen Gene wahrscheinlich auch regulative Prozesse, die die gesamte tandemartige Organisation betreffen und somit jeweils alle drei Gene zusammen an- oder abschalten.

Die Sequenzanalyse des Irx1-Gens ergab eine theoretische Proteinsequenz von 461 Aminosäuren, mit einem Molekulargewicht von 55 kDa. Dieses Protein weist als wesentliche Strukturen eine Homeodomäne mit Helix-Schleife-HelixMotiv und eine Iro-Domäne auf. Innerhalb der Homeodomäne zeigen alle Mausmitglieder der Iroquois-Homeobox-Genfamilie eine hohe evolutive Konservierung mit einer Aminosäurenidentität von 90 - 100\%. Die Homeodomäne der Iroquois-Gene zeichnet sich insbesondere dadurch aus, daß sie an der Aminosäureposition 50 der Erkennungshelix ein Alanin haben. Da 
dieses in keiner anderen bekannten Homeodomäne auftritt, deutet es auf eine besondere Bindungsfunktion hin. Die Aktivität als Transkriptionsfaktor wird durch saure Regionen, die sich auf der carboxyterminalen Seite des Proteins befinden, möglicherweise unterstützt.

Irx1 weist als ein weiteres spezifisches Motiv eine Iro-Domäne (Burglin, 1997) auf. Sie ist spezifisch für alle Iroquois-Proteine und zeichnet sich durch eine hohe evolutive Konservierung innerhalb der Genfamilie aus. Die Iro-Domäne dient der Protein-Protein-Interaktion, denn an sie bindet ein neu entdecktes Protein.

Als dritte interessante Region weist das Irx1-Protein eine MAP-KinaseErkennungstelle auf. Über sie kann die Aktivität des Irx1-Transkriptionsfaktors reguliert werden (Gómez-Skarmeta et al., 1996).

\section{DIE EXPRESSION DES IRX1-GENS}

$I_{r x 1}$ ist in einem spezifischen zeitlichen und räumlichen Muster während der embryonalen Entwicklung der Maus exprimiert. Die Aktivität startet im Stadium E6,5 kurz vor Einsetzen der Gastrulation und sie wird während der gesamten embryonalen Entwicklung aufrechterhalten. Die Genaktivität beginnt im Stadium E6,5 zunächst im extraembryonalen Bereich und ist einen Tag später $(E 7,5)$ im lateralen Mesoderm und im Primitivknoten nachweisbar. Die anteriore Expression ist im Zentralnervensystem deutlich ab E8,0 zu sehen.

Von diesem Stadium an ist Irx1 zusätzlich in den Mes- und auch Metenzephalonanlagen exprimiert. Es zeichnet sich durch eine sehr klare Grenzbildung zum expressionsfreien Telenzephalon und der ebenso expressionsfreien Mes- und Metenzephalon-Grenze aus. Weiterhin zeigt Irx1 Genaktivität im Rhombenzephalon und im ventralen Neuralrohr. Diese Aktivität ist spezifisch für IrxI und grenzt sie von den anderen Mitgliedern der murinen Irx-Familie ab. Die Expression ist nicht auf zentralnervöse Bereiche beschränkt, sondern zeigt sich auch während der Lungen- und Extremitätenentwicklung. Die Genaktivität von Irx1 in diesen Organen beschränkt sich zeitlich auf einen Abschnitt der jeweiligen Entwicklung. Irx1Expression markiert zum Beispiel die prospektiven Finger noch bevor sie morphologisch sichtbar werden. 


\section{UMFANGREICHE ZELLBEWEGUNGEN CHARAKTERISIEREN DIE MAUSGASTRULATION}

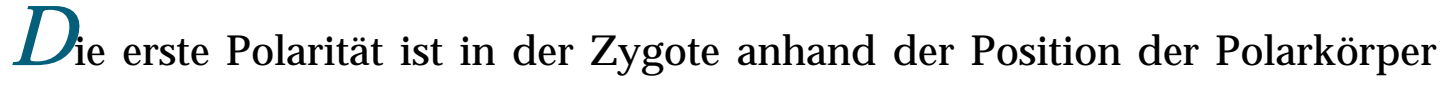
erkennbar und unterteilt sie in einen animalen und einen vegetativen Pol (Gardner, 1997). Drei Tage nach der Befruchtung liegt eine Blastozyste vor, in welcher sich zwei Gewebe abzeichnen: zum einen das Trophoektoderm und zum anderen die Innere Zellmasse (IZM).

Bisher ging man davon aus, daß die extraembryonalen Gewebe lediglich zum Schutz und der Versorgung des Embryos dienen (Gardner, 1998). Neuere Untersuchungen zeigen, daß der extraembryonalen Bereich auch für die Orientierung und die Musterbildung des embryonalen Bereichs wichtig ist (Beddington und Robertson, 1999; Pedersen, 2001). Die Polarität des präimplantierten Embryos läßt Vorhersagen über die Organisation des extraembryonalen Gewebes zu (Weber et al., 1999). Interessanterweise konnte in neuesten Untersuchungen ein Zusammenhang zwischen der Spermiumeintrittstelle und der extraembryonal-embryonalen Grenze gezeigt werden (Piotrowska und Zernicka-Goetz, 2001).

Die zukünftige Körperachse ist erstmals nach sechseinhalb Tagen der embryonalen Entwicklung morphologisch sichtbar, wenn mit der Bildung des Primitivstreifens die Gastrulation einsetzt (Wolpert et al., 1999). Die homogen erscheinenden Epiblastenzellen durchlaufen eine epitheliale-mesenchymale Veränderung und breiten sich lateral und anterior zwischen Ektoderm und viszeralem Endoderm aus und bilden das Mesoderm (Hogan et al., 1994; Tam und Behringer, 1997). Somit manifestiert sich mit der Bildung des Primitivstreifens die anterior-posteriore- (A - P) und zugleich die dorsoventrale- (D - V) Achse. Indirekt wird auch die links-rechts-Achse bestimmt, da diese von den beiden anderen Achsen abhängig ist (Beddington und Robertson, 1999).

Die Morphogenese und Musterbildung des Vertebratenembryos ist abhängig von der korrekten Interaktion zwischen benachbarten Geweben. Im prägastrulären Mausembryo liegt der Epiblast in einer Hülle aus viszeralem Endoderm, von dem eine Reihe von regulatorischen Funktionen im 
postimplantierten Embryo ausgehen (Rossant, 1995). So sind beispielsweise Signale aus dem viszeralen Endoderm für die Bildung der embryonalen Höhlen, das Wachstum und das Überleben des Ektoderms essentiell (Belaoussoff et al., 1998; Coucouvanis und Martin, 1999; Rossant, 1995). Die Musterbildung des anterioren Epiblasten wird initiiert durch eine differentielle Genexpression im darüberliegenden viszeralen Endoderm (Beddington und Robertson, 1999; Viebahn, 1999). In der Maus kann das anteriore viszerale Endoderm (AVE) lediglich mittels molekularer Marker charakterisiert werden, da es morphologisch nicht erkennbar ist (Beddington und Robertson, 1999). Differentielle Genexpression verschiedener Gene, wie das VE-1 Antigen (Rosenquist und Martin, 1995), Otx2 (Acampora et al., 1995; Ang und Rossant, 1994), Hesx1 (Thomas und Beddington, 1996), Lim1 (Belo et al., 1997), goosecoid (Belo et al., 1997), Hex (Thomas et al., 1997; Thomas et al., 1998), Gbx2 (Wassarman et al., 1997) und cereberus-related (Belo et al., 1997; Thomas et al., 1997) ist im AVE nachweisbar und zwar noch bevor ein Primitivstreifen gebildet ist (Beddington und Robertson, 1999).

Die Musterbildung des posterioren Epiblasten ist noch nicht geklärt. $\mathrm{Zu}$ Beginn der Gastrulation, wenn der Körperbau des eigentlichen Embryos etabliert wird (Tam und Behringer, 1997), sind Gene wie Brachyury (T) (Hermann, 1991; Kispert und Hermann, 1994), Nodal (Conlon et al., 1994), Wnt3 (Liu et al., 1999) und eomesodermin (Russ et al., 2000) im posterioren Ektoderm exprimiert und markieren noch vor der Primitivstreifenbildung das zukünftige Mesoderm (Dyer et al., 2001). Das Protein BMP4, welches zunächst durch extraembryonales Ektoderm sekretiert wird (Coucouvanis und Martin, 1999; Waldrip et al., 1998) und später in der Allantois und dem extraembryonalen Mesoderm am posterioren Teil des Primitivstreifens aktiv ist (Lawson et al., 1999; Winnier et al., 1995), scheint eine wesentliche, allerdings nicht essentielle Rolle in der Induktion des Mesoderms und der Formierung der hämatopoetischen und vaskulären Zellen zu haben (Lawson et al., 1999; Winnier et al., 1995).

Brachyury ( $T$ ) stellt einen der ersten Marker für den Primitivstreifen dar und ist anfangs im proximalen Epiblasten direkt anstoßend an das extraembryonale 
Ektoderm ringförmig exprimiert. Durch Zellbewegungen im proximalen Eizylinder verschiebt sich die Expression an den Ort der Gastrulationsinitiation (Thomas und Beddington, 1996; Hermann, 1991; Kispert und Hermann, 1994).

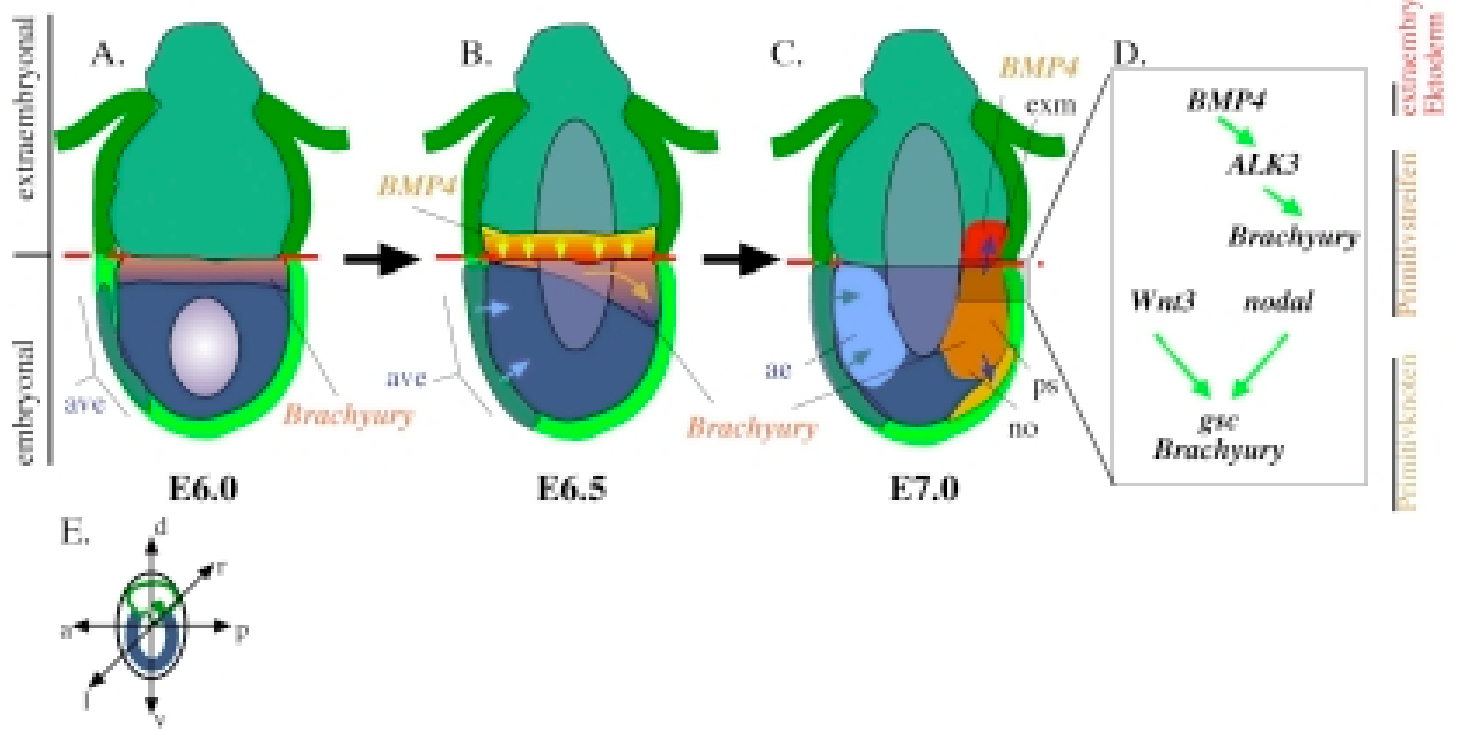

Abb. III.1: Schematische Darstellung der zellulären Bewegungen während der Gastrulation.

Das anteriore viszerale Endoderm (ave) induziert im darunter liegenden anterioren Ektoderm die anteriore Entwicklung (A-C; blaue Pfeile und induziertes blaues anteriores Ektoderm).

Die genetische Grundlage des mesoderm-induzierenden posterioren viszeralen Endoderms (PVE) ist noch nicht gekärt (Beddington und Robertson, 1999). Bei E6.0 beginnt die Brachyury ( $\mathrm{T}$ )-Expression am proximalen Teil des Epiblasten, angrenzend an den extraembryonalen Bereich. BMP4 ist ab dem Stadium E6.3 im extraembryonalen Ektoderm, mit der distalen Grenze zum embryonalen Teil exprimiert. Dabei interagiert BMP4 sowohl mit dem AVE (nicht gezeigt) als auch mit dem PVE. Im Stadium E6.5 wandern die T-exprimierenden Zellen nach caudal (brauner Pfeil in B.) und der Primitivstreifen wird genau gegenüber des AVE gebildet. Im Stadium E7.0 wird extrambryonales Mesoderm, welches BMP4 exprimiert, im posterioren Teil des Primitivstreifens gebildet (rotes Feld in C.). Der Primitivstreifen verlängert sich und es entsteht embryonales Mesoderm, welches $\mathrm{T}$ exprimiert (dunkelorange Feld in C.). Ferner entsteht der Primitivknoten am anterioren Ende des Primitivstreifens. Von dort aus wird das axiale Mesendoderm (oranges Feld in $\mathrm{C}$.) gebildet.

Die Abbildung D zeigt, daß die BMP4-Aktivität, kommend aus dem extraembryonalen Ektoderm, in der PVE-Region die Expression des BMP-Rezeptors ALK3 reguliert und dieser wiederum den Primitivstreifenmarker T. Wnt3 und Nodal kontrollieren im 
Primitivstreifen die Expression der wesentlichen Gene des Primitivknotens, wie gsc und $\mathrm{T}$.

In der Abbildung E sind die verschiedenen embryonalen Achsen dargestellt.

Abkürzungen: a: anterior; ae: anteriores Ektoderm; ALK3: Bmpr1-Genexpression; ave: anteriores viszerales Endoderm; BMP4: BMP4-Genexpression; d: dorsal; exm: extraembryonales Mesoderm; gsc: Goosecoid-Genexpression; I: links; no: Primitivknoten; nodal: Nodal-Genexpression; p: posterior; ps: Primitivstreifen(mit Mesodermbildung); pve: posteriores viszerales Endoderm; r: rechts; T: BrachyuryGenexpression; Wnt3: Wnt3-Genexpression; v: ventral

\section{DIE FUNKTION VON IRX1 WÄHREND DER MAUSGASTRULATION}

\section{IRX1-AKTIVITÄT IM POSTERIOREN BEREICH DES EMBRYOS}

Irx1 ist im embryonalen Stadium E6,5 im extraembryonalen Ektoderm exprimiert und zwar in einem breiten Streifen angrenzend an den Übergang von extraembryonalem zu embryonalem Gewebe. Dieser Expressionsbereich überlappt sowohl zeitlich als auch räumlich mit der BMP4-Expression. BMP4 ist $\mathrm{zu}$ diesem Zeitpunkt ebenfalls dort in einem schmalen Band exprimiert und definiert dieselbe Grenze zum embryonalen Bereich hin (Waldrip et al., 1998). Die BMP4-defizienten Embryonen stoppen ihre Entwicklung im Eizylinderstadium und es entsteht keine Expression des Primitifstreifenmarkers Brachyury (T) (Winnier et al., 1995).

In den Irx1-defizienten Embryonen ist die BMP4-Expressionen ganz wesentlich verändert. So ist in den Mutanten die Expressionsdomäne breiter als im Wildtyp, d.h. die BMP4-Expression stoppt nicht an der Grenze zum embryonalen Teil, sondern erstreckt sich weiter distal. Daraus läßt sich auf eine Interaktion zwischen Irx1 und BMP4 schließen, genauer gesagt, auf eine reprimierende Wirkung des Irx1-Proteins auf die BMP4-Expression. Fällt der Irx1-Repressor weg, so erstreckt sich infolgedessen die Expressionsdomäne von BMP4 auf einen größeren Bereich. In Xenopus laevis konnte gezeigt werden, daß Xiro1 (X. laevis-Homolog zu Irx1) die Bmp4-Expression reprimiert. Ferner zeigt es sich, daß Bmp4 reziprok Xiro1 reprimiert (Gómez-Skarmeta et al., 2001). Dieses deutet auf eine konservierte Regulation von Irx1 mit BMP4 hin. In der 
Maus markiert diese Regulation die Grenze zwischen extraembryonalem und embryonalem Bereich.

In den Irx1-defizienten Embryonen sind neben dem veränderten BMP4Expressionsmuster auch Fehlbildungen des extraembryonalen und ebenso auch des embryonalen Bereich zu beobachten. So sind die extraembryonalen Höhlen mit histologisch mesodermal erscheinenden Zellen angefüllt. Dieses deutet auf eine übermäßige Bildung an möglicherweise extraembryonalem Mesoderm hin, welches in extraembryonalen Höhlen akkumuliert. Im Wildtyp Fall scheint demnach Irx1 die Anzahl der Zellen zu begrenzen, die aus dem Epiblasten durch den Primitivstreifen wandern um extraembryonales Mesoderm zu bilden.

Ein weiterer Hinweis für die Interaktion von Irx1 mit dem BMP4-Signalweg ist in den Mausmutanten von Smad2 zu beobachten (Waldrip et al., 1998). Sie bilden vermehrt extraembryonales Mesoderm, das, aber im Gegensatz zu den Irx1-defizienten Mäusen, in der Amnionhöhle akkumuliert (Waldrip et al., 1998; Sirard et al., 1998; Nomura und Li, 1998). Andere Mitglieder des BMPSignalweges zeigen andere Veränderungen in der Mesodermproduktion. So ist in den defizienten Embryonen von BMP4 (Winnier et al., 1995), ALK2 (Gu et al., 1999), ALK3 (Mishina et al., 1995), Smad4 (Sirard et al., 1998) und Tlx-2 (Tang et al., 1998) eine Mesodermreduktion zu beobachten. In BMP-Rezeptor (BMPr1; ALK3)- defizienten Mäusen wird der Eizylinder gebildet, aber ohne jegliches Mesoderm (Mishina et al., 1995; Beppu et al., 2000).

Ein Aspekt des Phänotyps von Irx1-defizienten Mäusen ist im embryonalen Teil zu beobachten. In den Irx1-defizienten Embryonen ist keine Brachyury (T) Expression vorhanden. Im Wildtyp ist $T$ ab E6,0 in einem schmalen Band im embryonalen Bereich mit der proximalsten Expression an der Grenze zum extraembryonalen Bereich hin aktiv (Thomas und Beddington, 1996).

Das Fehlen der T-Expression weist auf eine direkte Regulation zwischen Irx1 und $T$ hin. Die T-Aktivität dient im allgemeinen als Marker für das frisch gebildete embryonale Mesoderm des Primitivstreifens und somit markiert es auch indirekt den Primitivstreifen selbst (Wilson et al., 1995; Hermann, 1991; Kispert und Hermann, 1994). Die fehlende T-Expression in den Irx1-defizienten Embryonen ist überraschend, da, bestimmt anhand histologischer Kennzeichen, 
embryonales Mesoderm gebildet wird. Demnach muß über die Verwendung von $T$ als allgemeiner Marker für neu gebildetes embryonales Mesoderm nachgedacht werden. Es scheint, daß $T$ nur eine Subpopulation von Mesodermzellen markiert. Das Fehlen von $T$, welches für den korrekten Ablauf von Zellbewegungen im Epiblasten verantwortlich ist (Wilson et al., 1995), kann bedeuten, daß die Rekrutierung von prospektiven Mesodermzellen gestört ist.

Denkbar ist, daß Irx1 zusammen mit BMP4 für der Bildung der Grenze zwischen embryonalem und extraembryonalem Bereich essentiell ist. Durch die Bildung dieser Grenze wird die Expression von $T$ reguliert und im weiteren Verlauf werden diese T-exprimierenden Zellen zum posterioren Teil gelenkt, wo sie den Bereich des beginnenden Primitivstreifens definieren. Da in der Irx1Mutante diese Grenzbildung, durch die fehlende Irx1-BMP4 Interaktion nicht mehr gewährleistet ist, findet keine T-Expression statt.

Es ist bekannt, daß das Entwicklungsschicksal des gebildeten Mesoderms abhängig ist, vom Ort des Einwanderns der Epiblastenzellen durch den Primitivstreifen (Beddington und Robertson, 1999). Am Zeitpunkt und Ort der Primitivstreifeninitiation entsteht extraembryonales Mesoderm (Belaoussoff et al., 1998). Der verlängerte Primitivstreifen bildet embryonales Mesoderm (Belaoussoff et al., 1998; Beddington und Robertson, 1999). Da in den Irx1defizienten Embryonen eine alleinige Überproduktion an mesodermalerscheinenden Zellen in den extraembryonalen Höhlen zu beobachten ist, muß es eine Trennung zwischen der Bildung des extraembryonalem und embryonalem Mesoderms geben.

Damit wird die Beobachtung gestützt, daß das posteriore viszerale Endoderm ohne Primitivstreifen eine mesoderm-induzierende Eigenschaft besitzt und somit der isolierte Epiblast des Vor-Primitivstreifensstadiums sich in extraembryonal-mesodermale Strukturen differenzieren kann (Belaoussoff et al., 1998). 
A.

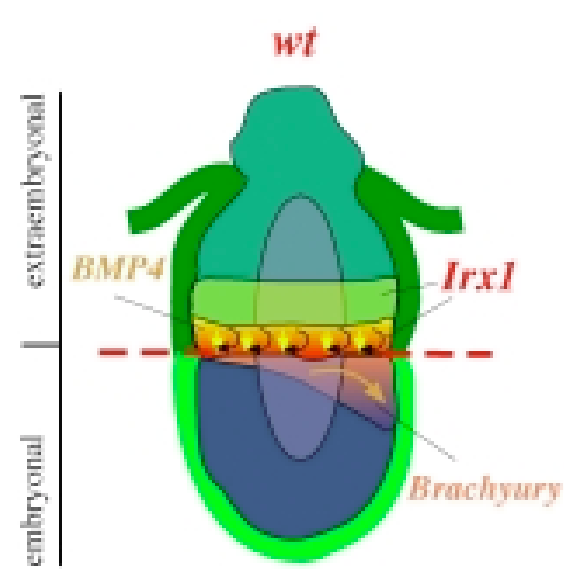

E6.5
B.

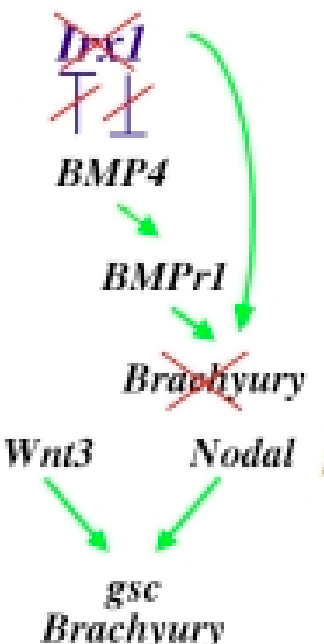

C.

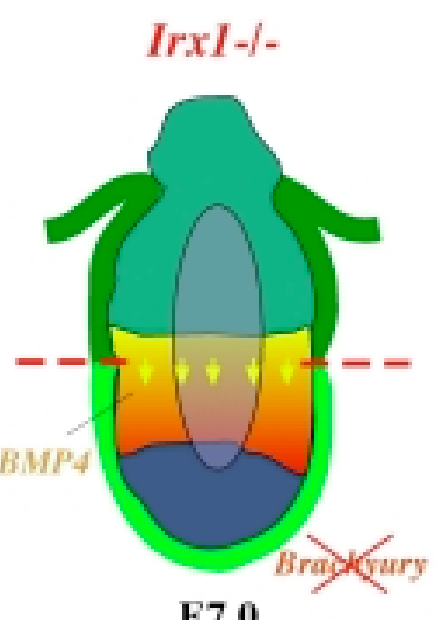

Abb. III.2: Veränderte posteriore Genexpression in den Irx1-defizienten Embryonen

Die Abbildung zeigt die Irx1-Expression im Verhältnis zu BMP4 und Brachyury (T) im Wildtyp (A) und im mutierten Embryo (C). In Irx1-defizienten Embryos ist die BMP4Expression nach distal ausgeweitet und hält nicht die Grenze zwischen embryonal und extraembryonal ein (C). Ferner ist der PrimitivstreifenmarkerT nicht exprimiert (C). Dies deutet auf eine gegenseitige Repression von Irx1 und BMP4 hin und auf eine Aktivierung von Irx1 auf $T$ im posterioren Bereich des Embryos (A; schwarze Pfeile: Irx1, gelbe Pfeile: BMP4).

Abkürzungen: ALK3: Bmpr1-Genexpression;T: Brachyury-Genexpression

\section{IRX1-AKTIVITÄT IM ANTERIOREN BEREICH DES EMBRYOS}

Interessanterweise ist in den Irx1-defizienten Embryonen auch eine Fehlexpression von Otx2 im Bereich des anterioren vizeralen Endoderms zu beobachten, denn es findet keine Konzentration der Transkripte in der AVERegion statt. Otx2 ist im Wildtyp-Fall einer der wesentlichen Marker dieser Region. Die Funktion von Otx2 wurde anhand von Otx2-defiziente Embryonen gezeigt. Sie führen zwar im Eizylinderstadium eine normale posteriore Rotation durch, das viszerale Endoderm aber verbleibt distal. Dies führt dazu, daß diese Embyonen weder Mittel- noch Vorderhirn entwickeln (Matsuo et al., 1995; Ang et al., 1996; Acampora et al., 1995). Die Bedeutung der extraembryonalen Interaktion mit dem AVE konnte mittels Otx2-defizienter Chimären gezeigt werden. In Blastozysten injizierte ES-Zellen bilden vorrangig den Epiblasten und seine Abkömmlinge. Auf diese Weise lassen sich Chimäre herstellen, bei 
denen das extraembryonale Gewebe einen Genotyp hat und der Epiblast einen anderen (Beddington und Robertson, 1998). Injiziert man Wildtyp ES-Zellen in Otx2-defiziente Morulae, findet keinerlei anteriore Entwicklung statt. Injiziert man andererseits Otx2-defiziente ES-Zellen in eine Wildtyp-Morula, so findet eine normale anteriore Entwicklung statt (Rhinn et al., 1998).

In Irx1-defizienten Mäusen ist neben der Otx2- auch die Gbx2-Expression (Wassarman et al., 1997) verändert und zwar ebenfalls wesentlich breiter als im Wildtyp-Fall. Ihre Genaktivitäten konzentrieren sich nicht auf das AVE. Beide Gene bleiben über den gesamten Epiblasten exprimiert. Daraus läßt sich schließen, daß Irx1 normalerweise beide Gene in ihrer Expression reprimiert. Das Fehlen der Irx1-Regulation führt dazu, daß die genetische Definierung des AVE durch Otx2 und Gbx2 gestört ist.

Ähnlich wie für den posterioren Bereich läßt sich aus den Beobachtungen eine Interaktion zwischen dem gastrulären Embryo und den Irx1exprimierenden extraembryonalen Zellen schließen.

Die BMP4-Genaktivität im anterioren Bereich ist für die Aktivierung des $B M P$-Repressors ALK3 (BMPr1) und indirekt von Hes $x 1$ verantwortlich (Beddington und Robertson, 1999). In den Irx1-defizienten Embryonen ist auch die anteriore BMP4-Expression betroffen, denn sie ist, wie oben beschrieben, nach distal verschoben.

Aus diesen Beobachtungen läßt sich nicht nur für den posterioren, sondern auch für den anterior viszeralen Endodermbereich eine Interaktion mit dem extraembryonalen Bereich schließen, denn auch hier hat das Fehlen des Irx1Gens einen wesentlichen Einfluß auf das weitere Entwicklungsschicksal. 
A.

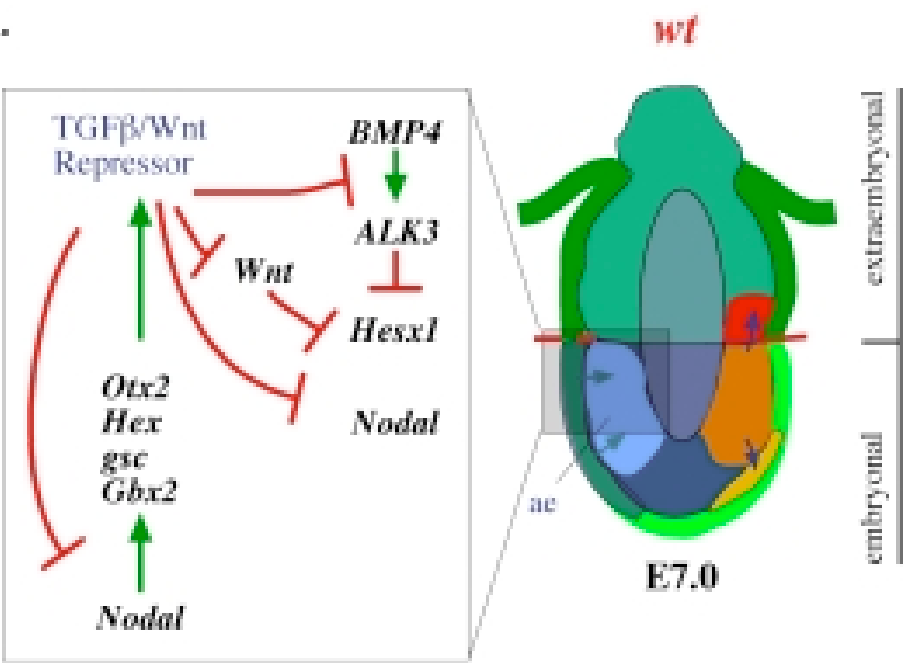

B.

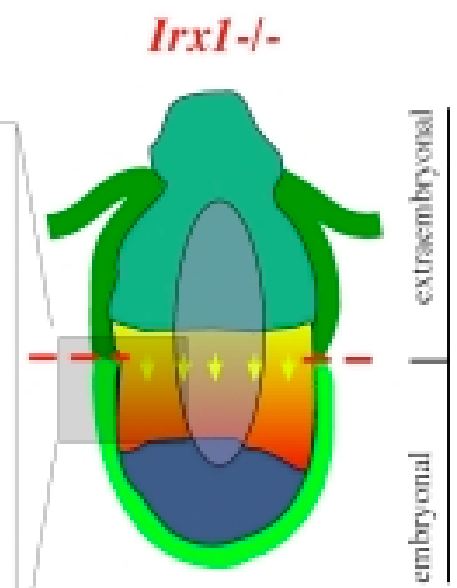

E7.0

Nodal

Abb. III.3: Postuliertes anteriores Regulationsschema sowie eine Darstellung der veränderten Genexpression in Irx1-defizienten Embryonen

Es gibt erste Ideen zur genetischen Regulation des anterioren Bereiches (Beddington und Robertson, 1999). Ähnlich wie im posterioren Teil des Embryos erfolgt auch hier eine Induktion mittels des BMP4-exprimierenden extraembryonalen Ektoderms auf die embryonalen Bereiche. So reguliert BMP4 in der AVE-Region die Expression des BMP-Rezeptors (ALK3) und dieser wiederum den AVE-Marker Hesx1 (A). Ferner postuliert R. Beddington die Existenz eines TGF $\beta /$ Wnt-Repressors (A). Dieser Repressor könnte Irx1 sein, denn bei Wegfall von Irx1 beobachtet man eine Verbreiterung der BMP4-Expressionsdomäne (B). Ist ein postulierter Otx2/Gbx2Repressor inaktiv, so werden beide Gene nicht mehr reprimiert und konzentriert sich auch nicht auf den AVE-Bereich. Exakt das ist in der Irx1-Mutante zu beobachten (B).

Zusammenfassend läßt sich sagen, daß Irx1 ein Vormustergen darstellt, das eine ganz essentielle Funktion während der Gastrulation hat. Irx1 ist wesentlich 
an der Regulation der extraembryonalen Mesodermbildung beteiligt und der beobachtete Phänotyp unterstützt die postulierte regulative Bedeutung des extraembryonalen Bereiches für die Entwicklung des Mausembryos. Erst durch die Interaktion von Irx 1 und BMP4 ist eine korrekte Grenzbildung zwischen extraembryonal und embryonal möglich. Das ist entscheidend für die Umsetzung der späteren anterior-posterioren Achse. Irx1 spielt sowohl in der Regionalisierung des AVE-Bereiches wie auch der posterioren Primitivstreifenregion eine wesentliche Rolle.

Nach der Diskussion der Irx1-Funktion in der Gastrulation des Mausembryos, soll nun eine mögliche Funktion in der späteren Embryonalentwicklung betrachtet werden. Grundlage dazu bilden die Funktionsanalysen der X. laevis Iroquois-Homologe.

\section{DIE FUNKTION DER XIRO-GENE WÄHREND DER ORGANOGENESE}

Die mögliche Funktion der Irx homologen Gene - Xiro1, Xiro2 und Xiro3 während der Neuralleistendifferenzierung in Xenopus laevis (Mayor et al., 1999), soll als Grundlage für eine mögliche genetische Funktionsdiskussion in der Maus dienen.

Die Determinierung der Neuralleistenzellen erfolgt in X. laevis während der Gastrulation. Bis zur Mitte der Gastrulation ist BMP4 im gesamten Ektoderm exprimiert (Schmid et al., 1995), wo es, vermutlich durch Smad1 vermittelt, die Expression an Neuralplattengenen inhibiert (Wilson et al., 1997). Auch Smad1 ist im gesamten Ektoderm exprimiert und BMP-Proteine konrollieren dessen Aktivität. Während der Gastrulation werden Neuralinduzierer, wie chordin, follistatin und noggin im dorsalen Mesoderm aktiviert und sie inhibieren BMP4. Aktives BMP4 liegt in einem ventrodorsalen Gradienten vor (HemmatiBrivanlou und Melton, 1997). Die höchste BMP4-Konzentration induziert die höchste Smad1-Aktivität (Suzuki et al., 1997). Dieser Gradient im dorsalen Mesoderm und der zukünftigen Neuralplatte wird durch den Wnt-Signalweg kontrolliert (Baker et al., 1999). Der Wht-Signalweg schaltet Xiro1 an, das seinerseits BMP4 reprimiert (Gómez-Skarmeta et al., 2001). Im Bereich abnehmender BMP4-Konzentration im dorsalen Ektoderm werden einige 
Neuralplattengene wie Zic3 (Nakata et al., 1997) aktiviert. Die Aktivität von Zic3 in der Neuralplatte schaltet einer Reihe von Proneuralgenen in dieser Region, indirekt an (Nakata et al., 1997). Dabei ist anzumerken, daß diese proneuralen Gene die achaete-scute-Homologen in der Maus darstellen. Die proneuralen Gene werden direkt durch die Vormustergene Xiro1, Xiro2 und Xiro3 reguliert (Gómez-Skarmeta et al., 1998). Eine Aktivierung der Xiro-Gene erfolgt wiederum durch die gli-Gene, welche Homologe zu den Gli-Genen der Maus bzw. zu cubitus interuptus der Fliege darstellen (Gómez-Skarmeta et al., 1998).

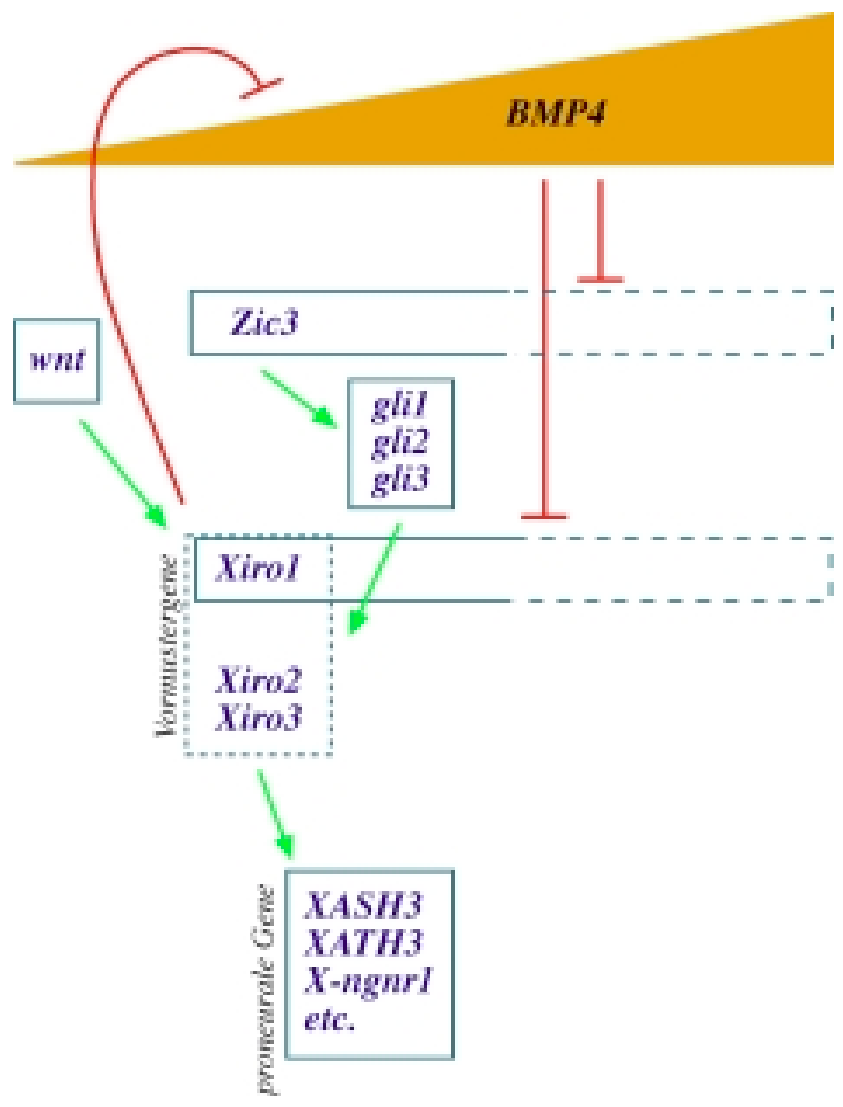

Abb. III.4: Die genetische Regulation der Iroquois-Gene in X. laevis bei der Bildung der Neuralleistenzellen.

Die Abbildung zeigt die genetische Regulation der Iroquois-Gene, Xiro1, Xiro2 und Xiro3, während der Determinierung der Neuralleistenzellen. Dabei liegt eine vereinfachte Regulation von Zic3-gli-Xiro- auf die proneuralen Gene vor. Ferner wird eine Regulation von Xiro1 durch den Wnt-Signalweg deutlich. Wnt-aktiviertes Xiro1 reprimiert BMP4, was zu einer gradientenartigen Expression von BMP4 führt. Hohe BMP4-Proteinkonzentrationen reprimieren wiederum die Xiro1-Aktivität. 
Die genetischen Interaktionspartner der Genkaskade sind zwischen X. laevis und Drosophila m. in ihrer gegenseitigen Regulation konserviert (Mayor et al., 1999). Es stellt sich die Frage, ob diese Regulation auch während der Mausentwicklung erhalten geblieben ist. Zwei Gene dieser Kaskade, Wnt3 und BMP4 bewirken in der Interaktion z.B. die Ausbildung des AVE in der Gastrulation. Für dies Entwicklung wird von R. Beddington die Existens eines TGF $\beta$-Repressors (BMP4-Repressors) postuliert (Beddington und Robertson, 1999). Irx1 könnte wie in X. laevis auch in der Maus regulativ zwischen Wnt und $B M P 4$ stehen.

In der weiteren embryonalen Entwicklung stellen die Gli- und Mash-Gene mögliche regulative Partner von Irx1 dar.

\section{DiE FUNKTION VON IRX1 WÄHREND DER ORGANOGENESE DER MAUS}

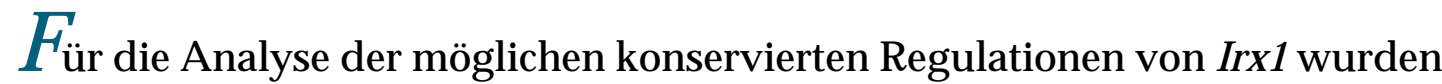
zwei methodische Ansätze genutzt. Zum einen wurden die Mausmutanten von Gli1 (Park et al., 2000) und Gli2 (Mo et al., 1997) und zum anderen der Mash1Promotor (Verma-Kurvari et al., 1998) auf eine Interaktion mit Irx1 untersucht.

\section{IRX1-GLI-EXPRESSIONSVERGLEICH WÄHREND DER EXTREMITÄTENBILDUNG}

Irx1 zeichnet sich durch ein spezifisches Expressionsmuster während der Entwicklung der Finger aus. Die Genaktivität in den Extremitäten beginnt ab dem Stadium E11,5, noch bevor die Phalangenstruktur erkennbar ist. Irx1 ist ein exzellenter Marker für die frühe Fingerentwicklung. Es ist zunächst im sich kondensierenden Mesenchym und später im sich entwickelnden Knorpel der Phalangen aktiv. Dabei zeichnet sich die Genaktivität stets durch eine scharfe Grenzbildung aus. Irx2 ist ebenfalls während der Extremitätenentwicklung aktiv. Allerdings startet die Expression einen Tag später und dabei zunächst in den Phalangen I und V und nicht II bis IV, wie dies bei IrxI der Fall ist. Bei dem Vergleich der Genaktivitäten von Irx1 und Irx2 mit den Genen Gli1, Gli2 und Gli3 während der Extremitätenentwicklung zeigten sich Übereinstimmungen. So zeigen Irx1-Gli1 und Irx2-Gli2 überlappende Expressionsdomänen. Dagegen 
ist das Aktivitätsmuster von Gli3 anders, und so erscheint eine mögliche Interaktion von Irx1 und Irx 2 mit Gli3 in diesem Organ unwahrscheinlich.

Eine Interaktion von Irx 1 mit Gli1 und Irx 2 mit Gli2 während der Entwicklung der Finger ist möglich.

\section{IRX1-EXPRESSION IN GLI-DEFIZIENTEN MÄUSEN}

In Gli1-defizienten Embryonen ist die Irx1-Expression verändert. Irx 1 ist im Telenzephalon und auch in der Mesenzephalon-Metenzephalon-Grenze exprimiert, wo es normalerweise nicht aktiv ist. Das deutet darauf hin, daß Gli1 für die Begrenzung der Irx1-Aktivität von Bedeutung ist, also reprimierend auf Irx1 wirkt. Im Neuralrohr der Gli1-defizienten Embryonen fehlt die Irx1Expression im medialen Teil. Dies läßt sich als eine positiv aktivierende Regulation von Irx1 durch Gli1 deuten. In einigen Regionen stellt Gli1 bezüglich Irx1 einen Repressor und in anderen einen Aktivator dar.

Auch in den Gli2-defizienten Embryonen ist die Irx1-Expression verändert. In Gli2-mutanten Embryonen gibt es keine Neuralrohrexpression, wohingegen die Gehirnexpression im Mesenzephalon und Metenzephalon unverändert ist. Dies deutet auf eine aktivierende Funktion von Gli2 auf Ir $x 1$ im sich entwickelnden Neuralrohr hin.

Zusammenfassend läßt sich die Interaktion zwischen Irx 1 und den beiden Gli-Genen wie folgt darstellen: Irx1 wird von Gli1 sowohl aktiviert als auch reprimiert. Bei Gli2 kann man von einer positiven Regulation sprechen.

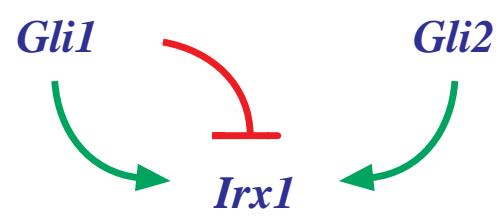

Abb. III.5: Regulation von Irx1 durch Gli1 und Gli2

Aus den in-situ-Analysen läßt sich ein Regulation von Irx1 durch Gli1 und Gli2 erkennen. So wird Irx1 durch Gli1 je nach Organ sowohl aktiviert wie auch reprimiert. Dagegen verhält sich Gli2 als reiner Aktivator gegenüber Irx1. 
Diese Ergebnisse entsprechen den Erkenntnissen aus Drosophila m. wie auch aus X. laevis. Die Regulationen zwischen Irx1 und Gli1 bzw. Gli2 sind somit evolutiv konserviert.

\section{ANALYSE DER POSTULIERTEN IRX1-Mash1-INTERAKTION}

$I_{r x 1}$ ist mit Beginn der Entwicklung der Intestinalanlage im Stadium E8,5 im Bereich des Vorderdarm exprimiert, exakt im Bereich der Lungeninduktion. Während der Bildung der Lungenknospen ist das Irx1-Transkript ausschließlich im Epithel, nicht aber in der mesenchymalen Schicht nachweisbar. Die epitheliale Expression bleibt bis zum Alveolarstadium erhalten.

Aufgrund dieser spezifischen Expression und der beschriebenen Funktion des humanen achaete-scute-Homologs, hASH1 während der Lungenkrebsbildung, wurde eine Zellkulturanalyse verschiedener humaner Lungenkrebszellinie durchgeführt. Die Analyse ergab, daß im Kleinzellkrebs ein verändertes Irx1-Expressionsmuster in der Northern-Blot-Analyse auftritt. So ist neben der Wildtyp-Transkriptbande eine weitere, nahezu doppelt so große zweite Bande vorhanden. Dies deutet auf eine Veränderung in der Transkription des des Irx1-Gens hin, was mit der Krebsentstehung in Zusammenhang stehen kann.

Das murine achaete-scute-Homolog Mash1 und Irx1 zeigen im weiteren im ZNS überlappende Expressionsbereiche. Die in vitro-Analyse des 5'-EnhancerElements des Mash1-Promotors (Verma-Kurvari et al., 1998) ergab, daß Irx1 nicht den Mash1-Promotor aktiviert. Dies kann bedeuten, daß Irx1 Mash1 nicht positiv reguliert, wie es von Drosophila $m$. her zu erwarten gewesen wäre.

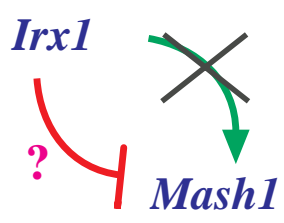

Abb. III.6: Irx1-Mash1-Interaktion

Irx1 aktiviert nicht das 5'-Enhancer-Element des Mash1-Promotors. Denkbar wäre nun eine negative Regulation (Repression) von Irx1 auf Mash1. 
Es ist daher denkbar, daß Irx1 den Mash1-Lokus reprimiert statt aktiviert. Für die reprimierende Funktion von Irx 1 spricht, daß Irx 1 sowohl in der Maus als auch in X. laevis (Gómez-Skarmeta et al., 2001) bezüglich BMP4 reprimierend agiert. Weiterhin sprechen neuere Daten für eine reprimierende Funktion des cIrx1 (Huhn) gegenüber Cash1 (K. Storey, Oxford, pers. Mitteilung). Außerdem umfaßt die Maus-Iroquois-Genfamilie fünf weitere Mitglieder, so daß auch andere Ir $x$-Gene Regulationspartner von Mash1 sein könnten. Demnach ist die Regulation von Gli-Irx-Mash in der Maus nur teilweise evolutiv konserviert. Die Interaktionspartner der regulativen Kaskade sind identisch, nicht aber die funktionelle Ausprägung.

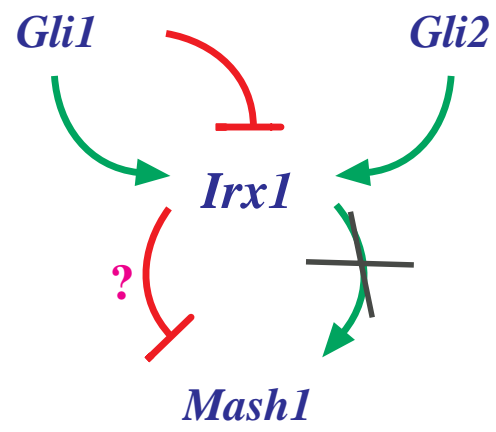

Abb. III.7: Regulation von Irx1 durch die Gli-Gene und das Mash1-Gen

Aus den in-situ-Analysen läßt sich ein Regulation von Irx1 durch Gli1 und Gli2 erkennen. Mash1 wird nicht direkt von Irx1 aktiviert.

Irx1 hat also neben der beschriebenen frühen Funktion während der embryonalen Entwicklung auch noch weitere Funktionen während der Organogenese. 


\section{MATeRial Und MeTHODEN}

\section{IV.1. ORGANISMEN}

\section{IV.1.1 MÄUSE UND EMBRYONEN}

NMRI (Weibchen) und C57Bl/6/xSJL oder B6D2/F1 Mäuse wurden vom Zentralinstitut für Versuchstierzucht Hannover bezogen. Zur Erzeugung von Embryonen für RNA-Präparationen, in-situ-Hybridisierungen und MorulaAggregationen, wurden die Mäuse ü.N. verpaart und der Tag des Vaginalpfropfes als Tag 0,5 post coitum der Embryonalentwicklung $(\mathrm{E} 0,5)$ gezählt. Der Tag der Geburt wurde als Tag 0 der postnatalen Entwicklung (P0) gezählt.

\section{Gli-Mäuse}

Die verwendeten Gli1- und Gli2-Mausmutanten wurden freundlicherweise von A. Joyner zu Verfügung gestellt (Park et al., 2000; Mo et al., 1997).

\section{IV.1.2 BAKTERIEN}

Transformationen wurden mit den E. coli-Stämmen DH5 $\alpha$ (Hanahan, 1985), XL-10-Gold (Stratagene), SURE (Stratagene) durchgeführt. Als Wirt für $\lambda$-gt10 Phagen wurde der Stamm LE392 verwendet.

\section{IV.1.3 ES-ZELLEN}

Zur homologen Rekombination wurden die embryonalen Stammzellen der MPI II Linie verwendet. Sie entstammen dem genetischen Mausstamm 129Sv/J. 


\section{IV.2 MATERIALIEN}

\section{IV.2.1 CHEMIKALIEN}

Chemikalien wurden von den Firmen Sigma (München), Merck (Darmstadt), BRL (Bethesda Research Laboratories, Karlsruhe), Serva (Heidelberg), Fluka (Buchs, Schweiz), J.T. Baker (Deventer, Holland), Roth (Karlsruhe), Biomol (Ilvesheim) und Gibco Laboratories (Detroit, USA) bezogen. Phenol verschiedener $\mathrm{pH}$-Werte wurde von der Firma Amresco (Solan, Ohio) bezogen. Alle Chemikalien besaßen den Reinheitsgrad "p.a." (zur Analyse).

\section{IV.2.2 RADIOCHEMIKALIEN}

Radiochemikalien (32P-dCTP und $\left.{ }^{35} \mathrm{~S}-\mathrm{dUTP}\right)$ kamen von der Firma Amersham (Braunschweig).

\section{IV.2.3 VERBRAUCHSMATERIAL}

Das Plastikmaterial wurde von den Firmen Falcon, Greiner, Eppendorf, Sarstedt und Nunc bezogen.

\section{IV.2.4 ENZYME}

Enzyme der Firmen Amersham-Buchler (Braunschweig), Stratagene (La Jolla), Gibco-BRL (Karlsruhe), Boehringer (Mannheim), Biolabs (Frankfurt), Promega und Pharmacia (Freiburg) wurden verwandt.

\section{IV.2.5 REAKTIONSSETS ("KITS")}

Es wurden folgende Kits benutzt:

Kit

BigDye Terminator Cycle Sequencing Ready

Reaction Kit

Multiprime DNA labelling system

Probe Quant G-50 Micro Columns

Qiagen Plasmid Maxi Kit
Hersteller

Perkin-

Elmer Corporation

Amersham Life Science

Amersham

Qiagen 


$\begin{array}{ll}\text { QIAprep Spin Miniprep Kit } & \text { Qiagen } \\ \text { QIAquick PCR Purification Kit } & \text { Qiagen } \\ \text { QIAquick Gel Extraction Kit } & \text { Qiagen } \\ \text { Trizol } & \text { Life Technologies } \\ \text { Oligotex mRNA Kit } & \text { Qiagen }\end{array}$

\section{IV.2.6 MEMBRANEN}

Es wurde mit Nylon-Membranen der Firma Qiagen (Düsseldorf) gearbeitet.

\section{IV.2.7 DNA-BIBLIOTHEKEN}

genomische $\lambda$-Phagenbibliothek

Die genomische Bibliothek wurde freundlicherweise von Dr. G. Schütz (Kaestner et al., 1993) zur Verfügung gestellt.

cDNA-Bibliothek

Das Durchmustern zweier Bibliotheken diente dazu, die Irx1-cDNA zu vervollständigen. Die ersten Fragmente wurden aus einer E8,5-cDNA-Bibliothek gewonnen (Zülch, 1997), die freundlicherweise von Dr. B. Hogan (Fahrner et al., 1987) zur Verfügung gestellt wurde. Bei der verwendeten E10,5-cDNABibliothek handelt es sich um eine Bibliothek der Firma Stratagene (Oligo-dT und Random-primed; E10,5; C57/Bl6; \#938303).

\section{IV.2.8 VEKTOREN}

Klonierungen wurden vorrangig mit dem Plasmid Bluescript II KS+ (Stratagene, USA), pGEM-T oder pGEM-T-Easy (Promega) oder dem "special .very.low.copy-Vector" (freundlicherweise von D. Treichel zur Verfügung gestellt) durchgeführt.

\section{IV.2.9 GRÖßENMARKER}

Für die DNA-Auftrennung wurden zwei verschiedene Größenmarker verwandt:

a) 1 kb-Marker (Biolabs):

kb: 10,0, 8,0, 6,0, 5,0, 4,0, 3,0, 2,0, 1,5, 1,0, 0,5 
b) 100 bp-Marker (Biolabs):

bp: 1517, 1200, 1000, 900, 800, 700, 600, 500, 400, 300, 200, 100

Als Größenmarker für die RNA-Auftrennung wurde der RNA-Marker 0,28$6,58 \mathrm{~kb}$ von Promega verwandt:

bp: 6583, 4981, 3638, 2604, 1908, 1383, 955, 623, 281

\section{IV.2.10 OLIGONUKLEOTIDE}

Alle Oligonukleotide wurden von den Firmen Eurogentec (Köln) oder NAPS (Göttingen) bezogen. Die Oligonukleotide dienten entweder als Sequenzierprimer oder sie wurden zur PCR benutzt.

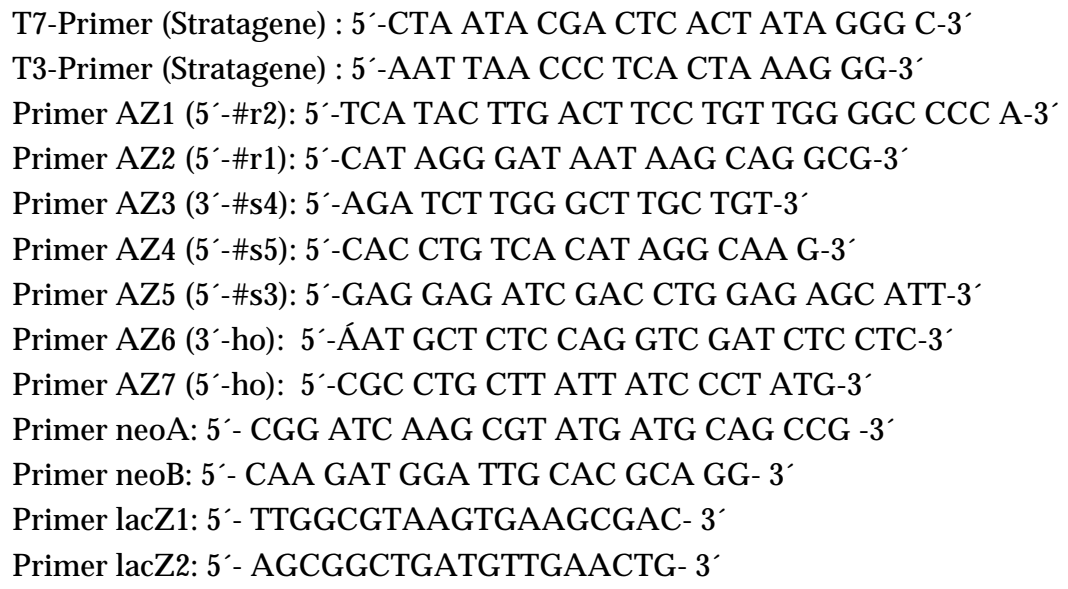

\section{IV.2.11 FILME}

Alle Farbfotografien wurden mit den Kunstlichtfilmen, Extrachrome $320 \mathrm{~T}$ und 64T der Firma Kodak gemacht. Die Autoradiogramme wurden auf XAR-3 oder BIOMAX-Filmen (beide von der Firma Kodak) exponiert, und die in-situHybridisierungen wurden in Kodak NTB-2 Flüssigfilm getaucht.

\section{IV.2.12 PHOTOARBEITEN UND SEQUENZBEARBEITUNG}

Die Photos der Embryonen bzw. Schnitte wurden mit Zeiss-Mikroskopen (Binokular und Axiophot) aufgenommen und digital weiterverarbeitet. DNASequenzbearbeitung wurden mittels der Computerprogramme Sequencher, DNA-Strider, GCG (Genetics Computer Group Inc.), Multialign und BLAST (NCBI) durchgeführt. 
Die Genbank-Nummern (Accession number) der bearbeiteten IroquoisSequenzen lauten: Irx1 (Y15002); Irx2 (Y15000); Irx3 (Y15001); Irx4 (AF124732); $\operatorname{Irx5}$ (AF271053); Irx6 (AJ271055).

\section{IV.2.13 ZELLINIEN}

Es wurde die noradrenerge PC12-Zellinie (Riken Cell Bank, Tsukuba, Japan; (Greene und Tischler, 1976)) und folgende Lungenkrebszellinien (SCLC: small cell lung cancer cell lines) der Gesellschaft American Type Culture Collection (ATCC) benutzt:
NCI-N417: ATCC No: CRL-5809
NCI-H592: ATCC No: HTB-116
NCI-H345: ATCC No: HTB-180
NCI-H82: ATCC No: HTB-175
NCI-H69: ATCC No: HTB-119

\section{IV.2.14 IN-SITU-HYBRIDISIERUNGSSONDEN}

Die folgenden in-situ Hybridisierungssonden wurden freundlicherweise zur Verfügung gestellt: Gli1, Gli2 und Gli3 von A. Joyner (Mo et al., 1997); Brachury (T) von B. Hermann (Herrmann et al., 1990); BMP4 von B. Hogan (Hogan, 1996); Mash1 von F. Guillemot (Guillemot et al., 1993); Otx2 von S.L. Ang (Acampora et al., 1995); Irx2 von M.B. Becker (Bosse et al., 2000); Gbx2 von M. Lewandowski (Wassarman et al., 1997)

\section{IV.2.15 MEDIEN, NÄHRBÖDEN, STANDARD-LÖSUNGEN}

Alle Lösungen wurden mit Wasser angesetzt, welches über eine „MilliporeAnlage" gereinigt war und danach autoklaviert oder sterilfiltriert wurde (vorhandene Ausnahmen werden bei der jeweiligen Methode erwähnt). Die folgenden Lösungen sind Bestandteil verschiedener Methoden und werden daher vorangestellt und bei der einzelnen Methode nur noch mit Namen erwähnt.

1x SSC:

$0,15 \mathrm{M} \mathrm{NaCl}$

15 mM NaCitrat, pH 7,0
TE:

$10 \mathrm{mM}$ Tris/ $\mathrm{HCl}, \mathrm{pH}$ 7,5

$1 \mathrm{mM}$ EDTA
STE:

$150 \mathrm{mM} \mathrm{NaCl}$

$8 \mathrm{mM}$ Tris-Cl pH 8

0,8 mM EDTA pH 8,0 


\section{$10 \times$ TBE:}

$108 \mathrm{~g}$ Tris base

$40 \mathrm{ml}$ 0,5M EDTA, pH 8,0

$55 \mathrm{~g}$ Borsäure

ad $1.000 \mathrm{ml} \mathrm{H}_{2} \mathrm{O}$

LB - Medium:

$10 \mathrm{~g} \mathrm{NaCl}$

$10 \mathrm{~g}$ Bacto-Trypton

$5 \mathrm{~g}$ Bacto-Hefe-Extract

in 11 VE-Wasser, $\mathrm{pH} 7,0$

Nährböden enthielten zusätzlich

1,5\% Agar und Topagar(-ose) 0,7 \%

Agar(-ose).

\section{Neutralisierungslösung: \\ $1.5 \mathrm{M} \mathrm{NaCl}$ \\ 0,5 M Tris/ $\mathrm{HCl}(\mathrm{pH} 7,4)$}

Hybridisierungslösung:

$7 \%$ SDS

0,5 $\mathrm{M} \mathrm{Na}_{2} \mathrm{HPO}_{4} \mathrm{pH} \mathrm{7,2}$

\section{Kanamycin:}

$10 \mathrm{mg} / \mathrm{ml}$ in $\mathrm{H}_{2} \mathrm{O}$ gelöst und bei -20

${ }^{\circ} \mathrm{C}$ gelagert

\section{Proteinase K:}

Proteinase K (Boehringer) wurde mit einer Endkonzentration von $20 \mathrm{mg} /$ $\mathrm{ml}$ in $\mathrm{H}_{2} \mathrm{O}$ gelöst und bei $-20{ }^{\circ} \mathrm{C}$ aufbewahrt.

\section{EtBr-Lösung:}

$100 \mathrm{mg}$ Ethidiumbromid in $10 \mathrm{ml} \mathrm{H}_{2} \mathrm{O}$ gelöst und im Dunkeln aufbewahrt; verwendete Konzentration betrug $2 \mathrm{mg} / \mathrm{ml}$.
10 x Ladepuffer für RNA:

$50 \%$ Glycerin (steril)

1 mM EDTA

$0,25 \%$ Bromphenolblau

0,25 \% Xylen Cyanol FF

10 x Ladepuffer für DNA:

0, $25 \%$ Bromphenolblau

$0.25 \%$ Xylen Cyanol FF

10x TAE

25\% Gycerin

$1 \%$ SDS

$1 \mathrm{mM}$ EDTA

Denaturierungslösung: 0,5 M NaOH (pH 14,0)

$1,5 \mathrm{M} \mathrm{NaCl}$

Waschpuffer für

Hybridsierungen:

$1 \%$ SDS

$40 \mathrm{mM} \mathrm{Na}_{2} \mathrm{PO}_{4} \mathrm{pH} 7,2$

Tetracyclin:

$12,5 \mathrm{mg} / \mathrm{ml}$ in Ethanol gelöst und bei $-20^{\circ} \mathrm{C}$ gelagert

\section{Phenol/Chloroform/}

Isoamylalkohol :

Mischung aus Phenol,

Chloroform und

Isoamylalkohol (PCI) im

Volumenverhältnis 25:24:1.

RNase A:

$10 \mathrm{mg} / \mathrm{ml}$ in $10 \mathrm{mM}$ Tris $/ \mathrm{HCl}$ (pH 7,5), 15 mM NaCl gelöst, zur Inaktivierung der DNasen für 15 Min. bei $95^{\circ} \mathrm{C}$ inkubiert und langsam auf RT abgekühlt; bei $-20^{\circ} \mathrm{C}$ gelagert
SM-Puffer:

$100 \mathrm{mM} \mathrm{NaCl}$

$10 \mathrm{mM} \mathrm{MgSO}_{4}$

$50 \mathrm{mM}$ Tris/ $\mathrm{HCl}, \mathrm{pH} 7,5$

0,01\% Gelantine

10 x PBS-Puffer:

$1,3 \mathrm{M} \mathrm{NaCl}$

$70 \mathrm{mM} \mathrm{Na}_{2} \mathrm{HPO}_{4}$

$30 \mathrm{mM} \mathrm{NaH}_{2} \mathrm{PO}_{4} \cdot 2 \mathrm{H}_{2} \mathrm{O} \mathrm{pH}$

7,0

\section{NZY-Topagar (Topagar):}

$21 \mathrm{~g}$ NZY-broth

$7 \mathrm{~g}$ Agarose

in $11 \mathrm{VE}-W a s s e r$

\section{Chloroform/Isoamylalkohol \\ (CI):}

Mischung aus Chloroform und Isoamylalkohol im Volumenverhältnis 24:1.

\section{Ampicillin:}

$25 \mathrm{mg} / \mathrm{ml}$ in $\mathrm{H}_{2} \mathrm{O}$, steril filtriert, und bei $-20{ }^{\circ} \mathrm{C}$ gelagert

\section{Zellkulturmedien}

Medien stammten von den

Firmen Gibco (Paisley, England), Flow Laboratories (Irvine, England) und Boehringer (Mannheim). 


\section{IV.3 METHODEN}

Alle molekularbiologischen Standardmethoden, die nachfolgend nicht aufgeführt sind, wurden nach der Beschreibung von Sambroock oder Ausubel durchgeführt (Sambroock et al., 1989; Ausubel et al., 1987).

\section{IV.3.1 ISOLIERUNG VON PLASMID-DNA AUS BAKTERIEN}

\section{PLASMIDPRÄPARATION MIT DEM QIAPREP SPIN MINIPREP KIT}

Zur schnellen Gewinnung kleinerer Mengen hochreiner Plasmid-DNA wurde der "QIAprep Spin Miniprep Kit" (Qiagen, 2000) von der Firma Qiagen (Düsseldorf) verwendet. Hierbei handelt es sich um eine modifizierte Form der alkalischen Lyse (Birnboim and Doly, 1979) in Verbindung mit einer Affinitätsaufreinigung an einer Silicongelmembran, die bei hohen Salzkonzentrationen DNA bindet und bei niedrigen eluiert. Die jeweiligen Zusammensetzungen der Puffer P1, P2, N3, PB, PE und EB sind in den Herstellerangaben zu finden.

Es wurden 3-5 ml einer E. coli-Kultur ü.N. in LB-Medium mit Selektionsmarker bei $37^{\circ} \mathrm{C}$ angezogen. Die Kultur wurde 10 Min. mit 4.000 rpm bei $4{ }^{\circ} \mathrm{C}$ pelletiert und der Überstand verworfen. Das Pellet wurde in $250 \mu \mathrm{l}$ Puffer P1 resuspendiert und die Lösung in ein Eppendorfgefäß überführt. Danach wurden $250 \mu$ l Puffer P2 zugeben, durch vorsichtiges Schwenken gemischt und nach maximal 5 Min. Inkubation bei RT $350 \mu$ l Puffer N3 zugegeben. Nach erneutem Mischen wurde 1 Min. mit $13.000 \mathrm{rpm}$ bei RT zentrifugiert und der Überstand auf die QIAprep Spin-Säule in das $2 \mathrm{ml}$ Auffangröhrchen gegeben. Durch nochmalige 1minütige Zentrifugation mit $13.000 \mathrm{rpm}$ bei RT wurde die DNA an die Säulenmatrix gebunden. Danach wurde einmal mit 0,5 ml Puffer PB und einmal 0,75 ml Puffer PE gewaschen. Dabei wurde jeweils der Waschpuffer auf die Säule gegeben, 1 Min. mit 13.000 rpm bei RT zentrifugiert und der Säulendurchfluß verworfen. Am Schluß wurde die DNA in ein sauberes Eppendorfgefäß eluiert. Dazu wurden $50 \mu 1$ Puffer EB 
auf die Säule gegeben, 1 Min. bei RT inkubiert und danach erneut 1 Min. mit $13.000 \mathrm{rpm}$ bei RT zentrifugiert.

Die Konzentration der so gewonnenen DNA entspricht ungefähr 200-400 ng/ $\mu 1$.

\section{PLASMIDISOLATION MIT DEM QIAFILTER MAXIPREP KIT}

Zur Aufreinigung größerer Mengen hochreiner Plasmid-DNA wurde der "QIAfilter Plasmid Maxi Kit" (Qiagen, 2000) nach den Angaben des Herstellers verwendet. Der Kit funktioniert ebenfalls nach einer modifizierten Form der alkalischen Lyse (Birnboim und Doly, 1979), diesmal in Verbindung mit einer Anionen-Austauschersäule. Die jeweiligen Zusammensetzungen der Puffer P1, P2, P3, QBT, QC, QF und TE sind in den Herstellerangaben zu finden.

Es wurden 50-100 ml E. coli-Kultur ü.N. in LB-Medium mit Selektionsmarker bei $37^{\circ} \mathrm{C}$ in einem Erlenmeyerkolben angezogen. Die Kultur wurde durch 10minütige Zentrifugation mit $4.000 \mathrm{rpm}$ bei $4^{\circ} \mathrm{C}$ pelletiert. Der Überstand wurde verworfen und das Pellet in $10 \mathrm{ml}$ kaltem P1-Puffer resuspendiert. Nach der Zugabe von $10 \mathrm{ml}$ P2-Puffer wurde 6 mal invertiert, 5 Min. bei RT inkubiert und $10 \mathrm{ml}$ gekühlter P3-Puffer zugegeben. Um die QIAfilter Cartridge nicht mit ausfallendem Protein zu verstopfen, wurde nach einer 5minütigen Inkubation bei RT nochmals 10 Min. mit 4.000 rpm zentrifugiert und der Überstand dann in die QIAfilter Cartridge gefüllt. Während der nun folgenden 10 Min. Inkubation bei RT wurden eine QIAGEN-tip 500-Säule mit $10 \mathrm{ml}$ QBT-Puffer äquilibriert. Das Zellysat wurde durch die QIAfilter Cartridge gedrückt und auf die QIAGEN-tip 500-Säule auftragen. Es folgte zweimaliges Waschen der Säule mit je $30 \mathrm{ml}$ QC-Puffer. Die DNA wurde mit $15 \mathrm{ml}$ QF-Puffer eluiert, durch Zugabe von 10,5 $\mathrm{ml}$ eiskaltem Isopropanol gefällt und durch eine $30 \mathrm{Min}$. Zentrifugation bei $4{ }^{\circ} \mathrm{C}$ und 15.000 g pelletiert. Der Überstand wurde verworfen, die DNA mit $5 \mathrm{ml} 70$ \%igem Ethanol gewaschen und erneut durch Zentrifugation mit $15.000 \mathrm{~g}\left(4^{\circ} \mathrm{C}, 10 \mathrm{Min}\right.$.) pelletiert. Nach dem vollständigen Entfernen des Überstandes wurde die isolierte Plasmid-DNA an der Luft getrocknet und in TE oder $\mathrm{H}_{2} \mathrm{O}$ resuspendiert. 


\section{IV.3.2 KONZENTRATIONSBESTIMMUNG VON NUKLEINSÄUREN}

Konzentrationsbestimmungen von DNA und RNA wurden durch einen optischen Vergleich der Ethidiumbromidfluoreszenz von Standard-DNA und Probe in Agarosegelen durchgeführt (Sambroock et al., 1989).

\section{IV.3.3 AGAROSE-GELELEKTROPHORESE}

Bei der Agarosegelelektrophorese (Thorne, 1966; Helling et al., 1974; McDonell et al., 1977; Johnson und Grossman, 1977; Southern, 1975) werden DNA-Fragmente ihrer Größe nach aufgetrennt. DNA wandert aufgrund der negativen Ladungen der Phosphatreste in einem elektrischen Feld zur Anode.

Für analytische und präparative Zwecke wurden Agarosegele angefertigt. Der aufzutrennenden Fragmentgröße entsprechend wurden 0,7 - 3 \%ige Agarosegele mit jeweils $0,1 \mu \mathrm{g} / \mathrm{ml}$ Ethidiumbromid versetzt verwendet. Als Laufpuffer diente 1x TBE. Die DNA wurde vor dem Auftragen mit Ladepuffer versetzt. Nach der Elektrophorese wurden die Gele bei kurzwelligem UV-Licht (258 nm) fotogafiert. Präparative Gele sollten, um die Bildung von ThymidinDimeren und Strangbrüche zu vermeiden, nur langwelligem, energieärmerem UV-Licht (Wellenlänge $>300 \mathrm{~nm}$ ) ausgesetzt werden.

\section{IV.3.4 GEWINNUNG VON DNA-FRAGMENTEN AUS AGAROSEGELEN MIT DEM QIA-QUICK GEL EXTRACTION KIT}

Die Gewinnung von DNA-Fragmenten aus Agaosegelen wurde mit Hilfe des "QIA-quick Gel Extractions Kit" von der Firma Qiagen durchgeführt. Das dabei verwendete "QIAquick Spin-Protokoll" (Qiagen, 2000) arbeitet mit dem Prinzip der selektiven Bindung von DNA an eine Selikon-Gel-Membran. Dabei macht man sich zunutze, daß DNA bei hohen Salzkonzentrationen an der Säulenmatrix haften bleibt, während Kontaminationen weggewaschen werden. Bei niedrigen Salzkonzentrationen kann die DNA eluiert werden. Die jeweiligen Zusammensetzungen der Puffer QG, PE und EB sind in den Herstellerangaben zu finden.

Dazu wurde die entsprechende Bande aus dem Gel ausgeschnitten und in 5 Volumina Puffer QG auf ein Volumen Gel aufgenommen. Dies wurde in einem 
Eppendorfgefäß bei $50{ }^{\circ} \mathrm{C} 10$ Min. unter gelegentlichem Vortexen inkubiert. Nachdem sich das Gel vollständig aufgelöst hatte, wurde die Farbe der Mischung kontrolliert. Hatte sie eine violette Färbung, so wurden $10 \mu 13 \mathrm{M}$ NaAc zugegeben, hatte sie eine gelbe Färbung, so wurde gleich zum nächsten Schritt übergegangen. Nun wurde die Lösung auf die QIAquick Spin Column gegeben und 1 Min. mit $13.000 \mathrm{rpm}$ bei RT zentrifugiert. Danach wurde der Säulendurchfluß verworfen und je einmal mit 0,5 ml Puffer QG und 0,75 ml Puffer PE gewaschen. Nach jedem dieser beiden Schritte wurde 1 Min. 13.000 rpm bei RT zentrifugiert und der Säulendurchfluß verworfen. Am Schluß wurden $30 \mu$ Puffer EB auf die Säule gegeben, 1 Min. lang bei RT inkubiert und die DNA durch eine letzte Zentrifugation 1 Min. mit 13.000 rpm bei RT eluiert.

\section{IV.3.5 RESTRIKTIONSSPALTUNG VON DNA}

Das Restriktionsschneiden wurde gemäß den Angaben des Enzymherstellers und nach Sambroock (Sambroock et al., 1989) durchgeführt. Restriktionsansätze mit mehreren Enzymen konnten gleichzeitig erfolgen, wenn die Enzyme dieselben Reaktionsbedingungen erforderten. Unterschieden sich die Reaktionspuffer nur in der $\mathrm{NaCl}$ Konzentration, wurde zuerst mit der niedrigeren Salzkonzentration und dem entsprechenden Enzym inkubiert, anschließend wurde die Salzkonzentration für das zweite Enzym eingestellt, bevor dieses zugegeben wurde. Benötigten die Enzyme unterschiedliche Ionen, mußte nach dem ersten Schneiden eine PCI-Extraktion mit anschließender Ethanolfällung durchgeführt wurden, bevor mit dem anderen Enzym geschnitten werden konnte.

\section{IV.3.6 AufREINIGUNG VON DNA-LÖSUNGEN MitTELS PHENOL/ CHLOROFORM-EXTRAKTION}

Bei der Phenol/Chloroform-Extraktion (Kirby, 1956; Marmur, 1960) wurde zu einem Volumen einer wässrigen DNA-Lösung ein Volumen einer Mischung aus Phenol, Chloroform und Isoamylalkohol gegeben (Mengenverhältnis $25: 24: 1$ ). Nach intensivem Mischen auf dem Vortexer wurde die Emulsion zur Phasentrennung bei RT mit $13.000 \mathrm{rpm}$ für 5 Min. zentrifugiert. Danach 
befanden sich denaturierte Proteine, Membranbestandteile und organisch lösliche Moleküle in der unteren Phenol/Chloroform-Phase und in der Interphase. Die DNA befand sich in der oberen wässrigen Phase.

Die obere Phase wurde vorsichtig abgenommen und in ein neues Röhrchen überführt. Je nach benötigtem Reinheitsgrad der DNA kann der Vorgang mehrmals wiederholt werden. Anschließend wurde, um Phenolspuren zu beseitigen, nach obigem Schema eine weitere Extraktion mit Chloroform/ Isoamylalkohol (24:1) durchgeführt. Die DNA wurde in der Regel nach der Extraktion mit Ethanol gefällt.

\section{IV.3.7 ETHANOLFÄLLUNG VON DNA AUS WÄSSRIGEN LÖSUNGEN}

Es wurde 1/10 des Volumens der DNA-Lösung 3M Natriumacetat zugegeben. Danach wurden 2,5 Volumina des jetzigen Volumens absoluten (oder 96 \%igen) Ethanols zugegeben und gemischt. Die Fällung wurde für ca. 30 Min. bei $4{ }^{\circ} \mathrm{C}$ oder $5 \mathrm{Min}$. bei $-20^{\circ} \mathrm{C}$ inkubiert. Zum Sedimentieren der gefällten DNA wurde für 5 bis $10 \mathrm{Min}$. bei $4{ }^{\circ} \mathrm{C}$ und $13.000 \mathrm{rpm}$ zentrifugiert und danach der Überstand abgenommen. Um die DNA zu waschen, z.B. um Salzreste zu entfernen, wurden $0,5 \mathrm{ml} 70 \%$ Ethanol in ein Eppendorfgefäß mit gefällter DNA gegeben und kräftig gemischt. Es folgte wieder eine Zentrifugation für 3 5 Min. Der Überstand wurde vorsichtig entfernt. Nach dem Trocknen des Pellets wurde die DNA in Puffer oder Wasser $(\mathrm{pH}>6.0)$ aufgenommen.

\section{IV.3.8 ISOPROPANOLFÄLLUNG VON DNA AUS WÄSSRIGEN LÖSUNGEN}

Eine Isopropanolfällung hat den Vorteil, daß zur Fällung nur weniger Isopropanol (als Ethanol im Vergleich) zugegeben werden muß und daß die DNA mit weniger Salz ausfällt. Nachteile der Isopropanolfällung sind die geringere Flüchtigkeit des Isopropanols und das weniger feste und durchsichtigere Pellet nach der Zentrifugation.

Anstatt Ethanol wurden 0,7 Volumina Isopropanol zur DNA-Lösung zugegeben. Weiter wurde wie bei der Ethanolfällung verfahren. 


\section{IV.3.9 LIGATION VON DNA-FRAGMENTEN}

Das Enzym T4-DNA-Ligase katalysiert die Bildung einer Phosphodiesterbindung zwischen der 3'-OH-Gruppe am Ende eines DNAStranges und der 5'-Phosphatgruppe am Ende eines anderen DNA-Stranges. Zum Ablaufen dieser endergonischen Reaktion ist ATP erforderlich. Die Produkte einer Ligation wurden in E. coli transformiert und so vermehrt.

Ligationen wurden mit 20 - 50 ng Vektor und dem 3-fachen molaren Überschuß des entsprechenden Fragments in Ligase-Puffer mit 1 mM ATP und 1 U T4-DNA-Ligase angesetzt. Überhang-Ligationen („sticky ends”) wurden 3 h. bei $20^{\circ} \mathrm{C}$ oder ü.N. bei $14{ }^{\circ} \mathrm{C}$, Ligationen mit stumpfen Enden („,blunt ends") stets ü.N. bei $14^{\circ} \mathrm{C}$ inkubiert.

10X LIGASE-PUFFER:

$660 \mathrm{mM}$ Tris/ $\mathrm{HCl}(\mathrm{pH} \mathrm{7,6)}$

$66 \mathrm{mM} \mathrm{MgCl}_{2}$

$0,1 \mathrm{M}$ DTT

\section{IV.3.10. „BLUNT END"-KLONIERUNG}

Sollten Fragmente mit überhängenden 5'- oder 3'- Enden in einen „blunt end"Vektor kloniert wurden, so wurden:

- 5' Überhänge mit Klenow-Fragment der DNA-Polymerase I (Boehringer Mannheim) und den entsprechenden Nukleotidmix direkt im Reaktionsansatz aufgefüllt (Klenow arbeitet in den meisten Puffern zufriedenstellend).

- 3' Überhänge mit T4-Polymerase (stärkere 3' - 5' Exonukleaseaktivität als Klenow) abgebaut.

\section{IV.3.11 TRANSFORMATION VON BAKTERIEN}

\section{HERSTELLUNG ELEKTROKOMPETENTER BAKTERIEN}

Bei der Elektroporation wird eine Mischung aus Bakterien und DNA einem kurzen, aber intensiven elektrischen Feld von 1,8 kV, welches einen exponentiellen Abfall zeigt, ausgesetzt (Dower et al., 1988). Dies führt zur vorübergehenden Bildung von Poren in der Membran von lebenden Zellen (Calvin und Hanawalt, 1988), durch welche die DNA in die Zelle gelangen kann. 
Die Porenentstehung ist vermutlich darauf zurückzuführen, daß sich die Membranmoleküle der Phospholipiddoppelschicht in einem elektrischen Feld als Dipol verhalten und die Struktur der Membran so verändert wird (Neumann et al., 1982).

Zur Herstellung elektrokompetenter Bakterien wurden E. coli auf einer LBPlatte ausgestrichen und ü.N. bei $37^{\circ} \mathrm{C}$ inkubiert. Von dieser Platte wurde eine einzelne Kolonie in $5 \mathrm{ml}$ LB-Medium angeimpft und $5 \mathrm{~h}$ bis ü.N. bei $37^{\circ} \mathrm{C}$ leicht geschüttelt. Mit diesen $5 \mathrm{ml}$ wurde 11 LB-Lösung angeimpft und bei $37{ }^{\circ} \mathrm{C}$ geschüttelt (300 rpm), bis eine $\mathrm{OD}_{600}$ von 0,6 erreicht wurde. Nun wurde das Wachstum gestoppt, indem die Bakterien ca. 15 - 30 Min. in einem Eiswasserbad abgekühlt wurden. Hiernach wurden die Zellen durch ein 15 Min. Zentrifugieren $\left(4200 \mathrm{rpm}, 4^{\circ} \mathrm{C}\right.$ ) pelletiert. Die Bakterien wurden in 11 eiskaltes $\mathrm{ddH}_{2} \mathrm{O}$ aufgenommen und nach dem Lösen wie bereits beschrieben erneut pelletiert. Dieser Waschschritt wurde zweimal wiederholt, doch diesmal wurde das Pellet nur in 0,5 $1 \mathrm{ddH}_{2} \mathrm{O}$ bzw. beim zweiten Mal in $20 \mathrm{ml} 10 \%$ Glycerinlösung aufgenommen. Nach erneuter Zentrifugation wurde das nun erhaltene Pellet in $2-3 \mathrm{ml} 10 \%$-Glycerinlösung aufgenommen und gut gemischt. Die Konzentration betrug nun in etwa $3^{*} 10^{10}$ Zellen/ml. Danach wurden die Bakterien aliquotiert und bei $-70{ }^{\circ} \mathrm{C}$ gelagert. Die Zellen sind nun fertig für eine Elektroporation und können nach Bedarf aufgetaut werden.

\section{TRANSFORMATION DURCH ELEKTROPORATION}

Die kompetenten Bakterien (ca. $50 \mu \mathrm{l}$ ) wurden auf Eis aufgetaut und mit dem Ligationsansatz gemischt. Danach wurden die Bakterien in kalte Elektroporationsküvetten überführt und der Elektroporationapparat eingestellt (1,8 kV, $25 \mathrm{mF}$ und $200 \mathrm{~W}$ beim Pulskontroller). Nach der Elektroporation wurde direkt $1 \mathrm{ml}$ SOC-Medium zu den Bakterien gegeben. Die Bakterienlösung wurde in ein steriles Reaktionsgefäß transferiert und ca. 30 Min. bei $37{ }^{\circ} \mathrm{C}$ leicht geschüttelt, bevor sie auf Selektivagar ausplattiert wurde.

SOC-MEDIUM:

Bacto-Trypton $2 \%$

Bacto-Yeast Extrakt 0,5 \%

$\mathrm{NaCl} 10 \mathrm{mM}$ 
$\mathrm{KCl} 2,5 \mathrm{mM}$

$\mathrm{MgCl}_{2} 10 \mathrm{mM}$ (nach dem Autoklavieren zugeben)

$\mathrm{MgSO}_{4} 10 \mathrm{mM}$ (nach dem Autoklavieren zugeben)

Glucose $20 \mathrm{mM}$ (nach dem Autoklavieren zugeben)

\section{IV.3.12 SEQUENZIERUNG ("CYCLE SEQUENCING")}

Zum Sequenzieren der DNA wurde ein Verfahren benutzt, das auf der kontrollierten Unterbrechung der DNA-Synthese beruht (Sanger et al., 1977; Tabor und Richardson, 1987). Einzelsträngige DNA dient dabei als Matrize für die Synthese eines neuen Stranges. Es wurde ein Primer zugegeben, der mit der DNA hybridisieren kann. DNA-Polymerasen benötigen für ihre Syntheseaktivität einen kurzen Abschnitt doppelsträngiger DNA. Zusätzlich zu den Desoxyribonukleotiden wurden auch Didesoyribonukleotide (ddNTPs) in den Reaktionsansatz gegeben. Diesen fehlt die Hydroxlgruppe am 3'-C-Atom des Zuckers. Werden die ddNTPs in den neuen DNA-Strang eingebaut, so stoppt das Kettenwachstum, da keine weitere Phosphodiesterbindung geknüpft werden kann. Über die unterschiedliche Länge der neu entstandenen DNAStränge läßt sich die Basenabfolge nach einer gelelektrophoretischen Auftrennung ermitteln. Längenunterschiede von einem Basenpaar können aufgelöst werden. Die ddNTPs sind je nach Base unterschiedlich fluoreszenzmarkiert, so daß nach einer Gel-Elektrophorese jedes DNA-Fragment mit einer Laserapparatur detektiert werden kann.

Die Bestimmung der Nukleotidsequenzen wurde auf einem ABI PRISM-377 DNA Sequencer durchgeführt. Im Reaktionsansatz wurden 300 - 400 ng DNA, 10 pmol Primer und 4,5 ml Big Dye Terminator Cycle Sequencing Kit-Lösung zugegeben. Die Reaktion fand in einem Gesamtvolumen von 11,5 - 13,5 $\mathrm{ml}$ statt. Das Cycle sequencing-Programm $\left(30^{\prime \prime} 95^{\circ} \mathrm{C}, 10^{\prime \prime} 50^{\circ} \mathrm{C}, 4^{\prime} 60^{\circ} \mathrm{C}, 25\right.$ Zyklen) wurde in einem Biometra Trio-Thermoblock durchgeführt. Nach der Reaktion wurde der Ansatz mit Ethanol gefällt und im Big Dye-Auftragspuffer aufgenommen. Die Reaktion wurde dann auf das Sequenziergel aufgetragen. Die Integrale werden mit der Computersoftware Sequencer ausgewertet. 


\section{IV.3.13 PolyMERASE-KETTENREAKTION (PCR)}

(Saiki et al., 1986; Saiki et al., 1988; Saiki et al., 1985; Mullis et al., 1986)

Die Konzentration der Primer wurde photometrisch bestimmt. Alle Primer wurden zur Genotypisierung von transgenen Mäusen eingesetzt. Primerpaar AZ-neo-\#1+2 wurden zur Detektion der Neo-Resistenz und AZ-lacZ-\#1+2 zur Detektion des LacZ-Markergens eingesetzt. AZ-Irx-\#1+2 erkannten das normale Irx1-Allel, welches in den transgenen Mäusen deletiert war.

Alle Primer wurden von der Firma Eurogentec bzw. NAPS synthetisiert und in lyophilisierter Form geliefert, so daß diese nur noch in $\mathrm{H}_{2} \mathrm{O}$ gelöst und die Konzentration bestimmt werden mußte.

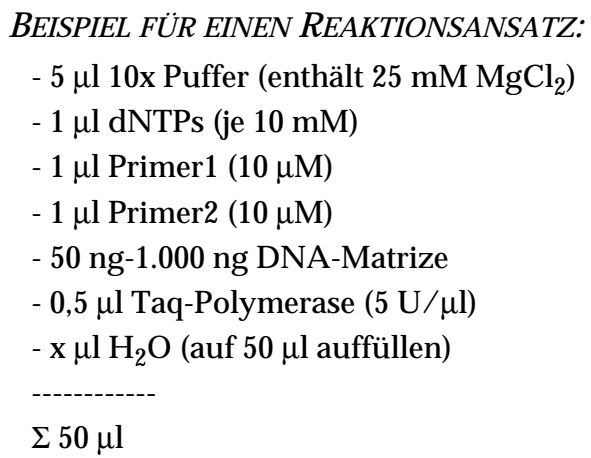


GENOTYPISIERUNGS-PCR:

Zum Genotypisieren wurde zum einen eine Irx1-PCR, die den deletierten Homeoboxbereich erfaßt, und zum anderen eine Neomycin- oder lacZ-PCR durchgeführt.

\begin{tabular}{|l|l|l|}
\hline \multicolumn{1}{|c|}{ IRX1-HOM-PCR } & \multicolumn{1}{|c|}{ NEO-PCR } & \multicolumn{1}{c|}{ LACZ-PCR } \\
\hline $\begin{array}{l}\text { Ansatz (wie oben beschrieben) } \\
\text { Primer: AZ-\#3 + AZ-\#7 }\end{array}$ & $\begin{array}{l}\text { Ansatz (wie oben beschrieben) } \\
\text { Primer: AZ-neoA + AZ-neoB }\end{array}$ & $\begin{array}{l}\text { Ansatz (wie oben beschrieben) } \\
\text { Primer: AZ-lacZ1 + AZ-lacZ2 }\end{array}$ \\
\hline $\begin{array}{l}\text { Protokoll (wie oben } \\
\text { beschrieben) }\end{array}$ & $\begin{array}{l}\text { Protokoll (wie oben } \\
\text { beschrieben) }\end{array}$ & $\begin{array}{l}\text { Protokoll (wie oben } \\
\text { beschrieben) }\end{array}$ \\
Annealingtemperatur: $58^{\circ} \mathrm{C}$ & Annealingtemperatur: $70^{\circ} \mathrm{C}$ & Annealingtemperatur: $60^{\circ} \mathrm{C}$ \\
Zyklenzahl: 30x & Zyklenzahl: $25 x$ & Zyklenzahl: 30x \\
\hline
\end{tabular}

Die PCR-Reaktion wurde in einem Biometra Trio-Thermoblock mit Deckelheizung durchgeführt.

\section{IV.3.14 SOUTHERN-BLOT-ANALYSE}

Die nachfolgend aufgeführt Analyse wurde nach der Beschreibung von Southern oder Chomczynski durchgeführt (Southern, 1975; Chomczynski und Quasba, 1984).

Mit Restriktionsenzymen geschnittene DNA wurde in Agarosegelen aufgetrennt, gefärbt und mit einem Längenmaß fotogafiert. Das Gel wurde 15 Min. lang unter Schütteln mit 0,25 M HCl behandelt (Depurinisierung; reduziert die Größe der DNA-Fragmente im Gel und verbessert dadurch die Effizienz, mit der große Fragmente auf die Filter transferiert werden können) und anschließend mit VE-Wasser gespült. Da ausschließlich Nylon-Memranen verwendet wurden, konnte der Transfer der DNA unter alkalischen Bedingungen erfolgen (,alkalisches Blotting”). Hierzu wurde die DNA für mindestens 30 Min. in Denaturierunglösung denaturiert und anschließend ca. 30 Min. in der Neutralisierungslösung geschwenkt. Zum Blotten wurde der Aufbau nach Southern verwendet. Als Transferlösung diente 20x SSC. Der Transfer dauerte 4 - 24 h, je nach Größe der Fragmente und Menge der DNA in dem Gel. Nach dem Blotten wurde die Membran in 2x SSC geschwenkt und 
luftgetrocknet. Anschließend wurde die DNA durch Bestrahlung mit langwelligem UV-Licht $\left(0,3 \mathrm{~J} / \mathrm{cm}^{2}\right)$ kovalent auf dem Filter fixiert.

DENATURIERUNGSLSG.:
$0,5 \mathrm{M} \mathrm{NaOH}$
$1,5 \mathrm{M} \mathrm{NaCl}$

DENATURIERUNGSLSG.:

$1,5 \mathrm{M} \mathrm{NaCl}$

\author{
NEUTRALISIERUNGSLSG.: \\ $1,5 \mathrm{M} \mathrm{NaCl}$ \\ $0,5 \mathrm{M}$ Tris \\ $\mathrm{HCl}(\mathrm{pH} 7,2)$
}

\section{IV.3.15 RADIOAKTIVE MARKIERUNG VON DNA- UND RNA-BLOTS}

\section{RADIOAKTIVE MARKIERUNG VON DNA-FRAGMENTEN}

Die radioaktive Markierung von DNA-Fragmenten erfolgte mit dem "Multiprime DNA labelling system" von Amersham. Bei diesem System (Feinberg und Vogelstein, 1983) wird doppelsträngige DNA bei $95^{\circ} \mathrm{C} \mathrm{zu}$ Einzelstrang-DNA denaturiert. $\mathrm{Zu}$ der ssDNA werden Klenow-Enzym, Zufallssequenz-Hexamerprimer, dNTPs und ${ }^{32}$ P-markiertes dCTP gegeben. Die Primer lagern sich auf der ssDNA-Matrize an, so daß das Klenow-Enzym mit der Polymerisation eines komplementären Stranges beginnen kann. Bei der Polymerisation werden auch ${ }^{32} \mathrm{P}-\mathrm{dCTP}$ in den Strang eingebaut, so daß man eine markierte DNA-Sonde erhält.

Es wurden $50 \mathrm{ng}$ DNA in linearer Form eingesetzt. Mit $\mathrm{H}_{2} \mathrm{O}$ wurde das Volumen auf $11,5 \mu \mathrm{l}$ aufgefüllt. Die DNA wurde für $5 \mathrm{Min}$. im $95^{\circ} \mathrm{C}$-Heizblock denaturiert und sofort 1 Min. auf Eis gestellt. Nach Zugabe von $5 \mu$ Puffer, 2,5 $\mu$ l Primern, 5 $\mu 1$ 32P-dCTP (50mCi) und $1 \mu 1$ Klenow-Polymerase ( $1 \mathrm{U} / \mu \mathrm{l})$ wurde die Reaktion für $30 \mathrm{Min}$. bei $37^{\circ} \mathrm{C}$ inkubiert.

Um die Reaktion zu stoppen, wurde die Probe auf $50 \mathrm{ml}$ mit STE aufgefüllt. Damit nicht eingebaute Nukleotide entfernt wurden, wurde die Reaktionsmischung über eine G-50-Mikrosäule (Sephadex G-50 Probe Quant; Pharmacia) gegeben. Die Säule wurde dazu zunächst kurz auf dem Vortexer geschüttelt und anschließend die Ausflußöffnung geöffnet. Die Säule wurde in ein Eppendorfgefäß gestellt und bei 735 xg eine Min. zentrifugiert. Die Säule wurde dann in ein neues Eppendorfgefäß gestellt, die Reaktionsmischung vorsichtig auf die Säule pipettiert und für zwei Min. bei 735 xg zentrifugiert. Der 
Durchfluß enthielt die aufgereinigte Sonde, die freien Nukleotide wurden von der Säule zurückgehalten.

Um die Qualität der Sonde zu prüfen, wurden $1 \mu \mathrm{l}$ von $50 \mu$ Säulendurchfluß für eine Szintillationszählung eingesetzt. Das Gesamtvolumen der Sonde sollte ein Signal von 15 - 25 Millionen counts liefern.

Die Sonde wurde für $10 \mathrm{Min}$. bei $95^{\circ} \mathrm{C}$ denaturiert und sofort danach in die Hybridisierungslösung gegeben.

\section{HYBRIDISIERUNG DER MEMBRANEN}

Die Prähybridisierung, Hybridisierung und das Waschen der Membran erfolgte in Hybridisierungsflaschen, die im $65^{\circ} \mathrm{C}$-Schrank kontinuierlich gedreht wurden.

Die Membranen wurden zunächst für mindestens 1 Stunde (meist ca. 2 h) mit $20 \mathrm{ml}$ Hybridisierungspuffer prähybridisiert. Nach der Prähybridisierung wurde die vorbereitete, radioaktiv markierte DNA-Sonde für 10 Min. im Heizblock bei $95^{\circ} \mathrm{C}$ denaturiert und sofort in $20 \mathrm{ml}$ Hybridisierungslösung (auf $65^{\circ} \mathrm{C}$ vorgewärmt) gegeben. Die Konzentration der Sonde sollte ungefähr $10^{6}$ counts/ $\mathrm{ml}$ betragen. Nach Verwerfen der Prähybridisierungslösung wurde die radioaktive Hybridisierungslösung in die Hybridisierungsflasche gefüllt. Die Hybridisierung wird im $65{ }^{\circ} \mathrm{C}$-Schrank über Nacht durchgeführt. Die Membranen wurden mehrmals je $30 \mathrm{Min}$. bei $65^{\circ} \mathrm{C}$ gewaschen.

Die Exposition erfolgte mit einem Biomax-Film bei $-70{ }^{\circ} \mathrm{C}$. Die Expositionsdauer betrugt meistens ein bis drei Tage. Die Entwicklung des Films wurde mit einer Entwicklermaschine durchgeführt.

\section{GENOTYPIEREN DER IRX1-MAUSMUTANTEN MITTELS SOUTHERN-BLOT ANALYSE}

Das Genotypisieren der Irx1-Mausmutanten erfolgte bis $\mathrm{zu}$ einem embryonalen Alter von E8,5 mittels Southern-Blot-Analyse. Da die homozygoten Embryonen so wenig Gewebe aufwiesen, wurde mit ihnen stets eine Genotypisierung mittels PCR durchgeführt. Dazu wurde die genomische DNA (aus Schwanz-Biopsie oder Embryonalehülle gewonnen) enzymatisch verdaut. Für die Analyse mit der externen Sonde (ga0,5) wurde die genomische 
DNA mit KpnI verdaut und aufgetrennt. Die Hybridisierung erfolgte dann mit der radioaktiv markierten ga0,5-Sonde. Zwei Modifikationen haben sich dabei als sinnvol herausgestellt. Zum einen wurde die markierte Sonde mit FischSperma-DNA gegenhybridisiert ( $5 \mathrm{Min}$. bei $95^{\circ} \mathrm{C}$ ) und zum anderen hat sich der Hybridisierungspuffer der Fa. Stratagene (Quickhyb-Solution) sehr als effizient erwiesen. Beides zusammen reduziert die Hintergrundreaktionen. Die so hybridisierten Blots wurden gewaschen und danach wie oben beschrieben exponiert.

$\begin{array}{lll}\text { Waschschritte: } & & \\ \text { Zeit: } & \text { Lösungen: } & \text { Temperatur: } \\ 2 \times 15 \text { Min. } & 2 \times \text { SSC } / 0,1 \% \text { SDS } & \text { RT } \\ 1 \times 30 \text { Min. } & 0,1 \times \text { SSC } / 0,1 \% S D S & 65^{\circ} \mathrm{C}\end{array}$

\section{IV.3.16 DURCHMUSTERN EINER CDNA- ODER GENOMISCHEN MAUS- DNA-BIBLIOTHEK NACH REKOMBINANTEN BAKTERIOPHAGEN UND DEREN ISOLIERUNG}

Das nachfolgend aufgeführte Durchmustern einer DNA-Bank, wurde nach der Beschreibung von Ausubel durchgeführt (Ausubel et al., 1995).

\section{VORBEHANDLUNG DER WIRTSBAKTERIEN}

Von dem Bakterienstamm LE392 wurde eine 100 ml-ü.N. Kultur in LBMedium mit 0,2 \% Maltose und $10 \mathrm{mM} \mathrm{MgSO} 4$ angesetzt. Am nächsten Tag wurden die Bakterien mit $4.000 \mathrm{rpm}$ bei $4{ }^{\circ} \mathrm{C}$ für $10 \mathrm{~min}$ abzentrifugiert. Das Pellet wurde in der Hälfte des ursprünglichen Volumens in $10 \mathrm{mM} \mathrm{MgSO}_{4}$ aufgenommen. Diese Bakterien waren nun für eine Infektion mit LambdaPhagen kompetent. Die Bakterien wurden bei $4{ }^{\circ} \mathrm{C}$ aufbewahrt und blieben etwa eine Woche verwendbar.

\section{Titerbestimmung eineR PHAgenbibliotheK}

Die Ausplattierung einer genügend hohen Anzahl von Phagen aus einer Bibliothek war Voraussetzung für die erfolgreiche Identifizierung eines bestimmten Klons. Daher mußte der aktuelle Titer der verwendeten Bibliothek 
bekannt sein. Hierzu wurde jeweils eine Verdünnungsreihe in SM-Puffer angesetzt, um den Titer der Bibliothek durch Auszählen von Phagenplaques bestimmen zu können. Diese Reihe umfaßte fünf Verdünnungen von $1: 10^{2}$ bis 1 : 106. Aus der Anzahl der Plaques und unter Berücksichtigung der Verdünnungsfaktoren ließ sich die Zahl der infizierenden Phagen pro Volumeneinheit der Bibliothek errechnen.

\section{AusplatTIEREN DER PHAGENBIBLIOTHEK}

Die Phagen wurden mit einer Dichte ausplattiert, die gerade noch Einzelphagen erkennen ließ. Die gewünschte Phagenzahl wurde mit der entsprechenden Menge Bakterien 30 Min. bei $37^{\circ} \mathrm{C}$ inkubiert. Danach wurden die infizierten Bakterien mit ca. $46{ }^{\circ} \mathrm{C}$ warmem Topagar gemischt und auf $37{ }^{\circ} \mathrm{C}$ vorgewärmte Agarplatten plattiert. Nach Erstarren der Topagar wurden die Platten umgekehrt für ca. $5-9 \mathrm{~h}$ bei $37{ }^{\circ} \mathrm{C}$ inkubiert, bis die Plaques einen Durchmesser von ca. 1,0 mm erreicht hatten. Anschließend wurden die Platten bis zum Herstellen der Filter bei $4{ }^{\circ} \mathrm{C}$ aufbewahrt.

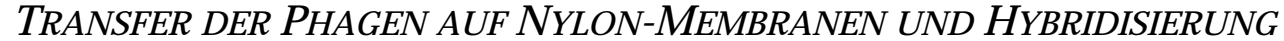

Trockene ungeladene Nylonmembranen wurden in passender Größe beschriftet und mit der unbeschrifteten Seite auf den Phagenrasen gelegt und die Markierungen auf den äußeren Plattenboden übertragen. Nach ca. 1 Min. wurde der Filter abgezogen. Von der Platte konnten mehrere Filter nacheinander gezogen werden. Die Filter wurden mit der DNA-Seite nach oben in getränktes Whatman mit folgenden Lösungen gelegt:

\section{DENATURIEREN:}

$5 \mathrm{Min} .1,5 \mathrm{M} \mathrm{NaCl}, 0,4 \mathrm{M} \mathrm{NaOH}$

2. NEUTRALISIEREN

$5 \mathrm{Min} .1 \mathrm{M}$ Tris $/ \mathrm{HCl}(\mathrm{pH} 8), 1,5 \mathrm{M} \mathrm{NaCl}$

\section{3. ÄQUILIBRIEREN}

5 Min. 2x SSC

\section{LUFTTROCKNEN}

Zuletzt wurde die Phagen-DNA durch UV-Bestrahlung $\left(300 \mathrm{~m} \mathrm{~J} / \mathrm{cm}^{2}, 302\right.$ nm) an die Nylonmembran kovalent gebunden. Mittels der Hybridisierung mit 
der radioaktiv markierten Sonde konnten die positiven, also die hybridisierenden Phagenklone, ermittelt werden.

\section{ISOLIERUNG REKOMBINANTER PHAGENKLONE}

Die Markierungen der hybridisierten Filter wurden auf die entwickelten Röntgenfilme entsprechend ihrer Lage übertragen, um die Signale den PhagenPlaques auf den Agarplatten zuordnen zu können. Die ausgewählten PhagenPlaques wurden mit sterilen Pipettenspitzen ausgestochen und in SM-Puffer transferiert. Die Phagen wurden ü.N. bei $4{ }^{\circ} \mathrm{C}$ oder $3-4$ h. bei Raumtemperatur eluiert. In den folgenden Selektionsrunden („Rescreenings”) wurden die im ersten Durchgang erhaltenen Phagen in verschiedenen Verdünnungen ausplattiert, die Phagen-DNA wurde, wie oben beschrieben, auf Nylonmembranen transferiert, diese dann mit der radioaktiven Sonde hybridisiert und die entsprechenden positiven Phagenplaques ausgestochen. Dieses Nachmustern wurde solange wiederholt, bis eindeutige Einzelphagen isoliert werden konnten.

\section{ANLEGEN EINEN PHAGENSTOCKS}

Mit dieser Methode wurde eine hochkonzentrierte Lösung ("high titer stock") der isolierten Phagen hergestellt, die als Grundstock für präparative Plattenlysate diente. Die Phagen wurden in einer Dichte ausplattiert, die eine konfluente Lyse ergab. Die Lysate wurden mit $10 \mathrm{ml}$ SM (bei $15 \mathrm{~cm}$ Plattendurchmesser) überschichtet, und langsam bei $4{ }^{\circ} \mathrm{C}$ üN geschüttelt. Bakterien oder Agarosestücke wurden durch 10 min Zentrifugieren mit 3.000 rpm abgetrennt. Zur Abtötung der Bakterien wurde der Überstand mit einigen Tropfen Chloroform versetzt und bei $4{ }^{\circ} \mathrm{C}$ aufbewahrt. Die Phagen sind in dieser Lösung mehrere Monate bis Jahre haltbar, wenn auch mit fallendem Titer.

\section{DNA-ISOlierung Aus LAMDA-PHAgEN (PLATTENLYSAT-METHODE)}

Der entsprechende Phagenklon wurde auf einer $150 \mathrm{~mm}$ Petrischale konfluent ausplattiert. Anschließend wurden die Phagen mit $10 \mathrm{ml}$ SM und einigen Tropfen Chloroform ü.N. bei $4{ }^{\circ} \mathrm{C}$ von der Platte gewaschen. Der 
Überstand wurde unter Zugabe von DNase und RNase (Endkonzentrationen jeweils $10 \mu \mathrm{g} / \mathrm{ml}$ ) $30 \mathrm{~min}$ bei $37^{\circ} \mathrm{C}$ in $50 \mathrm{ml}$ Röhrchen (Falcon) verdaut, zentrifugiert (3.500 rpm, 30 min, Minifuge T), und der Überstand mit gleichem Volumen $20 \%$ Polyethylenglykol-6.000/2 M NaCl für $2 \mathrm{~h}\left(4^{\circ} \mathrm{C}\right)$ präzipitiert. Die Phagen wurden pelletiert (3.500 rpm, $30 \mathrm{~min}$ ), getrocknet, in $500 \mu \mathrm{l} \mathrm{SM}$ gelöst und in ein Reaktionsgefäß überführt. Mit weiteren $200 \mu \mathrm{l} \mathrm{SM}$ wurden die Falcon-Röhrchen einmal nachgewaschen. Nach einer Chloroformextraktion erfolgte ein weiterer RNase-Verdau (Endkonzentration $20 \mu \mathrm{g} / \mathrm{ml} ; 15 \mathrm{~min}$ bei $37^{\circ} \mathrm{C}$ ) und ein Proteinase-K-Verdau (Endkonzentration von $10 \mu \mathrm{g} / \mathrm{ml}$; nach Zugabe von $5 \mu \mathrm{l} 10 \%$ SDS und $5 \mu \mathrm{l}$ 0,5 M EDTA-Lösung; $15 \mathrm{~min}$ bei $37^{\circ} \mathrm{C}$ ). Abschließend wurde eine Phenol- und Chloroform-Isoamylalkohol-Extraktion (nicht vortexen) der Phagen-DNA durchgeführt, diese mit dem gleichen Volumen Isopropylalkohol oder Ethanol gefällt und $30 \mathrm{~min}$ bei $13.000 \mathrm{rpm}$ zentrifugiert. Die Phagen DNA wurde mit 70 \% Ethanol gewaschen, in $100 \mu \mathrm{TE}$ gelöst und bei $4{ }^{\circ} \mathrm{C}$ aufbewahrt.

SM-PUFFER:

$\mathrm{NaCl} 100 \mathrm{mM}$

$\mathrm{MgSO}_{4} 10 \mathrm{mM}$

Tris/HCl, pH 7,5 $50 \mathrm{mM}$

Gelatine $0,01 \%$

\section{IV.3.17 PRÄPARATION GENOMISCHER MAUS-DNA}

Das Gewebe (ca. $1 \mathrm{~cm}$ Schwanz oder embryonales Gewebe) wurde in $500 \mu \mathrm{l}$ Proteinase K-Puffer, der $10 \mu \mathrm{l}$ Proteinase K $(10 \mathrm{mg} / \mathrm{ml})$ enthielt, gegeben und über Nacht bei $55{ }^{\circ} \mathrm{C}$ inkubiert. Die unverdauten Haare und Knochen wurden am nächsten Tag abzentifugiert (5 Min., 13.000 rpm, Heraeus Biofuge A), die genomische DNA im Überstand mit $500 \mu 1$ Isopropanol gefällt und zentrifugiert (5 min, 13.000 rpm, Heraeus Biofuge A). Das DNA Pellet wurde einmal mit 70 \% Ethanol gewaschen und in $100 \mu \mathrm{TE}$ gelöst (bei $37^{\circ} \mathrm{C}$ unter leichtem Schütteln). Für eine PCR-Analyse genügt bereits die embryonale Membran eines E8.0 alten Embryos. Für jüngere Embryonen muß der gesamte Embryo benutzt werden. Dies kann auch nach einer in-situ-Hybridisierungsanalyse erfolgen. 
Tris/HCl, pH $8.5100 \mathrm{mM}$

EDTA $5 \mathrm{mM}$

SDS $0,2 \%$

\section{IV.3.18 ARBEITEN MIT RNA}

Die nachfolgend aufgeführte RNA-Analyse, wurde nach der Beschreibung von Ausubel durchgeführt (Ausubel et al., 1995).

\section{VORBEREITUNGEN FÜR DAS ARBEITEN MIT RNA}

Voraussetzung für das erfolgreiche Arbeiten mit RNA ist die Minimierung der RNAse-Aktivität sowie die Vermeidung von RNAse-Kontaminationen. Zu diesem Zweck wurden bei der Gewebepräparation sowie bei allen anderen Arbeiten mit RNA stets Handschuhe getragen. Das frisch präparierte Gewebe wurde bei $-70^{\circ} \mathrm{C}$ aufbewahrt. Die Arbeitsfläche wurde vor Beginn gründlich mit Ethanol gereinigt. Sämtliche Glasgeräte wurden für $2 \mathrm{~h}$ bei $220^{\circ} \mathrm{C}$ gebacken und das Wasser für alle Lösungen mit 0,1 \% Diethylpyrocarbonat (DEPC) behandelt. Alle Lösungen wurden zusätzlich autoklaviert. Der Versuchsansatz wurde während der RNA-Präparation, wenn möglich, auf Eis gehalten. Verwendete Gelkammern, Schlitten und Kämme wurden vorher gründlich mit Seife bzw. 0,1 $\%$ SDS gereinigt, in 0,25 M NaOH eingeweicht, dann mit DEPC-Wasser und nochmal mit 100 \%igem EtOH gespült.

\section{ISOLIERUNG VON GESAMT-RNA AUS EMBRYONALGEWEBE MIT TRIZOL (LIFE} TECHNOLOGIES)

Bei dem TRIzol-Protokoll wurde das Gewebe in einer monophasischen Mischung aus saurem Guanidiniumthiocyanat, saurem Phenol und Chloroform homogenisiert (Chomczynski und Sacchi, 1987; Chomczynski, 1993). Guanidiniumthiocyanat ist ein sehr effektives Mittel zur Proteindenaturierung (Nozaki und Tanford, 1970); Extraktion mit saurem Phenol und Chloroform ermöglicht nach Zentrifugation die effektive Trennung von RNA in der wässrigen Phase von DNA und Protein in der Phenol/Chloroformphase.

Dazu wurden Embryonen verschiedenen Alters, Mausgehirne bzw. Lungen von 1 Tag und älteren Mäusen in PBS (mit DEPC) präpariert und sofort in 
flüssigem Stickstoff eingefroren. Das Gewebe wurde bei $-70{ }^{\circ} \mathrm{C}$ gelagert. Zur RNA-Präparation wurde eingefrorenes Gewebe direkt aus dem $-70{ }^{\circ} \mathrm{C}-\mathrm{Sch}$ rank in ein steriles Greinerröhrchen mit Trizol gegeben. Es wurde $1 \mathrm{ml}$ Trizol pro 50 $100 \mathrm{mg}$ Gewebe eingesetzt. Das Gewebe wurde solange homogenisiert, bis keine Gewebeteilchen mehr sichtbar sind. Die homogenisierte Probe wurde für $5 \mathrm{Min}$. bei Raumtemperatur inkubiert, um die vollständige Dissoziation von Nucleoproteinkomplexen zu ermöglichen. Nach Zugabe von 0,2 ml Chloroform pro $1 \mathrm{ml}$ Trizol wurde das Röhrchen für 15 Sek. intensiv geschüttelt. Es schloß sich eine Inkubation bei Raumtemperatur für 2 - 3 Minuten an. Die Probe wurde zur Phasentrennung mit $12.000 \mathrm{~g}$ bei $4{ }^{\circ} \mathrm{C}$ für $15 \mathrm{Min}$. zentrifugiert. Die farblose obere Phase enthielt die RNA und wurde in ein neues Greinerröhrchen überführt. Die rote untere Phase enthielt DNA und Proteine und wurde verworfen. Zur RNA-Fällung wurden $0,5 \mathrm{ml}$ Isopropanol pro eingesetztem $1 \mathrm{ml}$ Trizol zugegeben. Die Probe wurde für 10 Min. bei Raumtemperatur inkubiert und anschließend mit $12.000 \mathrm{~g}$ bei $4{ }^{\circ} \mathrm{C}$ für $10 \mathrm{Min}$. zentrifugiert. Die ausgefällte RNA bildete ein Pellet am Boden des Röhrchens. Der Überstand wurde entfernt und das Pellet mit mindestens $1 \mathrm{ml} 75 \%$ Ethanol pro $1 \mathrm{ml}$ eingesetztem Trizol gewaschen. Die Probe wurde mit einem Vortexer gemischt und mit 7.500g bei 4 ${ }^{\circ} \mathrm{C}$ für 5 Min. zentrifugiert. Der Überstand wurde abgenommen und das Pellet getrocknet. Das Pellet wird in RNase-freiem DEPC- $\mathrm{H}_{2} \mathrm{O}$ aufgenommen. Damit sich die RNA besser löste, konnte sie für $10 \mathrm{Min}$. bei $50^{\circ} \mathrm{C}$ inkubiert werden. Die RNA wurde bei $-70{ }^{\circ} \mathrm{C}$ gelagert.

ISOLIERUNG VON POLYA+-RNA AUS GESAMT-RNA MIT DEM OLIGOTEX MRNA-KIT (MINI-PRÄPARATION)

Der Oligotex-Kit von Qiagen beruht auf der Bindung von mRNA mit polyadenylierten 3'-Enden an Oligo-dT-Primer, die an eine Festphasenmatrix gekoppelt sind. Die Bindung erfolgt in einem Hochsalzpuffer, die Elution bei Niedrigsalzbedingungen (Qiagen, 2000).

Dazu wurde die Oligotex-Suspension auf $37^{\circ} \mathrm{C}$, der Elutionspuffer auf $70{ }^{\circ} \mathrm{C}$ erwärmt. Da die Gesamt-RNA weniger als $250 \mu \mathrm{g}$ betrug, wurde die MiniPräparation durchgeführt. Die RNA wurde in $250 \mu \mathrm{LEPC}-\mathrm{H}_{2} \mathrm{O}$ gelöst. Dazu 
wurden $250 \mu \mathrm{l} 2 \mathrm{x}$ Bindepuffer und $15 \mu$ l Oligotex-Suspension gegeben und das ganze 3 Min. bei $65^{\circ} \mathrm{C}$ inkubiert, um RNA-Sekundärstrukturen aufzulösen. Zur Hybridisierung der RNA an die Oligo-dT-Primer wurde 10 Min. bei RT inkubiert. Danach wurde 2 Min. mit $13.000 \mathrm{rpm}$ bei RT zentrifugiert und der Überstand verworfen. Das Pellet wurde in $400 \mu 1$ OW2 Waschpuffer resuspendiert und die Suspension auf Spin-Säule gegeben. Diese wurde 30 Sek. mit $13.000 \mathrm{rpm}$ bei RT zentrifugiert. Danach wurde ein zweites Mal mit $400 \mu \mathrm{l}$ OW2 Waschpuffer gewaschen. Nach erneuter Zentrifugation (30 Sek., 13.000 rpm, RT) wurde die Spin-Säule in RNase-freies Eppendorfgefäß gestellt und mit 30 - $50 \mu \mathrm{l}$ vorgeheiztem $\left(70{ }^{\circ} \mathrm{C}\right)$ Elutionspuffer durch eine 30 sekündige Zentrifugation mit $13.000 \mathrm{rpm}$ bei RT eluiert. Zur besseren Ausbeute kann der Elutionsschritt nochmals wiederholt werden. Die Lagerung der polyA+-RNA erfolgte bei $-70^{\circ} \mathrm{C}$.

\section{IV.3.19 NORTHERN BLOT}

Mit einem Northern Blot (Thomas, 1980; Sambroock et al., 1989) lassen sich spezifische Sequenzen in einem Gemisch von RNA-Molekülen, welche mittels denaturierender Agarosegelelektrophorese aufgetrennt werden, nachweisen.

Bei einem Northern Blot wird die RNA in einem denaturierenden Formaldehyd-Agarosegel aufgetrennt und danach mittels Kapillarkräften auf eine Nylonmembran übertragen und dort fixiert. Die Membran kann dann für eine Hybridisierung mit einer spezifischen Sonde benutzt werden.

\section{NORTHERN BLOT: ELEKTROPHORESE}

Um ein RNA-Gel mit einem Volumen von $100 \mathrm{ml}$ zu gießen, wurden $88 \mathrm{ml}$ DEPC- $\mathrm{H}_{2} \mathrm{O}$ mit $1 \mathrm{~g}$ Agarose aufgekocht und die Flüssigkeit auf $55^{\circ} \mathrm{C}$ abgekühlt. Erst dann wurden $10 \mathrm{ml}$ 10x MOPS-Puffer und 1,8 $\mathrm{ml}$ Formaldehyd zugegeben und das Gel gegossen. Die Elektrophorese wurde 1x MOPS-Puffer als Laufpuffer zugegeben. Für die Probendenaturierung wurden 4,5 $\mu 1$ RNALösung (ca. $20 \mu \mathrm{g}$ Gesamt-RNA oder 1-3 $\mu \mathrm{g}$ polyA+-RNA) mit 2,0 $\mu \mathrm{l}$ 10x MOPSPuffer, 3,5 $\mu$ l Formaldehyd und 10,0 $\mu$ l deionisiertem Formamid versetzt. Die Mischung wurde für $15 \mathrm{Min}$. bei $55^{\circ} \mathrm{C}$ inkubiert und danach auf Eis abgekühlt. 
Nach Zugabe von $2 \mu \mathrm{l}$ Auftragspuffer und $1 \mu \mathrm{l}$ EtBr wurden die Proben in die Geltaschen geladen. Der aufgetragene RNA-Marker wurde genauso behandelt. Der Gellauf erfolgte für ca. 3 Stunden bei 100 Volt, bis die BromphenolblauBande ungefähr 2/3 des Gels durchlaufen hatte.

Nach dem Gellauf wurde auf dem UV-Tisch mit einem fluoreszierenden Lineal neben der Markerspur fotografiert, damit sich später die Größe der Marker-Banden bestimmen läßt. Dann wurde das Gel für 20 Min. in 20x SSC inkubiert. MOPS-Puffer, verwendetes $\mathrm{H}_{2} \mathrm{O}$ und sonstige Lösungen müssen RNase-frei sein.

\section{NORTHERN BLOT: TRANSFER}

Der Aufbau und der Ablauf des Northern Blots entsprechen dem des Southern Blots. Allerdings bedarf die bereits einzelsträngig vorliegende RNA keiner Denaturierung und Neutralisierung. Nach dem Blotten wurde die RNA durch UV-Bestrahlung ( $300 \mathrm{~m} \mathrm{~J} / \mathrm{cm}^{2}, 366 \mathrm{~nm}$ ) kovalent auf der Membran fixiert. Die Membran war, trocken gelagert, bei RT mehrere Monate haltbar und konnte für Hybridisierungen eingesetzt werden.

\section{NORTHERN BLOT: HYBRIDISIERUNG}

Prähybridisierung, Hybridisierung und Waschschritte wurden in rotierenden Hybridisierungsflaschen in Wärmeschränken analog zur Hybridisierung von DNA-Blots durchgeführt:

PRÄHYBRIDISIERUNG

bei $65^{\circ} \mathrm{C}$ für 2 Stunden

HYBRIDISIERUNG

bei 63 - $65^{\circ} \mathrm{C}$ ü.N. mit radioaktiver Sonde (ca. $10^{6}$ counts $/ \mathrm{ml}$ )

NORTHERN BLOT: WASCHSCHRITTE UND EXPOSITION

Northernblots wurden auf folgende Weise gewaschen:

Waschschritt 1: frische Prähybridisierungslösung, 30 Min. bei $60^{\circ} \mathrm{C}$

Waschschritt 2 - 4: Waschpuffer 20 Min. bei $60^{\circ} \mathrm{C}$

Zwischen jedem Waschschritt wurde die Radioaktivität der Membran mit dem Geigerzähler gemessen, wobei darauf zu achten war, daß die Membran 
stets feucht blieb. War die Radioaktivität der Membran niedrig genug, wurden nicht mehr alle Waschschritte zu Ende ausgeführt.

Danch wurde die Membran noch feucht in Plastikfolie eingeschweißt oder in Frischhaltefolie eingeschlagen und mit Klebebändern in einer Expositionskassette befestigt. Es wurden immer zwei Filme aufgelegt, wobei der eine nach 3 Tagen und der zweite je nach Stärke des Signals nach 1,5 - 3 Wochen entwickelt wurde. Die Exposition wurde bei $-70{ }^{\circ} \mathrm{C}$ durchgeführt. Als Filmmaterial wurden Biomax-Filme benutzt. Die Entwicklung des Films erfolgte mit einer Entwicklermaschine.

\section{IV.3.20 RADIOAKTIVE MRNA IN-SITU-HYBRIDISIERUNG AN SCHNITTEN}

Das nachfolgend aufgeführte radioaktive in-situ-Hybridisierung wurde nach der Beschreibungen von McDougall, Manning, Wilkinson und Hogan durchgeführt (McDougall et al., 1972; Manning et al., 1975; Wilkinson, 1992; Hogan et al., 1994).

\section{ALLGEMEINES ZUR RADIOAKTIVEN IN-SITU-HYBRIDISIERUNG}

Die in-situ-Hybridisierung ist eine Methode, die zur Analyse von Expressionsmustern von Genen genutzt wird. Bei der radioaktiven mRNA-insitu-Hybridisierung wird eine radioaktiv markierte RNA-Sonde hergestellt, die zur im Gewebe vorhandenen mRNA komplementär ist, dadurch an diese hybridisiert und sie so erkennbar macht. Ein Überziehen der Schnitte mit einer Filmemulsion und anschließendes Exponieren und Entwickeln läßt das radioaktive Signal als eine weiß erscheinende Färbung im Dunkelfeldmikroskop sichtbar werden. Zusätzlich werden die Schnitte einer histologischen Färbung unterzogen, welche im Hellfeldmikroskop betrachtet werden kann.

Diese Methode ermöglicht organ-, gewebe- und unter Umständen auch zellspezifische Analyse des Expressionsmusters eines Gens. Zudem können im Gegensatz zum Whole-mount-in-situ-Hybridisierungsverfahren auch ältere Embryonen und adultes Gewebe leicht bearbeitet werden, da die Hybridisierung auf Gewebeschnitten stattfindet und somit das Problem der Penetration der Sonde ins Gewebe nicht entsteht. 
Die entsprechenden Fragmente befanden sich in einem pBluescriptKS+ Plasmid, das jeweils flankierend zum Polylinker hochspezifische Bakteriophagen-Promotoren besitzt (T3- und T7-Promotoren). Anschließend wurden mindestens $1 \quad \mu \mathrm{g}$ Plasmid-DNA mit einem geeigneten Restriktionsenzym geschnitten. Es ist für die spätere in-vitro-Transkription von Vorteil, wenn der Restriktionsverdau eine stumpfe Schnittstelle ergibt. Die Vollständigkeit der Enzymreaktion wurde auf einem Minigel kontrolliert. Nach einer Phenol- und Chloroformextraktion wurde eine Ethanolfällung durchgeführt. Die DNA wurde anschließend in $10 \mu \mathrm{l}$ DEPC-behandeltem Wasser aufgenommen.

\section{IN-VITRO-TRANSKRIPTION DER RNA-SONDEN}

Es wurde der Transkriptionskit von Boehringer (Ingelheim) verwendet. Folgender Transkriptionsansatz wurde bei RT pipettiert und danach $60 \mathrm{Min}$. bei $37^{\circ} \mathrm{C}$ inkubiert:

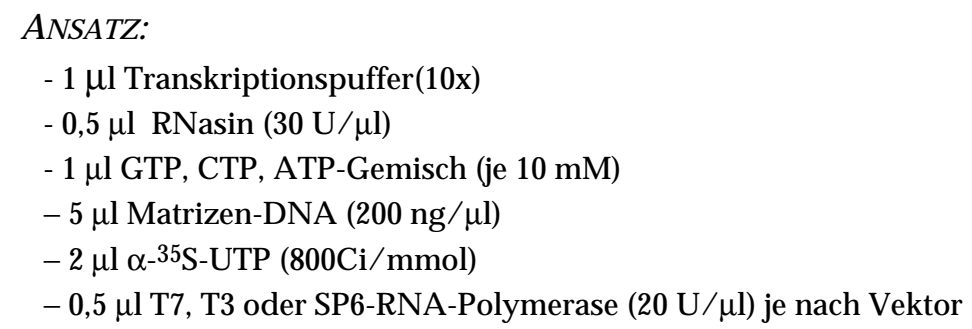

Zur späteren Auswertung des Signals wurde eine Sinnstrang- und eine Gegenstrang-Sonde präpariert. Die Gegenstrang-Sonde hybridisierte als Komplement an die zelluläre mRNA und bildete so stabile Hybride, die die Position der zellulären mRNA anzeigten. Die Sinn-Sonde war dagegen nicht in der Lage, mit dem zellulären Transkript zu hybridisieren, da sie der zellulären mRNA entsprach, und diente so als Kontrolle für eventuelle Hintergrundreaktionen. 


\section{AUFREINIGUNG DER RNA-SONDEN}

Nach der in-vitro-Transkription wurde die DNA-Matrize mit DNase verdaut, indem zum Transkriptionsansatz $3 \mu \mathrm{l}$ DNase I (RNase frei, $20 \mathrm{U} / \mathrm{ml}$ ) pipettiert wurden und der Ansatz 10 Min. bei $37^{\circ} \mathrm{C}$ inkubiert wurde. Anschließend wurde der Reaktionsansatz mit $40 \mu 1$ RNase-freiem STE-Puffer auf ein Volumen von 50 $\mathrm{ml}$ aufgefüllt und anschließend wie bei der Aufreinigung der DNA-Sonden auf eine vorbereitete G-50-Mikrosäule (Sephadex Probe-Quant; Pharmacia) gegeben und 2 Min. mit $735 \mathrm{~g}$ bei RT zentrifugiert. Die bei der Transkription nicht eingebauten Nukleotide wurden dadurch entfernt. Zur RNA-Sonde, die sich im Eluat befand, wurden $50 \mu 1$ deionisiertes Formamid gegeben und $1 \mu \mathrm{l}$ der Sonde mit einer Szintillationslösung im Szintillationszähler gemessen.

\section{PRÄPARIEREN DER EMBRYONEN UND GEHIRNE FÜR DIE RNA-IN-SITU-ANALYSE}

Die Embryonen wurden in 1x PBS frisch aus den Uteri präpariert, ab Stadium E15,5 die Gehirne aus den Embryonen isoliert, und ü.N. in 4 \% PFA in 1x PBS bei $4{ }^{\circ} \mathrm{C}$ fixiert. Am nächsten Tag wurden die Embryonen oder Gehirne mehrmals in 1x PBS gewaschen und danach folgendermaßen behandelt:

\section{Ablauf:}

\begin{tabular}{|c|c|c|}
\hline a. $1 \times$ PBS & $24 \mathrm{~h}$ & $\begin{array}{l}\text { h. } 75 \% \text { Isopropanol, } 25 \% \\
\text { Toluol }\end{array}$ \\
\hline b. $0,86 \% \mathrm{NaCl}$ (Saline) & $24 \mathrm{~h}$ & $\begin{array}{l}\text { i. } 50 \% \text { Isopropanol, } 50 \% \\
\text { Toluol }\end{array}$ \\
\hline c. $70 \%$ Ethanol & $24 \mathrm{~h}$ & $\begin{array}{l}\text { j. } 25 \% \text { Isopropanol, } 75 \% \\
\text { Toluol }\end{array}$ \\
\hline d. $80 \%$ Ethanol & $24 \mathrm{~h}$ & k. $100 \%$ Toluol \\
\hline e. $90 \%$ Ethanol & $24 \mathrm{~h}$ & 1. Paraplast-Plus, $60^{\circ} \mathrm{C}$ \\
\hline f. $100 \%$ Ethanol & $24 \mathrm{~h}$ & m. Paraplast-Plus, $60^{\circ} \mathrm{C}$ \\
\hline g. 100 \%Isopropanol & $24 \mathrm{~h}$ & n. Paraplast-Plus, $60^{\circ} \mathrm{C}$ \\
\hline
\end{tabular}

Nach der Dehydrierung wurden die Embryonen in der gewünschten Orientierung mit Hilfe einer Einbettmaschine in Paraffin eingebettet und bis zur Herstellung der Schnitte bei RT gelagert. 
$4 \%$ PFA IN 1X PBS:

$40 \mathrm{~g}$ Paraformaldehyd (PFA)

ad $1.000 \mathrm{ml}$ mit $1 \times$ PBS

bei $60^{\circ} \mathrm{C}$ gelöst

\section{HERSTELLUNGVON PARAFFINSCHNITTEN}

Dazu wurde der in Paraffin eingebettete Embryo in ein Mikrotom der Firma Leica eingespannt und geschnitten. Die 5 - $15 \mu \mathrm{m}$ dicken Schnitte wurden anschließend auf der Wasseroberfläche eines $45^{\circ} \mathrm{C}$-Wasserbades entspannt und von dort auf einen Superfrost-Objektträger der Firma Menzel Gläser (Braunschweig) aufgenommen. Diese geringe Schnittstärke ist von Vorteil, da sie eine zelluläre Analyse erlaubt. Die Schnitte wurden für $1 \mathrm{~h}$ auf eine $37^{\circ} \mathrm{C}$ Wärmeplatte gelegt, ü.N. bei $37^{\circ} \mathrm{C}$ getrocknet, am darauffolgenden Tag bei RT bis zur Verwendung gelagert.

\section{PRÄHYBRIDISIERUNG}

Die Prähybridisierung dient dem Entparaffinieren der Schnitte, außerdem zum Vorbereiten der Hybridisierung. Dazu wurden die Objektträger folgendermaßen behandelt:

Ablauf:
a. $100 \%$ Xylolersatz
b. $100 \%$ Xylolersatz
c. $100 \%$ Ethanol
d. $95 \%$ Ethanol
e. $90 \%$ Ethanol
f. $80 \%$ Ethanol
g. $70 \%$ Ethanol
h. $50 \%$ Ethanol
i. $30 \%$ Ethanol
j. $0,86 \%$ NaCl (Saline)
k. $1 \times$ PBS
1. $4 \%$ PFA
m. $1 \times$ PBS
n. $1 \times$ PBS

10 Min.
10 Min.
2 Min.
2 Min.
2 Min.
2 Min.
2 Min.
2 Min.
2 Min.
5 Min.
5 Min.
20 Min.
5 Min.
5 Min.

o. $10 \mathrm{mg} / \mathrm{ml}$ Proteinase-K

7 Min.

p. $1 \times$ PBS

5 Min.

20 Min.

5 Min.

r. 1x PBS

10 Min.

s. Acetyl.-Mix.

5 Min.

t. 1x PBS

5 Min.

u. $0,86 \% \mathrm{NaCl}$ (Saline)

2 Min.

v. $30 \%$ Ethanol

2 Min.

w. $50 \%$ Ethanol

2 Min.

x. $70 \%$ Ethanol

2 Min.

y. $80 \%$ Ethanol

2 Min.

z. $90 \%$ Ethanol

2 Min.

aa. 95 \% Ethanol

2 Min. 
Anschließend wurden die Objektträger mit den Schnitten für ca. 30 Min. bei RT getrocknet.

\section{ACETLYL.MIX: \\ 0,1 M Triethanolamin \\ $0,05 \mathrm{M}$ Acetanhydrid}

\author{
PROTEINASE-K-PUFFER: \\ 20mM Tris/HCl, $\mathrm{pH} 7,5$ \\ $1 \mathrm{mM}$ EDTA, $\mathrm{pH} 8,0$
}

\section{HYBRIDISIERUNG DER SCHNITTE}

Die RNA-Sonde wurde mit in-situ-Hybridisierungspuffer auf $1 \times 10^{5} \mathrm{cpm} / \mu \mathrm{l}$ verdünnt. Vor dem Auftragen wurde der Hybridisierungsmix 2 Min. bei $80{ }^{\circ} \mathrm{C}$ denaturiert. Für jeden Schnitt wurden ca. $10 \mu \mathrm{l}$ Hybridisierungsmix benötigt. Der Tropfen mit der Hybridisierungslösung wurde mit einem silikonisierten Deckgläschen möglichst luftblasenfrei abgedeckt. Die Hybrisierung erfolgte ü.N. bei $50{ }^{\circ} \mathrm{C}$ in einer dicht abschließbaren Plastikschüssel, die durch $50 \%$ Formamid/2x SSC feucht gehalten wurde und eine gesättigte Atmosphäre schaffte.

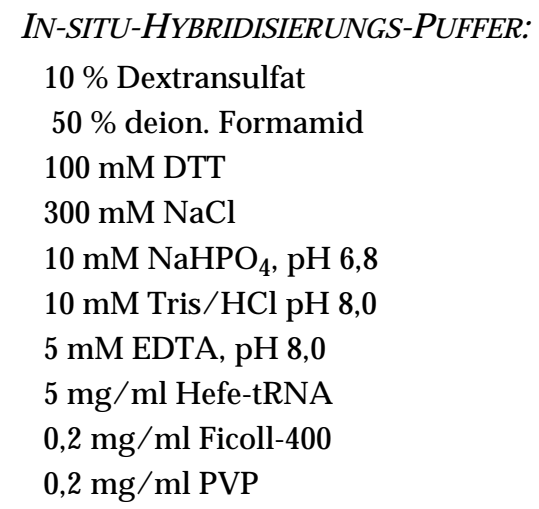

\section{WASCHEN DER OBJEKTE}

Die Objektträger wurden in Träger einsortiert und 20 - 30 Min. bei $65-70{ }^{\circ} \mathrm{C}$ in Waschpuffer bewegt, je nach der erforderten Stringenz. Anschließend wurden die Schnitte 3 - $5 \mathrm{~h}$ unter leichtem Schütteln bei $37^{\circ} \mathrm{C}$ gewaschen. Zur RNase-Behandlung wurden die Objektträger jeweils 15 Min. im NTE ohne RNase, dann 15 Min. im NTE mit 20 mg/ml RNase A und nochmals 15 Min. ohne RNase jeweils bei $37^{\circ} \mathrm{C}$ behandelt. Danach wurden die Schnitte $30 \mathrm{Min}$. in Waschpuffer bei $37^{\circ} \mathrm{C}$ und jeweils $15 \mathrm{Min}$. in 2x SSC und 0,1x SSC bei RT gewaschen. Anschließend erfolgte eine Dehydrierung der Schnitte in einer aufsteigenden Alkoholreihe (30\%, $50 \%, 70 \% 80 \%, 90 \%, 95 \%$ und $100 \%$ 
Ethanol, jeweils 2 Min.). Nachdem die Schnitte gut getrocknet waren, wurden sie in einer Röntgenfilmkassette ü.N. auf Standard-Röntgenfilm (BIOMAX, Firma Kodak) exponiert, um die Stärke des Signals für die Expositionszeit abschätzen zu können.

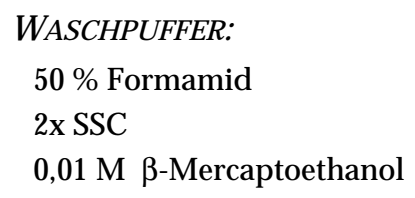

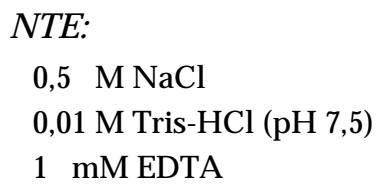

\section{EXPONIEREN, ENTWICKELN UND FÄRBEN DER IN-SITU-HYBRIDISIERUNGEN}

In einer Dunkelkammer (ohne Rotlicht) wurden die Objektträger in eine 1:1 mit Wasser verdünnte Kodak NTB-2 Emulsion getaucht, die auf $42{ }^{\circ} \mathrm{C}$ erwärmt wurde, und $2 \mathrm{~h}$ bei RT getrocknet. Die Objektträger wurden dann in eine lichtdichte Plastikbox einsortiert. Die Objektträger wurden so bei $4{ }^{\circ} \mathrm{C} 10$ Tage exponiert. Schließlich wurden die Objektträger in der Dunkelkammer (ohne Rotlicht) 3 Min. in D19 Entwickler ( 80 g/ 500 ml) der Firma Kodak entwickelt. Es folgten 1 Min. Behandlung in 1 \%iger Essigsäure, 3 Min. Fixierung in 30 \%iger Natriumthiosulfatlösung und mehrmaliges Waschen in $\mathrm{dH}_{2} \mathrm{O}(2 \times 10$ Min. bei RT, 5 Min. bei $42{ }^{\circ} \mathrm{C}, 10$ Min. bei RT und 30 Min. bei RT). Eine Färbung wurde für 20 Min. in einer gefilterten Giemsa-Lösung durchgeführt. Die gefärbten Objektträger wurden vorsichtig, aber gründlich mit Leitungswasser (nicht deionisiert) gespült. Nach dem Trocknen wurden die Schnitte mit Einschlußmittel (Eukitt) unter Deckgläschen eingedeckelt. Fotografien wurden mit einem Leitz Labovert Hellfeld-Dunkelfeld-Mikroskop und einem Kunstlichtfilm (Fa. Kodak, 320T) gemacht.

GIEMSA-STOCKLÖSUNG:
0,75 g Giemsa
$50 \mathrm{ml}$ Methanol
$50 \mathrm{ml}$ Glycerin

GIEMSA-STOCKLÖSUNG:

$50 \mathrm{ml}$ Methanol

\author{
GIEMSA FÄRBELÖSUNG: \\ $8 \mathrm{ml}$ Giemsa-Stocklösung \\ $4 \mathrm{ml} \mathrm{Na-Phosphat-Puffer} \mathrm{(0,2} \mathrm{M),(pH} \mathrm{6,0)}$ \\ $188 \mathrm{ml} \mathrm{ddH} \mathrm{H}_{2} \mathrm{O}$
}

\section{IV.3.21 MRNA-IN-SITU-HYBRIDISIERUNG AN GANZEN EMBRYONEN (,WHOLE-MOUNT"-HYBRIDISIERUNGSTECHNIK)}

Die whole-mount-in-situ-Hybridisierungstechnik erlaubt die Lokalisierung einer spezifischen mRNA in Geweben und ganzen Embryonen. Die whole- 
mount-in-situ-Hybridisierung wurde nach dem Protokoll von Wilkinson durchgeführt (Wilkinson, 1992).

\section{VORBEREITUNG DER EMBRYONEN UND GEHIRNE}

Die Embryonen wurden in 1x PBS bei RT präpariert und direkt in $4 \%$ PFA/ 1x PBS überführt. Über Nacht wurden sie dann bei $4{ }^{\circ} \mathrm{C}$ in der PFA-Lösung fixiert. Am nächsten Tag wurden die Embryonen auf folgende Weise dehydriert:

$\begin{array}{lll}1 \times \text { PBT } & 5 \text { Min. } & 4{ }^{\circ} \mathrm{C} \\ 1 \times \text { PBT } & 5 \text { Min. } & 4{ }^{\circ} \mathrm{C} \\ 25 \% \mathrm{MeOH} / \text { PBT } & 5 \mathrm{Min} . & \\ 50 \% \mathrm{MeOH} / \mathrm{PBT} & 5 \mathrm{Min} . & \\ 75 \% \mathrm{MeOH} / \mathrm{PBT} & 5 \mathrm{Min} . & \\ 100 \% \mathrm{MeOH} & 5 \mathrm{Min} . & \end{array}$

Schließlich wurden die Embryonen in frisches Methanol überführt, wo sie bei $-20{ }^{\circ} \mathrm{C}$ mehrere Tage aufbewahrt werden konnten.

HERSTELLUNG DER IN-VITRO-RNA-SONDE

Das Herstellen einer DNA-Matrize zur in-vitro-RNA-Synthese erfolgte wie oben beschrieben.

In-vitro-Transkription

Folgender Transkriptionsansatz wurde $2 \mathrm{~h}$ bei $37^{\circ} \mathrm{C}$ inkubiert:

$\begin{array}{lc}\text { TRANSKRIPTIONSANSATZ: } & \\ \text { DEPC- } \mathrm{H}_{2} \mathrm{O} & 11 \mu \mathrm{l} \\ \text { 10x Transkriptionspuffer } & 2 \mu \mathrm{l} \\ \text { DTT }(0,1 \mathrm{M}) & 2 \mu \mathrm{l} \\ \text { 10x DIG-Nukleotid-Mix } & 1 \mu \mathrm{l} \\ \text { linearisiertes Plasmid }(1 \mu \mathrm{g} / \mu \mathrm{l}) & 1 \mu \mathrm{l} \\ \text { RNasin }(30 \mathrm{U} / \mu \mathrm{l}) & 1 \mu \mathrm{l} \\ \text { RNA-Polymerase }(10-50 \mathrm{U} / \mu \mathrm{l}) & 1 \mu \mathrm{l}\end{array}$

Nach Entnahme eines $1 \mu \mathrm{l}$ Aliquots für ein Analysegel (1\% Agarose/TBE Gel) wurde der Ansatz unter Zugabe von $2 \mu \mathrm{l}$ DNase (20 U/ml, RNase-frei) 
weitere 15 min bei $37^{\circ} \mathrm{C}$ inkubiert, mit $100 \mu \mathrm{lE}$ aufgefüllt und mittels G50Säulen (Pharmacia) aufgereinigt..

\author{
10X DIG-NUKLEOTID MIX: \\ GTP, ATP , CTP, $10 \mathrm{mM}$ \\ UTP $6,5, \mathrm{mM}$ \\ DIG-UTP, 3,5 mM
}

\author{
10X TRANSKRIPTIONSPUFFER: \\ Tris/ $\mathrm{HCl}(\mathrm{pH} 7,5), 400 \mathrm{mM}$ \\ $\mathrm{MgCl}_{2}, 60 \mathrm{mM}$
}

\section{HYBRIDISIERUNG, ANTIKÖRPERINKUBATION UND FÄRBUNG}

Sämtliche Waschschritte wurden, wenn nicht anders vermerkt, bei RT für 5 Min. durchgeführt.

\section{Hybridisierung}

Zur Hybridisierung der Sonde wurden die Embryonen zunächst durch eine abfallende Methanolreihe (75 \% in PBT, 50 \% in PBT, $25 \%$ in PBT) rehydriert. Nach zweimaligem Waschen in 1x PBT wurden die Embryonen in $6 \% \mathrm{H}_{2} \mathrm{O}_{2}$ / PBT für $1 \mathrm{~h}$ bei RT gebleicht. Anschließend wurden sie dreimal in PBT gewaschen. Die Embryonen wurden je nach Alter unterschiedlich lange mit Proteinase $\mathrm{K}$ behandelt, wodurch die Zugänglichkeit der Sonde und des Antikörpers erhöht wurde. Hierfür wurden die Embryonen in $10 \mu g$ ProteinaseK/ml PBT gemäß folgenden Richtzeiten bei RT inkubiert.

$$
\begin{array}{ll}
\text { Embryoalter: } & \\
\text { Tag 6,5- 8,5 p.c. } & 2 \text { Min. } \\
\text { Tag 9,5-10,5 p.c } & 5 \text { Min. } \\
\text { Tag 9,5- 10,5 p.c } & 12 \text { Min. } \\
\text { ab Tag 12,5 p.c } & 15 \text { Min. }
\end{array}
$$

Der Proteinaseverdau wurde durch Waschen mit $2 \mathrm{mg}$ Glycin/ml PBT gestoppt. Nach zweimaligem Waschen in 1x PBT wurden die Embryonen in 0,2 $\%$ Glutaraldehyd in $4 \%$ PFA/PBT für 20 min refixiert. Anschließend wurden die Embryonen zweimal in 1x PBT gewaschen, bevor sie für $1 \mathrm{~h}$ bei $70{ }^{\circ} \mathrm{C}$ in Prähybridisierungslösung äquilibriert wurden. Die Hybridisierung erfolgte bei $70{ }^{\circ} \mathrm{C}$ ü.N. durch Zugabe der RNA-Sonde $(0,1 \mathrm{mg} / \mathrm{ml})$. 
(PRÄ-) HYBRIDISIERUNGSLÖSUNG:

SDS, $1 \%$

Formamid, $50 \%$

Heparin, $50 \mu \mathrm{g} / \mathrm{ml}$

Hefe-tRNA, $50 \mu \mathrm{g} / \mathrm{ml}$

SSC (pH 4,5), 5x

Waschschritte

Nach der Hybridisierung wurden die Embryonen wie folgt gewaschen und die nichthybridisierte RNA abgebaut.

\begin{tabular}{|c|c|c|c|c|c|}
\hline \multicolumn{3}{|l|}{ Ablauf: } & h. Lösung 2 & 5 Min. & \\
\hline a. Lösung 1 & 30 Min. & $70^{\circ} \mathrm{C}$ & i. Lösung 3 & 5 Min. & \\
\hline b. Lösung 1 & 30 Min. & $70^{\circ} \mathrm{C}$ & j. Lösung 3 & 30 Min. & $65^{\circ} \mathrm{C}$ \\
\hline c. Lösung 1/2 & 10 Min. & $70^{\circ} \mathrm{C}$ & k. Lösung3 & 30 Min. & $65^{\circ} \mathrm{C}$ \\
\hline d. Lösung 2 & 5 Min. & & 1. TBST & 5 Min. & \\
\hline e. Lösung 2 & 5 Min. & & m. TBST & $5 \mathrm{Min}$. & \\
\hline $\begin{array}{l}\text { f. Lösung 2/ } \\
\text { RNAseA }\end{array}$ & 5 Min. & $37^{\circ} \mathrm{C}$ & $\begin{array}{l}\text { n. TBST/ } \\
10 \% \text { FCS }\end{array}$ & 90 Min. & \\
\hline $\begin{array}{l}\text { g. Lösung 2/ } \\
\text { RNAseA }\end{array}$ & 5 Min. & $37^{\circ} \mathrm{C}$ & & & \\
\hline
\end{tabular}

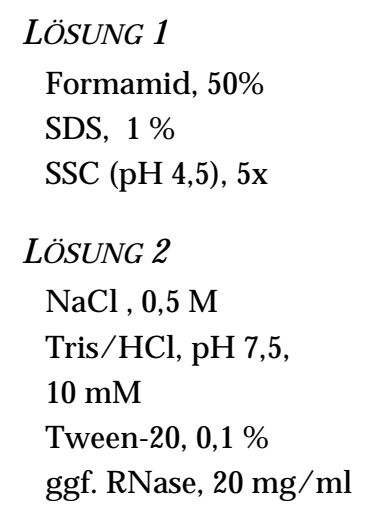

LÖSUNG 3:

Formamid, $50 \%$

$\operatorname{SSC}(\mathrm{pH} 4,5), 2 \mathrm{x}$

10X TBST (100ML):

$\mathrm{NaCl}, 8 \mathrm{~g}$

$\mathrm{KCl}, 0,2 \mathrm{~g}$

Tris/ $\mathrm{HCl}(\mathrm{pH} 7,5), 1 \mathrm{M}$

Tween-20, $10 \mathrm{ml}$

vor Gebrauch Verdünnung auf $1 \mathrm{x}$

und Zugabe von $0,48 \mathrm{mg} / \mathrm{ml}$

Levamisol
PBT:

$0,1 \%$ Tween-

20 in $1 x$ PBS

\section{Antikörperinkubation}

Die Sonde war mit DIG-dUTP markiert. Nach der Inkubation mit dem gegen die Digoxygenin-markierte RNA gerichteten Antikörper konnte die FarbEnzym-Reaktion gestartet werden. 
Um unspezifische Bindung des Antikörpers mit embryonalen Proteinen zu vermeiden, wurde der Antikörper vorbehandelt. Hierfür wurden 3 mg EmbryoPulver in $0,5 \mathrm{ml}$ TBST für $30 \mathrm{~min}$ bei $70{ }^{\circ} \mathrm{C}$ inkubiert. Nach Abkühlung auf Eis wurden $5 \mu \mathrm{l}$ FCS zugegeben. $1 \mu \mathrm{l}$ Anti-DIG-Antikörper-AP (BoehringerMannheim) wurden anschließend für $1 \mathrm{~h}$ bei $4{ }^{\circ} \mathrm{C}$ in dem Ansatz inkubiert. Nach 10 min Zentrifugation $\left(4{ }^{\circ} \mathrm{C}, 13.000 \mathrm{rpm}\right.$, Heraeus Biofuge A) wurde der Überstand mit 1\% FCS/TBST auf $2 \mathrm{ml}$ aufgefüllt. In dieser Lösung wurden die Embryonen ü.N. bei $4{ }^{\circ} \mathrm{C}$ leicht schwenkend inkubiert.

Embryo-Pulver: $1 \mathrm{~g}$ embryonales Gewebe wurde in 4 Volumina Aceton $\left(4^{\circ} \mathrm{C}\right)$ mit einem Polytron-Mixer homogenisiert und für 30 min auf Eis gehalten. Nach 10 Min. Zentrifugation (1500 rpm, Heraeus Biofuge A) wurde das Pellet mit kaltem Aceton gewaschen, wieder zentrifugiert und abschließend das Pellet zu einem feinem Pulver zerstoßen. Das Pulver wurde bei $4{ }^{\circ} \mathrm{C}$ gelagert.

\section{Entfernen des Antikörpers}

Um überschüssige Antikörper zu entfernen, sowie die Embryonen für die Färbung zu äquilibrieren ( $\mathrm{pH}-$ Wert und Salzkonzentration), wurde am Tag nach der Antikörperinkubation wie folgt bei RT gewaschen:

\begin{tabular}{|c|c|}
\hline \multicolumn{2}{|c|}{ Ablauf: } \\
\hline TBST & 5 Min. \\
\hline TBST & 5 Min. \\
\hline TBST & 5 Min. \\
\hline TBST & 60 Min. \\
\hline TBST & 60 Min. \\
\hline TBST & 60 Min. \\
\hline TBST & 60 Min. \\
\hline NTMT & 5 Min. \\
\hline NTMT & ü.N. \\
\hline \multicolumn{2}{|c|}{ NTMT-LÖSUNG } \\
\hline \multicolumn{2}{|c|}{$\mathrm{NaCl}, 100 \mathrm{mM}$} \\
\hline \multicolumn{2}{|c|}{ Tris- $\mathrm{HCl}(\mathrm{pH} 9,5), 100 \mathrm{mM}$} \\
\hline \multicolumn{2}{|c|}{ Levamisol, $2 \mathrm{mM}$} \\
\hline \multicolumn{2}{|c|}{$\mathrm{MgCl}_{2}, 50 \mathrm{mM}$} \\
\hline \multicolumn{2}{|c|}{ Tween-20, $1 \%$} \\
\hline
\end{tabular}




\section{Färbung und Analyse}

Zur Färbung wurden die Embryonen dreimal für $10 \mathrm{Min}$. in NTMT gewaschen. Anschließend wurde mit $200 \mu \mathrm{l}$ NBT/BCIP-Stammlösung (Boehringer-Mannheim) in $10 \mathrm{ml}$ NTMT bei RT (abgedunkelt) gefärbt. Nach $3 \mathrm{~h}$ bis ü.N. wurde die Farbreaktion durch Überführung der Embryonen in 1x PBT gestoppt. Anschließend wurden die Embryonen nochmals in PBT gewaschen (>15 Min.), über $50 \%$ Glyzerin/PBT in $80 \%$ Glyzerin/PBT überführt und bei 4 ${ }^{\circ} \mathrm{C}$ gelagert. Nun waren sie für weitere Untersuchungen und zum Fotografieren fertig.

Digoxygenin ist ein natürliches, im Fingerhut vorkommendes Steroid. DigdUTP wird anstelle von dTTP in die DNA inkorporiert. An digoxygenierte DNA oder DNA/RNA bindet ein mit alkalischer Phosphatase konjugierter, gegen Digoxygenin gerichteter Antikörper. Die alkalische Phosphatase katalysiert die Oxidation des farblosen Substrates BCIP (5-Bromo-4-chloro-3-indolylphosphat) zu Indigo (blau). In gekoppelter Reaktion wird farbloses NBT (Nitroblautetrazoliumchlorid) zu blauem Diformazan reduziert.

Die enzymatische Blaufärbung der Gehirne bzw. Embryonen gibt den spezifischen Ort der Hybridisierung zwischen zellulärer RNA und in-vitrotranskribierter Gegenstrang-Sonde wieder. Folglich ist so eine räumliche Aussage über die Expression des Transkripts möglich.

VIBRATOMSCHNEIDEN VON WHOLE-MOUNT-GEFÄRBTEN EMBRYONEN BZW. GEHIRNEN

Das Schneiden der durch die in-situ-Hybridisierung gefärbten Embryonen bzw. Gehirnen ermöglichte es, auch die Organstrukturen zu analysieren. Es wurden Embryonen der Stadien E9,5 und E10,5 und die Gehirne der embryonalen Stadien E13,5 bis E18,5 untersucht. Die Embryonen wurden sagital und quer geschnitten, die Gehirne E13,5 bis E17,5 horizontal und das E18.5Gehirn koronal.

Um das Gewebe näher zu untersuchen, welches das Gen exprimiert, wurden Vibratomschnitte von $40 \mu \mathrm{m}$ angefertigt. Sie ermöglichten es, einen Eindruck von tieferliegenden Gewebeschichten zu erhalten und auch dreidimensionalen 
Eindruck von der Schnittebene zu erhalten. Zunächst wurden die Embryonen bzw. Gehirne aus dem $80 \%$ Glycerol/PBT, über $50 \%$ Glycerol/PBT und schließlich in PBT überführt. Dann wurde das Gewebe in die Gelatine-AlbuminLösung gelegt, damit das Gewebe physiologisch ausgeglichen ist. Parallel wurden $2 \mathrm{ml}$ der Gelatine-Albumin-Lösung mit $80 \mu \mathrm{l}$ einer 50 \%igen Gluteralaldehydlösung gemischt. Dies wurde leicht angetrocknet bevor der Embryo auf diesem Block in der gewünschten Position plaziert wurde. Nun wurden $2 \mathrm{ml}$ einer frisch angemischten Gelatine-Albumin-Lösung mit $80 \mu \mathrm{l}$ einer 50 \%igen Gluteralaldehydlösung dazugegeben. Nach 30 minütigem Aushärten, wurde der Block auf dem Vibratomblock befestigt. Die 40- $\mu$ mSchnitte wurden mit einem Vibratomschneidegerät („Pelco-1.000”) unter Wasser durchgeführt. Die Schnitte wurden einzeln auf vorbehandelte Objektträger (s. mRNA-in-situ-Hybridisierung) aufgezogen und mit einer Lösung (Moviol, Fa. Hoechst) eingedeckelt.

GELATINE-ALBUMIN-MIX:
Gelatine $490 \mathrm{mg}$
Albumin $30 \mathrm{~g}$
Saccharose $20 \mathrm{~g}$

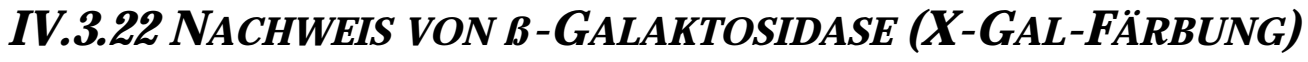

Embryonen bzw. Gehirne des gewünschten Alters wurden in 1x PBS präpariert und bei $4{ }^{\circ} \mathrm{C}$ in Fixierlösung für 30 Min. fixiert. Anschließend wurden die Embryonen/Gehirne zweimal bei RT in 1x PBS für 20 Min. gewaschen. Zum Nachweis der $\beta$-Galaktosidase wurden die Embryonen in X-Gal-Färbelösung bei $30{ }^{\circ} \mathrm{C}$ für mindestens $12 \mathrm{~h}$ inkubiert.

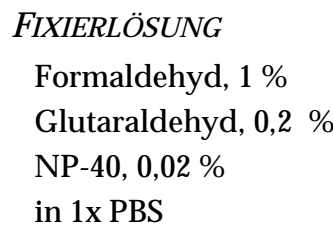

Nach erfolgter B-Galaktosidase-Färbung wurden die Embryonen/Geirne in PBS gewaschen und anschließend in einer ansteigenden Glycerin/PBS-Reihe (30

\author{
X-GAL-FÄRBELÖSUNG: \\ $X-G a l, 1 \mathrm{mg} / \mathrm{ml}$ \\ $\mathrm{K}_{3} \mathrm{Fe}(\mathrm{CN})_{6}, 5 \mathrm{mM}$ \\ $\mathrm{K}_{4} \mathrm{Fe}(\mathrm{CN})_{6}, 5 \mathrm{mM}$
}


\%, 50 \%, 80 \%) aufgeklärt. In jeder Lösung wurden die Embryonen für 1 - 2 Tage belassen.

\section{IV.3.23 METHODEN ZUR ARBEIT MIT EUKARYOTISCHEN ZELLEN}

Das nachfolgend aufgeführte Arbeiten mit eukaryotischen Zellen, wurde nach der Beschreibung von A. Mansouri durchgeführt (Mansouri, 2001).

Generell wurden die Zellen in wassergesättigter Atmosphäre unter $5 \% \mathrm{CO}_{2}$ bei $37{ }^{\circ} \mathrm{C}$ kultiviert. Medien und Lösungen wurden, wenn nicht anders angegeben, auf $37^{\circ} \mathrm{C}$ vorgewärmt. Alle Arbeiten wurden mit Plastikmaterial (Pipetten, Gewebekulturschalen und -platten) durchgeführt.

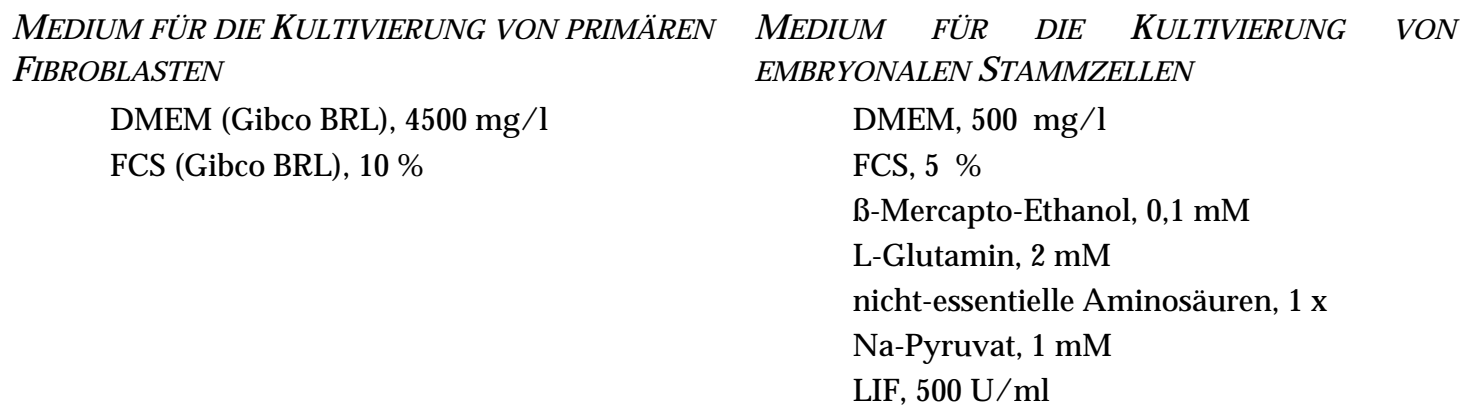

PRÄPARATION VON PRIMÄREN NEOMYCIN- BZW. PUROMYCIN-RESISTENTEN FIBROBLASTEN

Zehn Tage 13 - 15 p.c. Embryonen neomycin- bzw. puromycin-resistenter Mäuse wurden präpariert und mit 1x PBS gewaschen. Der Kopf wurde abgetrennt, Herz, Leber und andere Organe aus den Embryonen entfernt. Das Gewebe wurde mehrmals in 1x PBS gewaschen, um das Blut zu entfernen. Das Embryonengewebe wurde in einem sterilen Erlenmeyerkolben mit $50 \mathrm{ml} \mathrm{0,25}$ \%igem Trypsin und sterilen Glasperlen (ø 4-5 mm) 30 Min. bei $37^{\circ} \mathrm{C}$ gerührt. Die Zellen wurden pelletiert (5 Min., 1.200 rpm), der Überstand abgesaugt, das Pellet in Medium resuspendiert und die Zelldichte mit einer NeubauerZählkammer bestimmt. Die Fibroblasten wurden auf 14,5-cm-Zellkulturschalen plattiert und kultiviert. 


\section{MITOTISCHE INAKTIVIERUNG VON FIBROBLASTEN}

Konfluente Mausfibroblasten wurden unmittelbar vor Benutzung als Fibroblasten-Zellen durch Behandlung mit Mitomycin C mitotisch inaktiviert. Dazu wurde dem Fibroblastenmedium Mitomycin C zugesetzt $(100 \mathrm{mg} / \mathrm{ml})$ und die Mitomycin C-Behandlung 2,5 h bei $37^{\circ} \mathrm{C}$ durchgeführt. Das Medium wurde abgesaugt, die Zellen 2x mit 1x PBS gewaschen und trypinisiert. Anschließend wurden die Zellen in einer Dichte von $8 \times 104$ Zellen $/ \mathrm{cm}^{2}$ ausplattiert. Die Gewebekulturschalen waren zuvor mit einer 0,1 \%igen Gelatine-Lösung für 15 Min. behandelt worden.

\section{TRYPSINBEHANDLUNG VON ZELLEN}

Das Medium wurde von der Gewebekulturschale abgesaugt und die Zellen einmal mit 1x PBS gewaschen. Die Zellen wurden ca. 5 Min. mit 0,05 \% Trypsin/ EDTA bei $37{ }^{\circ} \mathrm{C}$ bis zur Abrundung der Zellen (mikroskopische Kontrolle) inkubiert. Die Reaktion wurde durch Zugabe von Medium gestoppt, die Zellen durch mehrfaches Aufsaugen mit der Pipette vereinzelt, die Zellzahl pro ml mit der Neubauer-Zählkammer bestimmt. Die Zellen wurden in der gewünschten Dichte ausgesät.

\section{KULTIVIERUNG EMBRYONALER STAMMZELLEN (ES-ZELLEN)}

Embryonale Stammzellen wurden auf Fibroblasten-Zellrasen aus mitotisch inaktivierten Mausfibroblasten kultiviert. Die Zellen wuchsen in scharf abgerundeten Kolonien und wurden täglich mikroskopisch kontrolliert. Dem Medium wurden 15 \% FCS zugesetzt und täglich gewechselt. Die Zugabe von LIF (Leukemia Inhibiting Factor) blockiert eine Differenzierung der embryonalen Stammzellen.

\section{DNA-TRANSFER IN EMBRYONALE STAMMZELLEN DURCH ELETROPORATION}

Die embryonalen Stammzellen wurden nach der Trypsinbehandlung gezählt und zweimal mit PBS gewaschen. Ca. 1,5 x 107 Zellen wurden in 0,8 ml PBS suspendiert, mit $25 \mathrm{mg}$ den Rekombinationskonstruktes sorgfältig gemischt und in die Elektroporationsküvette (Biorad; $4 \mathrm{~mm}$ Elektrodenabstand) überführt. Die 
Zellsuspension wurde für $5 \mathrm{Min}$. bei RT inkubiert und anschließend die Zellen mit einem Impuls von $500 \mu \mathrm{F}$ und $250 \mathrm{~V}$ elektroporiert. Mittels dieses Strompulses werden die ES-Zellen mit dem Rekombinationskonstrukt transformiert. Die Zellen wurden nach dem Strompuls für 5 Min. nicht bewegt, anschließend in ES-Zellmedium aufgenommen und auf den vorbereiteten Fibroblasten-Zellrasen ausplattiert.

SELEKTION EMBRYONALER STAMMZELLEN NACH ELEKTROPORATION, UM IRX1-KOLOXPNEOLOXP BZW. IRX1-KO-PURO POSITIVE ES-ZELLEN ZU ISOLIEREN.

Um die positiv transgenen ES-Zellen zu selektieren, wurden entsprechend der verschiedenen benutzten Rekombinationskonstrukte folgende Wege eingeschlagen:

Irx1-KO-loxPneoloxP

Das Medium elektroporierter ES-Zellen wurden $24 \mathrm{~h}$ nach der Elektroporation gegen ein mit G418 enthaltendes Selektionsmedium ausgewechselt (300 mg/ml G418). Das Selektionsmedium wurde täglich erneuert.

Irx1-KO-puro

Das Medium elektroporierter ES-Zellen wurden $24 \mathrm{~h}$ nach der Elektroporation gegen ein mit G418 und Puromycin Dihydrochlorid enthaltendes Selektionsmedium ausgewechselt $(4 \mu \mathrm{g} / \mathrm{ml}$ Puromycin Dihydrochlorid; $2 \mathrm{mM}$ Gancyclovier). Das Selektionsmedium wurde täglich erneuert. Ab dem fünften Tag wurde nur noch mit Puromycin Dihydrochlorid selektioniert.

SELEKTION EMBRYONALER STAMMZELLEN NACH ELEKTROPORATION, UM IRX1-KOLOXPANEO POSITIVE ES-ZELLEN HERZUSTELLEN.

In ES-Zellen, die für das Irx1-KO-loxPneoloxP positiv transgen waren, wurde das loxPNeomycin-Gen mittels einer Cre-Recombinasereaktion entfernt, um die Mauslinie Irx1-KO-loxPAneo herzustellen. Dabei wurden die Vorteile des sequenzspezifischen Cre/loxP-Rekombinasesystems des Bakteriophagen P1 benutzt (Sauer, 1993). Die Cre-Rekombinase vollzieht sowohl in Bakterien als 
auch in eukaryotischen Zellen eine Rekombinationsreaktion an der Position der loxP-Sequenz. DNA, welche von dieser loxP-Sequenz (ein 34 bp langes DNAElement, welches aus dem Bakteriophagen P1 gewonnen wird) flankiert wird, wird durch die Cre-Rekombinase herausgeschnitten. Daher kann das NeomycinGen, welches von diesen loxP-Sequenzen flankiert wird, nach der homologen Rekombination entfernt werden (Sauer, 1993).

Um das Neomycin-Gen bereits in den ES-Zellen zu entfernen, wurden die positiv transgen ES-Zellen ein zweites mal elektroporiert und zwar diesmal mit dem $p$ Cre-Pac-Plasmid (freundlicherweise von T. Yagi zur Verfügung gestellt; (Taniguchi et al., 1998; Watanabe et al., 1995)). Dieses Plasmid enthält das Puromycin-Gen und das Cre-Rekombinasegen. Nach der Elektroporation wird auf Puromycin selektiert (s.o.). In allen puro-positiven ES-Zellen erfolgt eine CreRecombinasereaktion (Taniguchi et al., 1998) und in diesem Verlauf wird das Neomycin-Gen entfernt. Die resultierenden ES-Zellen heißen im weiteren Verlauf Irx1-KO-loxPAneo.

\section{GEWINNUNG VON ES-ZELL-EINZELKLONEN}

Etwa am 8. Tag nach der Elektroporation konnten einzelne ES-Zellklone isoliert werden. Dazu wurden die Zellklone unter dem Stereomikroskop mit einer sterilen gestopften Pipettenspitze isoliert. Die Zellen eines ES-Zellklons wurden in $40 \mu \mathrm{l}$ Trypsin/EDTA in ein Loch einer 96-Loch-Platte überführt, 5 Min. bei RT inkubiert und durch mehrmaliges Aufziehen mit einer Pipette vereinzelt. Die Trypsinierung wurde durch Überführung der Zellen in eine mit inaktivierten Fibroblasten-Zellen vorbereitete 24-Loch-Gewebekulturplatten gestoppt. Die vereinzelten ES-Zellen wurden bis zum konfluenten Wachstum kultiviert. Danach wurden die Klone wiederum trypsiniert, die eine Hälfte in DMSO-haltigem Medium weggefroren und die andere Hälfte zur Gewinnung von genomische DNA weiterkultiviert. Die ES-Zell-DNA wurde mit Hilfe von Southern-Blot-Analysen auf homologe Rekombinationsereignisse untersucht. 


\section{EINFRIEREN UND AUFTAUEN VON EUKARYONTISCHEN ZELLEN}

\section{Primäre Fibroblasten}

Die Fibroblastenzellen wurden mit Trypsin behandelt, in Medium aufgenommen und 5 Min. bei $1.500 \mathrm{rpm}$ pelletiert. Nach Absaugen des Überstandes wurden die Zellen in $1 \mathrm{ml}$ Einfriermedium resuspendiert, in Kryoröhrchen überführt und langsam ü.N. auf $-70{ }^{\circ} \mathrm{C}$ abgekühlt und dann in flüssigem Stickstoff gelagert.

\section{Embryonale Stammzellen}

Die ES-Zellen wurden mit Trypsin behandelt, in Medium aufgenommen und pelletiert. Der Überstand wurde abgesaugt und das Zellpellet in Einfriermedium aufgenommen. In Gefrierröhrchen wurden die ES-Zellen langsam ü.N. auf $-70^{\circ} \mathrm{C}$ abgekühlt und dann in flüssigem Stickstoff gelagert.

MEDIUM FÜR FIBROBLASTEN:
Zellkulturmedium
$+10 \%$ DMSO

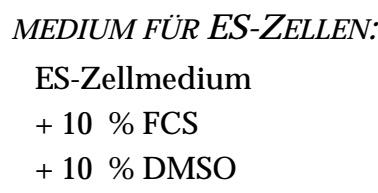

\section{Auftauen von Zellen}

Nach der Entnahme des Kryoröhrchens aus dem flüssigem Stickstoff wurden die Zellen bei $37^{\circ} \mathrm{C}$ aufgetaut. Die Zellsuspension wurde entnommen, in $5 \mathrm{ml}$ Medium überführt und die Zellen in der Labofuge pelletiert (1.500 rpm, 5 Min.). Der Überstand wurde abgesaugt, die Zellen in Medium aufgenommen und ausplattiert. Am nächsten Tag wurde das Medium gewechselt, um Reste von DMSO zu entfernen.

\section{IV.3.24 MAUS-FISH-ANALYSE DER TRANSGENEN ES-ZELLEN}

Die DNA-Sonden wurden bei $15^{\circ} \mathrm{C}$ für $1 \mathrm{~h}$ mittels des BioNick labeling Kits am dATP biotinyliert (Gibco BRL) (Heng et al., 1992).

Der Ablauf der FISH-Detektion erfolgte nach Heng et al, 1992, und Heng und Tsui 1993. Dabei wurde die Chromosomen auf den Objektträgern für $1 \mathrm{~h}$ bei 55 ${ }^{\circ} \mathrm{C}$ gebacken. Nach RNase-Behandlung wurden die Objekte bei $70{ }^{\circ} \mathrm{C}$ für $2 \mathrm{Min}$. in $70 \%$ Formamid/2xSSC denaturiert, gefolgt von einer Dehydrierung mittels 
einer EtOH-Reihe. Die Sonden wurden für 5 Min. in einem Hybridisierungsmix aus $50 \%$ Formamid $/ 10 \%$ Dextransulfat bei $75{ }^{\circ} \mathrm{C}$ denaturiert. Die entsprechende Sonde wurde dann auf die denaturierten ChromosomenObjektträgern aufgetragen und so ü.N. hybridisiert. Danach wurden die Objekte gewaschen und das Signal amplifiziert und detektiert. Die FISH-Signale und das DAPI-Bandenmuster wurde separat analysiert und fotogafiert. Das Herstellen der FISH-Kartierungs-Daten wurde durch Überlagerung der FISH-Signale und der DAPI-Chromosomen-Bandemuster erreicht (Heng und Tsui, 1993).

Als Material für die Maus-FISH-Analyse wurde Maus-ES-Zellen benutzt und für die humane Analyse Blutzellen.

\section{IV.3.25 HERSTELLUNG VON MAUS-CHIMÄREN AUS ES-ZELLEN DURCH MORULAAGGREGATION}

Das nachfolgend aufgeführte Arbeiten mit ES-Zellen, wurde nach der Beschreibung von A. Mansouri durchgeführt (Mansouri, 2001).

\section{GEWINNUNG VON 8-ZELLSTADIEN (MORULAE) AUS TRÄCHTIGEN MÄUSEN}

Superovulierte C57Bl/6J- oder NMRI-Weibchen, die am Tag E2,5 trächtig waren, wurden nach Betäubung mit $\mathrm{CO}_{2}$ durch eine zervikale Dislokation getötet. Die Tiere wurden auf den Rücken gelegt, das Abdomen mit $70 \%$ Ethanol desinfiziert und der Bauchraum geöffnet. Der Uterus wurde mit einer stumpfen Pinzette gefaßt, und mit einer spitzen Pinzette wurden Mesometrium und Fettgewebe abgestreift. Das Ovidukt wurde zwischen Uterus und Ovar abgetrennt und bis zur Durchspülung in M2 Medium bei RT inkubiert. Die 8Zellstadien, die sich zum Zeitpunkt der Präparation im Ovidukt befanden, wurden folgendermaßen gewonnen: Unter dem Binokular wurde das Fimbrium mit einer feinen, stumpfen Pinzette über ein Glasschälchen gehalten, eine 2,5 ml Spritze mit einer 27g-Kanüle vorsichtig in das Lumen Fimbriums eingeführt, und die 8-Zellstadien unter leichtem Druck herausgespült. Anschließend wurden die 8-Zellstadien unter dem Binokular mit einer ausgezogenen Pasteurpipette (über einen Schlauch mit Mundstück) aufgesaugt und die 8- 
Zellstadien mehrfach in M2 Medium gespült und in M16 Medium abgelegt. Alle weiteren Arbeitsschritte wurden unter dem Binokular durchgeführt.

$\begin{array}{lc}\text { M2 Medium: } & \\ \text { 10x Hank's Puffer } & 3 \mathrm{ml} \\ \mathrm{NaHCO}_{3} 7,5 \% & 141 \mu \mathrm{l} \\ \text { Hepes-Puffer 1 M } & 630 \mu \mathrm{l} \\ \text { Na-Pyruvat } 100 \mathrm{mM} & 99 \mu \mathrm{l} \\ \text { Pen/Strep10.000 U/ml } & 300 \mu \mathrm{l} \\ \text { NaOH 1 M } & 30 \mu \mathrm{l} \\ \text { BSA } & 120 \mathrm{mg} \\ \text { Na-Lactat } & 78 \mathrm{mg} \\ \text { ad } \mathrm{H}_{2} \mathrm{O} & 30 \mathrm{ml}\end{array}$

M16 Medium:

$\begin{array}{ll}10 \times \text { Earle's-Puffer } & 1 \mathrm{ml} \\ \mathrm{NaHCO}_{3} 7,5 \% & 270 \mu \mathrm{l} \\ \text { Na-Pyruvat100 mM } & 33 \mu \mathrm{l} \\ \text { Pen/Strep10.000 U/ml } & 100 \mu \mathrm{l} \\ \text { BSA } & 40 \mathrm{mg} \\ \text { Na-Lactat } & 26 \mathrm{mg}\end{array}$

ad $\mathrm{H}_{2} \mathrm{O}$

M16 Medium:

$10 \times$ Earle's-Puffer $\quad 1 \mathrm{ml}$

Die Medien wurden 1x pro Woche frisch angesetzt, sterilfiltriert und bei $4{ }^{\circ} \mathrm{C}$ gelagert.

\section{VORBEREITUNG DER ES-ZELLEN FÜR MORULA-AGGREGATION}

Die ES-Zellen einer 3,5-cm-Gewebekulturplatte wurden trypsiniert und in ES-Zell-Medium aufgenommen. Der Überstand mit den ES-Zellen wurde abgenommen und die Zellen pelettiert (1.300 rpm, 5 Min.). Diese wurden erneut in frischen ES-Zellmedium aufgenommen. Unter dem Binokular wurden anschließend ES-Zellaggregate geeigneter Größe mit einer ausgezogenen Pasteurpipette isoliert, mehrfach in M16 Medium gewaschen und auf die Aggregationsplatte übertragen.

\section{AGGREGATION VON ES-ZELLEN MIT 8-ZELLSSTADIEN}

Bevor 8-Zellstadien mit ES-Zellen aggregiert werden konnten, mußte die Zona pellucida von den 8-Zellstadien entfernt werden. Dazu wurden die 8Zellstadien nacheinander in Tyrode's Säure gewaschen, wodurch die Zona pellucida sich auflöste. Anschließend wurden die 8-Zellstadien mehrfach in M16 Medium gut gewaschen und in die Vertiefungen einer Aggregations-platte in M16 Medium abgelegt. In den Vertiefungen der Aggregationsplatte wurde ein Zellhaufen aus ca. 4 - 15 ES-Zellen an das 8-Zellstadium aggregiert und beides ü.N. bei $5 \% \mathrm{CO}_{2}$-Atmosphäre und $37^{\circ} \mathrm{C}$ inkubiert. Am nächsten Tag wurden 
die aggregierten Embryonen in einem Tropfen M16 Medium gewaschen, gesammelt und in pseudoschwangere Weibchen (Fostermäuse) übertragen.

$\begin{array}{ll}\text { TYRODE'S SÄURE: } & \mathrm{g} / 100 \mathrm{ml} \\ \mathrm{NaCl} & 0,800 \\ \mathrm{KCl} & 0,020 \\ \mathrm{CaCl}_{2} \times 2 \mathrm{H}_{2} \mathrm{O} & 0,024 \\ \mathrm{MgCl}_{2} \times 2 \mathrm{H}_{2} \mathrm{O} & 0,010 \\ \text { Glukose } & 0,100 \\ \text { Polyvenylpyrrolidone (PVP) } & 0,400\end{array}$

Die Lösung wird mit $5 \mathrm{M} \mathrm{HCl}$ auf pH 2,5 eingestellt und sterilfiltriert.

TRANSFER AGGREGIERTER EMBRYONEN IN PSEUDOSCHWANGERE FOSTERMÄUSE

Pseudoschwangere Fostermäuse wurden durch Verpaarung mit vasektomierten Männchen erzeugt. Zur Injektionsnarkose pseudoschwangerer Fostermäuse wurden 0,7 - 0,8 ml Avertin intraperitoneal injiziert. Die Maus wurde auf den Bauch gelegt und der Rücken wurde zwischen Rippenbogen und Beckenkamm mit 70 \% Ethanol desinfiziert. Die Haut wurde mit einem sagitalen Schnitt $(1 \mathrm{~cm})$ neben der Wirbelsäule, unmittelbar unter dem Rippenbogen eröffnet. Der Hautschnitt wurde über den Fettkörper oberhalb des Uterus verschoben, die Bauchdecke mit einer spitzen Pinzette gefaßt und mit einem Schnitt eröffnet. Der am Ovar anliegende Fettkörper wurde aufgesucht, mit einer stumpfen Pinzette gefaßt und zusammen mit Ovar, Ovidukt und Uterushorn aus der Bauchhöhle herausgehoben. Der Fettkörper wurde mit einer Arterienklammer fixiert. Der Uterus wurde mit einer feinen Pinzette kurz vor dem Übergang in das Ovidukt fixiert und mit einer $26 \mathrm{~g}$-Kanüle unterhalb der Pinzette perforiert. In diese Öffnung wurde eine Glaskapillare eingeführt, in die zuvor die aggregierten Embryonen (in ca. 10-20 $\mu$ l M16-Medium) aufgenommen worden waren. Die Embryonen wurden durch leichten Druck in das Lumen des Uterus eingespült. Die Arterienklemme wurde entfernt, der Uterus mit Ovidukt, Ovar und Fettkörper zurückgelegt und der Hautschnitt mit einer 
Wundklammer versorgt. Die Fostermäuse wurden bis zum Aufwachen aus der Narkose auf einer Wärmeplatte vor Unterkühlung geschützt.

$\begin{array}{ll}\text { AVERTIN: } & \\ \text { Tribromethanol } & 0,5 \mathrm{~g} \\ \text { Tert-Amylalkohol } & 0,25 \mathrm{~g} \\ \mathrm{H}_{2} \mathrm{O} & 39,5 \mathrm{~g} \\ \text { bei } 42^{\circ} \mathrm{C} 4 \mathrm{~h} \text { lösen, sterilfiltrieren } & \end{array}$

\section{IV.3.26 ZELLBIOLOGISCHE METHODEN}

\section{ZELLKULTUR MIT PC-12-ZELLEN UND LUNGENKREBSZELLINIEN}

Experimente wurden mit PC12-Zellen und den Lungenkrebszellinien NCIH69, NCI-H82, NCI-H345, NCI-H592 und NCI-N417 durchgeführt. Die Zellen wurden unter Standard-Zellkulturbedingungen bei $37{ }^{\circ} \mathrm{C}$ und $5 \% \mathrm{CO}_{2}$ kultiviert. Benutzt wurde DMEM-Medium (Seromed) mit 1,5\% Glukose und 10 $\%$ fötalem Kälberserum (FCS; Gibco/BRL) bei den Lungenkrebszellinien und 8 $\%$ FCS, $50 \mathrm{U} / \mathrm{ml}$ Penicillin (Meiji Seika Co., Tokyo, Japan) und $50 \mu \mathrm{g} / \mathrm{ml}$ Streptomycin (Meiji Seika Co.). Die Zellen wurden in Plastikschalen (Falcon) oder in Flüssigkultur (Falcon) inkubiert und alle zwei bis drei Tage durch Trypsin-Behandlung gesplittet. Das Medium wurde abgesaugt, der Zellrasen mit PBS gewaschen und mit 0,05\% Trypsin/EDTA (Flow) inkubiert, bis sich der Zellrasen ablöste und die Zellen keinen Kontakt mehr hatten. Die so vereinzelten Zellen wurden $1: 10$ verdünnt und mit frischem Medium auf neue Platten ausplattiert.

\section{REPORTER PLASMIDKONSTRUKTE}

Das Irx1-Gen wurde zum einen in einen $p c D N A 1.1$-Vektor (Invitrogen) mit $C M V$-Promotor (Irx1-pcDNA) und zum anderen in einen pTRACERTM-CMV2Vektor (Invitrogen) mit CMV-Promotor und Green-Fluorenzent-Protein (GFP) (Irx1-pTRACER) kloniert. Beide Klonierungen erfolgten über eine EcoRIKlonierung. 
Die Mash1-Reporterkonstrukte (AZ-JIB, AZ-JIS, AZ-JIH) wurde freundlicherweise von J. Johnson zur Verfügung gestellt (Verma-Kurvari et al., 1998).

CO-TRANSFEKTION MITTELS LIPOFECTAMIN (GIBCO,BRL)

Drei Tage vor der Transfektion wurden die Zellen gesplittet, so daß die Schalen 0,2 - 0,3 × $10^{6}$ Zellen pro Platte aufwiesen. Das entsprechende Mash1Promotorkonstrukt $(1 \mu \mathrm{g})$ wurde mit CMV-GFP (pTRACER; 0,5 $\mu \mathrm{g})$ und $2 \mu \mathrm{g}$ Irx1-pcDNA oder Irx1-pTRACER cotransformiert. Die Transfektion erfolgte mittels Lipofectamin (Gibco/BRL). Nach $48 \mathrm{~h}$ wurde die $\beta$-GalactosidaseAktivierung des Mash1-Promotors mittels lacZ-Färbung ermittelt.

\section{ZELLKULTUR MIT LUNGENKREBSZELLINIEN}

Die Lungenkrebszellinien (SCLC; small cell lung cancer) NCI-H69, NCI-H82, NCI-H345, NCI-H592 und NCI-N417 wurden wie oben beschrieben behandelt. Mit den geernteten Zellen wurde eine RNA-Northern-Blot-Analyse durchgeführt.

\section{IV.3.27 HERSTELLUNG VON ANTISERA (IRX1-ANTIKÖRPER)}

\section{EXPRESSION UND REINIGUNG VON IRX1 PROTEIN AUS E. COLI}

Mit Standardmethoden wurden über PCR (Primer: IR1-F, IR1-R, IR1-FC, IR1F3, IR1-FN; Anealingtemperatur: $58{ }^{\circ} \mathrm{C}$; 30 Cyclen) amplifizierte Irx1-cDNAFragmente in den Expressionsvektor $p E T$-HIS kloniert und unter die Kontrolle eines T7-Promotors gestellt. Diese wurden in E. coli BL21(DE3), einem mit IPTG induzierbaren Bakterienstamm, transformiert und selektiert (Studier et al., 1990). Einzelne Kolonien wurden in $5 \mathrm{ml} \mathrm{LB} / 1$ \% Glukose-Medium angeimpft und inkubiert, bis die Kultur leicht trübe war. Danach wurde zur Inkubation IPTG zugegeben $(0,5 \mathrm{mM})$ und weitere $3 \mathrm{~h}$ inkubiert. Die Zellen wurden dann mittels Zentrifugation geerntet und das Zellpellet in Phosphatpuffer mittels Lysozymzugabe, Sonifizierung und Einfrieren und Auftauen lysiert. Zur Affinitätsreinigung wurden die am Aminoterminus mit einem 
Histidinhexamer-Tag versehenen, löslichen Fusionsproteine auf eine Nickelsäule (NiNTA, Qiagen; $5 \mathrm{ml}$ Bettvolumen) gegeben. Die Säule wurde mit 10 Bettvolumen Waschpuffer gewaschen und das Protein mit $10 \mathrm{ml}$ Elutionspuffer durch einen pH-Sprung eluiert. Die $1 \mathrm{ml}$ große Fraktionen wurden aufgefangen und mit jeweils $100 \mu \mathrm{l} \mathrm{M}$ Tris- $\mathrm{HCl}(\mathrm{pH} 8,0)$ neutralisiert. Zum Nachweis des Fusionsproteins wurden Aliquots der Fraktionen in einem 10 \%igen SDS-Gel aufgetrennt und mit Coomassie-Blau gefärbt. Zur Quantifizierung wurde zu $5 \mu \mathrm{l}$ Proteinlösung $1 \mathrm{ml}$ verdünnte BradfordReagenzlösung (Biorad; 1 : 5 in $\mathrm{H}_{2} \mathrm{O}$ ) gegeben und die $\mathrm{OD}_{595}$ gemessen.

PHOSPHATPUFFER
$20 \mathrm{mM}$ Na-Phospat
$(\mathrm{pH} 7,8)$
$500 \mathrm{mM} \mathrm{NaCl}$

Primer IR1-F : 5'-CCGCTCGAGACTTGGGGGGCGCGCAGCAAGGA-3'

Primer IR1-R : 5'-GCAGACGGGAGGGCTGCGAGGATCC-3'

Primer IR1-FC : 5'-GACTCGAGACCTGTCACATAGGCAAGTTTT-3'

Primer IR1-F3 : 5'-ACCTCGAGAAGGCCGAGGACGACGAGGAGA-3’

Primer IR1-FN: 5'-CCGCTCGAGACTTGGGGGGCGCGCAGCAAGGA-3'

\section{IMMUNISIERUNG UND BLUTABNAHME}

Für jedes Peptid-Konjugat wurden je zwei Chinchilla-Bastard-Kaninchen immunisiert. Zur Injektion wurden je $250 \mu$ l Konjugat in einem Gesamtvolumen von $250 \mu \mathrm{l}$ mit $250 \mu \mathrm{l}$ komplettem Freund'schen Adjuvants gemischt und die Suspension durch vortexen und wiederholtes Aufziehen und Ausspritzen durch eine 25G-Kanüle homogenisiert. Dieses Gemisch wurde intramuskulär in den Oberschenkel injiziert. Immunisierungen wurden alle sechs Wochen wiederholt. Blut wurde jeweils ca. 10 Tage nach der Injektion aus der äußeren Ohrvene entnommen (max. $50 \mu \mathrm{l}$ je Tier). Das Rohblut wurde zum Gerinnen über Nacht in den Kühlraum gestellt und am nächsten Tag abzentrifugiert (Sorvall HB-4 Rotor, 20 Min. bei 8.000 U/Min.), das resultierende Serum aliquotiert und bei -20 ${ }^{\circ} \mathrm{C}$ gelagert. Diese Arbeit wurde in der Fa. Bioscience (Göttingen) durchgeführt. 


\section{REINIGUNG VON ANTISERUM}

Zur Reinigung des Serums wurde eine Antigenaffinitätssäule hergestellt, um Antigen-spezifische Antikörper zu isolieren. Dazu wurde das Fusionsprotein an eine Säulenmatrix gekoppelt. Affi-Gel10 (Biorad) besteht aus, durch UVBestrahlung miteinander verbundenen Agarosekügelchen, die NHydroxysuccinimid-Estergruppen trägt. Liganden, die freie Alkylamino- oder Arylaminogruppen tragen, koppeln unter milden, wäßrigen Bedingungen spontan über die Estergruppen und bilden eine stabile Amid-Bindung zu den Kügelchen aus.

Die Proteinlösung wurde mehrfach gegen Kopplungspuffer dialysiert (HEPES, pH 7,5), um Tris und andere Substanzen zu entfernen, die mit ihren Aminogruppen interagieren könnten. Weiterhin wurde das Säulenmaterial mit drei Bettvolumen eiskaltem $\mathrm{dH}_{2} \mathrm{O}$ gewaschen. Das dialysierte Protein wurde zur Kopplung zur feuchten Matrix gegeben und $4 \mathrm{~h}$ bei $4{ }^{\circ} \mathrm{C}$ unter leichtem Schütteln inkubiert. Nachdem die Lösung entfernt wurde, wurde die Matrix wie folgt gewaschen:

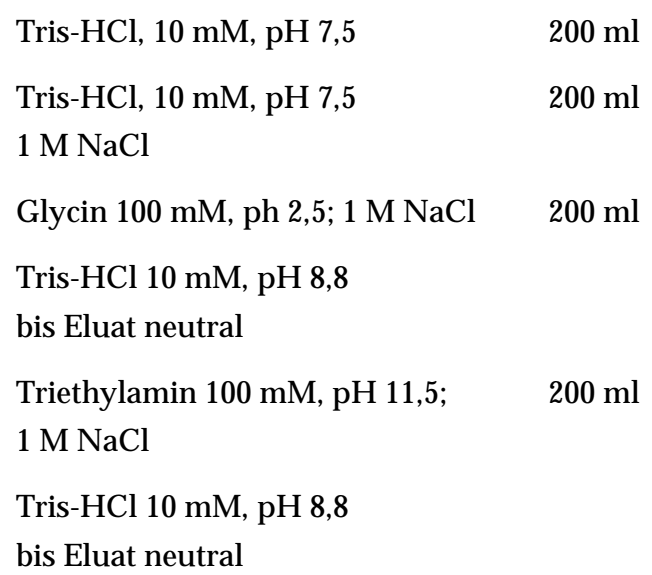

Die fertige Säule wurde bei $4^{\circ} \mathrm{C}$ stehend gelagert. Zur Reinigung wurden jeweils ca. $5 \mathrm{ml}$ Serum dreimal hintereinander über die Säule gegeben, um eine vollständige Bindung von spezifischen Antikörpern an die Säule zu erhalten. Danach wurde wie folgt gewaschen und eluiert: 


$\begin{array}{lc}\text { Tris- } \mathrm{HCl}, 10 \mathrm{mM}, \mathrm{pH} 7,5 & 100 \mathrm{ml} \\ \text { Tris- } \mathrm{HCl}, 10 \mathrm{mM}, \mathrm{pH} 7,5 & 100 \mathrm{ml} \\ 0,5 \mathrm{M} \mathrm{NaCl} & \\ \text { Glycin } 100 \mathrm{mM}, \mathrm{ph} 2,5 ; 1 \mathrm{M} \mathrm{NaCl} & 50 \mathrm{ml} \\ \text { Tris- } \mathrm{HCl} 10 \mathrm{mM}, \mathrm{pH} 7,5 & \\ \text { bis Eluat neutral } & \end{array}$

Die Antikörper wurden durch einen pH-Sprung mit dem Glycin-Puffer eluiert, mit Tris- $\mathrm{HCl}(10 \mathrm{ml} 1 \mathrm{M}, \mathrm{pH} 7,5)$ neutralisiert und gefällt. Zur Fällung wurde ein äquivalentes Volumen gesättigter Ammoniumsulfatlösung unter Rühren langsam zugegeben und die Lösung für $6 \mathrm{~h}$ bei $4{ }^{\circ} \mathrm{C}$ aufbewahrt. Danach wurde abzentrifugiert (Sorvall HB4-Rotor 30 Min., 8.000 U/Min.). Das Pellet wurde in PBS resuspendiert, gegen PBS dialysiert und der gereinigte Antikörper in Aliquots bei $-20^{\circ} \mathrm{C}$ gelagert.

\section{IV.3.28 WESTERN-BLOT}

Die nachfolgend aufgeführte Proteinanalyse, wurde nach der Beschreibung von Towbin durchgeführt (Towbin et al., 1979).

\section{SDS-POLYACRYLAMID-GELELEKTROPHORESE (LAEMMLI, 1970)}

Proben wurden in Laemmli-Ladepuffer gelöst, für $5 \mathrm{Min}$. auf $95^{\circ} \mathrm{C}$ erhitzt und abzentrifugiert. Gewebeproben wurden im Ladepuffer mit Hilfe eines Branson-Cell Disruptors zerschallt, bis eine nichtvisköse Lösung entstanden war. Zur Herstellung eines kleinen Gels (Trenngel $6 \times 11 \times 0,1 \mathrm{~cm}$ ) wurde die Trenngellösung angesetzt und zum Auspolymerisieren zwischen gereinigte, zusammengeklammerte Glasplatten gegossen und mit Isopropanol überschichtet. Nach dem Polymerisieren wurde das Isopropanol weggewaschen, die Sammelgellösung zugegossen und der Kamm zum Formen der Taschen eingeschoben. Nach dem Auspolymerisieren des Sammelgels wurde der Kamm herausgezogen und das Gel in eine vertikale Gelkammer eingespannt. Als Laufpuffer wurde Laemmli-Laufpuffer verwendet. Die Proben wurden mit einer Hamilton-Spritze geladen. Elektrophoretisiert wurde bei max. 150 V für 2-3 h, bis die Lauffront (Bromphenolblau) den unteren Rand des Geles erreicht hat. 


\begin{tabular}{|c|c|c|}
\hline LAEMMLI-LADEPUFFER: & TRENNGEL: & ACRYLAMIDMIX: \\
\hline SDS, $2 \%$ & $\mathrm{H}_{2} \mathrm{O}, 2 \mathrm{ml}$ & Acrylamid, 29,2 \% \\
\hline Glycerol, 10 \% & Acrylamidmix 1,7 ml & Methylenbisacrylamid \\
\hline Tris-HCl, pH 6,8, $60 \mathrm{mM}$ & Tris- $\mathrm{HCl}, \mathrm{pH} 8,8,1,5 \mathrm{M}$, & $0,8 \%$ \\
\hline DTT, $100 \mathrm{mM}$ & $1,3 \mathrm{ml}$ & in $\mathrm{H}_{2} \mathrm{O}$ \\
\hline \multirow[t]{3}{*}{ Bromphenolblau 0,01 \% } & SDS (10\%), $50 \mathrm{ml}$ & \\
\hline & $\operatorname{APS}(10 \%), 50 \mathrm{ml}$ & \\
\hline & TEMED, $2 \mathrm{ml}$ & \\
\hline SAMMELGEL: & LAEMMLI-LAUFPUFFER: & ACRYLAMIDMIX: \\
\hline $\mathrm{H}_{2} \mathrm{O} 2,1 \mathrm{ml}$ & Tris- $\mathrm{HCl}, \mathrm{pH} 8,3,25 \mathrm{mM}$ & Acrylamid, 29,2\% \\
\hline Acrylamidmix, $0,5 \mathrm{ml}$ & Glycin, $250 \mathrm{mM}$ & Methylenbisacrylamid \\
\hline Tris- $\mathrm{HCl}, \mathrm{pH} 6,3,1 \mathrm{M}$ & SDS, $0,1 \%$ & $0,8 \%$ \\
\hline $0,38 \mathrm{ml}$ & & in $\mathrm{H}_{2} \mathrm{O}$ \\
\hline \multicolumn{3}{|l|}{ SDS (10\%), $30 \mathrm{ml}$} \\
\hline APS (10\%), $30 \mathrm{ml}$ & & \\
\hline
\end{tabular}

Das Irx1-Protein wurde durch in-vitro-Translation mittels des Transkriptionsund Translationssystems (TNT, Promega) hergestellt.

\title{
ELEKTROBLOTTEN VON PROTEINGELEN
}

Das nachfolgend aufgeführte Elektroblotten von Proteingelen, wurde nach der Beschreibung von Khysen-Anderson durchgeführt (Khysen-Anderson, 1984).

Nach der Trennung der Proteine durch die SDS-PolyacrylamidGelelektrophorese wurden die Proteine durch elektrophoretischen Transfer auf Kunststoffmembranen (Immobilon, Millipore) übertragen. Dazu wurde folgender Aufbau verwendet:

ELEKTROBLOT:

\author{
Elektrode (-) \\ Drei Lagen Filtrierpapier in Transferpuffer \\ Membran \\ Polyacrylamid-Gel \\ Drei Lagen Filtrierpapier in Transferpuffer \\ Elektrode (+)
}

Zum Blotten wurde das Gerät "Novablot Electrophoretic Transfer Kit" der Firma LKB verwendet. Es wurde bei $0,8 \mathrm{~mA} / \mathrm{cm}^{2}$ Gelfläche $1,5 \mathrm{~h}$ lang geblottet. Nach dem Transfer wurden die Proteine reversibel mit Ponceau-Rot gefärbt, um 
die Position der Größenstandardproteine auf die Membran zu übertragen und die Qualität des Transfers zu beurteilen.

$\begin{array}{ll}\text { TRANSFERPUFFER: } & \text { FÄRBELÖSUNG: } \\ \text { Tris Base, } 48 \mathrm{mM} & \text { Ponceau-S, } 0,2 \% \\ \text { Glycin, } 39 \mathrm{mM} & \text { Trichloressigsäure, 3\% } \\ \text { SDS, } 0,037 \%(\mathrm{vol} / \mathrm{vol}) & \text { Sulfosalicylsäure, } 3 \% \\ \text { Methanol, } 20 \%(\mathrm{vol} / \mathrm{vol}) & \\ \text { add } \mathrm{H}_{2} \mathrm{O} & \end{array}$

IMMUNODETEKTION VON PROTEINEN AUF MEMBRANEN

Zum Entwickeln wurde die Membran nach dem Blotten eine Stunde unter ständiger Bewegung in Blockierungslösung inkubiert, um unspezifische Absorption von Antikörpern an der Membran zu verhindern.

Danach wurde das in Blockierungslösung verdünnte Antiserum zugegeben. Das Ganze wurde in einem Plastikbeutel eingeschweißt und die Inkubation erfolgte auf einem Schütteltisch ü.N. bei $4{ }^{\circ} \mathrm{C}$. Anschließend wurde der Blot viermal je 5 Min. lang bei Raumtemperatur in PBS gewaschen und für eine Stunde mit dem 1:200 in Blockierungslösung verdünnten Schwein-AntiKaninchenimmunglobulin-Peroxidase-Konjugat (DAKO No. P217) inkubiert. Nach erneutem Waschen (2x 5 Min., 2x 15 Min. PBS) wurde der Blot mit dem ECL-Chemiluminiszenz-Reagenz (Amersham) nach den Vorschriften des Herstellers entwickelt. Die gewaschene Membran wurde für 1 Min. in der frisch angesetzten Entwicklungslösung inkubiert, kurz mit Filtrierpapier abgetupft, in Haushaltsfolie eingeschlagen und sofort auf Kodak-XAR Röntgenfilmen exponiert. Die Exponierungszeit betrug in der Regel nur wenige Sekunden. Alternativ wurden Blots mit Diaminobenzidin oder Chlornaphtol als Substrat entwickelt (Harlow und Lane, 1988). Zur Größenbestimmung wurden die RfWerte der Markerproteine gegen den Logarithmus der bekannten Molekulargewichte aufgetragen. Die Größe des zu bestimmenden Proteins wurde duch Interpolation aus dem gemessenen Rf-Wert berechnet. 


\section{IV.3.29 IMMUNHISTOCHEMIE}

\section{HERSTELLEN VON GEFRIERSCHNITTEN}

Gefrierschnitte wurden auf einem Kryostaten (Leitz) angefertigt. Dazu wurde zunächst eine Schicht Einbettmittel (Tissue-Tec; Miles) auf einem auf Trockeneis liegenden Objekthalter aufgetragen und angefroren. Nach nochmaligem Auftragen von Tissue-Tec wurde der gefrorene Embryo auf der noch flüssigen Schicht in die zum Schneiden gewünschte Position gebracht. Langsam wurde schichtweise mehr Einbettmittel um den Embryo aufgetragen bis dieser vollständig umhüllt war (Embryo sollte beim Einbetten nicht auftauen).

Es wurden $5 \mathrm{~mm}$ dicke Schnitte angefertigt, die vom Messer mit einem mit Gelatine und Chromalaun beschichteten Objektträger aufgenommen wurden. Die Schnitte wurden $15 \mathrm{Min}$. bei $50{ }^{\circ} \mathrm{C}$ auf einer Wärmeplatte getrocknet und dann in einem mit Klebeband versiegelten Plastibrand-Objektträgerkasten trocken bei $-20^{\circ} \mathrm{C}$ aufbewahrt.

\section{IMMUNFÄRBUNG VON GEFRIERSCHNITTEN}

Die Gefrierschnitte wurden im Objektträgerkasten aufgetaut und in Färbegestelle einsortiert. Darin wurden die Schnitte mit Aceton nachfixiert (30 s, Raumtemperatur), die endogene Peroxidase inhibiert $\left(0,5 \% \mathrm{H}_{2} \mathrm{O}_{2}\right.$ in Methanol für 30 Min.) und mehrmals in PBS gewaschen. Danach wurden die Objektträger einzeln herausgenommen, PBS durch Papiertücher, der Antikörper, 1:200 verdünnt in Blockierungslösung, aufgetragen und für $6 \mathrm{~h}$ bei Raumtemperatur in einer feuchten Kammer inkubiert. Danach wurde viermal je 5 Min. in PBS gewaschen und der Nachweisantikörper (Ziege-Anti-KaninchenImmunglobulin-Peroxidasekonjugat DAKO No. P744) wie oben angegeben (1:200 verdünnt) aufgetragen. Nach 60 Min. Inkubation wurde erneut gewaschen und mit DAB-Lösung 5 Min. lang entwickelt.

$\begin{array}{cc}\text { BLOCKIERUNGSLÖSUNG } & \text { DAB-ENTWICKLUNGSLÖSUNG } \\ 5 \% \text { Milchpulver in PBS } & 0,5 \mathrm{mg} / \mathrm{ml} \text { DAB (Sigma) } \\ & \text { filtriert } \\ & 0,05 \% \mathrm{H}_{2} \mathrm{O}_{2}\end{array}$


Danach wurde erneut mit PBS gewaschen, mit einer Alkoholreihe dehydriert, in Eukitt eingedeckelt und im Lichtmikroskop mit NomarskiInterferenzkontrast beobachtet.

\section{IV.3.30 HISTOLOGISCHE METHODEN}

\section{HÄMATOXILIN-EOSIN-FÄRBUNG}

Die Hämatoxilin-Eosin-Färbung wurde zur Darstellung der frühen Embryonen im Uterus benutzt. Hämatoxilin bewirkt eine Blaufärbung der Zellkerne, während das Zytoplasma durch Eosin rot gefärbt wird. Die Schnitte werden wie o.a. als Paraffinschnitte hergestellt.

Ablauf:
a. Xylolersatz
3 Min.
1. $\mathrm{dH}_{2} \mathrm{O}$
1 Min.
b. Xylolersatz
3 Min.
m. Eosin
2 - 3 Min.
c. $100 \% \mathrm{EtOH}$
2 Min.
n. $\mathrm{dH}_{2} \mathrm{O}$
1 Min.
d. $96 \% \mathrm{EtOH}$
2 Min.
o. $50 \% \mathrm{EtOH}$
2 Min.
e. $90 \% \mathrm{EtOH}$
2 Min.
p. $70 \% \mathrm{EtOH}$
2 Min.
f. $80 \% \mathrm{EtOH}$
2 Min.
q. $80 \% \mathrm{EtOH}$
2 Min.
g. $70 \% \mathrm{EtOH}$
2 Min.
r. $90 \% \mathrm{EtOH}$
2 Min.
h. $50 \% \mathrm{EtOH}$
2 Min.
s. $96 \% \mathrm{EtOH}$
2 Min.
i. $\mathrm{dH}_{2} \mathrm{O}$
einmal kurz
t. $100 \% \mathrm{EtOH}$
2 Min.
eintauchen
j. Hämatoxilin
5 - 7 Min.
u. Xylolersatz
2 Min.
(Harris)
k. HCl-Alkohol
$3 \times 10-30$ s..
v. Xylolersatz
2 Min.

Im Anschluß wurden die Schnitte mit Eukitt-Einbettmedium eingedeckelt und ü.N. getrocknet.

$$
\begin{aligned}
& \text { HCL-ALKOHOL } \\
& 500 \mathrm{ml} 70 \% \mathrm{EtOH} \\
& 5 \mathrm{ml} \mathrm{konz} . \mathrm{HCl}
\end{aligned}
$$

EOSIN:

$0,5 \mathrm{~g}$ Eosin in $500 \mathrm{ml} \mathrm{dH}_{2} \mathrm{O}$ lösen unter Zugabe von zwei

Tropfen konz. Essigsäure,

filtrieren
HÄMATOXYLIN:

fertige Lösung, filtrieren 


\section{IV.3.31 ARBEITEN MIT GLI1- UND GLI2-MAUSMUTANTEN}

Die Gli1-Mauslinie wurde nach den Informationen von Dr. Park und die Gli2Mauslinie entsprechend nach den Informationen von Dr. Mo verpaart und genotypisiert (Park et al., 2000; Mo et al., 1997). 


\section{GlOSSAR, ABKÜRZUNGEN UND SYMBOLE}

\section{GLOSSAR}

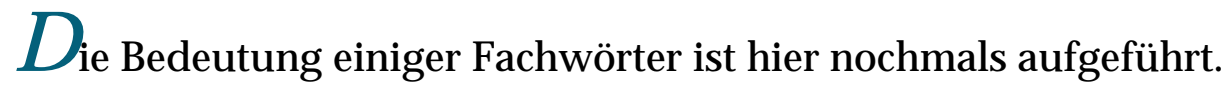

Aktivator: Molekül, das die Aktivität eines Gens anschaltet

Allel: Zustandsform eins Gens

Blastozyste: Embryonalstadium der Säugetiere, das der Blastula anderer Tierembryonen entspricht und in dem die Einnistung in die Uterusschleimhaut erfolgt (Wolpert et al., 1999); die Blastozyste stellt den Tag E4.0 der Mausembryogenese dar

Blotting: Unter Blotting versteht man den Übertrag (Transfer) von elektrophoretisch aufgetrennten DNA-, RNA- oder Proteingemischen auf spezielle Filter oder Membranen, die den spezifischen Nachweis einer bestimmten Nukleinsäuresequenz oder Proteinspezies erlauben

cDNA: komplementäre DNA; wird in der Gentechnik in vitro und mit Hilfe des Enzyms Reverse Transkriptase an isolierter, polyadenylierter, eukaryotischer mRNA, die als Matrize dient, erzeugt

Cre-Rekombinase: Enzym, welches die loxP-Sequenz erkennt und eine Rekombinasereaktion durchführt. Befinden sich zwei loxP-Stellen in der selben Orientierung, wird das Fragment, welches sich zwischen zweier solcher Sequenzen, einschließlich einer loxP-Stelle, entfernt. Sind beide loxP- 
Sequenzen in gegensätzlicher Orientierung, wechselt die Cre-Rekombinase die Orientierung des eingefaßten Fragmentes.

detektieren: nachweisen, erkennen

downstream: wörtlich: stromabwärts; in einer Kaskade: unterhalb, als nachgeschalteter Faktor; bei einem Gen: weiter 3’ gelegen

eigentlicher Embryo: der Bereich des Embryos, ohne den extraembryonalen Bereich; engl.: embryo proper (räumlicher Begriff) (Beddington und Robertson, 1999)

Embryo: Frühstadium der Entwicklung mit embryonalem und extraembryonalem Bereich (räumlicher Begriff)

Enhancer: DNA-Sequenzen in 5'-Richtung vor eukaryotischen Promotoren, deren Funktion die Erhöhung der Transkriptionsrate ist

Epiblast: primitives Ektoderm

ES-Zellen (embryonale Stammzellen): pluripotente Stammzellen, die aus der Mausblastozyste hergestellt werden und sich in vivo $\mathrm{zu}$ allen Geweben, einschließlich der Keimbahnzellen, differenzieren

gastrulärer Embryo: Embryo, der sich im Gastrulationsstadium befindet; Zeitraum E6,5 bis E8,0 (Hogan et al., 1994)

generieren: herstellen

Gen-Knock-out (KO): gezielte Deletion oder Inaktivierung (eines Gens); Verlustmutante

Genexpression: Aktivität eines Gens

Homologe Gene: Gene, die signifikante Ähnlichkeiten in ihrer Nukleotidsequenz besitzen, da sie von einem gemeinsamen Urgen abstammen

Homologe Rekombination: Rekombination zweier DNA-Moleküle an einer bestimmten Stelle, an denen sich ihre Sequenzen ähneln (Wolpert et al., 1999); Erzeugung neuer Kombinationen des genetischen Materials durch Austausch von Nukleinsäuremolekülen

Insert: Insert-DNA, Passagier-DNA, Fremd-DNA

in-situ-Hybridisierung: Technik, mit deren Hilfe man nachweisen kann, wo im Embryo bestimmte Gene exprimiert werden. 
IRES: interne ribosomale Verstärkerstelle (engl. internal ribosomal enhancer site)

Keimbahn: Zellen, die sich zu Spermien und Eizellen entwickeln

Kluster: Zellgruppe

Konservierung: evolutive Erhaltung

Konstrukt: DNA-Molekül, das durch in-vitro-Verknüpfung verschiedener DNAMoleküle entstanden ist

lacZ-Gen: $\beta$-Galaktosidase-kodierendes Cistron des Lac-Operons von E. coli

LoxP: 34bp-Sequenz, welche spezifisch von der Cre-Rekombinase erkannt wird

Mauschimären: Mäuse, die mittels ES-Zell-Aggregation oder ES-Zell-Injektion in Blastozysten hergestellt werden. Diese haben Organe und Gewebe welche ES-Zell- oder "Gastembryo"-Ursprungs sind. Weiterhin zeigt die Fellfarbe eine Mischfarbe, welche ein Hinweis über den Grad des Chimärismus darstellt.

Morula: frühes Stadium des Säugerembryos ab ca. 8 Zellen (Blastomere) oder mehr. Sie zeigt die Gestalt einer Beere (Morula)

Northern-Blot: RNA-Blot, RNA-Transfer

Pluripotenz: Kapazität von Zellen sich in die meisten Zelltypen des Organismus zu entwickeln. So entwickeln sich die Maus-ES-Zellen sich zu allen Geweben bis auf die Plazenta. Totipotente Zellen können sich dagegen in alle Zelltypen entwickeln.

prägastrulärer Embryo: Embryo, der sich vor dem Gastrulationsstadium befindet; Zeitraum E5,5 bis E6,5 (Hogan et al., 1994)

Primer: jede Oligonukleotidsequenz, die nach Hybridisierung mit einer einzelsträngigen Nukleinsäure einen kurzen doppelsträngigen Bereich mit freier 3'- OH-Gruppe liefert und damit eine weiteres Auffüllen über DNAPolymerasen oder Reverse Transkriptasen ermöglicht

Probe: Sonde (durch Denaturieren einzelsträngiger RNA oder DNA), welche zum Hybridisieren benutzt wird

Promotor: RNA-Polymerase-Bindungsstelle, Ort der Initiation der Transkription prospektiv: zukünftig

Repressor: Molekül, das die Aktivität eines Gens unterdrücken 
Reportergen: Im Gegensatz zu selektierbaren Markergenen, die eine Auslese rekombinanter Klone oder transgener Organismen gestatten, kann ein erfolgreicher Gentransfer auch über Reportergene anhand eines leicht erkennbaren Phänotyps erfolgen (z. B. $\beta$-Galaktosidase-Färbung).

Selektionsmarker: Bezeichnung für eine DNA-Sequenz, die es ermöglicht ein Auswahlverfahren für Organismen, die einen veränderten Geno- oder Phänotyp haben, durchzuführen

Southern-Blot: DNA-Blot, DNA-Transfer

transgene Maus: Maus mit verändertem Genom durch z. B. stabile Integration eines neuen Gens oder die Inaktivierung eines bestimmten Gens

targeting construct: Rekombinationskonstrukt

upstream: wörtlich: stromaufwärts; in einer Kaskade: oberhalb, als vorgeschalteter Faktor; bei einem Gen: weiter 5' gelegen

Western-Blot: Protein-Blot, Protein-Transfer

whole-mount-Hybridisierung: in-situ-Hybridisierung auf ganzen Embryonen whole-mount-in-situ-Hybridisierung: Gesamtkörper-in-situ-Hybridisierung 


\section{ABKÜRZUNGEN UND SYMBOLE}

Neben den konventionellen physikalischen Einheiten, chemischen Symbolen und dem Ein- und Dreibuchstabenkode für Aminosäuren finden folgende Abkürzungen und Symbole Verwendung:

\begin{tabular}{ll} 
Abb. & Abbildung \\
Ac & Acetat \\
Amp & Ampicillin \\
AP & alkalische Phosphatase \\
APS & Ammoniumpersulfat \\
As & Aminosäure \\
ATP & Adenosintriphosphat \\
bp & Basenpaar \\
cDNA & complementary DNA \\
Ci & Curie \\
CI & Chloroform/Isoamylalkohol (24:1) \\
CIP & Phosphatase aus Kälberdarm (calf intestinal phosphatase) \\
cpm & radioaktive Zerfälle pro Minute (counts per minute) \\
d & Tag \\
ddH & bidestilliertes Wasser (Millipore) \\
dATP & desoxy-Adenosintriphosphat \\
dCTP & desoxy-Cytidintriphosphat \\
dGTP & desoxy-Guanosintriphosphat \\
dTTP & desoxy-Thymidintriphosphat \\
DMEM & Dulbeccós Modified Eaglés Medium \\
dNTP & desoxy-Nukleotidtriphosphate \\
DEPC & Diethylpyrocarbonat \\
DMF & Dimethylformamid \\
DMSO & Dimethylsulfoxid \\
DNS & Desoxyribonukleinsäure \\
DNase & Desoxyribonuklease \\
ds & doppelsträngig \\
\hline
\end{tabular}




\begin{tabular}{|c|c|}
\hline DTT & Dithiothreitol \\
\hline EDTA & Ethylendiamintetraacetat \\
\hline $\mathrm{EtBr}$ & Ethidiumbromid \\
\hline ES-Zellen & embryonale Stammzellen \\
\hline FCS & ötales Kälber Serum (fetal calf serum) \\
\hline $\mathrm{g}$ & Gramm \\
\hline $\mathrm{h}$ & Stunde \\
\hline HEPES & N-2-Hydroxyethylpiperazin-N'-2-Ethansulfonsäure \\
\hline IPTG & Isopropylthio- $\beta$-D-Galaktosid \\
\hline LB & Luria-Bertani-Medium \\
\hline LIF & Leukaemia Inhibiting Faktor \\
\hline Lsg. & Lösung \\
\hline$\mu$ & micro \\
\hline $\mathrm{m}$ & milli \\
\hline M & molar \\
\hline Min. & Minuten \\
\hline MOPS & Morpholinopropansulfonsäure \\
\hline Neo & Neomycin \\
\hline mRNA & messenger RNA \\
\hline OD & optische Dichte \\
\hline p.a. & pro analysis \\
\hline PAA & Polyacrylamid \\
\hline PBS & Phosphat-gepufferte Salzlösung (phosphate buffered saline) \\
\hline p.c. & post coitum \\
\hline PCI & Phenol/Chloroform/Isoamylalkohol (25:24:1) \\
\hline PEG & Polyethylenglykol \\
\hline Pen/Strep & Penicillin/Streptomycin \\
\hline $\mathrm{pfu}$ & infektiöse Partikel (plaque forming units) \\
\hline PIPES & Pipazarin-N-N’-bis(2-Ethansulfonsäure) \\
\hline PVP & Polyvenyl-Pyrrolidon \\
\hline RNS & Ribonukleinsäure \\
\hline RNase & Ribonuklease \\
\hline rpm & Umdrehungen pro Minute (rounds per minute) \\
\hline RSA (BSA) & Rinderserumalbumin (bovine serum albumin) \\
\hline RT & Raumtemperatur \\
\hline s & Sekunden \\
\hline
\end{tabular}


SDS

ST I

SS

SSC

TBE

TE

TEMED

Tris

tRNA

$\mathrm{U}$

ü.N.

$\mathrm{V}$

Vol.

VE-Wasser

wt

X-Gal
Natriumdodecylsulfat (sodiumdodecylsulfate)

Standard-I Nährmedium/Agar

einzelsträngige

$\mathrm{NaCl} / \mathrm{NaCitrat}$ (standard saline citrate solution)

Tris-Borat-EDTA Puffer

Tris-EDTA Puffer

$\mathrm{N}, \mathrm{N}, \mathrm{N}^{\prime}, \mathrm{N}^{\prime}$-Tetramethylethylendiamin

Tris(hydroxymethyl)-aminomethan

transfer RNA

unit

über Nacht

Volt

Volumen

vollentsalztes Wasser

Wildtyp

5-Bromo-4-chloro-3-indolyl- $\beta$-D-galaktosid 


\section{ZUSAMMENFASSUNG}

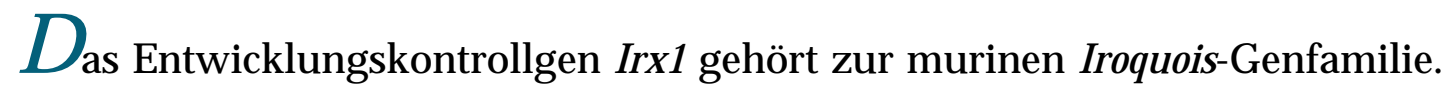
Diese umfaßt sechs Familienmitglieder, welche in zwei Tandemstrukturen im Genom organisiert sind. Irx 1 zeichnet sich durch eine konservierte Homeo- und eine Iro-Box aus. Die Homeobox stellt ein klassisches DNA-Bindungsmotiv dar, wohingegen die Iro-Box für ein neues Protein-Protein-Bindungsmotiv kodiert.

Das Gen Irx1 zeigt ein spezifisches räumliches und zeitliches Expressionsmuster. Irx1-Expression läßt sich im Embryo ab dem Stadium E6,5 und nach der Geburt nachweisen. Im prägastrulären Embryo ist Irx1 im extraembryonalen Ektoderm exprimiert und diese Expression verändert sich im Laufe der Gastrulation, so daß an deren Ende das embryonale Mesoderm und der Primitivknoten Irx1-Aktivität aufweisen. Während der Entwicklung zeigt Irx1 eine spezifische Expression sowohl während der Bildung des zentralen Nervensystems als auch während der embryonalen Lungen- und Extremitätenentwicklung. Dabei stellt Irx1 einen exzellenten Marker für die Entwicklung der Phalangen dar. Die Analyse der Expression von Irx1 während der Fingerentwicklung wurde im Vergleich zu Irx2 und den Gli-Genen, als potentielle Regulatorgene, durchgführt.

Für die Analyse der Funktion des Irx1-Gens in der späteren embryonalen Entwicklung wurden die potentiell evolutiv konservierten Regulationspartner untersucht. Die Analyse der Gli1- und Gli2-Mausmutanten konnte eine Interaktion mit Irx1 zeigen, was auf eine konservierte Regulatorfunktion hindeutet. Die in vitro-Analyse eines potentiellen Zielgens von Irx 1 ergab, daß keine Aktivierung des Mash1-Promotors vorliegt. Die Regulation Gli-Irx-Mash ist in der Maus nur teilweise evolutiv erhalten geblieben, so sind die 
Interaktionspartner der regulativen Kaskade identisch, aber nicht die funktionelle Ausprägung.

Die Funktion von Irx 1 wurde durch eine gezielte Inaktivierung des Gens über homologe Rekombination in ES-Zellen untersucht. Irx1-defiziente Embryonen sterben embryonal und letzte Reste mutanter Embryonen sind maximal bis zum Stadium E10,5 zu erkennen. Irx1-defiziente Embryonen weisen eine vermehrte Bildung an mesodermal erscheinenden Zellen im extraembryonalen Bereich auf. Dies führt dazu, daß die extraembryonalen Höhlen sich nicht ausbilden, sondern mit Zellen angefüllt sind. Es konnten Mißexpressionen verschiedener embryonal bedeutsamer Gene wie BMP4, Brachyury, Gbx2 oder Otx2 gezeigt werden. Sie sind die genetischen Marker für das extraembryonale Mesoderm, den Primitivstreifen oder das anteriore viszerale Endoderm. Anhand dieser Daten konnte gezeigt werden, daß Irx1 eine essentielle Rolle während der Gastrulation spielt und wesentlich an der Bildung und Umsetzung der induktiven Funktionen der posterioren und auch der anterioren viszeralen Entwicklung beteiligt ist. 


\section{LITERATURVERZEICHNIS}

Acampora, D., Mazan, S., Lallemand, Y., Avataggiato, V., Maury, M., Simeone, A., and Brulet, P. (1995). Forebrain and midbrain regions are deleted in Otx2-/- mutants due to the defective anterior neuroectoderm specification during gastrulation. Development 121, 3279-3290.

Ang, S.-L., Jin, O., Rhinn, M., Daigle, N., Stevenson, L., and Rossant, J. (1996). A targeted mouse Otx2 mutation leads to severe defects in gastrulation and formation of axial mesoderm and to deletion of reostral brain. Development $122,243-252$.

Ang, S. L., and Rossant, J. (1994). HNF-3 $\beta$ is essential for node and notochord formation in mouse development. Cell 78, 561-574

Artavanis-Tsakonas, S., Rand, M. S., and Lake, R. J. (1999). Notch signalling: cell fate control and signal integration in development. Science 284, 770-776.

Ausubel, F. M., Brent, R., Kingston, R. E., Moore, D. D., Seidman, J. G., Smith, J. A., and Struhl, K. (1987). Current protocolls in molecular biology. I + II (New York: John Wiley \& Sons).

Ausubel, F. M., Brent, R., Kingston, R. E., Moore, D. D., Seidman, J. G., Smith, J. A., and Struhl, K. (1995). Short protocols in molecular biology, 3rd Edition (New York: John Wiley \& Sons).

Baker, J. C., Beddington, R. S. P., and Harland, R. M. (1999). Wnt signalling in Xenopus embryos inhibits BMP4 expression and activates neural development. Genes Dev. 13, 3149-3159. 
Ball, D. W., Azzoli, C. G., Baylin, S. B., Chi, D., Dou, S., Donis-Keller, H., Cumaraswamy, A., Borges, M., and Nelkin, B. (1993). Identification of a human achaete-scute homologue highly expressed in neuroendocrine tumors. Proc. Natl. Agad. Sci. USA 90, 5648-5652.

Bao, Z. Z., Bruneau, B. G., Seidman, J. G., Seidman, C. E., and Cepko, C. L. (1999). Regulation of chamber-specific gene expression in the developing heart by Irx4. Science 283, 1161-4.

Bard, J. B. L., and Kaufmann, M. H. (1994). The mouse., J. B. L. Bard, ed. (London: Wolfe Publishing).

Becker, M. B., Zülch, A., and Gruss, P. (2001). Irx2 and Irx1 expression in early lung development. Mech. Dev. in Press.

Beddington, R. S. P., and Robertson, E. J. (1998). Anterior patterning in mouse. TIG 14, 277-284.

Beddington, R. S. P., and Robertson, E. J. (1999). Axis development and early asymmetry in mammals. Cell 96, 195-209.

Belaoussoff, M., Farrington, S. M., and Baron, M. H. (1998). Hematopoietic induction and respecification of A-P identity by visceral endoderm signaling in the mouse embryo. Development 125, 5009-5018.

Bellefroid, E. J., Kobbe, A., Gruss, P., Pieler, T., Gurdon, J. B., and Papalopulu, N. (1998). Xiro3 encodes a Xenopus homolog of the Drosophila Iroquois genes and functions in neural specification. EMBO J. 17, 191-203.

Belo, J. A., Bouwmester, T., Leyns, T., Kertesz, L., Gallo, N., Follettie, M., and De Robertis, E. M. (1997). Cerberus-like is a secreted factor with neuralizing activity expressed in the anterior primitive endoderm of the mouse gastrula. Mech. Dev. 68, 45-57. 
Beppu, H., Kawabata, M., Hamamoto, T., Chytil, A., Minowa, O., Noda, T., and Miyazono, K. (2000). BMP type II receptor is required for gastrulation and early development of mouse embryos. Dev. Biol. 221, 249-58.

Birnboim, H. C., and Doly, J. (1979). A rapid alkaline extraction procedure for screening recombinant plasmid DNA. Nucleic Acids Res. 7, 1512-1523.

Bosse, A., Stoykova, A., Nieselt-Struwe, K., Chowdury, K., Copeland, N. G., Jenkins, N. A., and P, G. (2000). Identification of a novel mouse Iroquois homeobox gene, Irx5, and chromosomal localization of all members of the mouse Iroquois gene family. Dev. Dyn. 218, 160-174.

Bosse, A., Zülch, A., Becker, M. B., Torres, M., Gomez-Skarmeta, J. L., Modolell, J., and Gruss, P. (1997). Identification of the vertebrate iroquois homeobox gene family with overlapping expression during early development of the nervous system. Mech. Dev. 69, 169-181.

Bronson, S., and Smithies, O. (1994). Altering mice by homologous recombination using embryonic stem cells. J. Biol. Chem. 269, 27155-8.

Bruneau, B., Bao, Z., Tanaka, M., Schott, J., Izumo, S., Cepko, C., Seidman, J., and Seidman, C. (2000). Cardiac expression of the ventricle-specific homeobox gene Ir $x 4$ is modulated by Nkx2-5 and $d H a n d$. Dev. Biol. 217, 266-277.

Burglin, T. R. (1997). Analysis of TALE superclass homeobox genes (MEIS, PBX, KNOX, Iroquois, TGF) reveals a novel domain conserved between plants and animals. Nucleic Acids Res. 25, 4173-4180.

Bürki, K. (1986). Experimental embryology of the mouse. (Basel: Karger).

Büscher, D., and Rüther, U. (1998). Expression profile of Gli family members and Shh in normal and mutant mouse limb development. Dev. Dyn. 211, 88-96.

Calvin, N. M., and Hanawalt, P. C. (1988). High-efficiency transformation of bacterial cells by electroporation. J. Bacteriol. 170, 2796-2801. 
Capecchi, M. R. (1989). Altering the mouse genome by homologous recombination. Science 244, 1288-1292.

Chitins, A., Henrique, D., J., L., Ish-Horowitcz, D., and Kintner, C. (1995). Primary neurogenesis in Xenopus embryos is regulated by homologue of the Drosophila neurogenic gene Delta. Nature 375, 761-766.

Chomczynski, P. (1993). A reagent for the single-step simultaneous isolation of RNA, DNA, and proteins from cell and tissue samples. Biotech. 15, 532-536.

Chomczynski, P., and Quasba, P. K. (1984). Alkaline transfer of DNA to plastic membrane. Biochem. Biophys. Res. Comm. 122, 340-344.

Chomczynski, P., and Sacchi, N. (1987). Single-step method of RNA isolation by acid guanidinium thiocyanate-phenol-chloroform extraction. Anal. Biochem. $162,156-159$.

Chou, and Fasman (1978). Prediction of the secondary structure of proteins from their amino acid sequence. Adv. Enzymol. 47, 45-178.

Cohen, D. R., Cheng, C. W., Cheng, S. H., and Hui, C. C. (2000). Expression of two novel mouse Iroquois homeobox genes during neurogenesis. Mech. Dev. 91, 317-321.

Conlon, F. L., Lyons, K. M., Takaesu, N., Barth, K. S., Kispert, A., Hermann, B., and Robertson, E. J. (1994). A primary requirement for nodal in the formation and maintenance of the primitive streak in the mouse. Development 126, 1919-1928.

Coucouvanis, E., and Martin, G. R. (1999). BMP signaling plays a role in visceral endoderm differentiation and cavitation in the early mouse embryo. Development 126, 535-46.

Dambly-Chaudière, C., and Leynes, L. (1992). The determination of sense organs in Drosophila: a search for interactimg genes. Int. J. Dev. Biol. 36, 85-91. 
Doetschman, T., Maeda, N., and Smithies, O. (1988). Targeted mutation of the Hprt gene in mouse embryonic stem cells. Proc. Natl .Acad. Sci. U S A 85, 8583-7.

Dower, W. J., Miller, J. F., and Ragsdale, C. W. (1988). High efficiency transformation of E. coli by high voltage electroporation. Nucleic Acids Res. $16,6127-6145$.

Dyer, M. A., Farrington, S. M., Mohn, D., Munday, J. R., and Baron, M. H. (2001). Indian hedgehog activates hematopoiesis and vasculogenesis and can respecify prospective neuroectodermal cell fate in the mouse embryo. Development $128,1717-1730$.

Fahrner, K., Hogan, B. L. M. and Flavell, R. A. (1987). Transcription of H-2 and Qa genes in embryonic and adult mice. EMBO J. 6, 1265-1271.

Feinberg, A. P., and Vogelstein, B. (1983). A technique for radiolabelling DNA restriction endonuclease fragments to high specific activity. Anal. Biochem. 132, 6-13.

Funayama, N., Sato, Y., Matsumoto, K., Ogura, T., and Takahashi, Y. (1999). Coelom formation: binary decision of the lateral plate mesoderm is controlled by the ectoderm. Development 126, 4129-38.

Gardner, R. L. (1998). Axial relationships between egg and embryo in the mouse. Curr. Top. Dev. Biol. 39, 35-71.

Gardner, R. L. (1997). The early blastocyst is bilaterally symmetrical and its axis of symmetry is aligned with the animal-vegetal axis of the zygote in the mouse. Development 124, 289-301.

Gardner, R. L., and Rossant, J. (1979). Investigation of the fate of 4 - 5 day postcoitum mouse inner cell mass cells by blastocyst injection. J. Embryol. Exp. Morphol. 52, 141-152. 
Garnier, J., Osguthorpe, D. J., and Robson, B. (1978). Analysis of the accuracy and implications of simple methods for predicting the secondary structure of globular proteins. J. Mol. Biol. 120, 97-120.

Gehring, W. J. (1994). Guidesbook to the Homeobox Genes., D. Duboule, ed. (Oxford: Oxford University Press).

Gómez-Skarmeta, J. L., del lel Calle-Mustiemces, E., and Modolell, J. (2001). The Wnt-activated Xiro1 gene encodes a repressor that is essential for neural development and downregulates Bmp4. Development 128, 551-560.

Gómez-Skarmeta, J. L., Diez del Corral, R., del lel Calle-Mustiemces, E., FerrésMarcó, M. D., and Modolell, J. (1996). araucan and caupolitan, two members of the novel Iroquois complex, encode homeoproteins that control proneural and vein forming genes. Cell 85. 95-105.

Gómez-Skarmeta, J. L., Glavic, A., del lel Calle-Mustiemces, E., Modolell, J., and Mayor, R. (1998). Xiro, a Xenopus homolog of the Drosophila Iroquois complex genes, controls development at the neural plate. EMBO J. 17, 181-190.

Gómez-Skarmeta, J. L., and Modolell, J. (1996). araucan and caupolitan provide a link between compartment subdivisions and patterning of sensory organs and veins in the Drosophila wing. Genes Dev. 10, 2935-2945.

Gómez-Skarmeta, J. L., Rodríguez, I., Martínez, C., Culí, J., Ferrés-Marcó, M. D., Belmonte, D., and Modolell, J. (1995). Cis-regulatorion of achaete and scute: Shared enhancer-like elements drive their coexpression in proneural clusters of the imaginal discs. Genes Dev. 9, 1869-1882.

Goriely, A., Diez del Corral, R., and Storey, K. G. (1999). c-Irx2 expression reveals an early subdivision of the neural plate in the chick embryo. Mech. Dev. 87, 203-6. 
Greene, L. A., and Tischler, A. S. (1976). Establishment of a noradrenergic clonal line of rat adrenal pheochromocytoma cells which respond to nerve growth factor. Proc. Natl. Acad. Sci. USA 73, 2424-2428.

Gu, Z., Reynolds, E. M., Song, J., Lei, H., Feijen, A., Yu, L., He, W., MacLaughlin, D. T., van den Eijnden-van Raji, J., Donahoe, P. K., and Li, E. (1999). The type I serine/threonine kinase receptor ActRIA (ALK2) is required for gastrulation of the mouse embryo. Development 126, 2551-2561.

Guillemot, F., Lo, L. C., Johnson, J. E., Auerbach, D. J., Anderson, D. J., and Joyner, A. L. (1993). Mammalian achaete-scute homolog 1 is required for the early development of olfactory and autonomic neurons. Cell 75, 463-476.

Guillemot, F., Nagy, A., Auerbach, D. J., Rossant, J., and Joyner, A. L. (1994). Essential role of Mash-2 in extraembryonic development. Nature 371, 333-336.

Hamburger, V., and Hamilton, H. L. (1951). A series of normal stages in the development of a chick. J. Morph. 88, 49-92.

Hanahan, D. H. (1985). Techniques for transformation of E. coli., D. M. Glover, ed. (Oxford: IRL Publisher).

Harlow, E., and Lane, D. (1988). Antibodies. A labratory manual., C. S. Harbour, ed. (New York: Cold Spring Harbour Labratory).

Heitzler, P., Bourouis, M., Ruel, L., Cateret, C., and Simpson, P. (1996). Genes of the Enhancer of Split and achaete-scute complexes are required for a regulatory loop between Notch and Delta during lateral signalling in Drosophila. Development 122, 161-171.

Helling, R. B., Goodman, H., and Boyer, H. W. (1974). Analysis of endonuclease R EcoRI fragments of DNA from lambdoid bacteriophages and other viruses by agarose-gel electrophoresis. J. of Virology 14, 1235-1244. 
Hemmati-Brivanlou, A., and Melton, D. A. (1997). Vertebrate embryonic cells will become nerve cells unless told otherwise. Cell 88, 13-17.

Heng, H. H. Q., Squire, J., and Tsui, 1.-C. (1992). High resolution mapping of mammalian genes by in situ hybridization to free chromatin. Proc. Natl. Acad. Sci. USA 89, 9509-9513.

Heng, H. H. Q., and Tsui, 1.-C. (1993). Modes of DAPI banding and simultaneous in situ hybridization. Chromosoma 102, 325-332.

Hermann, B. G. (1991). Expression pattern of the Brachyury gene in whole mount

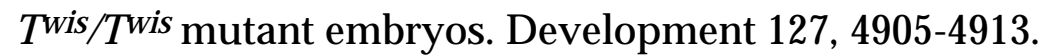

Herrmann, B. G., Labelt, S., Poustka, A., King, T. R., and Lehrach, H. (1990). Cloning of the $T$ gene required in mesoderm formation in the mouse. Nature $343,617-622$.

Hogan, B., Beddington, R., Constantini, F., and Lacy, E. (1994). Manipulating the Mouse Embryo. A Labratory Manual., 2nd Edition (New York: Cold Spring Harbour Labratory Press).

Hogan, B. L. (1996). Bone morphogenetic proteins: Multifunctional regulators of vertebrate development. Genes Dev. 10, 1580-1594.

Hogan, B. L., and Yingling, J. M. (1998). Epithelial/mesenchymal interactions and branching morphogenesis of the lung. Curr. Opin. Gene Dev. 8, 481-486.

Jessell, T. M., and Sanes, J. R. (2000). The decade of the developing brain. Curr. Opin. Neuro. Biol. 10, 599-611.

Johnson, P. H., and Grossman, L. I. (1977). Electrophoresis of DNA in agarose gels. Optimizing separations of conformational isomers of double- and singlestranded DNAs. Biochemistry 16, 4217-4225. 
Kaestner, K. H., Lee, K.-H., Schlöndorff, J., Hiemisch, H., Monaghan, A. P., and Schütz, G. (1993). Six members of the mouse forkhead gene family are developmentally regulated. Proc. Natl. Acad. Sci. USA 90, 76628-76631.

Kaufmann, M. H., and Bard, J. B. L. (1999). The anatomical basis of mouse development. (London: Academic Press).

Khysen-Anderson, J. (1984). Electroblotting of multiple gels: a simple apparatus without buffer tank for rapid transfer of proteins from polyacrylamide to nitrocellulose. J. Biochem. Biophys. Meth. 10, 203-209.

Kirby, K. S. (1956). A new method for the isolation of desoxyribonucleic acids: evidence on the nature of bonds between deoxyribonucleic acid and protein. Biochem. J. 66, 495-504.

Kispert, A., and Hermann, B. G. (1994). Immunohistochemical analysis of the Brachyury protein in wild-type and mutant mouse embryos. Dev. Biol. 161, 179-193.

Laemmli, E. K. (1970). Cleavage of structural proteins during the assembly of the head if bacteriophage T4. Nature 227, 680-685.

Lawson, K. A., Dunn, N. R., Roelen, B. A., Zeinstra, L. M., Davis, A., Wright, C. V., Korving, J. P., and Hogan, B. (1999). Bmp4 is required for the generation of primordial germ cells in the mouse embryo. Genes Dev. 13, 424-36.

Lewis, M. T., Ross, S., Strickland, P. A., Snyder, C. J., and Daniel, C. W. (1999). Regulated expression patterns of IRX-2, an Iroquois-class homeobox gene, in the human breast. Cell Tis. Res. 296, 549-54.

Leyns, L. (1991). Patterns des organes sensorieles: isolement et étude de génes. (Bruxelles: Université Libre de Bruxelles). 
Leyns, L., Gomez-Skarmeta, J., and Dambly-Chaudiere, C. (1996). iroquois: a prepattern gene that controls the formation of bristles on the thorax of Drosophila. Mech. Dev. 59, 63-72.

Liu, P. W., M., Shea, M. J., Albrecht, U., Behringer, R., and Bradley, A. (1999). Requirement for Wnt3 in vertebrate axis formation. Nat. Genet. 22, 361-365.

Ma, Q., Kintner, C., and Anderson, D. Q. (1996). Identification of neurogenin, a vertebrate neuronal determination gene. Cell 87, 43-52.

Manning, J. E., Hershey, N. D., Broker, T. R., Pellegrini, M., Mitchell, H. K., and Davidson, N. (1975). A new method of in situ hybridization. Chromosoma 53, 107-117.

Mansouri, A. (2001). Determination of gene function by homologous recombination using embryonic stem cells and knockout mice., Volume 175, P. M. Starkey and R. Elaswarapu, eds. (Totowa, NY: Humana Press Inc.).

Mansouri, A. (2000). Mouse Knockouts., 2nd, (Macmillian Refernce Ltd.).

Marmur, J. (1960). A procedure for the isolation of deoxyribonucleic acid from micro-organisms. J. Mol. Biol. 3, 208-218.

Matsuo, I., Kuratani, S., Kimura, C., Takeda, N., and Aizawa, S. (1995). Mouse Otx2 functions in the formation and patterning of rostral head. Genes Dev. 9, 2646-58.

Mayor, R., Young, R., and Vargas, A. (1999). Development of Neural Crest in Xenopus., Volume 43, R. A. Pedersen and G. P. Schatten, eds. (San Diego: Academic Press).

McDonell, M. W., Simon, M. N., and Studier, F. W. (1977). Analysis of restriction fragments of T7 DNA and determination of molecular weights by electrophoresis in neutral and alkaline gels. J. Mol. Biol. 110, 119-146. 
McDougall, J. K., Dunn, A. R., and Jones, K. W. (1972). In situ hybridization of adenovirus RNA and DNA. Nature 236, 346-348.

McMahon, A. P. (2000). Neural patterning: The role of $N k x$ genes in the ventral spinal cord. Genes Dev. 14, 2261-2264.

McNeill, H., Yang, C. H., Brodsky, M., Ungos, J., and Simon, M. A. (1997). mirror encodes a novel PBX-class homeoprotein that functions in the definition of the dorsal-ventral border in the Drosophila eye. Genes Dev. 11, 1073-1082.

Meyers, E. N., Lewandowski, M., and Martin, G. (1998). An Fgf8 mutant allelic series generated by Cre- and Flp-mediated recombination. Nat. Genet. 18.

Mishina, Y., Suzuki, A., Gilbert, D. J., Copeland, N. G., Jenkins, N. A., Ueno, N., and Behringer, R. R. (1995). Genomic organization and chromosomal location of the mouse type I BMP-2/4 receptor. Biochem. Biophys. Res. Commun. 206, 310-7.

Mishina, Y., Suzuki, A., Ueno, N., and Behringer, R. R. (1995). Bmpr encodes a type I bone morphogentic protein receptor that is essential for gastrulation during mouse embryogenesis. Genes Dev. 9, 3027-3037.

Mo, R., Freer, A. M., Zinyk, D. L., Crackower, M. A., Michaud, J., Heng, H. H., Chik, K. W., Shi, X. M., Tsui, L. C., and Cheng, S. H. (1997). Specific and redundant functions of Gli2 and Gli3 zinc finger genes in the skeletal patterning and development. Development 124, 113-123.

Motoyama, J., Liu, J., Mo, R., Ding, Q., Post, M., and C.C., H. (1998). Essential function of Gli2 and Gli3 in the formation of the lung, trachea and oesophagus. Nat. Genet. 20, 54-57.

Mullis, K., Faloona, F., Scharf, S., Saiki, R., Horn, G., and Erlich, H. (1986). Specific enzymatic amplification of DNA in vitro: the polymerase chain reaction. Nature 292, 635-638. 
Nakata, K., Nagai, T., Aruga, J., and Mikoshiba, K. F. i. (1997). Xenopus Zic3, a primary regulator both in neural and neural crest development. Proc. Natl. Acad. Sci. U S A. 94, 11980-5.

Neumann, E., Schaefer-Ridder, M., Wang, Y., and Hofschneider, P. H. (1982). Gene transfer into mouse lyoma cells by electroporation in high electric fields. EMBO J. 1, 841-845.

Nomura, M., and Li, E. (1998). Smad2 role in mesoderm formation, left-right patterning and craniofacial development. Nature 393, 786 - 790.

Ohsako, S., Hyer, J., Pangianiban, G., Oliver, I., and Caudy, M. (1994). hairy function as a DNA-binding helix-loop-helix repressor of Drosophila sensory organ formation. Genes Dev. 8, 2743-2755.

Orenic, T., Chidsey, J., and Holmgren, R. (1987). Cell and cubitus interruptus dominant: two segment polarity genes on the fourth chromosome in Drosophila. Dev. Biol. 124, 50-56.

Park, H. L., Bai, C., Platt, K. A., Matise, M. P., Beeghly, A., Hui, C. c., Nakashima, M., and Joyner, A. L. (2000). Mouse Gli1 mutants are viable but have defects in SHH signalling in combination with a Gli2 mutation. Development 127, 1593-1605.

Patten, B. M. (1971). The Early Embryology of the Chick. (New York: McGrawHill)

Pedersen, R. A. (2001). Sperm and mammalian polarity. Nature 409, 473 - 474.

Peters, T., Dildrop, R., Ausmeier, K., and Rüther, U. (2000). Organization of mouse Iroquois homeobox genes in two clusters suggests a conserved regulation and function in vertebrate development. Genome Res. 10.

Piotrowska, K., and Zernicka-Goetz, M. (2001). Role for sperm in spatial patterning of the early mouse embryo. Nature 409, 517-21. 
Posakony, J. W. (1994). Nature versus nature: Asymmetric cell divisions in Drosophila bristle development. Cell 76.

Qiagen. (2000). Qiagen-Handbook (Hilden).

Ramain, P., Heitzler, P., Haenlin, M., and P., H. (1993). pannier, a negative regulator of achaete and scute genes in Drosophila imaginal discs and their function in sensory organ development. Genes Dev. 3, 997-1007.

Rhinn, M., Dierich, A., Shawlot, W., Behringer, R. R., Le Meur, M., and Ang, S. L. (1998). Sequential roles for Otx2 in visceral endoderm and neuroectoderm for forebrain and midbrain induction and specification. Development 125, 84556.

Robertson, E. J. (1987). Embryo-derived stem cell lines, in Tertocarcinomas and Embryonic Stem Cells., E. J. Robertson, ed. (Oxford: IRL).

Rosenquist, T. A., and Martin, G. R. (1995). Visceral endoderm-1 (VE-1): an antigen marker that distinguishes anterior from posterior embryonic visceral endoderm in the early post-implantation embryo. Mech. Dev. 49, 117-121.

Rossant, J. (1995). Development of the extraembryonic lineages. Sem. Dev. Biol. $6,237-247$.

Rugh, R. (1990). The Mouse - Its Reproduction and Development. (Oxford: Oxford University Press).

Rushlow, C. A., Hogan, A., Pinchin, S. M., Howe, K. M. M., and Ish-Horowicz, L. (1989). The Drosophila hairy protein acts in both segmentation and bristle patterning and shows homology to N-myc. EMBO J. 8, 3095-3103.

Russ, A. P., Wattler, S., Colledge, W. H., Aparicio, S. A., Carlton, M. B., Pearce, J. J., Barton, S. C., Surani, M. A., Ryan, K., Nehls, M. C., and al., e. (2000). Eomesodermin is required for mouse trophoblast development and mesoderm formation. Nature 404. 
Saiki, R. K., Bugawan, T. L., Horn, G. T., Mullis, K. B., and Erlich, H. A. (1986). Analysis of enzymatically amplified $\beta$-globin and HLA-DQa DNA with allelespecific oligonucleotide probes. Nature 324, 163-166.

Saiki, R. K., Gelfand, D. H., Stoffel, S., Scharf, S. J., Higuchi, R., Horn, G. T., Mullis, K. B., and Erlich, H. A. (1988). Primer-directed enzymatic amplification of DNA with a thermostable DNA polymerase. Science 239, 487491.

Saiki, R. K., Scharf, S., Faloona, F., Mullis, K. B., Horn, G. T., Erlich, H. A., and Arnheim, N. (1985). Enzymatic amplification of $\beta$-globin genomic sequences and restriction site analysis for diagnosis of sickle cell anemia. Science 230, 1350-1354.

Sambroock, J., Fritsch, E. F., and Maniatis, T. (1989). Molecular cloning: a laboratory manual, 2nd Edition, C. S. H. Laboratory, ed. (New York: Cold Spring Harbor Laboratory Press).

Sanger, F., Nicklen, S., and Coulsen, A. R. (1977). DNA sequencing with chaintermination inhibitors. Proc. Natl. Acad. Sci. USA 74, 5463-5467.

Sauer, B. (1993). Manipulation of transgenes by site-specific recombination: use of Cre recombinase. Meth. Enzym. 225, 890-900.

Schmid, J. E., Suzuki, A., Ueno, N., and Kimelman, D. (1995). Localized BMP-4 mediates dorsal/ventral patterning in the early Xenopus embryo. Dev. Biol. $169,37-50$.

Simpson, P. (1997). Notch signalling in development: on equivalence groups and asymmetric developmental potential. Curr. Opin. Genet. Dev. 7.

Sirard, C., de la Pompa, J. L., Elia, A., Itie, A., Mirtsos, C., Cheung, A., Hahn, S., Wakeham, A., Schwartz, L., Kern, S.E. and Rossant, J. (1998). The tumor 
suppressor gene Smad4/Dpc4 is required for gastrulation and later for anterior development of the mouse embryo. Genes Dev. 12, 107-119.

Skeath, J. B., and Carroll, S. B. (1991). Regulation of achaete-scute gene expression and sensory organ pattern formation in the Drosophila wing. Genes Dev. 5, 984-995.

Southern, E. M. (1975). Detection of specific sequences among DNA fragments separated by gel electrophoresis. J. Mol. Biol. 98, 503-517.

Stern, C. (1954). Two or three bristles. Am. Sci. 42, 213-247.

Stüber, D., Matile, H., and Garotta, G. (1990). System for high-level production in E. coli and rapid purification of recombinant proteins: applications to epitope mapping, preparation of antibodies, and structure-function analysis. Immunol. Meth. 4, 121-152.

Studier, F. W., Rosenberg, A. H., Dunn, J. J., and Dubendorf, J. W. (1990). Use of T7 RNA polymerase to direct expression of cloned genes. Meth. Enzmol. 185, 60-89.

Suzuki, A., Ueno, N., and Hemmati-Brivanlou, A. (1997). Xenopus msx1 mediates epidermal induction and neural inhibition by BMP4. Development 124, 30373044 .

Tabor, S., and Richardson, C. C. (1987). DNA sequence analysis with a modified bacteriophage T7 DNA polymerase. Proc. Natl. Acad. Sci. USA 84, 4767-4771.

Tam, P. P. L., and Behringer, R. R. (1997). Mouse gastrulation: the formation of a mammalian body plan. Mech. Dev. 68, 3-25.

Tan, J. T., Korzh, V., and Gong, Z. (1999). Expression of a zebrafish iroquois homeobox gene, Ziro3, in the midline axial structures and central nervous system. Mech. Dev. 87, 165-8. 
Tanabe, Y., and Jessel, T. M. (1996). Diversity and pattern in the developing spinal cord. Science 274, 1115-1123.

Tang, S. J., Hoodless, P. A., Lu, Z., Breitmann, M. L., McInnes, R. R., Wrana, J. L., and Buchwald, M. (1998). The Tlx-2 homeobox gene is a downstream target of $B M P$ signalling and is required for mouse mesoderm development. Development 125, 1877-1887.

Taniguchi, M., Sanbo, M., Watanabe, S., Naruse, I., Mishina, M., and Yagi, T. (1998). Efficient production of Cre-mediated site-directed recombinants through the utilization of the puromycin resistance gene, pac: a transient geneintegration marker for ES-cells. Nucleic Acid Res. 26, 679-680.

Ten Have-Opbroek, A. (1991). Lung development in the mouse embryo. Exp. Lung Res. 17, 111-130.

Theil, T., Kaesler, S., Grotewold, L., Bose, J., and Rüther,U. (1999). Gli genes and limb development. Cell Tis. Res. 296, 75-83.

Theiler, K. (1989). The house mouse. Atlas of embryonic development. (Berlin, Heidelberg, New, York, Tokyo: Springer).

Thomas, K. R., and Capecchi, M. R. (1987). Site-directed mutagenesis by gene targeting in mouse embryo-derived stem cells. Cell 51, 503-512.

Thomas, P., and Beddington, R. S. P. (1996). Anterior primitive endoderm may be responsible for patterning the anterior neural plate in the mouse embryo. Curr. Biol. 6, 1486-1496.

Thomas, P. Q., Brickman, J., Pöpperl, H., Krumlauf, R., and Beddington, R. S. R. (1997). Axis duplication and anterior identity in the mouse embryo., Volume LXII (New York: Cold Spring Harbour Labratory Press). 
Thomas, P. Q., Brown, A., and Beddington, R. S. P. (1998). Hex: a homeobox gene revealing peri-implantation asymmetry in the mouse embryo and an early transient marker of endothelial cell precursors. Development 125, 85-94.

Thomas, P. S. (1980). Hybridization of denatured RNA and small DNA fragments transferred to nitrocellulose. Proc. Natl. Acad. Sci. USA 72, 3961-65.

Thorne, H. V. (1966). Electrophoretic characterization and fractionation of polyoma virus DNA. J. Mol. Biol. 24, 203-211.

Towbin, H., Staehelin, T., and Gordon, J. (1979). Electrophoretic transfer of proteins from polyacrylamide gels to nitrocellulose sheets: procedure and some applications. Proc. Natl. Acad. Sci. USA 76, 4350-4353.

Treisman, J., Gonczy, P., Vashishtha, M., Harris, E., and Desplan, C. (1989). A single amino acid can determine the DNA binding specificity of homeodomain proteins. Cell 59, 553-562.

Verma-Kurvari, S., Savage, T., Smith, D., and Johnson, J. E. (1998). Multiple elements regulate Mash1 expression in the developing CNS. Dev. Biol. 197, 106-116.

Vervoort, M. (2000). hedgehog and wing development in Drosophila: a morphogen at work? Bioassays 22, 460-468.

Viebahn, C. (1999). The anterior margin of the mammalian gastrula: comparative and phylogenetic aspects of its role in axis formation and head induction. Curr. Top. Dev. Biol. 46, 63-103.

Waldrip, W. R., Bikoff, E. K., Hoodless, P. A., Wrana, J. L., and Robertson, E. J. (1998). Smad2 signalling in extraembryonic tissues determines anteriorposterior polarity of the early mouse embryo. Cell 92, 797-808.

Wassarman, K. M., Lewandowski, M., Campbell, K., Joyner, A. L., Rubenstein, J. L., and Martinez, S. M., G. (1997). Specification of the anterior hindbrain and 
establishment of a normal mid/hindbrain organizer is dependent on Gbx2 gene function. Development 124, 2923-2934.

Watanabe, S., Kai, N., Yasuda, M., Kohmura, N., Sanbo, M., Mishina, M., and Yagi, T. (1995). Stable production of mutant mice from double gene converted ES cells with puromycin and neomycin. Biochem. Biophys. Res. Com. 213, 130137.

Weber, R. J., Pedersen, R. A., Wianny, F., Evans, M. J., and Zernicka-Goetz, M. (1999). Polarity of the mouse embryo is anticipated before gastrulation. Development 126, 5591-5598.

Wehner, R., and Gehring, W. (1995). Zoologie, Volume 23. Aufl. (Stuttgart, New York: Thieme-Verlag).

Wilkinson, D. G. (1992). in situ hybridisation; a practical approach. (London: Oxford University Press).

Wilson, P. A., Lagna, G., Suzuki, A., and Hemmati-Brivanlou, A. (1997). Concentration-dependent patterning of the Xenopus ectoderm by BMP4 and its signal transducer Smad1. Development 124, 3177-3184.

Wilson, V., Manson, L., W.C., S., and Beddington, R. S. P. (1995). The T gene is necessary for normal mesodermal morphogenetic cell movements during gastulation. Development 121, 877-886.

Winnier, G., Blessing, M., Labosky, P. A., and Hogan, B. M. (1995). Bonemorphogenic protein-4 is required for mesoderm formation and patterning in the mouse. Genes Dev. 9, 2105-2115.

Wolpert, L., Beddington, R., Brockes, J., Jessel, T., Lawrence, P., and Meyerowitz, E. (1999). Entwicklungsbiologie (Heidelberg, Berlin: Spektrum Akademischer Verlag). 
Zülch, A. (1997). Struktur- und Funktionsanalyse eines Iroquois-verwandten Gens der Maus -Irx2. In Abt. Molekulare Zellbiologie, MPIBPC (Göttingen: Universität zu Göttingen).

Zülch, A., Becker, M. B., and Gruss, P. (2001). Expression pattern of $\operatorname{Ir} x 1$ and Irx2 during mouse digit development. Mech. Dev. in Press. 


\section{DANKSAGUNG}

An dieser Stelle möchte ich mich noch bei all denen bedanken, die durch ihr Verständnis, ihre Geduld, ihre eigene Motivation und Begeisterungsfähigkeit mir den Laboralltag mit viel Freude erfüllt haben. Ich möchte mich bei all denjenigen bedanken, die mir jederzeit mit Rat und Tat zur Seite gestanden haben und mit am Gelingen meiner Promotion beteiligt waren.

Mein besonderer Dank gilt Herrn Prof. Dr. Peter Gruss für seine Unterstützung und die Möglichkeit, dieses faszinierende Thema in seinem Labor zu bearbeiten. Vielen Dank auch an Frau Prof. Dr. M. Schäfer für die vielen hilfreichen Diskussionen und für die Übernahme der Begutachtung. Ich bedanke mich auch bei allen Mitgliedern der Prüfungskommission für ihr Entgegenkommen.

Meinen großen Dank möchte ich Ahmed Mansouri und auch Maria Belaoussoff aussprechen, die mit hilfreichen Erklärungen und Diskussionen maßgeblich zu dieser Arbeit beigetragen haben.

Ein ganz herzliches Dankeschön geht an Christopher Brink für die täglichen Hilfen und gesellschaftspolitischen Unterhaltungen.

Danken möchte ich auch meinen Laborstudenten Nora Speer, David Hecker und Wencke Armsen, mit denen es immer einen riesen Spaß gemacht hat zusammenzuarbeiten.

Ich richte meinen Dank an Dieter Treichel, Barbara Meyer und Joachim Berger für ihre tolle Unterstützung.

Weiterhin möchte ich mich bei meinen Kolleginnen und Kollegen im Labor Maria Belaoussoff, Christopher Brink, Guy Goudrou, Nicole Andrejewski und Martin Balastik bedanken, die durch ihre Hilfsbereitschaft zu dieser Arbeit beigetragen haben. 
Danken möchte ich auch der "Iroquois-Gruppe" mit Juan Modolell (Spanien), José Luis Gómez-Skarmeta (Spanien), Roberto Mayor (Chile), May-Britt Becker, Kate Storey (England) und Peter Gruss für die vielen Ideen und Diskussionen.

Besonders herzlicher Dank gilt May-Britt Becker, Nora Speer, Christopher Brink und Maria Belaoussoff, für die Hilfe, Korrektur und kritischen Kommentare in den letzten Tagen.

Marianne Schuster möchte ich für die Rechtschreibkorrekturen danken, die sie trotz ihrer eigenen vielen Arbeit gerne übernahm.

Ich möchte all jenen danken, die mir vielseitig geholfen haben, wie Jens Krull, Sabine Geisendorf, Silke Eckert, Silke und Sharif, den Mitgliedern der TierstallTruppe unter der Leitung von Rainer Libal und dem Spül-Küchen-Team.

Ich danke meiner geliebten May-Britt - einfach für alles !

Mein Dank gilt meinen geliebten Eltern, die mich immer in jeder erdenklichen Weise unterstützt und gefördert haben. 


\section{Publikationen}

Bosse, A., Zülch, A., Becker, M. B., Torres, M., Gomez-Skarmeta, J. L., Modolell, J., and Gruss, P. (1997). Identification of the vertebrate iroquois homeobox gene family with overlapping expression during early development of the nervous system. Mech. Dev. 69, 169-181.

Zülch, A., and Gruss, P. (2000). Functional analysis of the two gene trap lines 9A-85 and 6A-126. AMGEN report, 205-211.

Becker, M.-B., Zülch, A., and Gruss, P. (2001). Von der undifferenzierten Zelle zum komplexen Organismus. Biologie in unserer Zeit 2, 88-97.

Zülch, A., Becker, M. B., and Gruss, P. (2001). Expression pattern of Irx1 and Irx2 during mouse digit development. Mech. Dev. in Press.

Becker, M. B., Zülch, A., and Gruss, P. (2001). Irx2 and Irx1 expression in early lung development. Mech. Dev. in Press.

Zülch, A., Becker, M.-B., and Gruss, P. (2001). Irx1, a prepattern gene essential during murine gastrulation. in Vorbereitung.

Zülch, A., Becker, M. B., Mansouri, A., Guillemot, F., and Gruss, P. (2001). The proneural gene Mash1 is essential for C-cell differentiation. in Vorbereitung.

Lemaire, L., Zülch, A., and Gruss, P. (2001). PAX4 is misexpressed in human pancreatic cancer. in Vorbereitung. 


\section{LEBENSLAUF}

Persönliche Daten:

$1980-1989$

$1989-1991$

Okt. 1991 - Jan. 1997

Okt. 1993

Nov. 1993 - Okt. 1995

Nov. 1995

Jan. 1996 - Jan. 1997

Feb. 1997

März 1997- Mai 2001

\section{Armin Uwe Zülch}

Am Weendespring 24A

37077 Göttingen

${ }^{*} 16.01 .1970$, in Homberg/Efze

ledig

deutscher Staatsbürger

Besuch des Gymnasiums in Homberg/Efze

Abschluß: Allgemeinen Hochschulreife;

Note "sehr gut"

Wehrdienst

Studium der Biologie an der Universität Göttingen

Diplomvorprüfung: Molekulare Genetik, Zoologie, Anorganische Chemie und Physik;

Note: "gut"

Haupstudium mit Schwerpunkt

Molekulare Genetik

Mündliche Diplomhauptprüfung im

Hauptfach Molekulare Genetik und den

Nebenfächern Entwicklungsbiologie und Biophysik

Diplomarbeit am Max-Planck-Institut für

Biophysikalische Chemie, Abt. Molekulare

Zellbiologie, Prof. Dr. Peter Gruss.

Thema: "Struktur- und Funktionsanalyse eines

Iroquois-verwandten Gens der Maus - Irx2 "

Verleihung des Hochschulgrades Diplom-Biologe an der Universität Göttingen;

Note: "sehr gut"

Doktorarbeit am Max-Planck-Institut für

Biophysikalische Chemie, Abt. Molekulare

Zellbiologie, Prof. Dr. Peter Gruss.

Thema: "Funktionsanalyse des Irx1-Gens" 